\title{
NOT JUST Fun AND GAMES: EXPLORING LUDIC ELEMENTS IN GREEK AND LATIN LITERATURE
}

\author{
A Dissertation Presented to the Faculty of the Graduate \\ School at the University of Missouri \\ In Partial Fulfillment of the Requirements for the Degree \\ Doctor of Philosophy \\ by
}

CHRISTOPHER S. DoBbS

May 2018 
(C) Copyright by Christopher S. Dobbs 2018

All Rights Reserved 


\begin{abstract}
APPROVAL PAGE
The undersigned, appointed by the dean of the Graduate School, have examined the dissertation entitled

Not Just Fun AND GAMES:

EXPLORING LUDIC ELEMENTS IN GREEK AND LATIN LITERATURE

presented by Christopher S. Dobbs, a candidate for the degree of Doctor of Philosophy, and hereby certify that, in their opinion, it is worthy of acceptance.
\end{abstract}

Professor Raymond Marks, Chair

Professor Sean Gurd

Professor Daniel Hooley

Professor Dennis Kelley

Professor Anatole Mori

Professor Dennis Trout 


\section{ACKNOWLEDGMENTS}

I have incurred a great many debts on the journey to where I am today. A list of those whose guidance, friendship, and encouragement led to the completion of this project would rival the Catalogue of Ships in Book 2 of Homer's Iliad. Much like the Catalogue of Ships, that list would hold significance, but not be particularly enjoyable to read. I therefore limit myself to only the most influential and ask forgiveness from the rest.

Kay Fluharty first showed me how enjoyable the study of the ancient world could be. Every day for four years, she brought patience and kindness to a high school student who seemed incapable of understanding participles no matter how fascinated he was with antiquity. As an undergraduate, I had the distinct privilege of learning from three more of the best educators I have ever met. Steve Tuck, Zara Torlone, and Steve Nimis shaped my career and approach to education in more ways than I can count. To all four of you, thank you for inspiring me as a scholar, nurturing me as a person, and continually demonstrating all the best practices in teaching.

Of the many people I am proud to call my friends, I must give special thanks to Mike Savnik. You helped draw a map for an awkwardly loud college freshman trying to find his place in the world. Best of all, for reasons I think only you can explain, you're still talking to me a decade later.

I give my thanks to the many graduate students with whom I have shared conversations, laughs, and frustrations. Our frequent exchange of ideas has helped me immensely with my research and in life. To Justin Arft I offer my sincerest gratitude for particularly stirring conversations and years of continued guidance in professional 
matters. For Dominick Price, Chris Younger, and especially Corey Cook, I am at a loss for what to say. No words can ever describe the years spent forging our brotherhood over video game controllers, scintillating conversations, and a few pitchers-usually all at the same time. Life has taken us in different directions, but I know that some day, the Four Horsemen will ride again.

I turn now to the Department of Classical Studies, which has only recently become the Department of Ancient Mediterranean Studies. There is not a single professor who has not had a positive influence on me as a scholar and as a person. I owe special thanks, however, to a few. Thanks to Barbara Wallach for her unflinching positivity and encouragement. Thanks to Dennis Trout for always asking probing questions and for always having a firm, but gentle hand on the wheel. Thanks to Sean Gurd for forcing me be precise in my scholarship and in planning my career. Thanks to Anatole Mori for demonstrating how to balance being productive and having fun, as well as encouraging me to do the same. Thanks to David Schenker for always making time to talk and for prioritizing the needs of graduate students in the department. Thanks to Jim Crozier for his unfailing friendship and unflappable honesty. I don't know how many chicken wings we've eaten together over the years, but I'm sure we've cleaned out a few farms by now. Thanks to Dan Hooley for his many years of guidance, both in person and from afar, for his finesse of the English language, and for always making me keep the big picture in mind. A special thanks to Ray Marks for his tact and affable direction of this dissertation even though, as he reminded me almost every dissertation meeting, this isn't his specialty. Here I also thank Dennis Kelley from the Department of Religious Studies for serving on my committee and always being excited to talk about anything. To all of you 
on my committee, I thank you for reading my dissertation with an unrelenting attention to detail for which I hope some day to forgive you.

I am eternally grateful to my family. Whether related by blood or by marriage, every family member has shown unswerving optimism that I would succeed. My family has been a rock or, rather, series of equally firm rocks that have weathered the storms of my exasperation as I found my path. Thank you all for your support.

My greatest thanks go to Lisa Dobbs, my wife and best friend, who married a graduate student —on purpose. You have been everything I have ever needed. You forced me to relax when I worked too hard and pushed me back to the books when I didn't work hard enough. I can never express my gratitude for the years of support, encouragement, and letting me bounce ideas off of you in languages you don't know. Talking at you has become an integral part of my creative process and I am looking forward to many decades more of it. I know you are too. 


\section{TABLE OF CONTENTS}

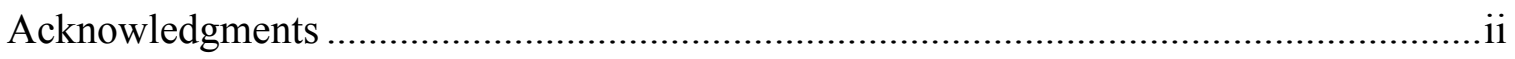

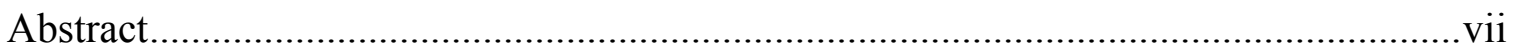

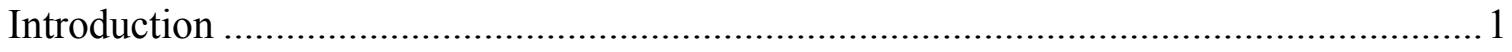

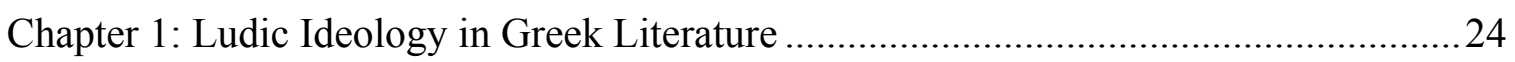

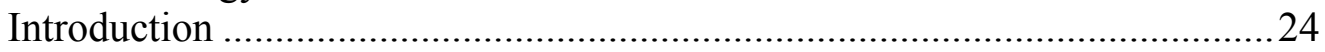

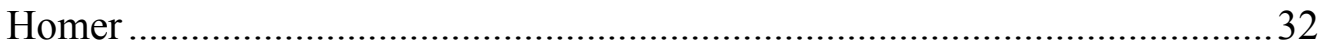

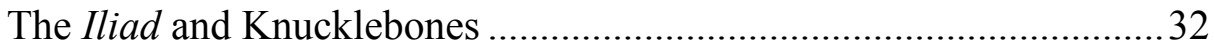

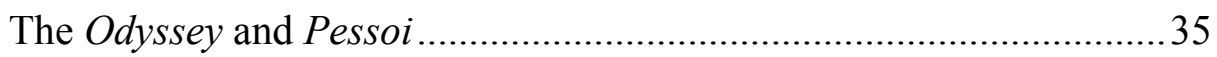

The Cosmic Game ……….............................................................................. 41

The Cosmic Game in Sophocles ..........................................................52

Cities and Citizenship: Embodied Citizenship ................................................6 60

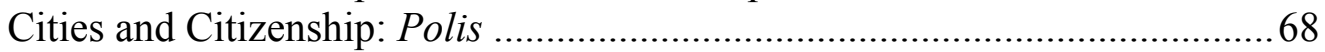

Cities and Citizenship: The Game of Citizenship ..........................................72

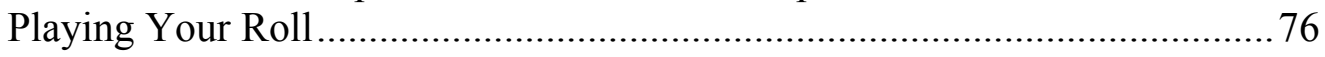

Conclusion ............................................................................................. 85

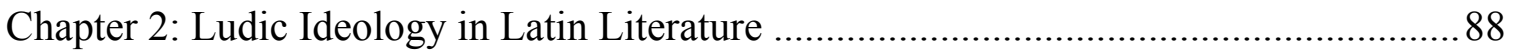

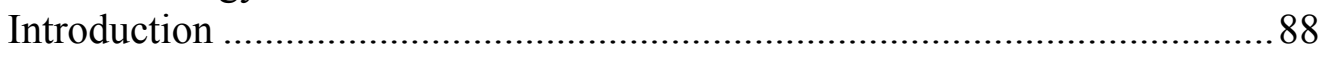

Terence: Playing Your Roll in the Adelphoe .................................................93

Horace: The Cosmic Game and Playing Your Roll in Sermones 2.8............ 100

Horace: The Cosmic Game in the Carmina .................................................106

Horace: Carmina 1.34 and 1.35 ........................................................ 107

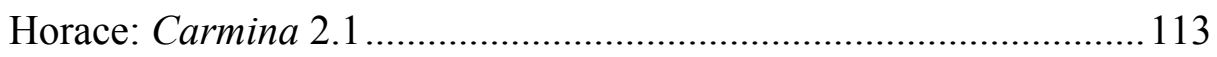

Horace: Carmina 3.29 ................................................................ 116

Cities and Citizenship in the Laus Pisonis ...............................................126

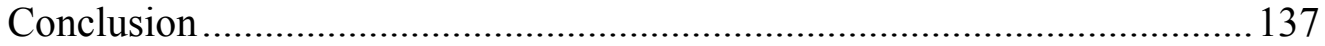

Chapter 3: Games and Morality in Greek Literature.................................................... 141

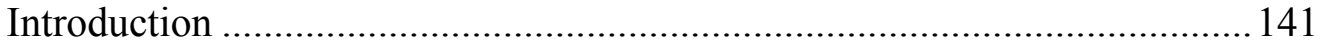

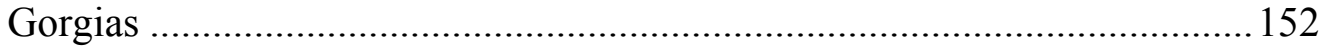

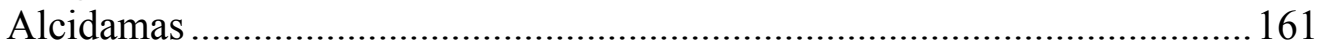

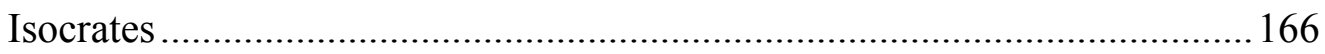

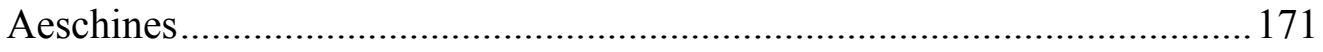

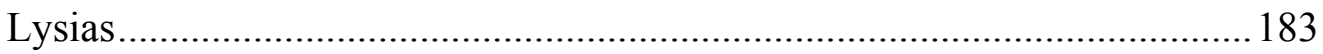

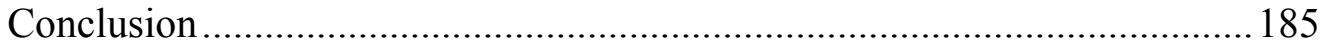

Chapter 4: Games and Morality in Latin Literature …………................................... 188

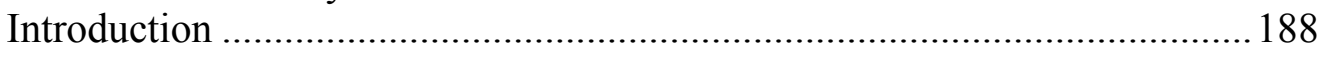

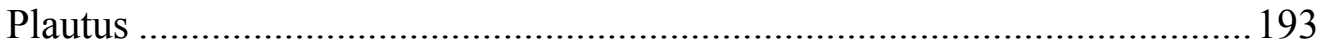

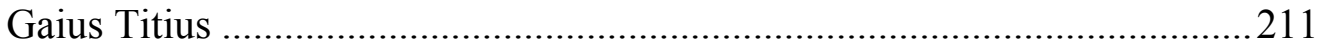




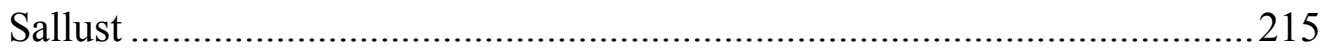

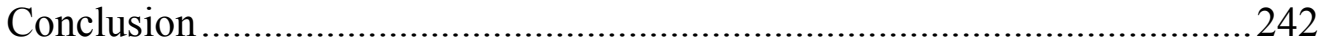

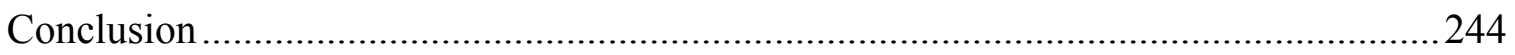

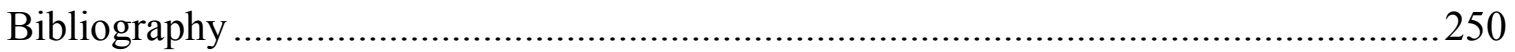

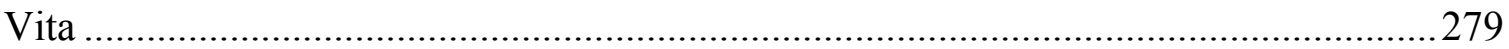




\begin{abstract}
This dissertation explores how Greek and Roman authors use board games and games of chance to answer complex questions about humanity and the relation of the self to the cosmos. I isolate literary topoi rooted in gaming imagery and survey them across a broad diachronic and generic expanse to reveal the application of ludic themes as an important conceptual tool. Specifically, I demonstrate how authors employ gaming imagery to engage in ongoing discussions about the nature of the universe and human behavior; I trace these ludic themes in passages often overlooked as mere metaphor and shape them into an analytical framework that spans major genres from the $8^{\text {th }}$ century $\mathrm{BCE}$ to the early $1^{\text {st }}$ century CE.
\end{abstract}




\section{Introduction}

Games and play are ubiquitous in human societies. ${ }^{1}$ From the games children play, inventing the rules as they go along, to the organized national and world championship events with voluminous rulebooks to be followed dogmatically, games are an inescapable element of contemporary society. Our language is as filled with games as our backyards and television screens: ludic imagery, metaphors, and idioms abound in human communication. Games likewise pervade the Greek and Roman worlds, but they have traditionally received quite a different level of consideration. This dissertation stems from my longstanding interest in gaming in the ancient world and seeks to level the playing field, as it were, by showing the influence of games on Greek and Roman literary culture.

For all of the attention games - in particular athletics - receive in contemporary culture, scholars have largely ignored their roles in the ancient world, save, perhaps unsurprisingly, athletic contests, such as chariot races and gladiatorial combat. Games fall within the purview of many disciplines, yet also fall through the cracks between them; for example, one can view games through the lens of history, anthropology, or sociology, but can also examine them for their mathematical or psychological components. ${ }^{2}$ Games also often suffer from the assumption that they are trivial or childish phenomena and

\footnotetext{
*All translations in this dissertation are my own.

${ }^{1}$ Huizinga (1949) remains the best introduction to this idea.

${ }^{2}$ For mathematical aspects of games, see, e.g., Pennick (1989) passim; Beal (2001) 123132; Donkers, Uiterwijk, and de Voogt (2001) 133-146. For the psychology of games, see, e.g., N'Guessan Assandé and Retschitzki (2001) 175-182; Haddad-Zubel (2001) 191-202; Gobet, de Voogt, and Retschitzki (2004).
} 
consequently not worthy of serious investigation. ${ }^{3}$ History, however, refutes such a notion. Games are a human universal; games of some kind have flourished in nearly every society in the ancient and modern worlds, reflecting a shared human heritage, while adults have usually played the majority of games — or at least games played with boards, pieces, and, when the games call for them, randomizing agents. ${ }^{4}$ Board games, which boast the most recognizable playing apparatus, appear in the archaeological record as early as the Pre-Pottery Neolithic B period, roughly 7,000 BCE. ${ }^{5}$

Board games and games of chance offer a largely unexplored window into the cultures that play them, for although humans seem naturally drawn to games like moths to light, societies vary in the kinds of games they play, as well as their attitudes toward those games. Bourdieu illuminates how quotidian practices mold the habitus, the system of dispositions an individual agent acquires in response to social structures. ${ }^{6}$ Part of that habitus is doxa, the learned, unconscious beliefs and values that inform the agent's thoughts. ${ }^{7}$ In Bourdieu's words, "what is essential goes without saying because it comes without saying: the tradition is silent, not least about itself as a tradition." ${ }^{8}$ More specifically, doxa is the inverse of institutionalized education; it is the "diffuse education which moves directly from practice to practice without passing through discourse." ${ }^{9}$ As Kurke notes, games are a model subject for analyzing such a process, as from early

\footnotetext{
${ }^{3}$ Cf. Toner (1995) 7; Mackenzie and Finkel (2004) 13; Finkel (2007) 1. That scholars feel compelled to introduce their studies of games with an apology or justification both corroborates and compounds the problem. See, for example, Kurke (1999a) 247.

${ }^{4}$ Mackenzie and Finkel (2004) 13; Finkel (2007) 1

${ }^{5}$ See Simpson (2007) 5-10 for an examination of the evidence. Cf. Finkel (2007) 1.

${ }^{6}$ Bourdieu (1977) 72-158; Bourdieu (1984) 466-484; Bourdieu (1990) 52-111

${ }^{7}$ Bourdieu (1977) 159-170; Bourdieu (1984) 240-241, 471-472; Bourdieu (1990) 36, 6669

${ }^{8}$ Bourdieu (1977) 167 , italics in original

${ }^{9}$ Bourdieu (1990) 103
} 
childhood, people continuously "participate in these symbolic, rule-bound structures that teach them how to behave in 'real life. ${ }^{, 10}$ Bourdieu himself points to the significance of games, for he not only addresses the games of Kabyle society as representative of life in the community, but also refers to life itself as a game; the way an agent behaves, that is, the interaction between the habitus and the field, is the agent's "feel for the game."

The power of games to inculcate values, to teach participants how to play the game of life, may be rooted in practice, but discourse preserves the vestiges of that practice. Although the passage of time prevents us from personally observing the games of ancient cultures, the physical and literary artifacts of cultural production fossilize traces of those games' impact. By amassing evidence that shows the influence of games, we can trace patterns that suggest convention. Nevertheless, although it is possible to sketch a broad, cultural disposition, we cannot assume uniformity; we may hear a resounding chorus of evidence, but it comprises many voices, some of them at odds with one another. When assessing the melody of the prevailing attitude and the harmonies that support it, we sometimes discern a counter-melody resisting the other voices, a secondary stance that textures the overall effect. At other times, a lone voice seems to be out of key, for which it is branded as heretical and shunned.

This dissertation explores the roles board games and games of chance play in Greek and Latin literature. I show how Greek and Roman authors use games to address complex questions about humanity, propriety, and the relation of the self to the cosmos. I

\footnotetext{
${ }^{10}$ Kurke (1999a) 247

${ }^{11}$ For games reflecting life, see Bourdieu (1977) 130, 217 n. 37; (1990) 74-75, 293-294 n. 10, 315-316 n. 38. For life as a game, see Bourdieu (1977) 22, 232 n. 5; Bourdieu (1990) 66-68, 80-82, 104-105. Cf. Bourdieu (1990) 147-148, 187-188 for the more specific "game of marriage," where each marriage is likened to playing a card in a game and each family must make the best use of the hand it has been dealt.
} 
isolate literary topoi rooted in gaming imagery and survey them across a broad diachronic and generic expanse to reveal the application of ludic themes as an important conceptual tool. Specifically, I demonstrate how authors employ consistent gaming imagery to discuss the nature of the universe and human behavior; I trace these ludic themes in passages often overlooked as mere metaphor and shape them into an analytic framework that spans major genres from the $8^{\text {th }}$ century BCE to the $1^{\text {st }}$ century CE. Although material remains can reveal much about the cultures that produced them, I do not seek to reconstruct antiquity as a whole; by limiting my focus to only one type of evidence, I am able to explore the literature more deeply than if I included artifacts in this study.

In assessing the literary roles games play, it is useful to delineate the terms of the inquiry. Games enjoy no single definition. As Patterson notes, "games are easy to identify but difficult to define concretely." 12 Parlett similarly observes that "the word is used for so many different activities that it is not worth insisting on any proposed definition. All in all, it is a slippery lexicological customer, with many friends and relations in a wide variety of fields. ${ }^{, 13}$ The difficulties of defining the word, however, have not prevented scholars from trying, with varying degrees of specificity. Perhaps the most successful is Bernard Suits, who first defines the "elements of game-playing," then uses those elements to define what a game is: ${ }^{14}$

"To play a game is to attempt to achieve a specific state of affairs [prelusory goal], using only means permitted by rules [lusory means], where rules prohibit use of more efficient in favor of less efficient means [constitutive rules], and where the rules are accepted just because they make possible such activity [lusory attitude]. I also offer the following

\footnotetext{
${ }^{12}$ Patterson (2015) 6

${ }^{13}$ Parlett (1999) 1

${ }^{14}$ Suits (1978) 184-191, quote from 190. The terms in brackets are what Suits terms the "elements of game-playing."
} 
simpler and, so to speak, portable version of the above: playing a game is the voluntary attempt to overcome unnecessary obstacles."

Suits' definition neatly ties together games and another term equally difficult to define: play. Indeed, it is nearly impossible to discuss one without referencing the other. ${ }^{15}$ For a definition of play, we turn to Huizinga, who first sparked cultural game studies: ${ }^{16}$

"Play is a voluntary activity or occupation executed within certain fixed limits of time and place, according to rules freely accepted but absolutely binding, having its aim in itself and accompanied by a feeling of tension, joy and the consciousness that it is 'different' from 'ordinary life."'

Huizinga continues by noting that this definition embraces "everything we call 'play' in animals, children and grown-ups," including all the various kinds of games, exhibitions, and performances. ${ }^{17}$ The difference between games and play, then, is one of hierarchy, where "play" is the concept and a "game" is an instantiation of it. ${ }^{18}$ As one scholar puts it, "Although they are often related, game and play are not synonymous. As activities that are finite and rule-governed, games involve play but play is not bound to games." ${ }^{19}$ In other words, games are a subset of play. ${ }^{20}$

We must note, however, that this ordering is not universal, as it relies on a peculiarity of the English language. In English, "game" and "play" have different etymologies and different sentence functions: in ludic contexts, "game" is a noun, while "play" is primarily a verb, though sometimes a noun; using the words otherwise invites

${ }^{15}$ Cf. Edwards (1998) 12; Parlett (1999) 1; McCormick (2015) 210

${ }^{16}$ Huizinga (1949) 28. Regarding the final part of the definition, cf. Suits (1978) 189: "But games are, I believe, essentially different from the ordinary activities of life."

${ }^{17}$ Huizinga (1949) 28

${ }^{18}$ Cf. Patterson (2015) 6: "Games, in essence, become the object of play."

${ }^{19}$ Edwards (1998) 12

${ }^{20}$ Juul (2005) 29 
separate meanings, such as "gaming the system" or "seeing a play." ${ }^{21}$ Many other languages do not have the sharp contrast English does: for example, both concepts of "game" and "play" are contained in the nouns of the French jeu, Spanish juego, Italian gioco, and German Spiel, along with their respective verbs jouer, jugar, giocare, and spielen. ${ }^{22}$ Juul likewise observes that "Scandinavian languages have a stronger distinction with leg = play and spil = game with verbs for both-you can play play ('lege en leg') and game game ('spille et spil'), so to speak." ${ }^{23}$ Greek and Latin likewise have both noun and verb forms for the same words, including different words with similar meanings:

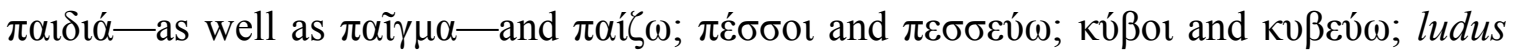
and ludere; and iocus and iocari, this last pair being the root of so many game/play words in Romance languages. ${ }^{24}$ In sum, while we must differentiate "game" from "play," where the former is an organized activity subsumed by the latter, the necessity derives from a peculiarity of the English language not present in the languages of the sources discussed in this dissertation or in many other modern languages.

The indeterminacy of these ancient words for game/play likewise reflects an indeterminacy of the activity, such as whether it is a board game or an athletic contest.

\footnotetext{
${ }^{21}$ Parlett (1999) 1-2; Juul (2005) 29

${ }^{22}$ Cf. Huizinga (1948) 28-45, who discusses many other languages from several language families; Parlett (1999) 1; Juul (2005) 29; Patterson (2015) 5. The same rule also holds true for other Romance languages, such as the Portuguese jogo and jogar and the Rumanian joc and $a j u c a$.

${ }^{23}$ Juul (2005) 29. He continues "When writing about games in Danish, it is therefore not self-evident that games are a subset of play, whereas while writing about Spiel in German, it is not obvious that one should distinguish between games and play from the outset."

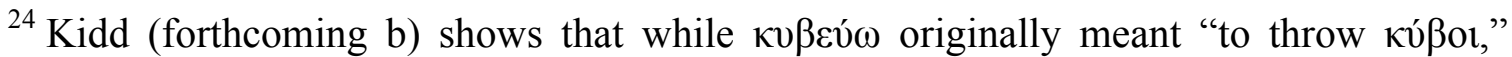
through broken metonymy it later means only "to gamble" and in many contexts has nothing to do with dice. This evolution of the Greek language should be noted, but it has no impact on the argument here, as the verb derives from the noun and originally refers specifically to throwing dice.
} 
The word ludus, for example, can indicate a board game, a public spectacle, a stage-play, mockery, open-ended free play, or a school, as well as many finer distinctions within these categories. ${ }^{25}$ Context and the apparatus involved determine the correct usage. The games under discussion in this dissertation are tabletop games, which require a flat surface and equipment used according to skill, chance, or a combination of both. Depending on the game in question, the apparatus includes one or more of the following elements: a board, whether portable or scratched into the pavement; counters to be moved on the board; and randomizing agents, such as dice or knucklebones. The difference between these games and athletic games is the apparatus used; following Suits' definition, the prelusory goal of an athletic game is to defeat all opponents with the lusory means of physical prowess, whereas the tabletop games I discuss require victory from the gaming equipment, such as by creating a better disposition of game counters on the board or having the best roll of the randomizing agents.

It is useful here to move from abstractions to the actual games of the ancient world. Scholars have offered many reconstructions, but the evidence simply does not allow a full view of these games; the sundry references that comprise our literary evidence predominantly assume the audience's familiarity with the games in order to function, while the many boards, counters, and randomizing agents that survive from antiquity offer few hints as to their proper use. As one scholar puts it, "Some of the difficulties may be realized by trying to reconstruct a game of Ombre entirely from Pope's Rape of the Lock, or a game of cricket from Dickens' account of All Muggleton v.

${ }^{25}$ OLD s.v. ludus 
Dingley Dell. ${ }^{26}$ Nevertheless, a brief overview of what is known about the major games from antiquity helps focus our discussion.

Greek authors as early as Homer refer to pessoi or petteia, but these are generic terms for board games played with pieces rather than the games themselves. ${ }^{27}$ One specific game about which we have concrete information is pente grammai, the game of five lines. This game is for two players, who each have five counters that they move on a board with five parallel lines, the central one of which is called "the holy line." ${ }^{28}$ This is the game that Achilles and Ajax play on so many Attic vases. ${ }^{29}$ According to some interpretations, each player has five lines, with a central "holy line" between them, for a game board with a total of eleven lines, which may be a later version of the game. ${ }^{30}$ Material remains preserve boards of other numbers of lines, including nine and thirteen lines, indicating enlarged versions of the game, in which each player has one counter per line, as with the five-line version. ${ }^{31}$ Players either begin with all pieces off the board or with their pieces in a row, with one piece at the end of each line, facing the opponent's pieces at the other end. ${ }^{32}$ The object of the game is to put all of one's pieces on the holy line by moving them according to the roll of a six-sided die. ${ }^{33}$ According to Schädler's reconstruction, points, i.e. the ends of each line, can have only one piece on them, save

\footnotetext{
${ }^{26}$ Austin (1940) 257

${ }^{27}$ Cf. Austin (1940) 260

${ }^{28}$ Schädler (2009) 173-177; Schädler (2013) 2842; Kidd (2017) 83-99

${ }^{29}$ Schädler (2013) 2842. Woodford (1982) provides a catalog of vases with this decoration.

${ }^{30}$ Schädler (2009) 173-174; Schädler (2013) 2842

${ }^{31}$ Schädler (1998) 17-18; Schädler (2009) 177-181

${ }^{32}$ Kidd (2017) prefers the first reconstruction, Schädler (2009) the second.

${ }^{33}$ Schädler (1998) 17-18; Schädler (2009) 177, 180, 196; Kidd (2017) 96
} 
the sacred line, and there is no method of capture. ${ }^{34}$ In Kidd's reconstruction, players may capture pieces by landing on them and captured pieces must then be reintroduced to the board with a dice roll on the opponent's next turn, similar to modern backgammon; pieces are safe from capture if on the sacred line or if multiple pieces are on the same point, which Kidd's reconstruction permits. ${ }^{35}$

The Romans too played a game that involved moving pieces disposed on a board: duodecim scripta. This game uses a board of three rows of six spaces in two adjacent columns, giving the overall appearance of a three by twelve board with a decoration or a blank space dividing each row in half. ${ }^{36}$ The material remains of these boards show playing spaces marked variously with squares, circles, or letters, these last examples often forming a sentence comprising six words of six letters each ${ }^{37}$ Each player moves fifteen pieces around the track according to the throws of two dice; single counters on any given playing space are captured by landing on them, after which they must be reentered onto the board, but two or more pieces on any playing space are immune to capture. ${ }^{38}$ Players perhaps win by moving all of their pieces into the final table, i.e. sixcharacter section, or by removing them from there, but this cannot be known for certain. ${ }^{39}$ At a later period, somewhere between the late first century BCE and the third century $\mathrm{CE}$, the game develops into alea, previously the term for gambling, but now a specific

\footnotetext{
${ }^{34}$ Schädler (2009) 196

${ }^{35}$ Kidd (2017) 96-97

${ }^{36}$ Schädler (2013) 2843

${ }^{37}$ Lanciani (1892) 97-100; Austin (1934) 30-34; Schädler (1995) 74-81, who cautions the association of these boards with the game of this name, though in later publications he adopts the convention; Purcell (1995) 17-28; Purcell (2007) 90-97; Habinek (2009) 125127; Trifilò (2011) 321.

${ }^{38}$ Austin (1934) 33-34; Schädler (1995) 83-84; Schädler (2013) 2843

${ }^{39}$ Austin (1934) 34
} 
game. ${ }^{40}$ In this popular adaptation, each player still has fifteen pieces, but uses three dice on a board that uses only two of the twelve-character rows, not three. ${ }^{41}$

The other game that appears most often in our sources is the Greek game polis, which appears to be identical to the Roman ludus latrunculi. ${ }^{42}$ This is a game for two players, who move their pieces, called "dogs" and differentiated by color, on a grid of squares, most often eight by eight. ${ }^{43}$ According to Richmond, players take turns moving their pieces an unlimited number of orthogonal spaces until reaching the desired square, save that pieces could not go through others, so movement must stop if the next square is occupied by another counter. ${ }^{44}$ Schädler argues instead that players may move pieces only one square per turn, but with a leap mechanism permitted. ${ }^{45}$ Players captured pieces by interception, surrounding them with two of their own in either rank or file. ${ }^{46}$ The winner appears to be the player who captures all of the opposing pieces after breaking through their formation. ${ }^{47}$

These games help clarify another distinction in terms: games of skill and games of chance. Games of chance are those that rely only on the throws of a randomizing agent, such as players alternating turns rolling knucklebones, with whoever gets the best roll

\footnotetext{
${ }^{40}$ Austin (1935) 76 notes that the transition may have been early enough that Suetonius and Juvenal mean the specific game when they say alea. Schädler (1995) 95 argues for a date of c. 250-400 CE on the basis of two game boards from Ostia. We cannot, however, trace the evolution of a game to a specific date, nor can we know for certain where the adaptation occurred or how it spread.

${ }^{41}$ Austin (1935) 76-79; Schädler (1995) 86; Schädler (2013) 2843

${ }^{42}$ Austin (1940) 264; Schädler (2002) 99; Schädler (2007) 361; Schädler (2013) 2843

${ }^{43}$ Austin (1934) 26; Austin (1940) 263-264; Richmond (1994) 166-167; Hansen (2002) 11-13; Schädler (2013) 2842-2843

${ }^{44}$ Richmond (1994) 167-169

45 Schädler (1994) 47-67

${ }^{46}$ Austin (1934) 26; Richmond (1994) 169-173

${ }^{47}$ Austin (1934) 26; Richmond (1994) 174
} 
named as the winner. ${ }^{48}$ The last game discussed above, polis or ludus latrunculi, is a game of skill, in which the players use only their proficiency at the game to win, as there is no randomizing agent. The other games above, pente grammai, duodecim scripta, and alea, are all games of skill with a chance element, meaning that randomizing agents impact gameplay, but players must use those chance rolls strategically in order to achieve victory. In practice, the ancient world seems to have operated in a binary system, seeing only games of skill and games of chance; those with both qualities were grouped with games of chance, as will be seen throughout this dissertation.

Ancient authors do not use different terms for games of skill and games of chance. Rather, when they emphasize either quality, they mark the difference contextually with an appeal to chance or skill generally. The Athenian in Plato's Laws grounds the discussion when he remarks upon the element of chance in human affairs, especially the creation of laws. He then broadens his view and says that a god ( $\theta \varepsilon$ có$_{\text {) }}$ ) controls everything, but helping steer human affairs are the elements of chance (TYXH), opportunity (KAIPOE), and skill (TEXNH) ${ }^{49}$ The Athenian elsewhere refers several times to lawmaking as playing a game, offering a link between these ideas. ${ }^{50}$ In the game of human lawmaking, there may at times be more TYXH and at other times more TEXNH, just as different games use one or both element. Appeals to one or the other in passages concerning games make clear whether the game concerned is a game of skill or a game of chance, as will be seen throughout this dissertation.

\footnotetext{
${ }^{48}$ Kidd (forthcoming a) gives the most thorough account of games of chance in the ancient world.

${ }^{49}$ Plato, Laws 709a-b. On these "divine qualities," here anthropomorphized abstractions, being presented in small capitals, see the introduction to Chapter 1.

${ }^{50}$ Plato, Laws 685a, 739a, 769a, 797a-c, 820c-d, 968e-969a
} 
In the Roman world, the same principle holds true, as references to FORTUNA indicate chance and references to ars indicate skill. The distinction is not always clearcut, as when Micio tells his brother that life is like a game played with dice, for in both you must set right with skill (arte...corrigas) what fell by chance (cecidit forte) $)^{51}$ The ambiguity of the statement further complicates matters, as Micio perhaps means using the chance dice rolls skillfully, implying a game with dice and counters, or perhaps means using skill to alter the chance rolls, violating the rules in order to achieve victory; I examine both possible implications in greater detail in Chapter 2 .

Roman law offers the sharpest divide between games of skill and games of chance. Gambling received repeated attention in Roman law beginning in the late third century BCE, when Roman assemblies began to enact laws to enforce morality. ${ }^{52}$ As our ancient sources make clear, games of chance, including games that combined both chance and skill, were inextricably associated with gambling and therefore outlawed save during Saturnalia. ${ }^{53}$ The Digest preserves three laws passed as part of Sulla's reforms in or before $81 \mathrm{BCE}$ and a senatus consultum that establish the exception to this rule: playing for money (pecuniam ludere) is permitted for games of uirtus, such as throwing a javelin and running. ${ }^{54} \mathrm{We}$ do not know whether non-athletic games of skill, such as ludus latrunculi, qualified as contests of uirtus and were thus exempt from gambling legislation. We do know, however, that these games were permitted in public, while

\footnotetext{
${ }^{51}$ Terence, Adelphoe 739-741

${ }^{52}$ Botsford (2001 [1909]) 337; Faris (2002) 205. See Faris (2002) 199-219 for a discussion of the laws and their evolution.

${ }^{53}$ See Toner (1995) 89-101 for an overview of the evidence and the relationship between gambling and morality. Cf. Trifilò (2011) 323-325.

${ }^{54}$ Digest 11.5.2-3. On the dating of these laws, see Berger (1953) 549; Williamson (2005) 463-464. Cf. Faris (2012) 207.
} 
games of chance were not. Cicero condemns Lenticula for being convicted of gambling, which he dared to do in the forum. ${ }^{55}$ Roman fora, meanwhile, are riddled with hundreds of gaming boards carved into the pavement, all of them - at least those actually in Rome - games of skill, further attesting to what was publicly acceptable and what was not. $^{56}$

In assessing the primary sources of games in the ancient world and their contexts, a few scholarly works are critical reading for their comprehensive approach and the depth of their analyses. Hans Lamer's extensive treatise remains crucial despite its age. ${ }^{57}$ Lamer presents an extensive list of sources for both Greek and Roman games, for each of which he weighs the evidence and offers reconstructions where possible. More recent scholarship has fine-tuned or supplanted sections of Lamer's $R E$ entry, but nothing has replaced it. While Lamer's work may no longer be taken as authoritative on all the matters it discusses, it remains an invaluable source, whether taken as an overview of the subject or as a starting point for further investigation. Leslie Kurke, a much more recent scholar, devotes a chapter of her book Coins, Bodies, Games, and Gold to Greek games in the Archaic period, though she uses evidence from the Classical period as well. ${ }^{58}$ She argues that the regulated movement of pieces on a game board "appealed to the Greeks as

\footnotetext{
${ }^{55}$ Cicero, Philippics 2.23.56

${ }^{56}$ See, for example, Thédenat (1904) and Trifilò (2011), who provide plans of the Forum Romanum with the dozens of extant game boards mapped. Cf. the anecdotal evidence of Lanciani (1892) 97: "[W]herever I have excavated the pavement of a portico, of a basilica, of a bath, or any flat surface accessible to the public, I have always found gaming tables engraved or scratched on the marble stone slabs."

${ }^{57}$ Lamer (1927) 1900-2029

${ }^{58}$ Kurke (1999a) 247-298. Kurke lightly reformulates this chapter in her subsequent articles Kurke (1999b) and Kurke (2002).
} 
an image of various forms of symbolic order," especially civic governance ${ }^{59}$ Moreover, she sees certain games as having elite associations and therefore representative of the conflict between elitist and middling ideologies, between the aristocratic, private setting of the symposium and the egalitarian, public setting of the agora.

Nicholas Purcell offers a comparable exploration of games in his article "Literate Games: Roman Urban Society and the Game of Alea. ${ }^{, 60} \mathrm{He}$ explores alea in ancient Rome both as the concept of gambling generally and as the name of a specific game. He puts alea into its wider cultural setting, touching upon many of its associations, including numeracy, symbolism, economic interests, the social aspirations of the players, and literacy. The fact that many Roman game boards use letters rather than squares or circles to mark playing spaces, often creating phrases, allows Purcell to consider the literacy of alea and its players in detail. He concludes that the game boards reflect a quasi-literary culture parasitical upon the elite, including conceptual links to the renegotiation of social status and the formation of protective structures for the societally disadvantaged. The elite response, Purcell continues, is condemnation of alea, taken as representative of all encroachment upon the elites' traditional place at the top of the social hierarchy. This response, in turn, explains the hostility to alea in our sources: alea was the preserve of the non-elites and, worse yet, was ultimately an emanation from the high culture of the elites' own self-definition. ${ }^{61}$

The study of games in general enjoys greater attention than the study of games in antiquity. Here too a few works remain the bedrock upon which later studies are built.

\footnotetext{
${ }^{59}$ Kurke (1999) 264

${ }^{60}$ Purcell (1995) 3-37

${ }^{61}$ Purcell (1995) 36
} 
The most commonly cited are H.J.R. Murray's A History of Chess and A History of Board-Games other than Chess. ${ }^{62}$ The first of these has three aims: to present as complete a record as possible of the varieties of chess that have ever existed, to discover the origin of these games and the circumstances that led to the invention of chess, and to trace the development of the modern game from the first appearance of its ancestor chaturanga in the $7^{\text {th }}$ century CE. ${ }^{63}$ In achieving these goals, Murray explores the gaming history of numerous cultures, touching upon not only chess variants, but also other strategy games that may have influenced them. The nine-hundred-page tome endures as the most influential single source for the history of chess; many studies have offered updates or correctives to sections or specific ideas, but none have come close to replacing Murray's work as a whole. ${ }^{64}$

Murray's other compendium seeks to examine the history of all board games other than chess throughout world history. Murray balances the scope of this project by providing only cursory details of many games. He provides names and basic information where possible, but at times admits his limited knowledge of games' rules and histories. Much work on specific games and game families has emerged since Murray's publication over half a century ago, but it remains authoritative for the breadth, even if not the depth, of the history of board games and their interrelations. The one volume that challenges Murray's work is David Parlett's The Oxford History of Board Games ${ }^{65}$ Parlett, like Murray, divides games into families, which he then explores in detail. He focuses on traditional games with long histories, such as backgammon, but extends his study to more

\footnotetext{
${ }^{62}$ Murray (1913) and Murray (1952)

${ }^{63}$ Murray (1913) 5

${ }^{64}$ Cf. O’Sullivan (2012) 5

${ }^{65}$ Parlett (1999)
} 
recently developed games that compete with them for commercial success. As a game designer himself, Parlett is particularly attuned to the intricacies of game design, a fact that aids his discussion of each game's mechanics and balance-in other words, what keeps games fun.

As we turn our attention back to ancient games, we should note that most of the evidence must be assembled from scattered allusions and references, as the only extended accounts from antiquity are lost or of late date. ${ }^{66}$ Searching for gaming material in Greek and Latin literature often requires an awareness of which words have ludic meanings and how to distinguish their usage in a given context. Of the many possible gaming words, I isolate a few common examples here to help the reader navigate their difficulties.

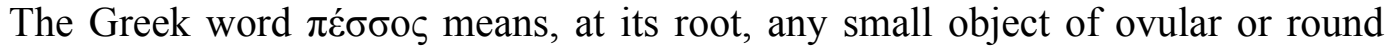
shape, which leads to many diverse uses. For example, the word can mean a medical pessary, a piece of lead, or the dark edge of the pupil. ${ }^{67}$ The most important definition for present purposes is as a piece in a board game or, in the plural, as a generic term for a board game. ${ }^{68}$ When we first see the suitors of Penelope, they are delighting themselves

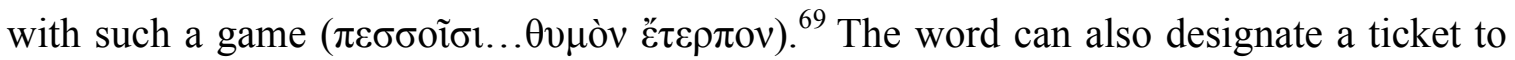
the Assembly, a meaning shared by the related word $\psi \tilde{\eta} \varphi \circ \varsigma$, which likewise indicates both a game piece and a voting stone. ${ }^{70}$

\footnotetext{
${ }^{66}$ Among the lost works are Claudius' treatise on alea, wholly lost but mentioned in Suetonius, Claudius 33.2, and Suetonius' own Peri Paidiōn, the few surviving fragments of which are collected in Taillardat (1967). Late works include those of Pollux and Eustathius, which, though valuable, have inconsistencies and were written sometimes many centuries after the subjects they discuss.

${ }^{67} L S J$ S.V. $\pi \dot{\varepsilon} \sigma \sigma 0 \varsigma$ II.1, II.2, and IV, respectively

${ }^{68}$ LSJ S.V. $\pi \varepsilon ́ \sigma \sigma 0 \zeta ~ I .1-3$

${ }^{69}$ Homer, Odyssey 1.107

${ }^{70} L S J$ s.v. $\pi \varepsilon \dot{\sigma} \sigma \sigma \circ \varsigma$ II.3; LSJ s.v. $\psi \tilde{\eta} \varphi \circ \varsigma$ II.2 and II.5, respectively
} 
A similar word is $\kappa$ six-sided die, typically appearing in the plural as dice. ${ }^{71}$ The word can also mean the single pip on a die, that is, the lowest roll of "one," as used in the expression "three sixes

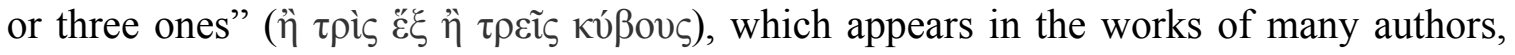
including Plato and Aristotle. ${ }^{72}$ The word also means materials cut into cubes, for instance stone, fish, and cake, these last two being early examples of the culinary technique of dicing, which appears in Greek as well as English. ${ }^{73}$ A similar term is $\dot{\alpha} \sigma \tau \rho \alpha ́ \gamma \alpha \lambda \mathrm{o}$, which indicates the knucklebone of various animals, typically referring to quadrupeds. ${ }^{74}$ Greeks and Romans used these knucklebones as four-sided randomizing agents, later fashioning imitation knucklebones; in these cases, even if an actual knucklebone is used, the term refers to gaming equipment. ${ }^{75}$

As mentioned above, the Latin word ludus presents many difficulties that can only be solved from context, though even then some ambiguity may still exist. The term most often indicates a game, with a vast range of different games possible. For example, Cicero, through the character Crassus, comments that when people accustomed to daily labor are prevented from their work, they turn to a ball game, knucklebones, or dice or they even invent a new game for themselves in their leisure (ad pilam se aut ad talos aut ad tesseras conferunt aut etiam nouum sibi aliquem excogitant in otio ludum). ${ }^{76}$ Contextually, Cicero subsumes playing ball, knucklebones, and dice under the umbrella

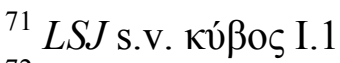

${ }^{72} L S J$ s.v. $\kappa o ́ \beta$ o I.2. For the expression and examples of it, see the discussion in Chapter 1.

${ }^{73} L S J$ s.v. кúßos III.2-4

${ }_{75}^{74} L S J$ s.v. $\dot{\alpha} \sigma \tau \rho \dot{\gamma} \gamma \alpha \lambda \circ \mathrm{CI}_{\mathrm{II}}$

${ }^{75}$ LSJ s.v. $\dot{\alpha} \sigma \tau \rho \alpha ́ \gamma \alpha \lambda \circ \zeta$ IV

${ }^{76}$ Cicero, de Oratore 3.15.58 
of game, as it is in contrast to these existing games that a new one is created. The word also designates athletic games, including public games. ${ }^{77}$ Rather than these specific definitions, ludus can indicate frivolity in the most general senses, either innocuous, as in the playing of children, or malicious, as in mockery. ${ }^{78}$ Context indicates the kind of game meant; for the tabletop games discussed in this dissertation, other ludic words will be present, such as those indicating counters or randomizing agents.

Finally, one of the most important words in the gaming lexicon is alea. The word can indicate any risk, hazard, or gamble, as it were, not only those that involve financial exchange, necessitating a careful eye for the appropriate meaning in any given text. ${ }^{79}$ More problematic is that, as mentioned above, alea comes to be the name of a specific game, though that development cannot be accurately dated. Columella refers to making a living via the "hazard of the sea and of trade" (maris et negotiationis alea), where he certainly does not mean a game, but shortly afterward warns his audience about the lazy kind of slaves accustomed to leisure and enjoyable pastimes, including public games, the theater, alea, cookshops, and brothels (socors et somniculosum genus id mancipiorum, otiis, campo, circo, theatris, aleae, popinae, lupanaribus consuetum); in this latter example, Columella certainly does mean gambling and/or the game named alea. ${ }^{80}$ Context is often not enough to distinguish alea as gambling from alea as a game, especially since, as noted above, games with a chance element became equated with gambling in ancient Rome. When we also see a reference to a game piece or a board, then the game alea is most likely intended, though this does not preclude gambling on that

\footnotetext{
${ }^{77}$ OLD s.v. ludus 3

${ }^{78}$ OLD s.v. ludus 1 and 4 , respectively

${ }^{79}$ OLD s.v. alea $1-2$

${ }^{80}$ Columella, de Re Rustica I.praefatio 8 and I.8, respectively
} 
very game. Only in rare cases does the answer appear straightforward, as in Suetonius' description of Claudius as playing alea zealously (aleam studiosissime lusit), writing a book on the subject, and playing while in his chariot, using a board (alueus) modified so that the movement of the chariot would not disturb his game. ${ }^{81}$ The lack of any reference to money and the presence of a board indicate that this is the game alea.

I return now from the minutiae of weighing our sources to what the assembled evidence tells us. As stated above, ancient literature preserves ludic themes, which authors incorporate into their works in ways that become systematized over time, allowing us to connect the dots and discern patterns, modes of expression consistently used to address specific concerns. Authors take recourse to the same ludic images across time and genre, but the direction of influence is not always traceable; passages may be similar because one author alludes to another or because both writers are operating within the same literary traditions. ${ }^{82}$ In either case, Greek and Latin literature reflects a ludic vocabulary that authors employ in passages concerning existence and propriety.

I argue that these passages expose a dichotomy between descriptions of people as though part of or playing a game and, conversely, portrayals of people actually playing games. On the one hand, games serve as a readily accessible, abstract screen on which to project concerns about the vicissitudes of fortune, civic responsibility, and human agency. On the other hand, although it is games' prevalence - the very fact that people play them — that makes them recognizable and relatable images, literary representations

\footnotetext{
${ }^{81}$ Suetonius, Claudius 33.2

${ }^{82}$ At times, the incomplete nature of our evidence also precludes considering the direction of influence. For instance, no fewer than four playwrights of Greek Middle Comedy-Alexis, Amphis, Antiphanes, and Eubulus - wrote plays entitled Kubeutai, all of them fragmentary at best. Likewise, the Roman dramatist Pomponius wrote an Aleones. Cf. Hunter (1983) 142.
} 
of people playing games are often fraught with moral anxiety: authors regularly describe games of skill as morally neutral, but condemn games of chance, the chief concern being their use as a vehicle for gambling. ${ }^{83}$ I contend that ancient authors portray gambling as symptomatic of the mismanagement of property and, as such, use accusations of gambling as a polemic.

This dissertation comes in two parts, one devoted to each half of the divide between games as metaphor and games in practice. Each section consists of two paired chapters, which explore the same topic in Greek and Latin literature, respectively. In order to show the pervasiveness of the ludic vocabulary in ancient texts, for the most part I avoid including the same genre or author in more than one chapter. I thus largely accept the indeterminacy of influence and do not try to trace direct connections from one author to the next, which may be impossible to prove, but rather use a wide range of authors and genres to show the prevalence and regularity of ludic themes in the literary landscape. In the few instances where I argue for a direct connection between authors, I do so to show how one deviates from his model, a divergence that corroborates the author's awareness of ludic themes as he consciously shapes his use of them.

Chapter 1 explores Greek expressions about how life is or is like a game. Greek authors commonly refer to a deity or cosmic force playing pessoi with human affairs. Pessoi is not a specific game, but rather a class of games played with counters and without randomizing agents, such as dice. ${ }^{84}$ This cosmic player, then, is playing a game of pure skill, without a chance element, though the humans without a view of the master

\footnotetext{
${ }^{83}$ See Mackenzie and Finkel (2004) 14 on the moral implications of games, especially games of chance, in many cultures.

${ }^{84}$ Cf. Austin (1940) 260-261
} 
plan may feel subject to the vagaries of random chance. I trace this theme of a cosmic pessoi player from the hints in Homer through firmer occurrences in Heraclitus and Plato, as well as its continuation in later dramatists. Examination of this theme includes using the framework I establish to resolve a textual crux in Sophocles' Ajax. I then show how tragedians and philosophers also use games to explain civic matters, including city formation and legislation. I end the chapter by returning to expressions of a cosmic force controlling human affairs, but this time with a chance element explicitly present: in the game of life, one cannot control the rolls of the metaphorical dice, but can only react to them and use one's circumstances as shrewdly as possible.

Chapter 2 is the counterpart to Chapter 1 and explores the same ideas in Latin literature. To emphasize the enduring pertinence of ludic themes, the passages in this chapter come from genres absent from or only briefly discussed in the earlier chapter: comedy, satire, lyric, and panegyric. I argue that even across a diachronic, cultural, and generic expanse, we can identify the same gaming imagery at work. I analyze a few passages at length to show how Roman authors adopt and adapt the ludic themes of their Greek predecessors; these deep readings show how the lusory material textures our understanding of the passages as a whole. Chapter 2 begins with the final theme from Chapter 1. I show that Terence's description of life as a game of chance has roots in Greek tragedy and philosophy, though his explicit model is Menander, and then show how the wording of the passage allows for a second interpretation that one should cheat in the game of life. Next, I explore Horace's bathetic inversion of the same theme in his final satire and his use of a cosmic player in his first three books of odes, most prominently in 3.29 , the final poem of the collection before the sphragis of 3.30 . The 
chapter ends with a consideration of the anonymous Laus Pisonis, which I argue takes up the theme of games and civic matters when it casts Piso as an alternative emperor because of his skill at a board game.

The end of Chapter 2, the panegyric account of Piso playing ludus latrunculi, segues into Chapter 3, which introduces the other half of the divide: rather than surveying literary descriptions of people as though part of or playing a game, Chapter 3 examines portrayals of people actually playing games. In order to facilitate discussion, this chapter focuses on oratory, a genre that purports to describe real events and impugn or defend those actions. Oratory is thus an ideal genre for examining the moral qualms that accompany attributions of game playing: orators outline contemporary practices as they actually stand while they consider possible infringements upon accepted norms. When orators appeal to their audience members' values, they simultaneously define exactly what those values are—or at least what are publicly hailed as their values.

In order to consider why Greek authors ascribe specific moral judgments to games, I explore patterns in the literary sources. Authors consistently contest games of pure skill as a morally neutral pastime, the value of which is itself open to debate. Games of chance, however, consistently meet condemnation and are charged with immorality, especially when used for gambling. Perhaps as a way to rationalize why games of chance are denounced, orators frequently associate them with other activities that similarly may be morally neutral, but become iniquitous when monetized or taken to excess: sex and ingesting food and alcohol. I use this vice trio of gam(bl)ing, fornication, and consumption as a lens to explore the moral valuation of games in Greek literature and possible reasons for those judgments. 
Chapter 4 examines episodes in Latin literature that portray people actually playing games. Like Chapter 2, Chapter 4 eases the transition from Greek literature to Latin by beginning with an early dramatist, who openly follows Greek models: Plautus. I trace Plautus' use of the vice trio and how he employs the motif to create humor. Gaius Titius' denunciation of his contemporary magistrates appeals to the same assemblage of iniquities, to which his peers devote their entire days at the expense of their juridical obligations. I end this chapter by examining a long-debated textual crux in Sallust's Bellum Catilinae. I argue that the likeliest emendation is the one that incorporates the vice trio, corroborated by an examination of probable models and comparanda.

The list of works I explore in this dissertation is far from exhaustive; this dissertation is not a catalog, nor is it intended to be one. Rather, I identify recurring themes and examine their specific instantiations in a broader context to investigate the implications of ludic passages in our ancient sources. This dissertation sheds light on some of the ways ancient authors employ games and connects to larger discussions about how they portrayed their world. Additionally, while no sourcebook for games in the ancient world exists, the research for this project is perhaps a start. 


\section{Chapter 1: Ludic Ideology in Greek Literature}

\section{Introduction}

The ancient Greeks offer many ways of understanding the world and one's place in it. The present chapter explores one of these modes of thought: that human existence is - or is like - a game. Whose game is a seemingly simple question, but in fact produces

a multitude of complex answers. Ultimately, life is not just one game, but many: humans can consider themselves pieces on a cosmic game board controlled by a preternatural player, yet have their own games, such as citizenship and legislation, and must accept whatever the dice rolls of their fortune produce. This chapter explores the texts that preserve this ludic mentality and sheds light on one way the Greeks portray their place in the universe.

I identify three primary ludic themes, related ideas that recur in Greek literature. These ludic themes correspond to the games mentioned above. "The cosmic game" is a motif by which Greek authors explain the organizing principle of the universe by considering it an anthropomorphic being playing a game of pessoi, in which humans are the pieces. "Cities and citizenship" shows how authors link games and citizenship, resulting in the establishment and governance of cities being described as games. This theme plays on the dual sense of polis as both the Greek word for "city" and the name of a specific board game. Finally, "playing your roll" explores ascriptions of chance to the rolls of cosmic dice, such that a human's role in life is not to control his or her circumstances, but rather to react to them appropriately.

As is to be expected from a line of thinking rooted in metaphor, symbolism 
abounds in the texts considered here. The symbolism often works on multiple levels, such that what is presented as a game may be—or someone may desire it to be-a reflection of reality, while what seems to be grim reality may be nothing more than a game. Once the surface meaning has been laid aside, the texts authorize us to dig deeper and uncover relationships with other ludic sources, revealing significance through verbal echoes and mirrored contexts. In other words, the ludic imagery invites us to play an interpretive game.

The passages discussed below span genres and time periods. With that in mind, one remarkable feature is the consistency of the ludic material in the passages: games permeate Greek literature despite generic conventions and changes in the social circumstances of the authors. Themes recur time and again, so consideration of the broader context elucidates otherwise baffling passages and fleshes out the connotations of seemingly straightforward ones. Some metaphors are, of course, just metaphors; not every reference to games in the Greek corpus functions as a window into an ideology, nor can one expect to find unilateral evidence in expressions rooted in a wide-ranging aspect of daily life. The salient point is how different Greek authors take recourse to the same ludic themes when considering life and humans' place in the world. By demonstrating the consistency of ludic ideology in Greek literature, this chapter shows how passages that might be overlooked as mere metaphor can serve as an important conceptual tool for investigating a largely unexplored facet of ancient Greek thought.

This chapter divides the material thematically. It begins with an exploration of the two games in Homer, whose influence on later Greek authors is well established. Building on the Homeric material, the first theme is "the cosmic game," the notion that 
humans may be little more than pieces in a cosmic game of pessoi played by a divinity or superhuman force. The distinction between forces and divinities is not always clear, so the identity of this cosmic player, even when named, is often murky. As one scholar puts it, "It seems more than likely that our superficial familiarity with personification as a mode of literary and artistic representation leads us to draw a much sharper distinction between the categories of abstract, personification and goddess than would have been felt by most ancient Greeks." ${ }^{85}$ While the differentiation of majuscule and miniscule letters has made texts more accessible, it has also introduced problems of interpretation. For example, TYCHE is a deity in some Greek passages, but is elsewhere a personified force and still elsewhere simply a concept. As Feeney summarizes the problem, "[t]he clarity enforced by modern printing conventions... may obscure the advantages accruing to a mentality that did not rigidly impose demarcations between words, qualities, and instantiations, and that could fruitfully mobilise this indeterminacy." ${ }^{" 86}$ As Clark cautions, "[t]he default solution— to note the problem, remark on its difficulties, and then continue to employ initial lower- and upper-case characters-is actively unhelpful. ${ }^{, 87} \mathrm{I}$ follow Clark's lead and present divine qualities such as TYCHE in small capitals throughout this dissertation "to reflect the 'indeterminacy' integral to them." divine qualities is most frequent in "the cosmic game," where they often serve as the

\footnotetext{
${ }^{85}$ Stafford (2000) 230-231

${ }^{86}$ Feeney (1998) 88. Giannopoulou (2000) 257 exemplifies the opposite approach and argues that "[t]he fundamental distinction is between a static sense, i.e. tyche as factum (seen as a state, a condition or an event), and a more dynamic sense, i.e. Tyche (with a capital T) as agens (seen as an indefinite, supernatural agent capable of effecting changes in human life)," though she admits that "[t]his distinction...does not represent an absolute and clear-cut dichotomy."

${ }^{87}$ Clark (2007) 20-21

${ }^{88}$ Clark (2007) 21
} 
cosmic player. As Clark notes about this practice, "[t]he device does not prevent active consideration of where, on the spectrum [from quality to deity], any utterance or inscription of a 'word' from the vocabulary might be situated, and it helps to remind us that we are indeed dealing with a spectrum and not two separable categories.. 89

In a similar effort to remain as true to the source material as possible, I transliterate, but do not translate, the names of divine qualities. Offering a single translation for qualities such as TYCHE or AIŌN restricts consideration of their broad array of meanings, while providing different or multiple definitions in each circumstance is taxing for the reader and likewise dilutes the polysemy inherent in the words in their original language. ${ }^{90}$ In passages where the cosmic game is present contextually, but no quality or deity is named, I supply FORTUNE, which retains the spirit of the ludic theme and the essence of the cosmic player in all its various appellations; this scheme allows for consideration of the theme in isolation, apart from specific instantiations and without giving preference to any individual name attributed to the cosmic player in Greek literature.

"The cosmic game" begins with Heraclitus and Plato to show a continuity of imagery that transcends their differences in time and philosophy, then traces the same idea of the cosmic game through later dramatists, such as Menander. It is unknown exactly to what extent each individual author responds to his predecessors and contemporaries, but the accumulated evidence demonstrates consistent use of the same theme. Invoking the cosmic game to explain the nature of the universe and seeming

\footnotetext{
${ }^{89}$ Clark (2007) 21

${ }^{90}$ Contra Giannopoulou (2000) 257, who finds the distinction between "tyche as factum" and "Tyche as agens" useful precisely because it "can help use decide which translation of tyche is better in a given case."
} 
chance occurrences crosses genres and time periods; whether it is a philosopher declaring his own beliefs or a fictional character's lines in a play, we find a remarkable regularity of imagery and wording throughout centuries of Greek writing that speaks to an enduring trope in Greek literature. Consideration of this theme closes with a final subsection that resolves a much-debated passage in Sophocles.

The second theme is "cities and citizenship," which explores the ways Greek authors describe citizenship in ludic terms. I subdivide this theme into three subthemes: "embodied citizenship," "polis," and "the game of citizenship." In "embodied citizenship," I move beyond "the cosmic game" and argue that humans are not just pieces in the cosmic pessoi game, but are also parts of the complex system of a city. Beginning with the tragedians Euripides and Aeschylus, I show how Greek authors use imagery from pessoi to create a symbolic relationship between cities and games. That polis is both the Greek word for a city and the name of a Greek board game strengthens the relationship between the two and allows for wordplay. The tragedians equate people to game pieces that gather together to form cities; the pieces come to be defined by their relationships with one another. A century later, Aristotle considers a man who is citiless by nature in terms of an isolated pessoi piece: in each case, the subject is deprived of the symbolic structure that grants it meaning.

The next subtheme, "polis," reinforces the association of people with game pieces and groups of the latter with cities. I trace the game polis through the lexicographical tradition to outline what is known of the game and its key wording, though a reconstruction of the rules of play is beyond the scope of this study. I also show how Socrates — or rather the character Socrates that Plato employs — describes his ideal city in 
ludic terms in the Republic, even going so far as to apologize at one point for taking his game too seriously. With the equation of cities and gameplay established, "the game of citizenship" explores governance and legislation, that is, participating in in the affairs of the city at the deepest level, as a kind of game. When in an anecdote Heraclitus prefers playing knucklebones with children to writing laws for the Ephesians, I consider how the philosopher likens the two: he implies that he is not choosing between two disparate activities, but rather between two games. Plato goes even further and claims that children's games have the utmost authority over legislation, for men govern the way they played as children. He says that those who enjoy an ordered program of games legislate with earnestness and permanence, while those who continually play new games constantly change their laws, for they learn to love novelty itself above all else.

"Playing your roll" is the final theme and combines elements from the previous sections. Similar to "the cosmic game," this theme centers on human affairs as governed by a cosmic force, but with a component of human agency. Rather than a cosmic player maintaining complete control over mortals, the throws of cosmic dice determine one's fate. ${ }^{91}$ While humans may have no power over what those rolls are, they do have to ability to react to them; in the dice game of life, one must play as well as possible whatever FORTUNE bestows. In other words, once the dice of fate are cast, it is up to each individual to play his or her roll. Aeschylus, Sophocles, and Euripides all contribute to this theme and their characters show its pertinence to a variety of circumstances, both

\footnotetext{
${ }^{91}$ Dice are a subset of randomizing agents, as the latter term encompasses dice, knucklebones, casting sticks, coins, and a variety of other small objects. The relevant sources for this theme, however, either name dice explicitly or leave the instrument unspecified, but with dice as the likeliest choice. As such, I use the term "cosmic dice" to discuss this theme, though the equation of dice and randomizing agents is not appropriate in other contexts.
} 
good and ill. Working in the wake of the tragedians, Socrates and Plato offer a more general application to all aspects of one's life, but especially misfortune.

Notions of embodiment prove important to my discussion of many passages in this chapter. The term carries many implicit meanings and deserves careful consideration. As Traub notes, embodiment is increasingly used in scholarship, including in fields where it has not been substantively theorized. ${ }^{92}$ Tribble highlights the difficulties of the word $:^{93}$
"The term 'embodiment' is already labile. In the humanities, it is used in a diversity of registers, ranging from the ways in which an actor inhabits a part, to the foregrounding of the body through the performance of gender, to Foucauldian-inflected discussions of the social inscription of the body, to the peculiarly early modern nature of embodiment as it is experienced within the humoral tradition. In the cognitive sciences, the body has only recently been seen as coming within the ambit of research, where it is studied under the rubric of 'embodied cognition', which refers 'to the assumption that thoughts, feelings, and behaviors are grounded in sensory experiences and bodily states'."

Given the multitude of connotations the term evokes, I here situate my use within the scholarly milieu. By "embodiment" I mean the representation of an idea, being, or ideology in a different, often physical form, such as a personified and/or deified TYCHE as an amalgam of ideas about chance and fate; in this I follow recent work done in the field of Classics. ${ }^{94}$ This is not quite the same as Bourdieu's embodied practical logic, though I do consider the ancient Greeks' disposition to a cosmic player to exist at a level deeper than the discursive, that is, they could in reality consider themselves powerless against the divine or the universe toying with them, not that they believed that power actually

\footnotetext{
${ }^{92}$ Traub (2016) 32

${ }^{93}$ Tribble (2016) 629-630. The definition of 'embodied cognition' she cites is from Meier et al. (2012) 706.

${ }^{94}$ For similar uses of embodiment, see Stafford (2000) 28, 45, et passim; Seaford (2004) 1-2, 14, et passim; Clark (2007) 15-16, 74-75, et passim; Halliwell (2008) 343.
} 
took the form of a pessoi player. ${ }^{95}$ While aspects of this chapter are indebted to Kurke, I do not follow her use of embodiment to refer to an ideology of personal, bodily action, in which noble men adopt that ideology into their own bodies and take action themselves, such as personally making contact with xeinoi and participating in warfare. ${ }^{96}$ Similar to Kurke, the field of gender studies, particularly feminist scholars, uses embodiment as the process by which societal values are inscribed on the body, that is, the various ways that societally determined gender roles shape human bodies and thereby reinforce cultural norms. ${ }^{97}$ Threadcraft offers more specificity: ${ }^{98}$

"Embodiment is a central concern of feminist theory insofar as the body is a site for the symbolic construction of sexual difference, a ground for political exclusion or inclusion, a locus of subjectivity, a prospect for selfrealization, and the material focus of many labors that typically fall to women and/or define femininity. Not only have women been primarily responsible for caring for the bodies of men, children, and elders, but ideals of Western feminine subjectivity call on them to fashion their own bodies as ornamental surfaces for the male gaze."

Scholars in sociology and performance studies likewise use embodiment with a focus on the human body itself and its interactions with its environments. ${ }^{99}$

My usage diverges from these approaches in that I do not focus on the body as such, but rather on the way ideas are reified into forms, which include, but are not limited to, human bodies. My approach is closer to the description proffered by Traub, whose

\footnotetext{
95 Bourdieu (1990) 69-79

${ }^{96}$ Kurke (1999a) 255-260; Kurke (1999b) 253-255; Kurke (2002) 21-24

${ }^{97}$ On this use of the term embodiment in gender studies and feminist theory, see Bordo (1999) 107-138; Connell (2002); Orr (2006) 1-10; Kimmel (2011); Threadcraft (2016) 207-226.

98 Threadcraft (2016) 207

${ }^{99}$ For sociological work on embodiment and the body, see the recent volumes Waskul and Vannini (2006) and Smith (2017). For recent work on embodiment in Classics that is tied to scholarship in sociology, performance studies, and gender studies, see, e.g., the volume Fögen and Lee (2009); Worman (2014) 1-12; Worman (2018) 428-442.
} 
background is in feminist Shakespeare studies: "As that which assumes or is given corporeal form, embodiment as a critical concept bridges the material and the discursive, the experiential and the analytical, the sensory, the affective, and the cognitive." ${ }^{, 100}$ While I acknowledge that the term has broad and sometimes competing meanings for scholars working in and with other fields of study, I use embodiment for hermeneutic convenience to mean encapsulating a concept in a (new) body or form, quite literally positioning it in a body; my usage of the word is not intended to invoke all of its diverse implications across disciplines.

The writings under examination in this chapter do not demonstrate unequivocal evidence for one specific interpretation, but rather draw attention to what I would call a ludic mentality in Greek literature. Understanding life as a game is not the only way of reading this material, nor is it mutually exclusive of alternate considerations of the world, but it reflects one facet of Greek thought. This chapter proceeds as chronologically as possible for each theme, but at times material is introduced out of sequence for the sake of an argument's coherence. While the focus of this chapter is on board games and games of chance, parallels to other modes of play are included where appropriate.

\section{Homer}

\section{The Iliad and Knucklebones}

Homer mentions non-athletic games just twice. It is perhaps fitting that these references follow a perfect divide of works and typology: we see a game of chance near the end of the Iliad and a board game near the beginning of the Odyssey. The two

${ }^{100}$ Traub (2016) 32 
passages yield different, but related effects. The Iliad portrays the destructive consequences of uncontrollable emotions that arise from astragaloi, while the Odyssey uses the game of pessoi as shorthand for inappropriate activity. Both episodes also expose notions of embodiment, as well as connections between ludic activity and reality that, as I will argue, inform a Greek perception of the self and the world, mediated through the symbolic character of games.

The sole appearance of a game of chance in the Homeric corpus is near the end of the Iliad. Patroclus' shade appears to the sleeping Achilles with a request for the future and a reminder of the past: ${ }^{101}$

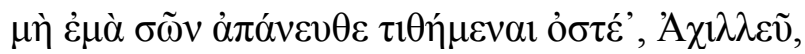

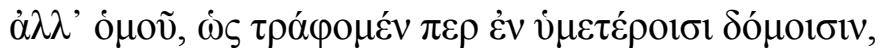

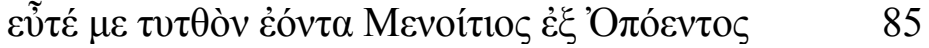

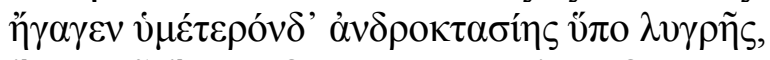

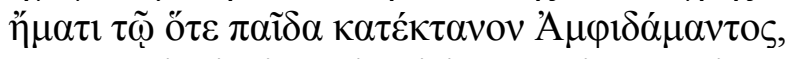

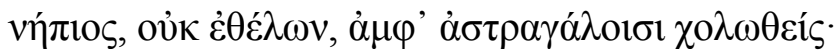

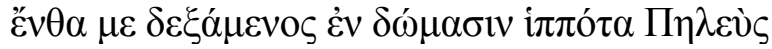

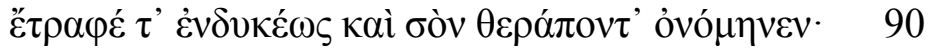

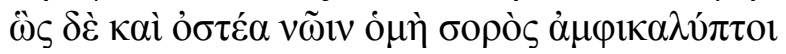

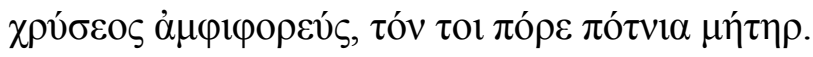

Do not lay my bones far away from yours, Achilles, but together, just as we were reared in your house, when Menoetius led me, still quite young, from Opus to your country because of grievous manslaughter on the day that I killed the son of Amphidamas, childishly, unwillingly, angered over a game of knucklebones; then the horseman Peleus accepted me into his house and kindly raised me and named me as your squire; so let one and the same golden, two-handled vessel enfold our bones, the urn your queenly mother gave you.

Patroclus became angry while playing a game and murdered Amphidamas' son. He describes his own unwitting behavior as nēpios, meaning both "foolish" and "childish," but the fact that Patroclus actually was a child at the time does not seem to excuse his

${ }^{101}$ Homer, Iliad 23.83-92 
conduct, evidenced by his need to leave his homeland. Rather, the wording subtly suggests a level of symbolic embodiment, one that can be explored more deeply. ${ }^{102}$ Patroclus was unable to keep his ludic contest separate from physical violence. Put another way, his figurative competition for victory bled into an actual life and death struggle, the ultimate heroic challenge. Knucklebones function as embodiments of chance and signifiers of fate; although Amphidamas' son presumably played for fun, his rolls called into question his ultimate fate: when he would die.

That the kind of substitution in this scene involves Patroclus is exceptionally appropriate. Patroclus, after all, consciously engages in substitution with symbolic resonance by donning Achilles' armor and leading troops into battle under the guise of his more famous comrade. ${ }^{103}$ As much as he is able, Patroclus embodies what Achilles represents to the opposing armies: a warrior recognizable by his martial prowess and military equipment rather than his face or true identity. When Patroclus adopts the façade of Achilles, however, he also unknowingly assumes part of the latter hero's fate, dying on the shores of Troy. ${ }^{104}$

Patroclus' childhood game of knucklebones led to death and now after dying himself, he wants his own bones cast beside those of Achilles. The juxtaposition of knucklebones with Patroclus' bones is a reminder that the ludic apparatus comes from

${ }^{102}$ Cf. Kurke (1999a) 292 and (2002) 40: "Patroklos kills 'foolishly, unwittingly,' because he is unable to keep play competition from verging into real violence, as the players come to embody the game."

${ }^{103}$ Homer, Iliad 16.130ff.

${ }^{104}$ In the scenes leading to his death, Patroclus is for the first time and then repeatedly

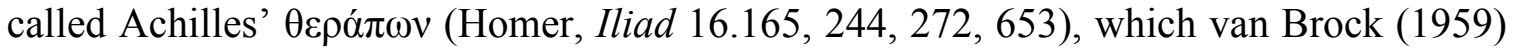
117-146 has shown originally meant "ritual substitute" when borrowed into Greek from Anatolia. Cf. Nagy (1979) 33, 291-292; Nagy (1990) 129-130; Lowenstam (1981) 126131, 174-177. 
once-living animals, whose death is necessary for the game. In the same way, the hero's words suggest another form of embodiment, as the bones of mortals are identified as the playthings of the gods; the mingled bones on the battlefield are nothing more than the gods' game of astragaloi, the death of the warriors involved simply part of the game. ${ }^{105}$ This interpretation foreshadows the literary theme of "the cosmic game," played by the divine using mortals as the pieces, discussed below.

\section{The Odyssey and Pessoi}

The lone non-athletic game in the Odyssey appears near the beginning of the poem, when the suitors of Penelope, in their very first appearance in the poem, amuse themselves with pessoi. Although seemingly an unserious pursuit, the game is far from inconsequential. Rather, it serves a programmatic role, indicating the suitors' violations of xenia and vicarious activity, as all their game playing does: ${ }^{106}$

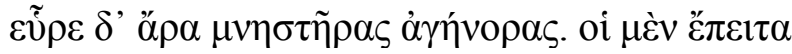

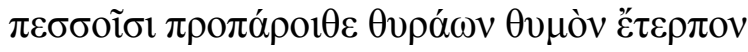

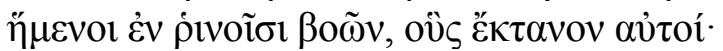

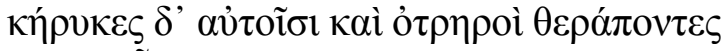

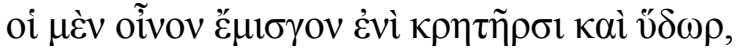

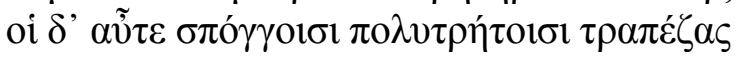

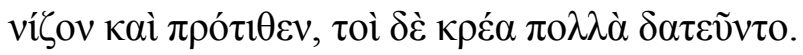

There [Athena disguised as Mentes] found the arrogant suitors. Sitting on the hides of oxen they themselves had killed, they were delighting themselves with pessoi in front of the doors. The heralds and servants

${ }^{105}$ Kurke (1999a) 292; Kurke (2002) 40-41. Kurke also notes that $\alpha \sigma \tau \rho \alpha ́ \gamma \alpha \lambda$ os occurs three other times in the Homeric corpus, each time indicating the vertebra of a mortally injured hero (Iliad 14.466; Odyssey 10.560 and 11.65), strengthening the association. Cf. Plato's claim (Laws 644d) that each living being is a puppet $(\theta \alpha \tilde{v} \mu \alpha)$ of the gods and that we do not know whether we are created as a mere plaything ( $\pi \alpha$ í $\gamma v i o v$ ) or for an earnest engagement ( $\sigma \pi \mathrm{ov} \delta \tilde{\eta} \tau \imath \mathrm{\imath} \iota)$.

${ }^{106}$ Kurke (1999a) 255-260; Kurke (1999b) 253-255; Kurke (2002) 21-24. The quotation is from Homer, Odyssey 1.106-112. 
were busy all around them: some were mixing wine and water in mixing bowls, others were cleaning tables with porous sponges and setting them out again, and others were cutting large amounts of meat.

The suitors' non-athletic amusement is connected to their expropriation of Odysseus' home and stores: they recline on the hides of Odysseus' oxen that they themselves slaughtered before they drink his wine and eat his livestock. The suitors are depicted transgressing the bounds of hospitality, partaking heavily of Odysseus' household while contributing nothing from their own, violating the reciprocity inherent in xenia. While the suitors did previously kill Odysseus' oxen themselves, their one action is drastically overshadowed by their violation of the customs inherent in xenia, which principally involves embodied exchange, that is, the giving of gifts that represent the affection of one party to the other. Moreover, the servants doing real work to prepare a feast for the suitors provide a sharp contrast to the suitors' own indirect actions and symbolic game.

The suitors' game was a matter of debate already in antiquity: ${ }^{107}$

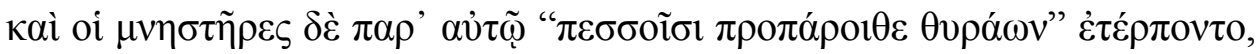

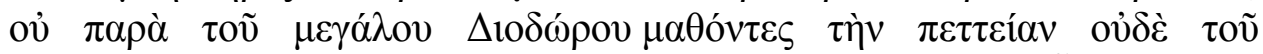

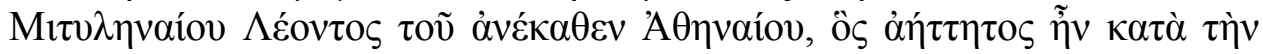

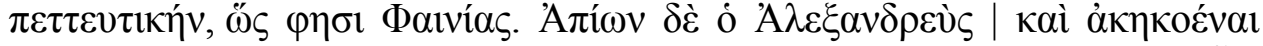

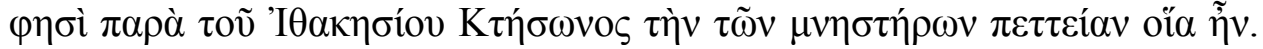

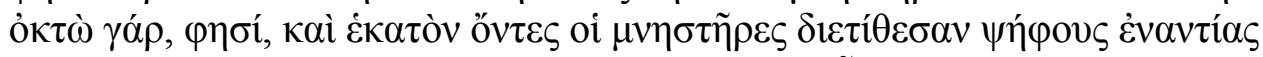

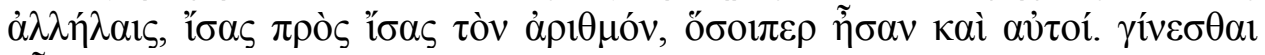

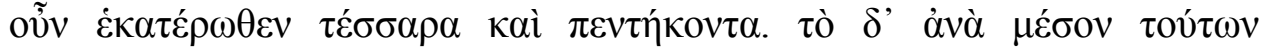

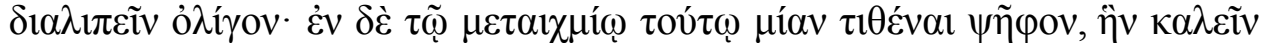

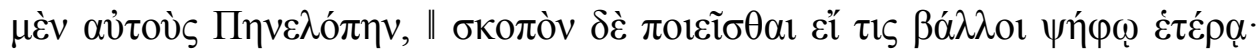

\footnotetext{
${ }^{107}$ Athenaeus, Deipnosophistae 16e-17b. Not only was the nature of the suitors' game debated in antiquity, but the number and identities of the suitors were as well. The number of suitors Cteson gives, one hundred eight, matches the number Telemachus gives to his father in Homer, Odyssey 16.245-253: fifty-two suitors from Dulichium, twenty-four from Same, twenty Achaeans from Zacynthus, and twelve from Ithaca. Apollodorus, Library epitome 7.26-30 purports to name all the suitors, but this account does not conform to the Homeric version: Apollodorus says there were one hundred thirty-six suitors, though he names only one hundred twenty-nine, and his list does not include all of the suitors explicitly named in the Odyssey.
} 


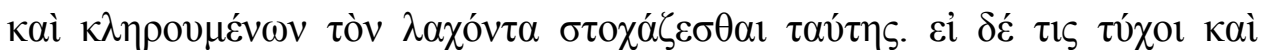

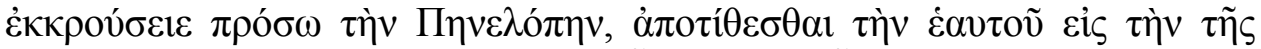

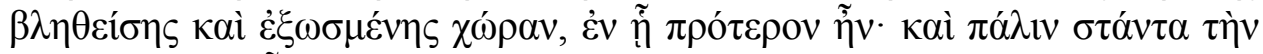

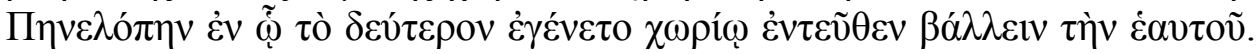

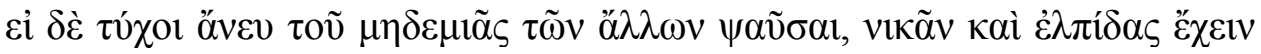

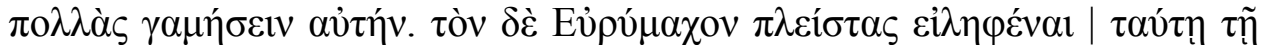

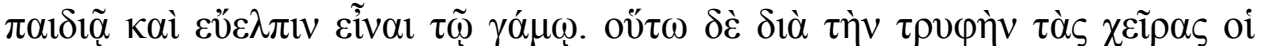

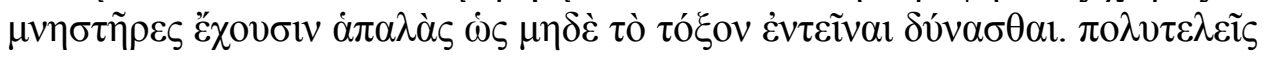

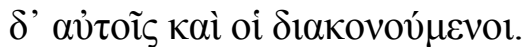

The suitors in Homer delighted themselves "with pessoi in front of the doors," but they did not learn the game from the great Diodorus, nor from Leon of Mitylene, originally of Athens, who was unconquered at the game, as Phainias says. Apion of Alexandria says he heard from Cteson of Ithaca that the suitors' game was like this: he says that since there were one hundred eight of them, the suitors arranged pebbles opposite one another so that there were equal numbers facing equal numbers and there was one for each of them. Thus there were fifty-four on each side. They left a little space in the middle. In this space between the two armies they placed a single stone, which they called Penelope, and they made the object of the game seeing if anyone could hit it with another stone. After drawing lots, whoever was chosen took aim at it. If anyone happened to knock the Penelope stone forward, he put his down in the spot where the Penelope stone was struck and displaced, where it had been earlier. Once the Penelope stone stood still again in its second position, he threw his stone from where it had been before. If he succeeded without touching any of the other stones, he won and had great hopes that he would marry her. Eurymachus had won the most times in this game and was optimistic about the marriage. And so because of their luxurious living, the suitors had soft hands, so that they were not able to stretch the bow.

In his reconstruction of the game, Cteson points to the significance of the Homeric scene even in antiquity. Having failed to convince Penelope to wed one of their number, the suitors idly pass time while they wait for her choice, an answer that never comes. ${ }^{108}$ The suitors therefore substitute Penelope with an eponymous piece in a game, exchanging true courtship for a symbolic pursuit of marriage. The Penelope stone embodies everything that Penelope represents to the suitors, not only the woman herself, but also

${ }^{108}$ That is, Penelope never chooses a suitor directly. She does eventually say that she will wed the winner of the contest of the bow, on which see below. 
Odysseus' estate and the prestige of replacing that hero. According to Cteson, the suitors believe that capturing the Penelope stone will result in taking Penelope herself in marriage, as though the game serves as a microcosm of reality; just as Penelope has been embodied into a marble, the suitors believe that they will (re-)embody the result of the game in their actual lives, such that Eurymachus, who was most often victorious in his ludic aim, was confident that he would emerge triumphant in his actual objective.

Cteson's explanation of the suitors' game of pessoi also mentions the best-known game of the Odyssey: the contest of the bow. The ancient commentator states that the suitors weakened themselves through their pessoi playing, with the result that they were unable to stretch Odysseus' bow; their years of vicarious living left their bodies unable to succeed in a physical competition. As we leave Cteson's exegesis and return to the Odyssey itself, it is interesting that Penelope provides the bridge between the suitors' first game and their last, offering marriage to herself as the stakes, seemingly giving credit to their notion that she is a prize to be won rather than a woman to be wooed. ${ }^{109}$ The suitors participate in what they believe is only a symbolic contest, shooting Odysseus' bow without violence, but Odysseus literalizes the game and uses the bow for its original, martial purpose by turning the suitors into targets. ${ }^{110}$ In other words, just as Cteson states that the suitors hoped their success at pessoi would be actualized, transforming victory in the game into victory in their true objective, Odysseus actualizes the contest of the bow,

\footnotetext{
${ }^{109}$ Homer, Odyssey 21.68-79. Scodel (2001) 321-322 notes that the contest of the bow introduced by Penelope's speech marks the formalization of a new kind of game, for Penelope has offered only herself, not the possessions of Odysseus' household, as the prize; since Penelope says she will leave the house with the winner, the game is winnertake-Penelope rather than winner-take-all, Telemachus properly inheriting the estate now that the suitors are averse to killing him (20.241-246).

${ }^{110}$ Kurke (1999a) 258-259; Kurke (1999b) 254-255; Kurke (2002) 23
} 
triumphing in the game before using the bow to achieve his real goal: taking revenge on the suitors. ${ }^{111}$

After Odysseus achieves success at the game, he announces that the evening's amusements must be arranged: ${ }^{112}$

vข̃v $\delta$ '

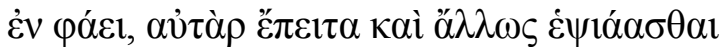

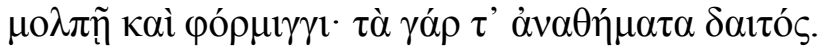

But now is time for dinner to be prepared for the Achaeans, while there is still daylight, and then for others to amuse themselves with song and lyre, for these are the ornaments of a feast.

Odysseus compares the imminent murder of the suitors to the slaughter of animals for the evening meal; they are metaphorically transformed from uninvited dinner guests into dinner itself. ${ }^{113}$ The verb $\dot{\varepsilon} \psi(\alpha \dot{\alpha} \alpha \sigma \theta \alpha$ in the passage above is of double significance. First, while Odysseus associates it with musical entertainments, its only other appearance in Homer, four books earlier in the same poem, describes the suitors' merriment sitting at the doors or inside the house, slaying and eating Odysseus' livestock, reveling and drinking his wine, and generally wreaking havoc on his wealth while their own stores remain untouched at home. ${ }^{114}$ The verb therefore recalls the suitors' violations of xenia explicitly, while the scene mirrors the setting of their initial appearance, sitting in the doorway playing a game, slaughtering livestock, drinking, and feasting. Second, the subject and subject matter have

${ }^{111}$ It should not be overlooked that Odysseus competes in and wins the contest of the bow before attacking the suitors: Homer, Odyssey 21.404-423.

${ }^{112}$ Homer, Odyssey 21.428-430

${ }^{113}$ Kurke (1999a) 259; Kurke (1999b) 255; Kurke (2002) 23. There are interesting similarities between this scene and that of Odysseus and his men in Polyphemus' cave, where they were the uninvited guests who ate their unwitting host's food before the cyclops killed and ate half of Odysseus' comrades.

${ }^{114}$ Homer, Odyssey 17.530-538, verb on 530. Cf. Apollonius, Argonautica 3.118, where the Hellenistic poet's only use of the word describes Eros and Ganymede playing with knucklebones. 
changed: it is not only time for other entertainments than those the suitors favored, but it is also time for other people to entertain themselves, a subtle reference to the grim pleasure Odysseus and Telemachus take in killing the suitors.

The suitors' actions are rooted in real and symbolic substitution: they consume Odysseus' food and wine instead of their own, are served by others, and have sex with the maidservants in their quest to wed and have sex with Penelope. ${ }^{115}$ Symbolism remains central even when they use others for their amusement, itself another substitution. For example, in the boxing match between Irus and the disguised Odysseus, a fight between two beggars, Antinous sets the prize as the winner's choice of any of the goats' bellies being cooked for dinner. A beggar's stomach is his motivation, but these beggars are now fighting to obtain another stomach in order to fill their own. ${ }^{116}$ The suitors, meanwhile, do not box themselves, but instead hold up their own fists in imitation of the two boxing combatants and "die with laughter," marking both their vicarious participation and distance from any real danger. ${ }^{117}$ Moreover, Antinous has symbolically supplanted Odysseus as master of the house, giving away goods to a guest. The full scope of the suitors' surrogate, transgressive actions is signaled by their first appearance, when we, through Athena's eyes, see them playing pessoi.

${ }^{115}$ Cf. Kurke (1999a) 260; Kurke (1999b) 255; Kurke (2002) 23

${ }^{116}$ Russo (1992) 49-50 observes that the belly as a prize literalizes Odysseus' recurring complaints about the coercive power of the stomach. Rose (1992) 108-110 likewise notes the repeated stress on the compulsions of the belly throughout the Odyssey.

${ }^{117}$ The suitors' pretend boxing pose in 18.99-100 ("But the noble suitors, holding up their

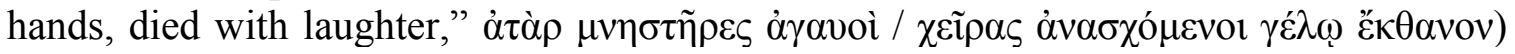

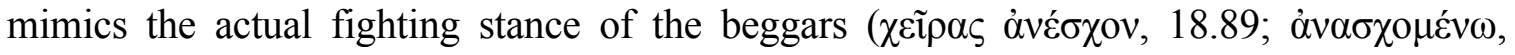
18.95). The suitors' actions hint at Odysseus' ability to kill Irus with a single blow (though he decides against it, 18.90-94) and foreshadow Odysseus' later pleasure at the suitors' death by his hand. The suitors' vicariousness and laughter combine again two books later:

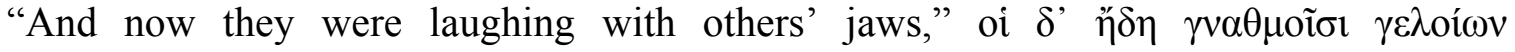

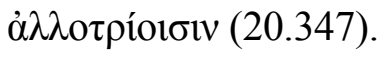


The two instances of games in Homer resound with symbolism and embodiment. The Iliad exposes the ruinous consequences of overwhelming emotions that result from astragaloi, blurs the line between figurative and physical struggles for dominance, and implies that human lives may be no more than the playthings of the divine in a cosmic game. The suitors' game of pessoi in the Odyssey, meanwhile, signifies their inappropriate behavior, including their continuous involvement with real and symbolic substitution; according to an ancient commentator, it is through this very process that they seek to effect changes in reality. Both episodes mark the connection between ludic activity and reality, informing a Greek perception of the self and the surrounding world mediated through the symbolic character of games.

\section{The Cosmic Game}

The idea that human lives may merely be pieces in a divine game is not unique to Homer's Iliad. Rather, while the epic poet implies the connection between mortals and a cosmic game in the speech by Patroclus' shade to Achilles, later authors more explicitly employ this cosmic, ludic imagery. In a fragment noted for the difficulties it poses for interpreters, Heraclitus claims that: ${ }^{118}$

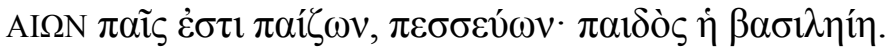

AIŌN is a child playing, playing pessoi; kingly power is the child's.

\footnotetext{
${ }^{118}$ Heraclitus fr. B 52 DK. Cf. Marcovich (1967) 493, who states that "the meaning of the fragment is obscure, and the attempts to interpret it are many"; Kahn (1979) 227, who describes it as the "most enigmatic of Heraclitean riddles"; Kurke (1999a) 263 and (1999b) 257 n.28, who calls this "a famously obscure fragment"; Halliwell (2008) 349, who labels it "one of the most famous, but also most contentious" of Heraclitus" fragments; and Schädler (2009) 185, who calls it "one of Herakleitos' most enigmatic sentences."
} 
The passage seems to rationalize the ostensibly random occurrences of life by comparing existence to the game of a child, one whose power may exceed his judgment. Here AIŌN, the embodiment of time, is a universal principle that affects all beings. ${ }^{119}$ The Heraclitean portrait of a child playing is perhaps best understood through parallel reading with a Homeric passage: ${ }^{120}$

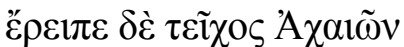

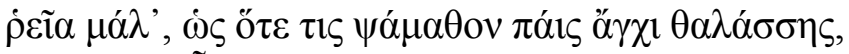

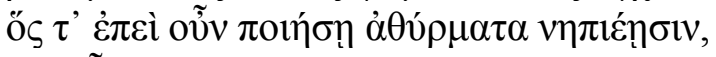

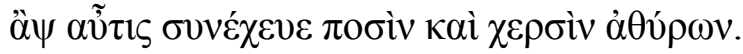

And [Apollo] very easily cast down the wall of the Achaeans, just as when a child scatters sand down by the sea, a child who first builds playthings in his childishness, then demolishes them again with his hands and feet while playing.

Homer's child constructing and destroying sandcastles on the beach is carefree, in stark contrast to the Achaeans, whose wall Apollo topples with equivalent ease. The boy behaves however it pleases him best at the moment, manipulating the materials of his domain as he sees fit. Heraclitus' child—the personification AIŌN, whose power is clear but whose divinity is not-acts the same way, but the philosopher adds a sense of embodiment to the image. The boy with absolute power is at play, moving pieces around a board, as indicated by naming pessoi as his game. ${ }^{121} \mathrm{He}$ does not play with stone counters, however, but with the lives of mortals, directing them as he wishes; we the

${ }^{119}$ Contra Most (2011) 106, who believes that Heraclitus can only have meant "the concrete life-time belonging to real, individual humans." Most argues that this is the original meaning of the word and its most likely meaning in Heraclitus' lifetime despite its evolution in usage to encompass a generation, a historical period or eon, and eternity. I find this argument too restrictive for an evolving word; I do not feel that we can use general chronologies to limit so extensively what one author indicated with one usage of a particular word.

${ }^{120}$ Homer, Iliad 15.361-364

${ }^{121}$ I use the translation "boy" and masculine pronouns because the Greek text uses the masculine, not because I wish to imply that the cosmic player is always depicted as male. 
pieces are bound to whatever fate(s) his imagination devises. ${ }^{122}$

The Heraclitean fragment raises many questions about the nature of life. Another fragment lends explanatory power: ${ }^{123}$

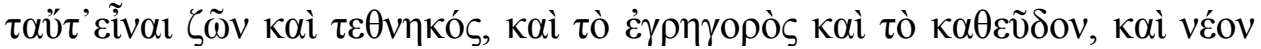

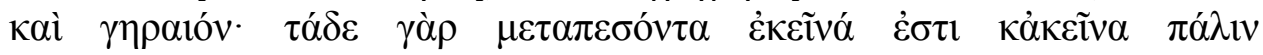
$\mu \varepsilon \tau \alpha \pi \varepsilon \sigma o ́ v \tau \alpha \tau \alpha \tilde{\tau} \tau \alpha$.

To be living and dead are the same, and to be awake and asleep are the same, and to be young and old are the same; for the former when shifted are the latter and the latter when shifted back are the former.

There is a verbal echo between $\pi \varepsilon \sigma \sigma \varepsilon v \omega \nu$ in the first fragment and $\mu \varepsilon \tau \alpha \pi \varepsilon \sigma o ́ v \tau \alpha$ in the second. While the words are not identical, their linguistic resonance allows us to see a continuity of thought and imagery between the two fragments. ${ }^{124}$ Mortal lives are embodied as pieces on the game board of the child, who changes humans' conditions with each move; all are imbued with the same potential, but the outcome for each piece - and therefore each human life-depends on the whims of the cosmic player. ${ }^{125}$ The imagery of

${ }^{122}$ Contra Halliwell (2008) 349-350, who believes the fragment is easier to see as "an image that trivialises general human ambitions (the totality of a 'lifetime' as lived by most people) than as a code for lawlike cosmic processes: it is hard, otherwise, to account for the stress on a child as a person playing the game" (quote from 350). As discussed below, the idea of a child organizing the universe makes sense with the ludic theme of the cosmic game. Cf. Schädler (2009) 186-187, who considers time the measured framework of the cosmos, while the image of the child indicates a lack of strategy, just as time itself has no predetermined plan for the universe.

${ }^{123}$ Heraclitus fr. B 88 DK

${ }^{124}$ Kahn (1979) 227

${ }^{125}$ Kahn (1979) 227 rightly points to the verbal resonance of the two fragments, but holds the view that "the fundamental thought is not the childlike and random movements of the game (as some interpreters have supposed) but the fact that these moves follow a definite rule, so that after one side plays it is the other's turn, and after the victory is reached the play must start over from the beginning." While I concur that the two fragments share imagery, I cannot agree with his conclusion of players taking turns or restarting the game after victory: Heraclitus mentions only one child, the cyclic progression is better understood as shifting a piece between two spaces than beginning the game anew, and nowhere do we find a reference to an end-either victory or loss - to the cosmic game. 
the child is particularly significant, for he is likely not a master game player who has honed his skills, but someone inexperienced on account of his age. ${ }^{126}$ Moreover, the etymological link between $\pi \alpha \tilde{\varsigma} \varsigma$, "child" and $\pi \alpha i \zeta \omega$, "to play" clarifies the boy's inexpert status, for the verb at its root means "to play like a child," showing that the child AIŌN is behaving exactly as one would expect from a child. ${ }^{127}$ The double participles are likewise not redundant, as they may seem at first glance, but rather convey a remarkably lucid picture: the boy is playing like a child while playing pessoi. The second half of the fragment lends gravity to the scene, for the child, regardless of the manner of his play, maintains control over his dominion.

Lucian of Samosata reinforces the connection between the two fragments from Heraclitus. In Philosophies for Sale, Lucian imagines Zeus and Hermes selling various philosophies at a slave market, with a potential buyer conversing with each new ware being peddled. While the work is humorous, it nevertheless portrays the tenets of each philosophical school, thereby identifying and differentiating them. When the buyer reaches

To his credit, Kahn leaves possible the interpretation of "arbitrary and random movement" (228-229). Cf. Seaford (2004) 239-240, who likewise connects the fragments and sees a game of alternating moves, remarking that "[t]he fundamental idea of the unity of opposites, inherited by Heraclitus from mystic wisdom, becomes the rule-governed, harmonious conflict of opposites" (quote from 240, italics in original).

${ }^{126}$ Cf. Schädler (2009) 186-187, who comments that Greek children did not play board games, so Heraclitus' child is in reality only playing as if he were playing a board game.

${ }^{127} L S J$ s.v. $\pi \alpha i \zeta \omega$ I. For $\pi \alpha i \zeta$ as the root of $\pi \alpha i \zeta \omega$, see Frisk (1960-1970) 462-463; Chantraine (1968-1980) 849; Beekes (2010) 1143, who defines $\pi \alpha i \zeta \omega$ as originally meaning "to behave like a child." Halliwell (2008) 20 adds notes that "the extended application of the paizein word-group" even to adult behaviors may still carry "traces of the spirit of children or the young." On AIŌN playing like a child, cf. Marcovich (1967) 494: "Now, my point is that the implication of the verb [sc. $\pi \varepsilon \sigma \sigma \varepsilon v \varepsilon \varepsilon v]$ : 'a fortuitous or meaningless action'... is much more likely than: 'a thoughtful and skillful one'; because it is played by a $\pi \alpha \tilde{\tau} \varsigma "$ (italics in original). 
the Heraclitean, he inquires why the latter is weeping. ${ }^{128}$ The Heraclitean responds that he grieves for humans because all their affairs are lamentable and the universe is destined to end in conflagration and misfortune. ${ }^{129}$ He then explains another cause for his sadness: ${ }^{130}$

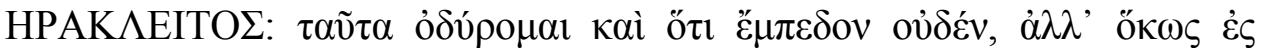

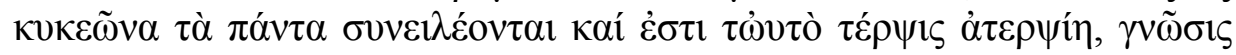

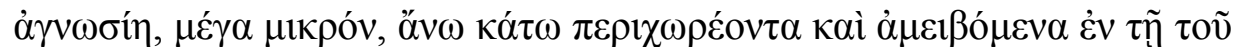

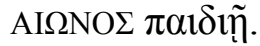

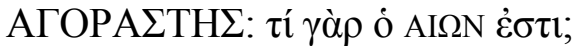

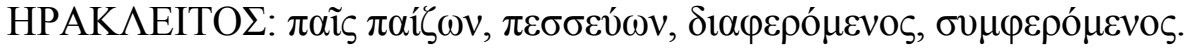

HERACLITEAN: I mourn for these things and because nothing is constant, but, just as in a concoction, all things are pressed together and pleasure is the same thing as unpleasantness, knowledge is the same thing as ignorance, the great is the same thing as the slight, all going round, up and down, and alternating in the game of AIŌN.

BUYER: But what is AIŌN?

HERACLITEAN: A child playing, playing pessoi, causing discord, causing concord.

The Heraclitean philosophy for sale explicitly links the chief ideas of the two fragments above: the Heraclitean first remarks that opposites are in fact equivalents, fluctuating from one to the other, then positions that transformation in the pessoi game played by the child AIŌN. Moreover, the Heraclitean's series of participles contains several key features: 1) that all of the participles are present tense shows contemporaneous action; 2) the antithesis inherent in the final two participles, occurring together, reinforces the idea that opposites are actually equivalents; and 3) that the child AIŌN is the subject reveals him to be the agent of the alternations. The passage, then, clarifies that AIŌN is separating and uniting, causing strife and harmony, while playing pessoi. In other words, the oscillating process by which

${ }^{128}$ The weeping Heraclitus is on half of a diptych with a laughing Democritus. For a full discussion of this theme, see Halliwell (2008) 343-371.

${ }^{129}$ Halliwell (2008) 346-348 argues that Heraclitus did not weep for human ignorance or folly, but rather mocked it.

${ }^{130}$ Lucian, Philosophies for Sale 14 
opposites become one another is or is part of AIŌN's game of pessoi. While this passage's author is Lucian rather than Heraclitus himself, it nonetheless reflects Heraclitus' own thoughts, especially since a central element of the work is the accurate portrayal of each philosophy, though with humorous elements added. ${ }^{131}$

Like Heraclitus before him, Plato portrays the universe as operating like a board game. Through the character of the Athenian, he claims that all physicians and craftsmen make parts that contribute to the good of the whole, not vice versa, then characterizes the

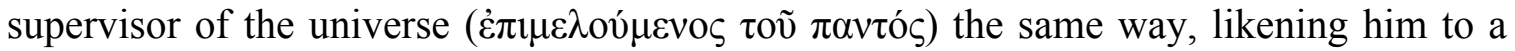
pessoi player ( $\pi \varepsilon \tau \tau \varepsilon v \tau \eta ́)$ ) who redistributes souls to different bodies as he works for the sake of the cosmos as a whole. ${ }^{132}$ Just a few lines later, Plato refers to the supervisor of the universe as the king ( $\beta \alpha \sigma i \lambda \varepsilon v ́$, 904a), echoing Heraclitus' claim that kingship ( $\beta \alpha \sigma i \lambda \varepsilon i ́ \alpha)$ belongs to AIŌN, the boy playing pessoi.

We can advance the ludic elements at play even further. The cosmic player in both Heraclitus and Plato alters human affairs by moving the pieces in his pessoi game, but an additional element of chance is also subtly implied by the words used to indicate the changes. Heraclitus' $\mu \varepsilon \tau \alpha \pi \varepsilon \sigma o ́ v \tau \alpha$ derive from $\mu \varepsilon \tau \alpha \pi i \pi \tau \omega$, a verb that in its deracinated form can mean the throw of dice, knucklebones, or other randomizing agents. ${ }^{133}$ When Plato describes a soul the divine pessoi player will redistribute, he says

${ }^{131}$ As Lucian makes clear in The Dead Come to Life, or The Fisherman, his sequel to Philosophies for Sale, he used only the various philosophers' own ideas in the earlier work, a fact that the character Plato admits, though claims was only for the purpose of using the philosophers' own words against them. See Lucian, The Dead Come to Life, or The Fisherman 6-7.

${ }_{132}^{132}$ Plato, Laws 903c-d

${ }^{133}$ LSJ s.v. $\pi i \pi \tau \omega$ V. Kahn (1979) 227 notes that "the verb metapesein...could immediately suggest the fall of a die" and remarks that the continuity between fr. 52 and fr. 88 "would be guaranteed if we could be sure that the game of pessoi envisaged in [fr. 


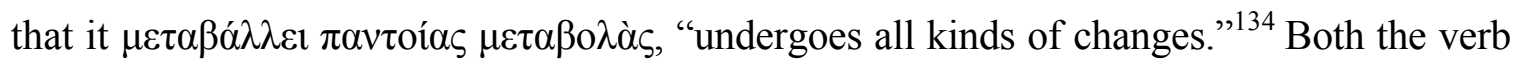
and the polyptotonic noun mean "change," but their uncompounded forms are also used for casting randomizing agents. ${ }^{135}$ In fact, Plato and Heraclitus use words that are not only linguistically similar, but share definitions as well: through suppletion, $\mu \varepsilon \tau \alpha \pi i \pi \tau \omega$ is often used as the passive of $\mu \varepsilon \tau \alpha \beta \alpha \dot{\alpha} \lambda \lambda \omega .{ }^{136}$ Both philosophers, then, describe the celestial overseer not only a pessoi player and as a king, but also use words compounded with $\mu \varepsilon \tau \alpha$ that can otherwise suggest the throw of a randomizing agent, such as dice or knucklebones.

Although the changes that Plato says a soul experiences may echo Heraclitus linguistically, contextually they are a key difference in how the philosophers depict the cosmos. Whereas Heraclitus gives full power to a superhuman force, Plato ascribes some control to humans. Plato remarks that a soul is joined now to one body, now to another, and undergoes all kinds of changes, some self-imposed and some caused by another soul, so the pessoi player, that is, the supervisor of the universe, transposes souls that have improved to a better place and those that have worsened to a worse place, such that each is allotted the destiny it deserves. ${ }^{137}$ Plato continues by stating that this king, again the supervisor of the universe, saw that all actions involve the soul and have both much good and much evil in them, so he devised where to place souls so that good would triumph

52] involved the use of dice." The terms "dice" and "randomizing agents" are not synonymous, but this oversight does not invalidate Kahn's contention.

${ }^{134}$ Plato, Laws 903d

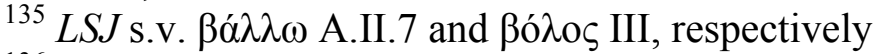

${ }^{136} L S J$ s.v. $\mu \varepsilon \tau \alpha \pi i \pi \tau \omega$

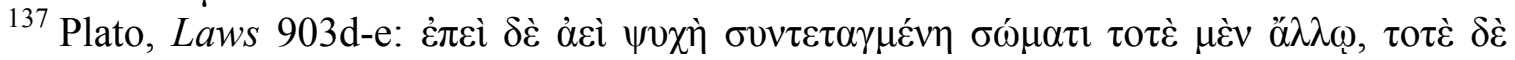

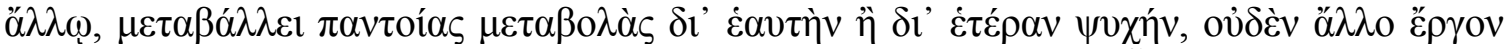

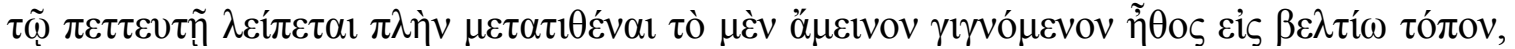

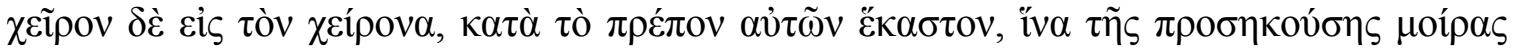
$\lambda \alpha \gamma \chi \alpha ́ v \eta\rceil$. 
and evil would be defeated in the universe as a whole. ${ }^{138}$ Human choice, however, has a part to play: the universe's orchestrator designed the rule for where each soul goes in accordance with its changes, but he left the responsibility for that movement, whether a soul improves or worsens, up to each individual's will. ${ }^{139}$ Plato, then, portrays the supervisor of the universe as a pessoi player with a well-planned strategy, taking each piece's strengths and weaknesses into account and using each of them for the maximum benefit of the whole army. Heraclitus mentions only that the child AIŌN plays pessoi and, if we read both fragments together, implies moving the pieces back and forth, but does not expand on the ludic imagery, instead focusing on the unity of opposites. Lucian's Heraclitean philosopher states that while playing pessoi, AIŌN causes concord and discord, opposites that find unison in AIŌN's game. Plato's supervisor of the universe is a different kind of player, as he produces only concord. The two philosophers, then, invoke the same ludic theme, but do so to explicate dissimilar models of the cosmos.

Although playing pessoi did not require a randomizing agent, the implications of a chance element remain salient in these passages, as mentioned above. While the cosmic player — child or otherwise-marshals his forces as seems appropriate to him, his decisions may seem rooted in mere chance to the pieces, that is, the mortals whose lives

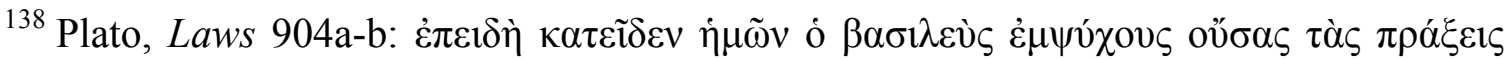

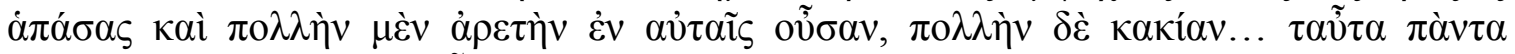

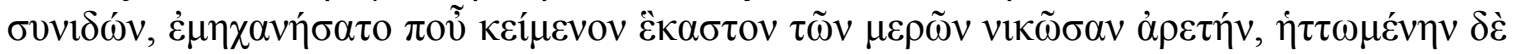

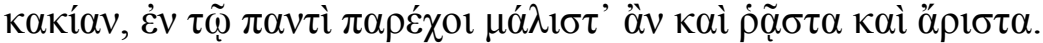

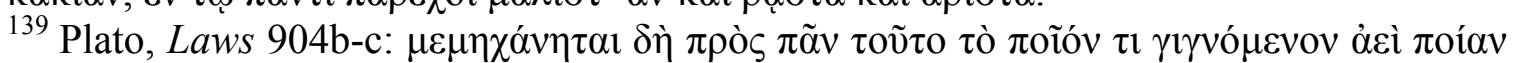

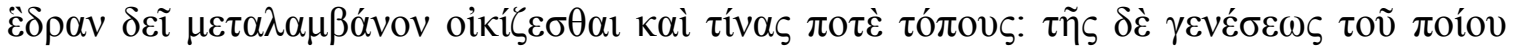

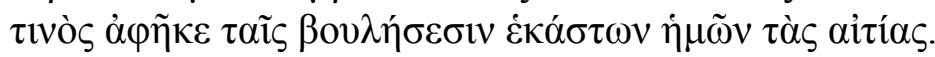


play out on the cosmic game board. ${ }^{140}$ In other words, humans may feel subject to the vicissitudes of random fortune because they know only their own circumstances, since they are without full view of the master plan. Indeed, Plato's Athenian, the speaker of the lines discussed above, claims that his interlocutor is irritated because he does not understand how his lot in life is best for the universe and best for him as well. ${ }^{141}$

One of Menander's characters expresses the same perspective: "The affairs of

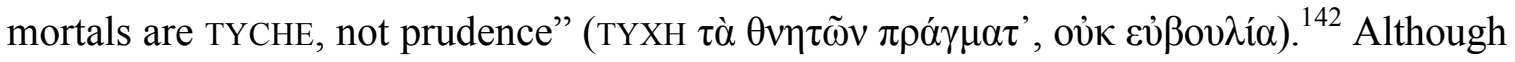
an absolute divide is impossible, the matter becomes more complicated when one considers the anthropomorphic personification of TYCHE, not the disembodied notion, as the crux of the argument. In this understanding, good planning does not determine human affairs, for, as Daos in Menander's line implies, a superhuman force holds the cards, to use a modern ludic idiom. Evidence for the prevalence of this mode of thought is strengthened by the fact that Menander borrowed this line from Chaeremon's now-lost Achilles, Slayer of Thersites. ${ }^{143}$ Daos is feigning lament in order to trick the miser Smicrines, pretending that the latter's brother has died, and begins reciting lines from various tragedies to emphasize his sorrow. He chooses quotations that highlight the human capacity for misery and the powerlessness of mortals against preternatural forces. The idea that human life is determined by TYCHE is pervasive enough in Menander's literary landscape that the single line Daos quotes, even devoid of its original context, retains significance and

${ }^{140}$ Cf. Plato's earlier claim (Laws 644d) that each living being is a puppet $(\theta \alpha \tilde{v} \mu \alpha)$ of the gods, though we do not know whether we are created as a mere plaything ( $\pi \alpha i$ íviov) or for an earnest engagement ( $\sigma \pi \mathrm{ov} \delta \tilde{\eta} \tau \imath \mathrm{v})$.

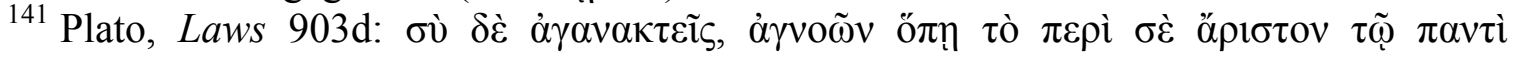

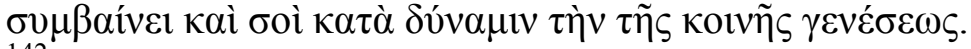

${ }^{142}$ Menander, Aspis 411. Cf. Chaeremon fr. 19 Nauck: "TYCHE conquers and overturns

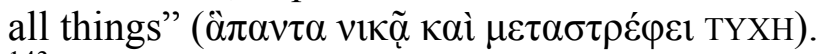

${ }^{143}$ Arnott (1979) 69 n.2. The fragment is Chaeremon fr. 2 Nauck. 
accessibility. ${ }^{144}$ Aiding this interpretation is the fact that none other than a personified TYCHE delivers the prologue of the play. ${ }^{145}$

That a personified TYCHE is likely intended here is bolstered by the other eight citations Daos gives. Around half of the quotations remark upon human vulnerability and unhappiness, while the others explicitly call attention to the gods' dominion over mortals. ${ }^{146}$ Considering the TYCHE of the passage above to be an anthropomorphized deity thus fits perfectly into the context Menander establishes. Moreover, it corresponds with one of Daos' other quotations, which combines both the idea of human providence and a god's

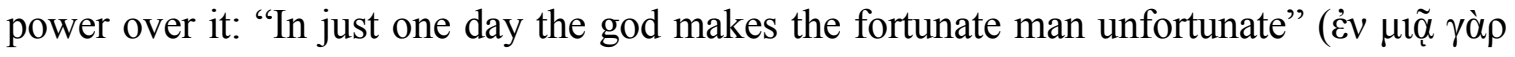

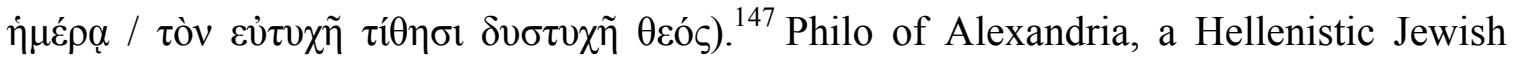
philosopher living in Rome three and a half centuries after Chaeremon and Menander, sums up the unifying principle of all these passages and shows the durability of their message: "For nothing is more unstable than TYCHE, playing pessoi with human affairs, moving them back and forth, who often in a single day brings down the lofty and lifts the

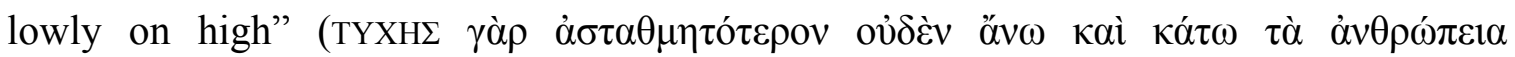

\footnotetext{
${ }^{144}$ Comic characters of the fourth century BCE often treat earlier tragedy as an irrefutable source of authority, though at times this is used for humorous effect. See Hanink (2014) 175; Farmer (2017) 59-60.

${ }^{145}$ Cf. Gutzwiller (2007) 57, who discusses the metatheatricality of the Aspis and notes that "by granting the prologue to personified Fortune (Tyche), Menander encourages the audience to understand that this play dramatizes the mechanics of a comic plot with its reversal in fortune."

${ }^{146}$ For economy of space I do not reproduce all of the quotations here, but they are, in order of appearance, Euripides, Stheneboia fr. 661 Nauck; Chaeremon, Achilles, Slayer of Thersites fr. 2 Nauck; Aeschylus, Niobe fr. 166 Nauck; a fragment from an unknown tragedy; Carcinus fr. 5a Snell; a fragment from an unknown tragedy; Euripides, Orestes $1-2$; Chaeremon fr. 42 Snell.

${ }^{147}$ Menander, Aspis 417-418. The quotation is a fragment from an unknown tragedy. Cf. Arnott (1979) $71 \mathrm{n} .2$. The root $\tau$ o - of the adjectives in this quotation should not be overlooked.
} 


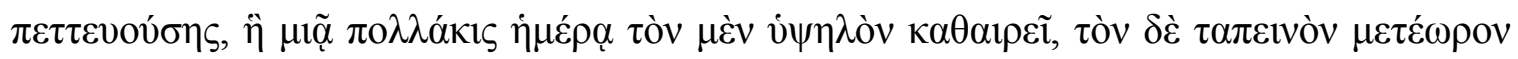
$\left.\dot{\varepsilon} \xi \alpha i^{\prime} \varepsilon \imath\right) .{ }^{148}$

Throughout Greek literature, ascriptions of ultimate responsibility for human affairs follow a progression from specificity to abstraction, from particular deities to generalized gods to cosmic forces, and the development of TYCHE conforms perfectly to this change. ${ }^{149}$ While this chapter investigates Greek literary tropes, not religion, it is worth noting briefly a contemporaneous cultural development. TYCHE begins as an abstraction and over time grows to occupy an important place in Greek religion and thought, even coming to be seen as the mistress of the world and of the gods. ${ }^{150}$ There is a semantic slide that escalates over time and suggests a gradual loss of control over one's fate, especially following the weakening of religious ties at the end of the fifth century BCE. ${ }^{151}$ The idea of random chance is not prominent in Homer, but grows more prevalent in Greek literature over time

${ }^{148}$ Philo of Alexandria, On the Life of Moses I 6.31. Cf. Philo of Alexandria, On the

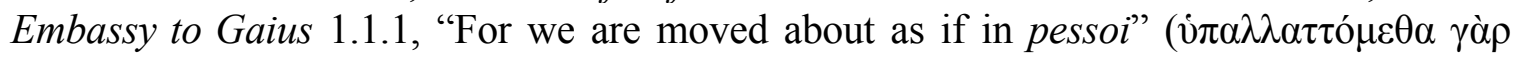

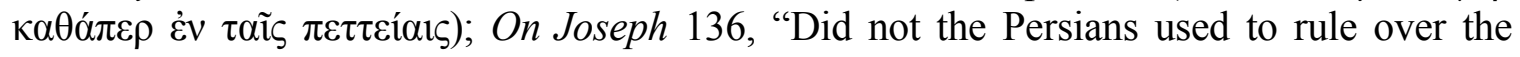
Parthians, but now the Parthians rule over the Persians according to the twists of human

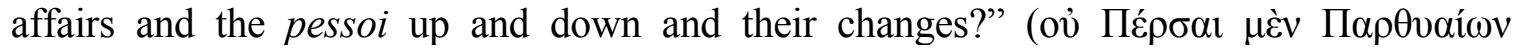

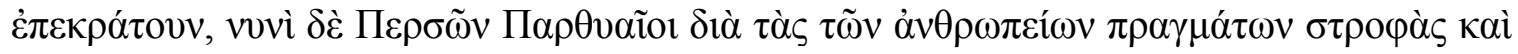

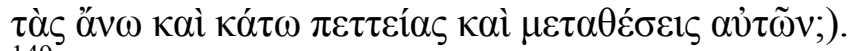

${ }^{149}$ Green (1990) 400

${ }^{150}$ Goulet-Cazé (1996) 55. Cf. Demosthenes, On the Crown 194, "I was not master of

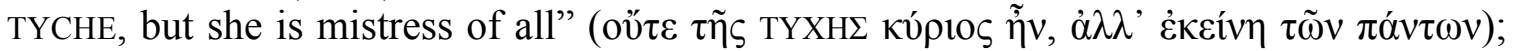
Anonymous fr. 506 Nauck, once attributed to Aeschylus, "TYCHE is tyrant of all the

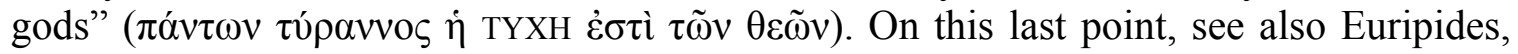
Phoenician Women 1202, where Jocasta states that "The gods and TYCHE treat us well"

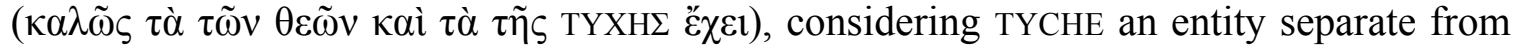
the gods that nevertheless has power over humankind. Eutychides' statue of an anthropomorphized TYCHE as the tutelary deity of Antioch demonstrates the same perspective. Cf. the discussion in Gutzwiller (2007) 10: "While the traditional deities of Zeus and Apollo protected the city as well, this figure of Tyche heralds the Hellenistic awareness that the future is controlled as much by Lady Luck as by the gods of Olympus."

${ }^{151}$ Green (1990) 401 
as a way of explaining the world, just as ascriptions of events to fate or cosmological forces do, such that they may be one and the same. ${ }^{152}$

\section{The Cosmic Game in Sophocles}

With the cosmic game in mind, we can now reassess a particularly troublesome passage in Sophocles. After recovering from the madness Athena cast on him, Ajax realizes that he has killed livestock rather than the Greek leaders who, to his mind, betrayed him. Ajax, too ashamed to face the rebukes of the other Greeks or return home to his father, decides that he must die: ${ }^{153}$

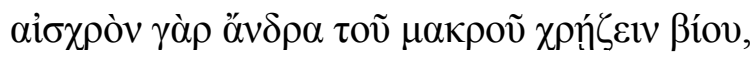

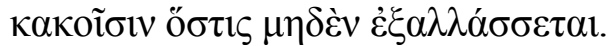

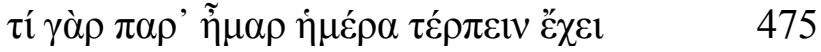

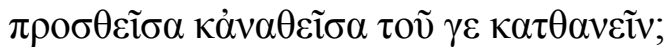

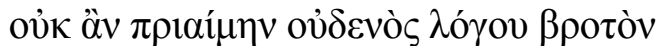

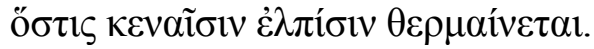

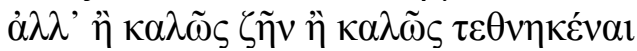

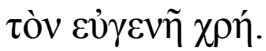

It is shameful for a man who sees no change in his woes to desire a long life. For what pleasure is there day after day, moving us toward and pulling us back from death? I would not buy at any price a man who is warmed by empty hopes. But it is necessary that the noble man either lives well or dies well.

Line 476 continues to cause problems for commentators, not least because the manuscripts contain variant readings. ${ }^{154}$ Scholars have proposed many solutions, including textual emendations and novel interpretations. Comparing this episode to others that employ "the cosmic game" can clarify the passage's meaning and help harmonize the scholarly

152 On this last point, see Herzfeld (1982) 646. Cf. Versnel (2011) 212-231. See Giannopoulou (2000) 257-261 for a brief overview of the development of the various meanings of TYXH in Greek literature, including possible connections to historical events. 153 Sophocles, Ajax 473-480

${ }^{154}$ See West (1978) 109-110 for the variants and the scholia that explain them. 
disagreement. In order to be as accurate as possible, I reproduce many of the scholars' arguments in their own words below.

The typical explanation of line 476 is that death is a line or fixed point, the terminus of life's journey, and any day can move someone closer to or further from that boundary. ${ }^{155}$ Over a century ago, Jebb identified board game imagery in this passage. In his understanding, "death is the boundary-line ( $\gamma \rho \alpha \mu \mu \eta$ ) on the field of life" and "the man who is captive to evil fortune is like a $\pi \varepsilon \sigma \sigma o ́ \varsigma$ on the draughtboard, at one moment moved close up to the line, and then again withdrawn from it a little." ${ }^{156}$ West criticizes this interpretation by saying it "assumes a curious mixture of imagery from the racetrack and the gaming-board" and, after acknowledging that "our knowledge of the principles of $\pi \varepsilon \sigma \sigma o$ í is very incomplete," notes that "we know nothing of a line on the board that represents a fearful terminus." " the fixed point or line, so crucial to the overall picture, is odd." ${ }^{\prime 58}$ West concludes by saying he is "quite unable to understand in what way additional days of life move a man both forward towards and back away from death." ${ }^{159}$ Dawe offers a similar argument: "the idea of moving Ajax now closer to death and now away from it is intrinsically peculiar."160

Lloyd-Jones and Wilson, however, follow Jebb in seeing gaming imagery in the

${ }^{155}$ Finglass (2011) 276; cf. Garvie (1998) 168 for the difficulties of interpretation.

${ }^{156} \mathrm{Jebb}$ (1907) ad loc. The identification of pessoi with draughts (or any other modern game) is incorrect, but all too common in scholarship, especially before the work of R.G. Austin in the 1930s and early 1940s. Jebb can perhaps be forgiven as being a product of his times.

${ }^{157}$ West (1978) 110

${ }^{158}$ Finglass (2011) 276

${ }^{159}$ West (1978) 110

${ }^{160}$ Dawe (1973) 1.141 


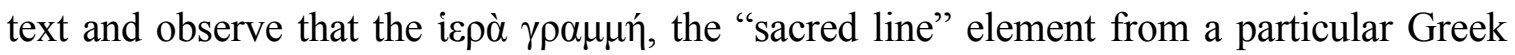
board game, gained enough cultural importance to become used proverbially for making a desperate, final attempt, such as in Theocritus, Idylls $6.18 .{ }^{161}$ They argue further that Sophocles "is not tied down to the exact details of the game," but instead "has an imagination, and is free to imagine the way in which one day brings a man nearer to death and another moves him away from it, rather as if there were a board on which one could move one's pieces forward and backward, either towards or away from a line that stands for death." ${ }^{162}$ They add that since some Greek games involve randomizing agents, "the fortune each day brings may correspond to the fortune given by each throw," resulting in the differences of each successive day. ${ }^{163}$ Lloyd-Jones and Wilson feel the ludic interpretation is strong enough to discount their own previously published textual emendation in the OCT and elsewhere. ${ }^{164}$ Finglass, however, finds their explanation of Sophocles' imaginative scene untenable, especially coming after Ajax's claim of invariable miseries. ${ }^{165}$

Reading the passage in light of the cosmic game can help unify these disparate interpretations. In this interpretation, the missing piece is the cosmic player: it, not the days themselves, is the agent responsible for moving mortals toward and away from death each day. Mortals, the pieces in the divine pessoi game, may distinguish the cosmic player's

${ }^{161}$ Lloyd-Jones and Wilson (1997) 19. See Cilley (1986) 41-44 for a discussion of the proverb, including other examples.

${ }_{162}$ Lloyd-Jones and Wilson (1997) 19-20

${ }^{163}$ Lloyd-Jones and Wilson (1997) 20. These scholars in fact use the word "dice" rather than the more general "randomizing agents," resulting in verbiage that needlessly excludes knucklebones and other casting devices used in such games. Despite this unnecessary - and likely unintentional-limitation, their point remains valid.

${ }^{164}$ See, e.g. Lloyd-Jones and Wilson (1990) 20

${ }^{165}$ Finglass (2011) 276: "[S]uch an image, in itself difficult to grasp, contradicts the immediately preceding emphatic statement of Ajax's unchanging woe (473-474)." 
impact temporally, considering each day to have its own fortune, but the progression of time is not itself responsible for their shifting fates. Additionally, Sophocles' play emphasizes the power of a day in order to reinforce Ajax's binary fate: Athena's anger will last for one day, during which Ajax will either be saved from it or die. ${ }^{166}$ In the prologue, it is Athena herself who foreshadows Calchas' revelation that her anger will last for only one day and who underscores the temporality of shifting fortunes: ${ }^{167}$

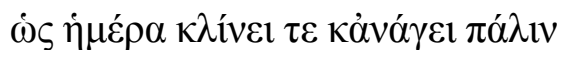

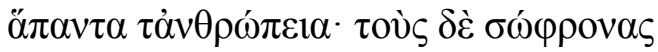

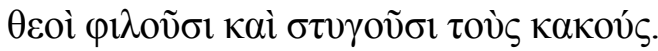

For a day lays low all human affairs and raises them up again. The gods love the wise and hate the wicked.

Athena mentions a day changing all human affairs in wording strikingly similar to the transposals of the cosmic player discussed in the previous section; in Menander's Aspis, one of Daos' quotations from an unknown tragedy even marks one day as the time it takes for the cosmic player to reverse a man's fortunes. ${ }^{168}$ Athena, however, emphasizes the temporal aspect of the inversion, not the causative agent, since she knows full well both the extent and the power of her own anger. In other words, Athena at first labels the day as the agent of change, even describing it as the subject of active verbs, but then reveals that the gods are the true reason human affairs are laid low and raised up again. The similarity of content suggests that these passages inform one another, as does, perhaps, a parallel in

\footnotetext{
${ }^{166}$ Sophocles, Ajax 748-783. Cf. Easterling (1993) 82-84; Finglass (2011) 357-358.

167 Sophocles, Ajax 131-133

168 Menander, Aspis 417-418: "In just one day the god makes the fortunate man

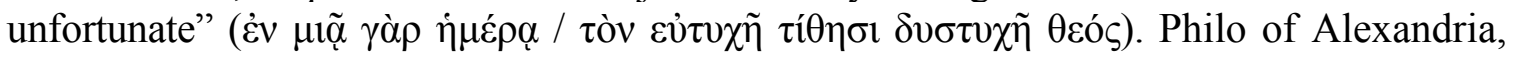
On the Life of Moses I 6.31 comes centuries later, but shows reception of the same idea combined with the cosmic game. For other examples of mortal circumstances being inverted in one day, see Mastronarde (1994) ad Euripides, Phoenissae 1689; Finglass (2011) 175. Cf. Mastronarde's comment ad loc.: "human fortune is so fragile that it may undergo a complete reversal in a single day."
} 
form: these are the first two of just four instances in the play where a character presents an antithetical formulation at the end of a speech. ${ }^{169}$

Tecmessa's response to Ajax's speech and decision to commit suicide reinforces the idea that a cosmic player is pulling the strings. After assuring Ajax that she believes his words are true to his character, she expounds upon the power of fate: "Lord Ajax, there is

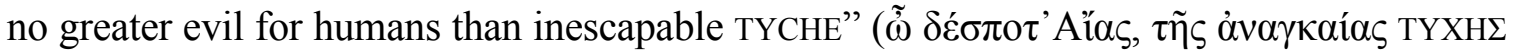

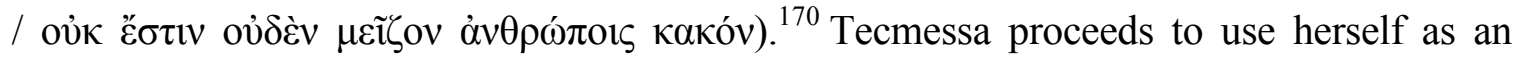
example, reminding Ajax that she is his slave despite being born free into a prominent and influential Phrygian family, but her words are general enough to allude to Ajax's situation simultaneously; she suggests that because they have each suffered ill fortune they share a bond of mutual suffering and sympathy. ${ }^{171}$ Moreover, she explains that she has not only accepted the complete reversal of her circumstances, but even cares for Ajax, the person to whom she now belongs and who is chiefly responsible for her drastic change of status, as she herself admits. She does not propose that Ajax succumb to his present misery, but rather seeks to curb his obstinacy about killing himself by showing that he is not the only person to suffer misfortune. ${ }^{172}$ In all of this, she identifies TYCHE as the individual that visits all mortals and upends their circumstances: after Ajax bemoans the joylessness of each successive day for a man of constant sorrow, being moved closer to and further from death, Tecmessa pauses only to assure him that she knows his words are not contrived

\footnotetext{
${ }^{169}$ The others are Sophocles, Ajax 691-692 and 1314-1315 (the line numbers refer to each speech's final two lines, which contain the antithetical formulation). Cf. Finglass (2011) 175. It is noteworthy that the character Ajax delivers lines 691-692, in which he expounds upon whether he is suffering ill fortune or has been saved.

${ }^{170}$ Sophocles, Ajax 485-486

${ }^{171}$ Heath (1987) 182; Finglass (2011) 280

${ }^{172}$ Lawrence (2005) 23-24
} 
before immediately lamenting that TYCHE is both inescapable and the greatest adversity humans face. It is no great leap, then, to deduce that Tecmessa picks up on the gaming imagery in Ajax's speech and sees TYCHE as the cosmic player toying with his life each day. ${ }^{173}$

Having established that the cosmic game fits conceptually into Ajax's speech, we can now return to the scholarly debate about the passage to resolve the particulars Jebb correctly sees ludic imagery in the text and rightly identifies man as like a pessoi piece in a divine game, but incorrectly brands death as a line on the board. Moreover, he fails to name the underlying principle of the entire passage: a preternatural force is in command and all mortals, not just those "captive to evil fortune," are subject to its will. The cosmic player moves its human game counters around the board, causing the fluctuations and changes integral to all its representations, as discussed in the previous section; the words $\pi \rho \circ \sigma \theta \varepsilon i \tilde{\alpha} \alpha$

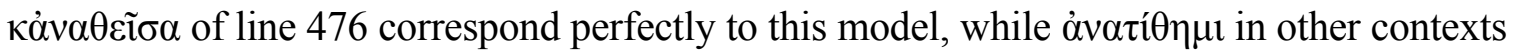
is used of moving a piece in a pessoi game, discussed below.

Seeing this passage as relating to the cosmic game satisfies West's skepticism, since additional days of life do not move a man to and from death, but rather a cosmic player does over the course of those days. Dawe's critique is likewise answered, since an agent responsible for moving Ajax is introduced. West is correct that there is no fearful terminus on the game board, but Sophocles does not intend one: death is a natural human fear, not part of the game, and the ludic element is not the terminus itself, but rather what moves mortals to and fro. Furthermore, death to a mortal is the equivalent of capture to a

${ }^{173}$ For divine imposition and human perception of it, see Williams (1993) 104: "Agents, typically, are not fully conscious of... supernatural necessities in advance. They may have a sense that there is a necessity involved, but not be sure what it is; for them, the outcome may, at the time, seem like luck." 
game piece, as later literary sources record; if death is a game mechanic, capturing pieces is far more plausible than a location on the board. ${ }^{174} \mathrm{~A}$ counter can move (or be moved) toward and from danger without reference to any fixed point or line on the game board: the real danger lies in proximity to enemy pieces, which may be approached or evaded at will. Capture can occur at many places on the board, not only at one location or terminus, just as death can occur anywhere and at any stage of life, so the gaming imagery does not pose the problem that West and Finglass imagine. For instance, if the game envisioned is pente grammai, as Lloyd-Jones and Wilson suggest, then pieces are moved circularly around five or eleven lines and are only safe on the central one, so they are continually shifted closer to and further from safety; from the perspective of the pieces, they may be moving to or from not safety, but death, itself represented by the enemy pieces on the board. ${ }^{175}$ Moreover, the joylessness being moved to and from death day after day at the whim of a superhuman force certainly qualifies as unchanging woe, so the disparity Finglass sees between lines 473-474 and 475-476 is not present; death is not the source of Ajax's misery, living without control over his own life is. Lastly, the passage is rooted in metaphor, so while Ajax's speech is in fact consistent with considering his life part of a game, Sophocles has an imagination, as Lloyd-Jones and Wilson put it, and need not portray every game mechanic accurately.

One final consideration is the verb $\dot{\alpha} v \alpha \tau i \theta \eta \mu \mathrm{r}$ in line 476. Elsewhere, it is found in gaming contexts and is sometimes employed metaphorically; the meaning of retracting a

\footnotetext{
${ }^{174}$ See the next chapter for examples of game pieces described as dying when captured.

${ }^{175}$ On these game mechanics, see Cilley (1986) 41-55; Schädler (1998); Schädler (2009); Kidd (2017).
} 
piece in a pessoi game gave rise to an expression for taking back one's opinion. ${ }^{176}$ Although the middle voice is customarily used in such contexts, Sophocles' use of the active voice in this passage poses no problems, as $\tau^{i} \theta \eta \mu$ and $\tau^{\prime} \theta \varepsilon \mu \alpha \iota$ are interchangeable in some expressions. ${ }^{177}$ Finglass argues that the verb "means not 'move a piece backwards' (i.e. from some terminus on the board), but 'retract a move'; and Ajax of all people should be aware that human actions cannot be annulled." ${ }^{178}$ While his point is sensible, it is not enough to countermand the gaming sense of the passage. First, while Ajax certainly knows his actions cannot be undone, the main thrust of the line is changing proximity to death, not nullifying the past. Second, since a preternatural force is at play, human limitations are not the most relevant detail to future outcomes. Third, the exact nature of the cosmic game is open-ended or at least unknown to mortals, so the reversal may not be of Ajax's actions, but of his fortunes and esteem among the other Greeks, which he makes clear throughout the play is his primary concern - until his death, that is.

Lastly, it has been objected that a board game would be an unexpected metaphor in Ajax's speech. ${ }^{179}$ The cosmic game, however, conforms perfectly to the tone of the passage: in someone's rumination on providence, the workings of the universe, and the human condition is exactly where we should expect to find it. Although the speakers in the

${ }^{176}$ LSJ s.v. óv $\alpha \tau i \theta \eta \mu \mathrm{B}$ B.II and B.II.2. Cf. Herodotus, Histories 8.77, where the subject is an anthropomorphized divine quality; Antiphon the Sophist fr. B 52 DK, who states that one

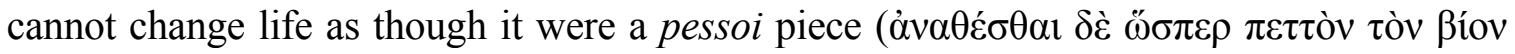

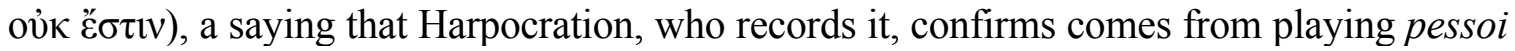

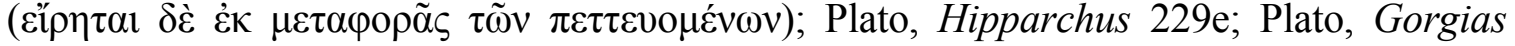
461d-462a.

${ }^{177}$ See Diggle (1983) 50. Cf. Lloyd-Wilson and Jones (1997) 20 and Finglass (2011) 276, who concur and also cite Diggle as evidence. West (1978) 109-110 and Garvie (1998) 168 mention the ludic use of $\alpha v \alpha \tau i \theta \eta \mu$ in the middle voice, but maintain that Sophocles' use of the active voice in this passage is problematic.

${ }^{178}$ Finglass (2011) 276

${ }^{179}$ Finglass (2011) 276 
Ajax are all characters in a play rather than real people recording their beliefs or explanations of the world, Sophocles nevertheless presents an internally consistent picture that fits the metaphorical pattern traced in this and the previous section. It would be fruitless to speculate about Sophocles' own views, but at a minimum the playwright incorporates into his work the same system of explaining the world that is found throughout Greek literature.

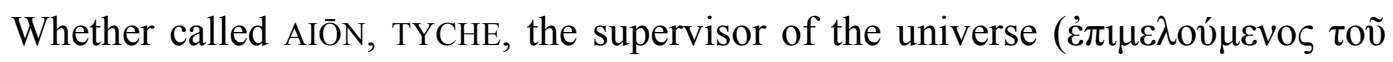
$\pi \alpha v \tau o ́ \varsigma)$, an unspecified god $\left(\theta \varepsilon \varepsilon_{\varsigma}\right)$, or some other name, Greek authors envision a preternatural power managing a cosmic game board on which people are the pieces. ${ }^{180}$ Portrayals of ludic embodiment offer one way for author to make sense of the world and one's place in it. The theme of an external force playing with humanity is a common one in Greek literature, but it is just one of the diverse ways the Greeks imaged their world as a kind of game.

\section{Cities and Citizenship: Embodied Citizenship}

There is a thread of Greek thought that extends the imagery of games and embodiment entirely onto the mortal plane. Besides being pieces on the cosmic game board, humans are also pieces in the complex system of the city. ${ }^{181}$ Polis, the word for city, also indicates a game, discussed below, so the ludic metaphor holds true for citizenship as a kind of game.

\footnotetext{
${ }^{180}$ See Versnel (2011) 268-280 for "the god" or "the gods" becoming "near identical to the all-embracing power of Fate," especially 276: "The terms ho theos, hoi theoi, to theion, ho daimon, hoi daimones referring to an anonymous and mysteriously interfering supernatural power abound in Greek idiom of all periods."

${ }^{181}$ See Sakellariou (1989) 92-135 for a detailed discussion of the polis as defined by its connection with humans.
} 
Euripides provides an early glimpse into this civic symbolism in the Suppliants. A messenger arrives from Thebes with a message for the ruler of the land, prompting a discussion of rival systems of government: ${ }^{182}$

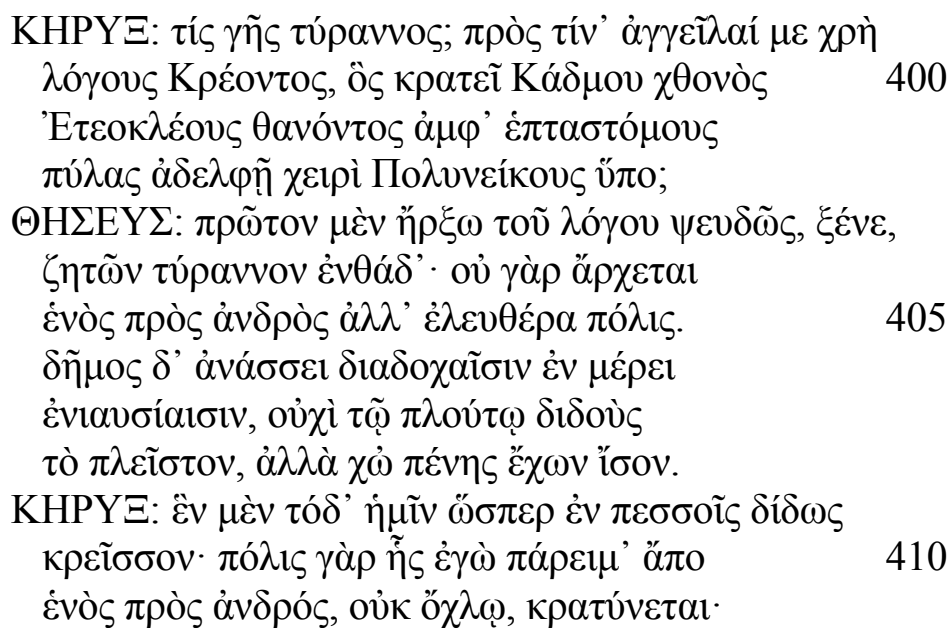

HERALD: Who is this land's tyrant? To whom should I deliver the words of Creon, who controls the land of Cadmus since Eteocles was slain by the fraternal hand of Polyneices near the seven-mouthed gates?

THESEUS: First of all, you began your speech falsely, stranger, by seeking a tyrant here; for the city is not ruled by one man, but is free. The people rule in turn by yearly successions, not giving the greatest portion to the rich, but the poor man also has an equal share.

HERALD: This one thing you give to us is superior, just as in pessoi; for the city from which I come is ruled one man, not by the masses.

The herald's comparison to pessoi in a discussion of city governance introduces a parallel between games and politics. While there is unfortunately not enough evidence to assess exactly what the messenger's simile means, we may still draw several conclusions. ${ }^{183}$ First, the fact that polis is the name of a game, discussed in the next section, invites us to extend the symbolism introduced by the mention of pessoi. Second, there is a symbolic

\footnotetext{
${ }^{182}$ Euripides, Suppliants 399-411

${ }^{183}$ While the thrust of the Theban messenger's last statement seems clear enough, commentators share perplexity at the specific mechanics involved in the game(s) mentioned, either omitting any notes or remarking that there is wordplay with $\pi$ ó $\lambda 1 \varsigma$ ( 405 , 410) and $\pi \varepsilon \sigma \sigma o i ̃ \zeta ~(409)$. Collard (1975) 219-220 provides a succinct overview of what pessoi could indicate and offers parallels for the $\pi$ ó $\imath$ ı $/ \pi \varepsilon \dot{\varepsilon} \sigma \sigma o t$ joke.
} 
relationship between the city and a game board. Third, the lack of a single Athenian leader makes the herald feel he has an advantage, just as he would in a game of pessoi. ${ }^{184}$ The circumstances of the polis, therefore, resemble the disposition of pieces in a game, providing advantages and disadvantages to each opposing faction. ${ }^{185}$

In the passage above, it is fitting that the Athenians were not the ones to invoke ludic imagery, for in another Euripidean play, Praxithea describes the Athenians' autochthony as specifically counter to the disposition of pieces on a game board: ${ }^{186}$

$$
\pi \rho \tilde{\omega} \tau \alpha \mu \grave{\varepsilon} v \pi \lambda_{\lambda} w v
$$

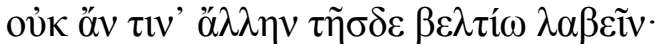

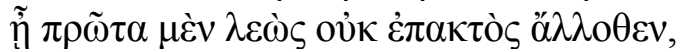

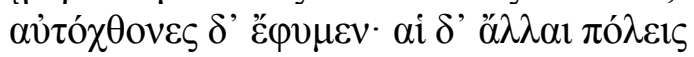

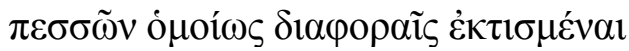

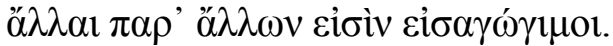

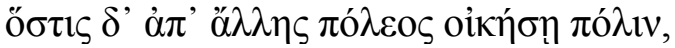

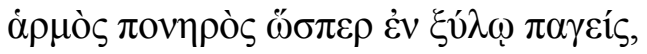

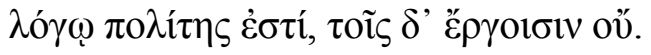

5

For starters, it is not possible to get a city better than this one. First, our people are not imported from some other place, but we were born from the land itself; but other cities were founded hither and thither, just like pessoi, different ones imported from different places. But anyone who settles in one city from another city is like a faulty peg fixed in a piece of wood: he is a citizen in word, but not in deed.

${ }^{184}$ The advantage in question could be that a "king piece" is lacking, but I find the evidence too scanty to support this conclusion. Collard (1975) 219 notes that the Greeks had games "played with dice to determine the moves...and those dependent entirely on

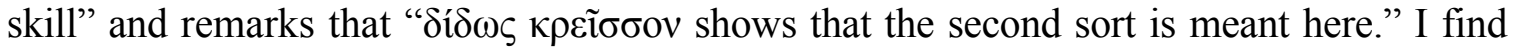
this presumption too hasty: one may use the throw of a randomizing agent suboptimally when moving pieces, thereby giving an advantage to one's opponent.

${ }^{185}$ Cf. Kurke (1999a) 266: "The Theban herald's use of the simile of pessoi in the midst of this debate confirms the political resonances of board games, but it almost seems that Theseus and his interlocutor are modeling according to two different games within the same generic rubric. Theseus imagines Athens on the model of the game of polis, in which all pieces have equal standing. The Theban, in contrast, seems to be envisioning a different game, in which Theseus's assertion that there is no single ruler on his side is the greatest concession he can make to his opponent. Thus the collision of regimes is also a clash of game structures."

${ }^{186}$ Euripides, Erechtheus 5-13 
The Athenian woman claims the superiority of her city to others on the grounds of autochthony. In Praxithea's conception, Athens is the best city because it is the only one whose inhabitants are not there by chance. ${ }^{187}$ The comparison is to pessoi appeals to the same $\pi$ ó $\lambda ı \varsigma / \pi \varepsilon ́ \sigma \sigma o \imath$ wordplay in the previous passage. The pieces, people, move from place to place, forming cities as they do. Athens is special because its people retain their original position on the board, as it were, marking them as safe from the harshest vicissitudes of FORTUNE.

With her claim, Praxithea details what a city is in terms of embodiment. She asserts that people move and cities are founded in varied locations, their citizens imported from elsewhere, and likens the situation to a game of pessoi. The basis of her claim is not that the cities themselves change places, but that people migrate and cities are founded. A city, therefore, is a conglomeration of dispossessed people; humans are the pieces of the pessoi game, their clusters forming cities. Praxithea's assertion of Athens' superiority functions, at least in part, by using the metaphor of the world as a game board and people as pieces whose (re)location founds cities, marking citizenship as part of a larger game.

Aeschylus too portrays displacement in ludic terms. At the outset of the Suppliants, Danaus' daughters, serving as the chorus, describe their miserable situation as they flee from marriage to their cousins, the sons of Aegyptus: ${ }^{188}$

\footnotetext{
${ }^{187}$ What matters here is that the Athenians grew from their native soil rather than migrating there; the actual location of Athens, whether guided by divine providence or sprung by pure happenstance, is immaterial for this argument. The claim of autochthony was a point of Athenian pride: see, for example, Euripides, Ion 589-590; Thucydides, History of the Peloponnesian War 1.2.5-6, 2.36.1-2; Isocrates, On the Peace 49, Panathenaicus 124-125, Panegyricus 23-25; Aristophanes, Wasps 1076.

${ }^{188}$ Aeschylus, Suppliants 11-15. See Johansen and Whittle (1980) 2.16-19 for a thorough explanation of the linguistic difficulties and implications of these lines.
} 


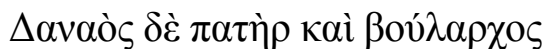

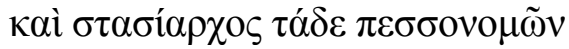

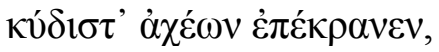

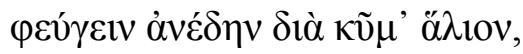

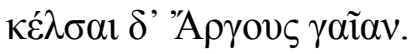

Danaus, our father and the advisor of this plan and the leader of our group, strategizing as though playing pessoi, determined the most honorable of grievous options: to flee recklessly across the waves of the sea and put to harbor in the land of Argos.

The Danaids' description of Danaus playing pessoi holds dual significance. First, the Danaids conjure the notion of analytical acuity, seen in Danaus' planning and weighing of options. Second, the girls symbolically liken themselves to the pieces of their father's game: he is the strategist and they are his counters to be maneuvered as he thinks best. ${ }^{189}$

The chorus' words have conspicuous resonance with Praxithea's claim, for by deserting their home, the Danaids are—at least temporarily—citiless. They are pieces scattered on a board, émigrés traveling to a new destination; on their way to Argos, the Danaids are the very imports Praxithea describes. Of particular consequence is that the Suppliants is part of a foundation—or re-foundation—story, telling the history of Argos. ${ }^{190}$ The passage from Aeschylus also shows the manner in which Euripides used material from the earlier dramatist. In Aeschylus' Suppliants, the leader of a wandering, citiless band is referred to as playing pessoi. Euripides' play of the same name-a parallel not to be overlooked-shows a character alluding to pessoi in a discussion of

${ }^{189}$ As Bakewell (2013) 43 puts it: "Danaus resembles someone playing a board game, and his ability to outwit his Egyptian opponents under difficult circumstances is a testament to his strategic vision and tactical abilities." Cf. Bakewell (2008) 303-304. See Bakewell (2008) 305-307 and (2013) 44-45 for exploration of possible connections between games and politics throughout Aeschylus' Suppliants.

${ }^{190}$ Argos underwent several re-foundations. According to Apollodorus, Library 2.1.1-2, Inachus founded the kingdom, his grandson Apis renamed it Apia, and later Argus renamed it Argos. The influx of the Danaids and Danaus receiving sovereignty from Pelasgus Gelanor is therefore one of a series of Argos' re-foundations. 
ideal leadership for a city. Another Euripidean play discusses how people wandering like pessoi pieces on the game board of the world found cities. Euripides, then, subtly recalls his predecessor in his ludic allusions. In all cases, the two playwrights combine the elements of games, where people serve as the pieces, and cities or "citilessness." The tragedians' imagery reinforces the idea of citizenship as a kind of game, cities properly being a cluster of pessoi pieces.

Aristotle, working in the century after these dramatists, provides a continuation of their conception about the citizenry. Near the outset of his work on the polis, the philosopher states that partnerships grow into larger affiliations, the city being the end goal of all such bonds. In a well-known statement about the nature of man, he concludes that: ${ }^{191}$

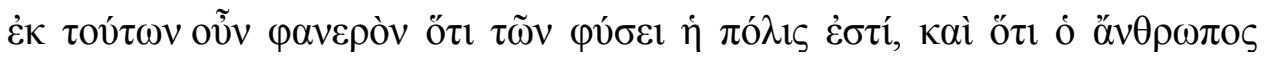

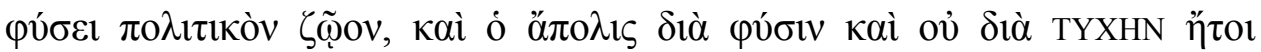

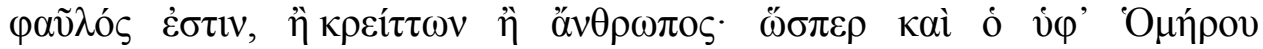

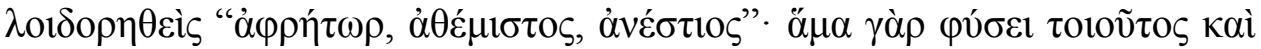

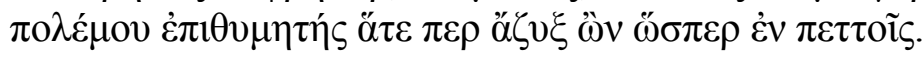

From these things, therefore, it is clear that the city is among the things that exist by nature, and that man is by nature a political animal, and a man who is citiless because of his nature and not because of TYCHE is, truly, either a lowly man or greater than man, and he is just like the one reviled by Homer as "clanless, lawless, hearthless," for this man is also by his nature desirous of war, inasmuch as he is like an isolated piece, as in pessoi.

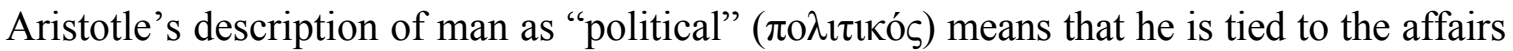
of the polis; man is a city animal. A man without a city, therefore, is subhuman or superhuman, though Aristotle makes an important distinction: the man possesses his irregular quality only when he is citiless by his nature, since TYCHE too can leave him deprived of hearth and home. The philosopher does not clarify exactly what he means by

${ }^{191}$ Aristotle, Politics 1.1.9. The quotation from Homer is Iliad 9.63. 
TYCHE, but the cosmic player can perhaps be seen in the background of this passage. ${ }^{192}$ The citiless man is like an isolated pessoi piece, meaning he has been separated from the other counters, his remoteness leaving him vulnerable to attack while potentially posing a threat to his foes. ${ }^{193}$ As I argue above, the ancient Greeks could see mortals as the pessoi pieces in a celestial game, so any attribution to TYCHE might also be seen as the intentional move of the cosmic player. In other words, the cosmic player may have isolated the man, who knows only his own circumstances, not the master plan, and attributes his desperate situation to what he perceives as TYCHE, whether the vicissitudes of the abstract concept or the deliberate actions of the personification and/or deity. The man who has lost his city because of TYCHE, then, is merely playing his role on the game board and may rejoin civilization; hence, Aristotle distinguishes him from the man who is apolis by nature, who because of his disposition voluntarily shuns the bonds of society, the natural end goal of human partnerships. Each pessoi piece, moreover, is understood in relation to the others, as none can be isolated without reference to its disjunction from the larger group. The man who is citiless, then, is deprived of his position in the symbolic structure that grants him identity. ${ }^{194}$

Aristotle expands on the idea of civic symbolism a little further in the same work. Just as a city comprises many citizens, Aristotle clarifies the reliance of each citizen on

${ }^{192}$ For full discussions of play in Aristotle, see Solmsen (1964) and Kidd (2016).

${ }^{193} \mathrm{Cf}$. Austin (1940) 265: the $\alpha \zeta v \xi$ piece is one that "has become cut off from the main force and so is in danger itself and a danger to others." Thraede (1967) 122-124 argues that Aristotle uses $\alpha \zeta v \xi$ only because it is a poetic word that accentuates the metrical clausula

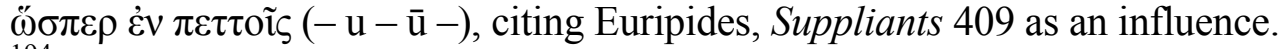

${ }^{194}$ Cf. Vernant (1978) 492, 500 n.68; Kurke (1999a) 269; Kurke (1999b) 259-260; Kurke (2002) 26 
the city: ${ }^{195}$

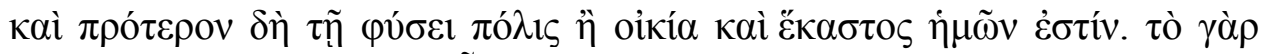

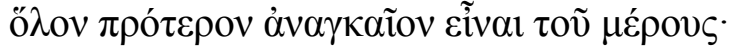

$\cdots$

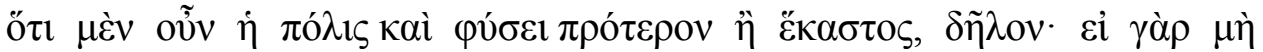

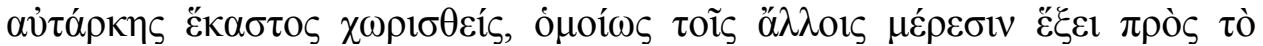

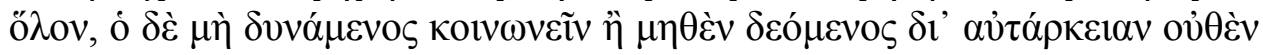

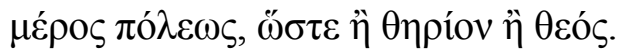

And indeed the city is by nature superior to the household and each of us. For the whole is necessarily superior to the part.

That the city is in fact superior to each individual by nature is clear; for if each person is not self-sufficient when he has been separated, then he must be related to the whole in like manner with the other parts, but he who is not able to engage in partnerships or, on account of his self-sufficiency, in no way needs any share of the city, in that case he is either a beast or a god.

This excerpt is reminiscent of a passage in Plato's Laws quoted above, as both philosophers insist that parts must work for the sake of the whole. It is likewise significant that the earlier Aristotelian passage comes almost immediately after a reference to the gods being ruled by a king (1.1.7); the proximity of the sections is suggestive because of the contextual parallels with quotations seen throughout this chapter: a god imbued with kingship, governance, cities, pessoi, and mortals embodying the pieces of the game. The continuities in theme and language allow us to see continuities in the ludic elements as well. The citiless man who is so by nature, that is, because of his self-sufficiency, is not a man at all, but subhuman or superhuman: he is not

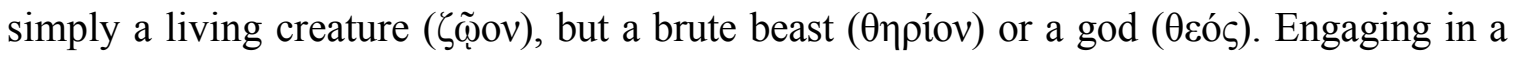
bit of conjecture, it seems that the citiless man, then, is no longer even a piece on the celestial game board. If the pessimistic reading is taken, his inability to fulfill mankind's natural task of participating in the polis has rendered him without identity, ontologically

${ }^{195}$ Aristotle, Politics 1.1.11-12 
changed from man to beast as though from an active piece to one captured and removed from the game. On the optimistic view, he has transcended the game, eclipsing it as well as humanity; he is separate from people and their cities, yet still defined in relation to them, perhaps - and only perhaps - a subtle indication that he himself is the cosmic player.

\section{Cities and Citizenship: Polis}

Since the ancient Greeks could portray a city as a gathering of pieces in the cosmic pessoi game, it is fitting that they likewise played a board game called polis, as mentioned above. Although the exact rules and apparatus are unknown, Greek literature preserves enough material for a partial reconstruction. Most importantly, the texts concerning polis reinforce the associations of people with game pieces and clusters of the latter with cities.

At the outset of the fourth book of Plato's Republic, Socrates and Adeimantus consider their ideal polis. Adeimantus fears destruction if compelled to wage war against a large and wealthy city, but Socrates assures his interlocutor that their trained guardians would emerge victorious, like lean dogs among fat sheep, and would gain allies by leveraging their neighbors' greed for each others' possessions, as the ideal city would not take any share of the spoils (422a-d). Adeimantus concurs, but then imagines the unification of all other cities: ${ }^{196}$

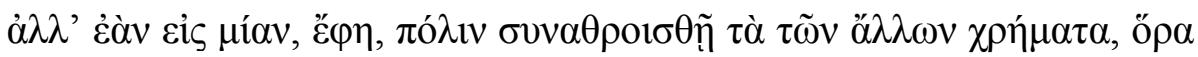

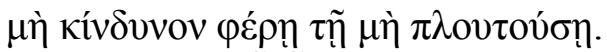

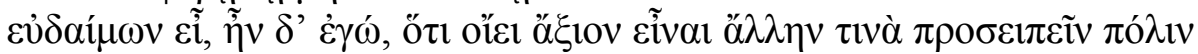

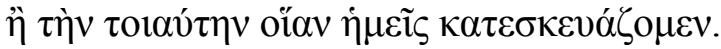

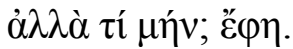

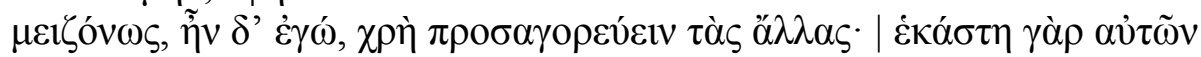

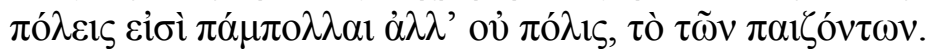

${ }^{196}$ Plato, Republic 4.422d-e 
"But," he said, "if the riches of the others are gathered together into one city, I think that would bring danger to the city that is not wealthy."

"You are blessed," I said, "because you think it is appropriate to call something other than the kind we were establishing a city."

"But what, then?" he said.

"It is necessary to address the others in grander fashion," I said, "because each of them is a great many cities, but not a city, as said in the game."

Socrates explains that each city — other than their ideal one — is internally divided: a city of the rich and a city of the poor are constantly at odds with one another, as well as each comprising many smaller factions. As such, each city is in reality many different cities, a situation reflected by a game and its associated proverb. Since Plato's audience was likely as familiar with the game as the two interlocutors, the passage includes little additional information. We can still glean much, however, from Plato and later commentators.

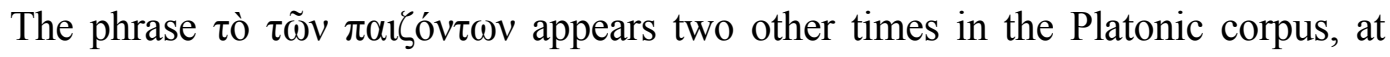
Republic 573d and Laws 780c, where it means "as they say jestingly" or "as the saying goes. ${ }^{, 197}$ In the passage under consideration, however, the phrase refers to a proverb derived from the game polis. ${ }^{198}$ The first piece of evidence comes from the scholion to the passage, which states that "to play poleis is a kind of board game; metaphorically it is also

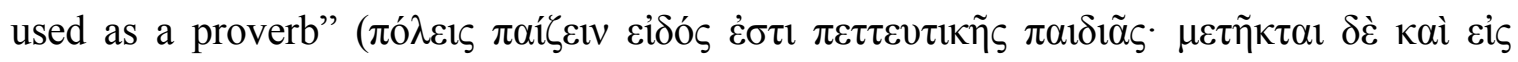
$\pi \alpha \rho o u$ í $\alpha v) .{ }^{199}$ Provided that the scholiast's information is correct, there is no reason to doubt his gloss that Socrates refers to this proverb drawn from the game polis. ${ }^{200}$

Similar expressions about the board game and its associated maxim recur in Greek

197 Jowett and Campbell (1894) 3.167-168; Hansen (2002) 9

${ }^{198}$ Contra Stewart (1893) 359, who believes that Republic 422e contained no reference to a game called polis, though he admits that one "has been generally assumed by the interpreters ancient and modern."

199 Scholia Platonica ad loc.; Greene (1938) 221

${ }^{200}$ Lamer (1927) 1974; Ridgeway (1896) 288; Hansen (2002) 10 
lexicographers. In his paroimiographic lexicon, Zenobius records "To play poleis: Cratinus makes mention of it in The Runaway Women. Polis is a kind of board game. Also, using it metaphorically seems to come from those who play with stone counters, which now are

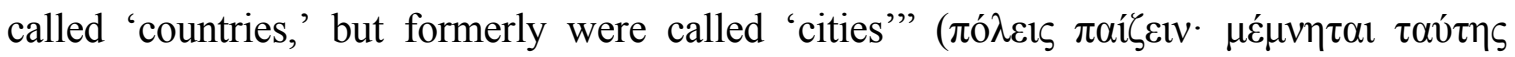

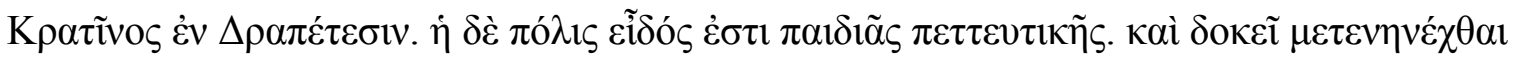

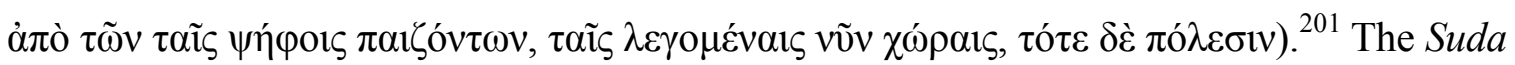

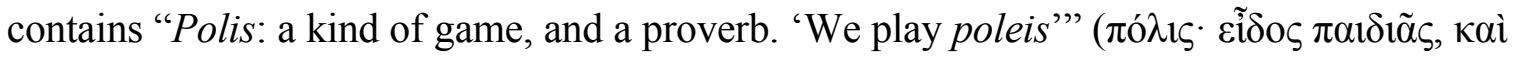
$\pi \alpha \rho \circ \mu i ́ \alpha . ~ \pi o ́ \lambda \varepsilon ı \varsigma ~ \pi \alpha i ́ \zeta o \mu \varepsilon v){ }^{202}$ Hesychius notes "To play poleis: a proverb. Also, using it metaphorically seems to come from those who play with stone counters, which on the one hand are now called 'countries,' but on the other hand were formerly called 'cities"'

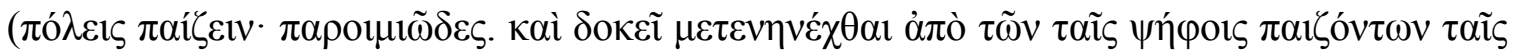

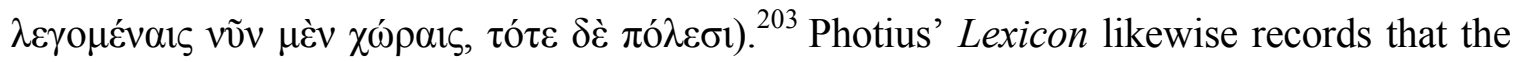
squares of the game were later called countries: "To play poleis: what are now called

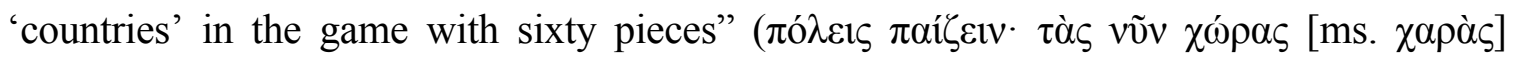

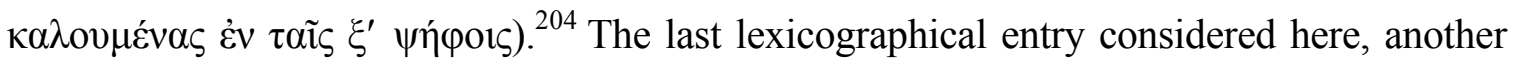
manual of aphorisms, mistakenly ascribed to Plutarch, includes "We play poleis: polis is a

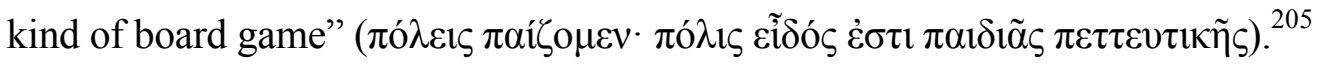

Lastly, the second-century CE author Julius Pollux's compendious Onomasticon

${ }^{201}$ Corpus Paroemiographorum Graecorum 1.147 no. 5.67

${ }^{202}$ Suda s.v. Пó $\lambda$ 1s, Adler number $\pi .1911$

${ }^{203}$ Hesychii Alexandrini Lexicon col. 1257

${ }^{204}$ Naber (1865) 2.97; Porson (2010 [1822]) 439.1-2. Porson emends $\xi^{\prime}$ (sixty) to $\zeta^{\prime}$ (seven), which is at odds with Pollux's statement that polis is played with many pieces (see below), as well as that it resembles the game diagrammismos (9.99) and Eustathius' claim that this latter game is played with sixty pieces (ad Il. 2.728.6-7). Cf. Adam (1963) ad Plato, Republic 422d-e.

${ }^{205}$ Corpus Paroemiographorum Graecorum 1.323 no. 1.14 . On the mistaken attribution, see Sandbach (1969) 404-405. 
includes several sections (9.94-103) devoted to various games, including board games. Regarding polis, Pollux states that: ${ }^{206}$

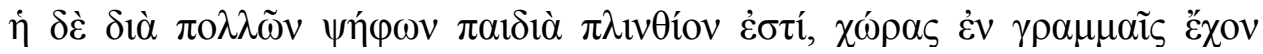

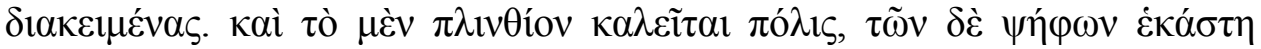

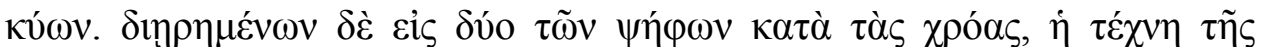

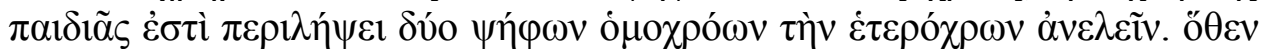

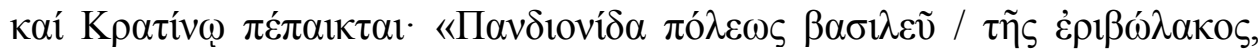

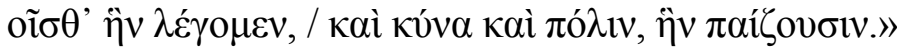

There is a board game of many pieces, which has spaces arranged by lines. And while the board is called polis, each of the pieces is called a dog. Once the pieces are divided into two camps according to their colors, the art of the game is to capture a piece of the opposite color by surrounding it with two pieces of the same color. The game is played with in Cratinus: "Descendant of Pandion, king of the fertile city, you know the one of which we speak, and you know the dog and the city, the one people play."

The addressee of Cratinus' fragment is most likely Theseus, whose paternal grandfather was Pandion and who was celebrated as having united the various small cities of Attica into the one city of Athens. ${ }^{207}$ In his mythological play, Cratinus probably alludes to an opposition between one polis and multiple poleis, just as Plato does in Republic 422d-e. ${ }^{208}$ Cratinus' mention of a dog next to a clear reference to the game polis almost certainly plays on the fact that pieces in polis were called dogs. ${ }^{209}$ By unifying the disparate cities into one great city, Theseus won the game, his kingship over the polis of Athens a reflection of his success at using his kuōn in the game polis.

It is telling that Socrates characterizes the guardians of his ideal polis as "hard and

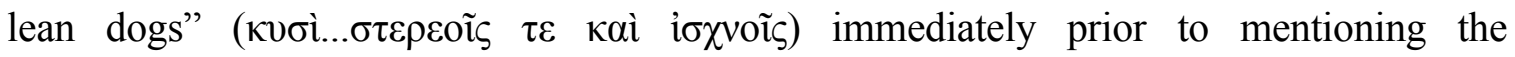

${ }^{206}$ Pollux, Onomasticon 9.98-99. The quotation from Cratinus is fr. 61.

${ }^{207}$ Bakola (2010) 147-148 and n. 96. For the genealogy of the royal family of Athens, see Gantz (1993) 233-235, 247-249. For Theseus' synoecism of Attica into Athens, see Thucydides, History of the Peloponnesian War 2.15.1-2.

${ }^{208}$ Hansen (2002) 11

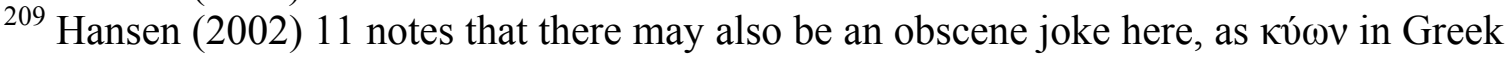
comedy was used as a euphemism for male genitalia. Cf. Henderson (1990) 127, 133. 
homonymous game and its associated proverb. ${ }^{210}$ Socrates' envisioning of his ideal city is itself a manner of game, as he admits after catching himself taking the enterprise too seriously. ${ }^{211}$ Just as the name of the game is a singular polis, but people say "to play poleis" in the plural, as seen numerous times in the lexicographers above, Socrates establishes his polis against the other poleis on the board. His city will be united, one that does not devolve into warring factions, and his guardians, likened to dogs and therefore to game pieces, will conquer any foe. Socrates' gameplay mirrors the workings of his ideal city: emerge victorious by shunning greed, distributing resources with the utmost economy, and maintaining cohesion. Aristotle's description of the apolis man can be read in this light, the latter's improper post endangering both himself and the city; on Socrates' game board, no piece is isolated.

\section{Cities and Citizenship: The Game of Citizenship}

If mankind's utmost good is to participate in the affairs of the city and if a city is a gathering of pieces in the divine pessoi game, it is interesting to see citizenship itself as a kind of game. After all, citizens are, in one viewpoint, game pieces, so the ludic symbolism can extend from the cosmic level to the localized polis, as seen in the tragedians. Diogenes Laertius records an anecdote in which Heraclitus seems to have understood civic duty as a kind of play: ${ }^{212}$

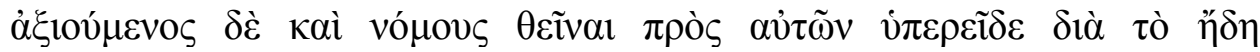

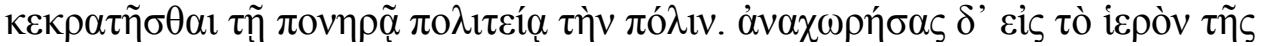

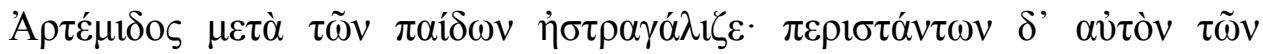

\footnotetext{
${ }^{210}$ Plato, Republic $4.422 \mathrm{~d}$

${ }^{211}$ Plato, Republic 7.536c. For the role of play in Platonic philosophy, see Ardley (1967), who goes so far as to claim that "the whole of the Republic is play" (236).

212 Diogenes Laertius, Lives of the Eminent Philosophers 9.1.2-3
} 


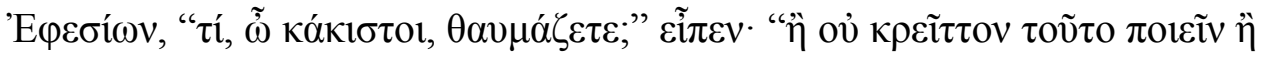
$\mu \varepsilon \theta$ '

And when he was asked [by the Ephesians] to lay down laws for them, he refused because the city was already ruled by a wicked constitution. But he would withdraw to the temple of Artemis and play knucklebones with the boys; and when the Ephesians stood around him, he said, "Why are you astonished, you worst of men? Is it not better to do this than to govern the city with you?"

The issue at play in this story is, like many Heraclitean adages and anecdotes, rooted in paradox: the philosopher's ostensibly bizarre preference for seemingly unserious children's games over the terribly serious matter of lawmaking. ${ }^{213}$ Children, however, may take their knucklebones very seriously, as when such a game enraged the young Patroclus so much that he slew Amphidamas' son. Moreover, laying down laws is as much a symbolic activity as playing a game, so Heraclitus may not be contrasting an unserious matter with a serious

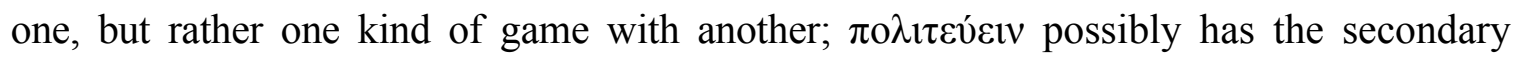
meaning "to play polis," just as $\pi \varepsilon \sigma \sigma \varepsilon v ́ \varepsilon v$ means "to play pessoi." ${ }^{214}$ Heraclitus is perhaps invoking the game polis to chastise the Ephesians by implying that they are only playing at governance, as evidenced by their extant wicked constitution. Given a choice, the philosopher finds knucklebones with children the preferable game.

The equation of children's games with legislation persists in Greek thought. Plato makes the comparison explicit: ${ }^{215}$

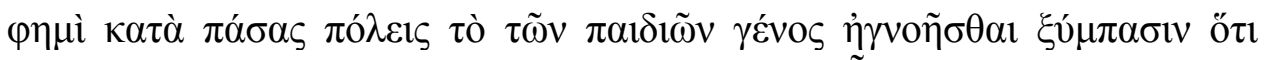

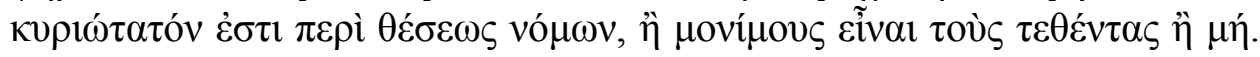

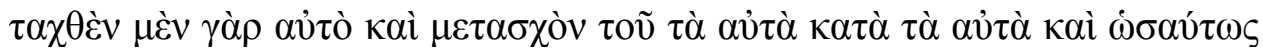

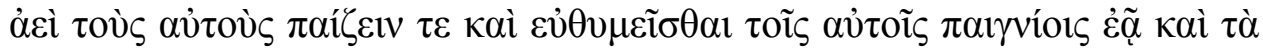

${ }^{213}$ Kurke (1999a) 268; Kurke (1999b) 259

${ }^{214}$ Kurke (1999a) 268; Kurke (1999b) 259. It is important to remember that Heraclitus himself uses $\pi \varepsilon \sigma \sigma \varepsilon v \varepsilon \varepsilon v$ in fr. B 52 DK. I would also add the parallel that $\alpha \sigma \tau \rho \alpha \gamma \alpha \lambda i \zeta \varepsilon \varepsilon v$ means "to play astragaloi."

${ }^{215}$ Plato, Laws 797a-b 


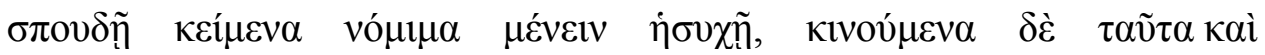

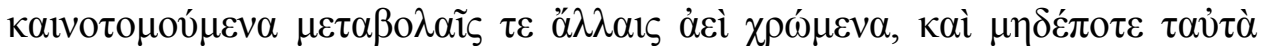

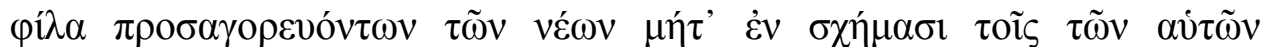

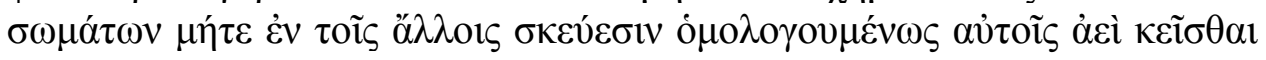

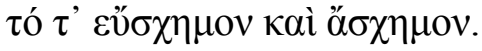

I assert that among all cities there is total ignorance about the class of children's games, that it has the utmost authority over laying down laws, whether those enacted are permanent or not. For when the program of games is arranged and participated in such that the same children always play the same games and delight in the same playthings under the same conditions and in the same way, then it is at rest and allows the laws passed in earnestness to remain, but when these games are disturbed and innovated and always undergo changes, then the same ones are never loved because new games are introduced, so that neither in the shapes of their bodies nor in their playing apparatus do they have a permanent standard of propriety and impropriety.

In the mind of the speaker, the Athenian, the manner in which children play predicts how laws will be treated. Children who play in consistent fashion learn to respect what exists, but those who enjoy continual innovations learn to cherish only novelty itself. Consequently, the latter children, once they have grown into adult citizens, change laws merely for the sake of change, not because of necessity. The ultimate conclusion is a citizenry devoid of propriety and therefore susceptible to unproductive modification to its laws.

This passage from Plato's Laws furthers the idea that citizenship — and therefore legislation - is a kind of game. ${ }^{216}$ In the Athenian's account, adults pass laws in the same fashion that they played as children, either with constancy or with superfluous variation. It is little wonder, then, that laws are elsewhere in the work referred to as a game played by old men. ${ }^{217}$ As in Heraclitus' exchange with the Ephesians, the Athenian states that

\footnotetext{
${ }^{216}$ Cf. Jacobson (1999) 769: "The politics of the Laws is a game... The action of the political game is law-giving."

${ }^{217}$ Plato, Laws 685a, 769a
} 
citizens' legislation is their game, one that they may in fact be playing poorly. It is perhaps unsurprising that Heraclitus seems to have foreshadowed the connection between children's manners of play and their adult modes of thinking; as Iamblichus asks, "Truly, how much more fittingly [than another thinker] did Heraclitus believe that men's opinions were the playthings of children?" ${ }^{218}$ Whether Plato followed the earlier philosopher or reached the same conclusion independently, the Laws show the same comparison.

In the Minos, Socrates furthers the ludic connotations of legislation. His interlocutor takes issue with Socrates' logical progression, a complaint that the philosopher attempts to dissuade by providing an analog from a game: ${ }^{219}$

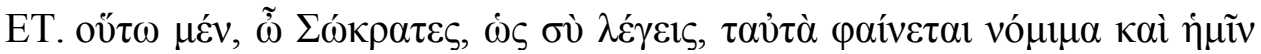

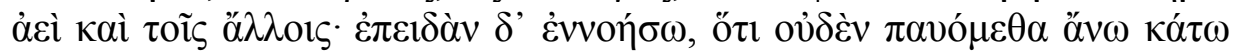

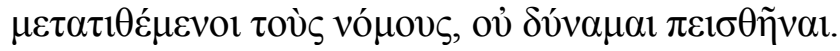

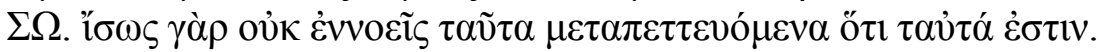

COMPANION: In the way you are speaking, Socrates, the same things appear always lawful both to us and to others; but whenever I consider that we never stop changing the laws back and forth, I am unable to agree.

SOCRATES: Perhaps you do not understand that things moved in a game of pessoi are the same things.

Socrates argues that when pieces are moved in a game of pessoi, they remain pessoi pieces, just as laws remain laws even after being changed. His appeal to ontological permanence may be open for debate, but the comparison he makes is not: Socrates provides game pieces as an equivalent for laws as things that retain their existential purity

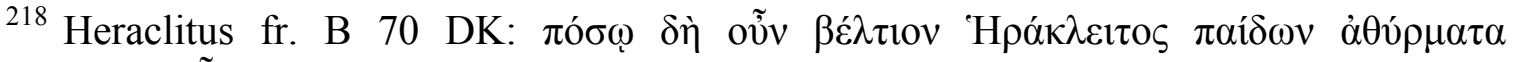

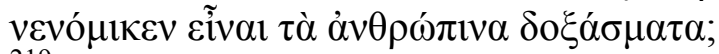

${ }^{219}$ Plato, Minos 316b-c. Whether this dialogue is authentic to Plato or is "a fairly able and plausible imitation of Plato's early work" (Lamb 1927: 386) is extraneous to the present discussion, which concerns a mode of Greek thought, not a restrictive list of authors; if anything, additional writers only strengthen the evidence.
} 
even when altered in some way. ${ }^{220}$ Since citizens with juridical power are necessarily those who amend legal codes, they are the game players moving the pessoi counters in Socrates' analogy, that is, lawmaking is a game that citizens play.

\section{Playing Your Roll}

As seen above, humans may be seen as pessoi pieces controlled by a superhuman force, but they also cluster into cities and play their own game, that of legislation. In other words, there is a secondary level of embodiment, in which the pieces of the divine game become players themselves and move pieces of their own. Even the changing affairs of the polis are reflected in the homonymous game played by citizens. People, then, possess agency and alter the conditions of their cities, both the ones they inhabit and their microcosmic counterparts on the game board. While ultimately subject to the cosmic player, humans maintain a certain level of control, adapting to the shifting conditions on the game board.

As stated earlier in this chapter, the mortals who are the pieces in the cosmic pessoi game may feel subject to the vicissitudes of (random) FORTUNE because they know their own circumstances but do not comprehend the master plan. Despite such limited knowledge, people's task is to make the best use of their state of affairs, whatever they may be. The dramatist Aeschylus first shows the notion of utilizing what FORTUNE provides. In the Agamemnon, the watchman spots the signal beacon marking his king's return home. He declares, "I will take advantage of what has fallen well for my masters,

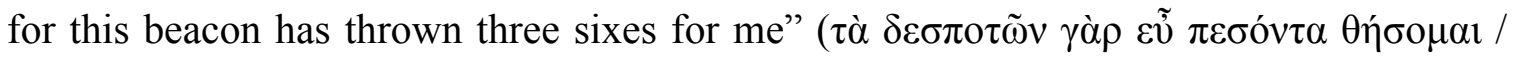

\footnotetext{
${ }^{220}$ Socrates' statement is all the more interesting when considering Heraclitus' view of the unity and exchanges of seeming opposites as part of the cosmic pessoi game.
} 


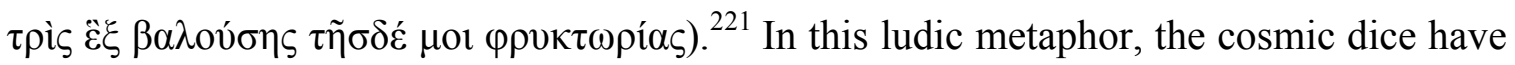
rolled well ( $\varepsilon \tilde{\tilde{v}} \pi \varepsilon \sigma o ́ v \tau \alpha)$ for the royal house, so the watchman's own position is improved; he has the fortune of announcing Agamemnon's return, which he equates to three sixes, the best possible throw. ${ }^{222}$ In other words, although the watchman does not dictate his circumstances, he is nevertheless bound to them and behaves accordingly. In the cosmic game of life, one cannot control what FORTUNE bestows, but can only react to it.

For consideration of this theme, I shift from using the more general term "randomizing agents" to the word "dice," as seen in the paragraph above. Dice are a subset of randomizing agents, as the latter term encompasses dice, knucklebones, casting sticks, coins, and any other devices used to produce chance outcomes beyond the control of their throwers. The relevant sources for this theme, however, either name dice explicitly or leave the instrument unspecified, but with dice as the likeliest choice: kubos could refer to both a die and the single hollow on it, as in some instances of the proverb "three sixes or three ones"; when the ancient Greeks played games with knucklebones, they threw five knucklebones; and no sources mention using other randomizing agents in sets of three. ${ }^{223}$ As such, I use the term "cosmic dice" to discuss this theme, though the equation of dice and randomizing agents is not appropriate in other contexts.

Later in the same trilogy, Aeschylus again invokes the notion of one's fate being

${ }^{221}$ Aeschylus, Agamemnon 32-33. The ludic metaphor is strengthened by the fact that the watchman refers to himself as a dog in line 3 .

${ }^{222}$ In later Greek, "throwing three sixes or three ones" became a proverb for the vicissitudes of FORTUNE, which was sometimes excellent and sometimes dreadful.

${ }^{223}$ For kubos meaning both a die and the single hollow on it, see Pollux, Onomasticon 9.95. For the proverb "three sixes or three ones" and variations on it, see, for example, Pherecrates fr. 129; Plato, Laws 968e; Aristotle, Eudemian Ethics 8.2.6-7 (1247a 21-28); Persius, Satires 3.48-50; Lucian, Saturnalia 4; Zenobius, Proverbs 2.29. For the ancient Greeks playing with five knucklebones, see Kidd (forthcoming a). 
assigned by cosmic dice rolls. Just before Orestes displays the corpses of Clytemnestra and Aegisthus, the chorus prays for harmony to return to the household, ending with the following statement: ${ }^{224}$

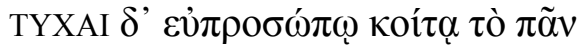
i $\delta \varepsilon \tilde{\mathrm{i}} \mathrm{s}, \pi \rho \varepsilon v \mu \varepsilon v \varepsilon \tilde{\mathrm{i}} \zeta$

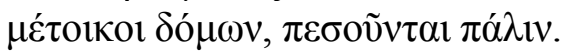

But their TYCHES will lie presenting a face entirely fair to see, settling into the house as favorable, for they will fall out again.

The chorus likens the fate of the royal house to dice rolls. Under Clytemnestra and Aegisthus these casts were poor, but the next throw, Orestes' revenge, will bring peace once more, as the household's fortunes, themselves embodied as dice, will fall so that they show favorable faces. ${ }^{225}$ In this passage, FORTUNE and the dice rolls it allots to mortals are one and the same, showing TYCHE, personified or as an abstraction, to be the randomizing agent of mortals' fates.

In a similar vein, Sophocles notes in an unassigned fragment that game players must make the best of their dice throws: "It is fitting for the clever gambler to acquiesce to

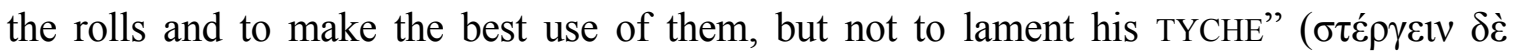

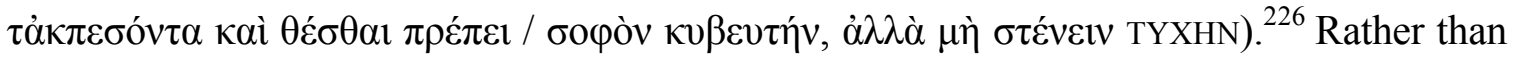
gripe about good or bad throws, the wise player accepts them for what they are and utilizes them in the most suitable fashion. ${ }^{227}$ Sophocles' statement is not applicable only to game players, however, but is allegorical for the proper behavior of humanity: in the game of life,

\footnotetext{
224 Aeschylus, Libation Bearers 969-971

${ }^{225}$ Cf. $L S J$ s.v. $\varepsilon \dot{\pi} \pi \rho о \sigma \omega \pi$ окоí $\eta$ s, which notes that this saying is a metaphor derived "from the dice."

${ }^{226}$ Sophocles fr. 947

${ }^{227}$ See $L S J$ s.v. $\tau i \theta \eta \mu$ A.VII.2 for the meaning "to place as skillfully as possible the pieces which have been assigned to one by the luck of the dice."
} 
one must make the best use of whatever TYCHE bestows. The linguistic parallels with Aeschylus' earlier work ( $\pi \varepsilon \sigma o ́ v \tau \alpha$ for what has befallen someone, $\tau i ́ \theta \eta \mu$ in the middle voice for using what has befallen someone, TYXH as the assigner of what befalls someone) show that the later playwright's sentiment is best seen in light of a ludic metaphor for proper living.

Euripides, the dramatic successor of Aeschylus and Sophocles, includes in his plays explicit claims about life as a form of game and the need to adapt to seeming chance occurrences. While it is unclear whether Euripides intentionally channels his literary predecessors in this regard, all three tragedians incorporate the same mode of thought in their works. In the Eurpidean corpus, the idea of life as a cosmic game of chance is perhaps nowhere as explicit as in the Rhesus. ${ }^{228}$ When Hector asks Dolon what reward he desires in exchange for spying on the Greek camp, the latter replies "The horses of Achilles: it is necessary that I, risking my life in the dice game of DAIMŌN, work for worthy rewards"

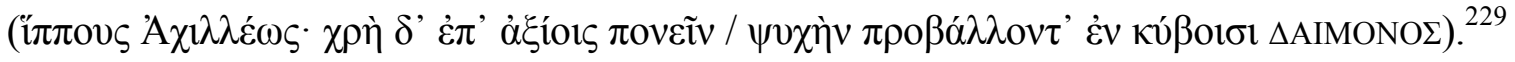
Dolon acknowledges that his success or failure rests on a roll of the dice, as it were; even the verb he uses for "risk" in its uncompounded form means to throw dice. ${ }^{230}$

Dolon may be taking the risk, but he does not control the dice: he throws his life into danger, but the dice belong to his fate, in the control of an external force. What seems like random chance to humans may be the unknown plan of the cosmic game player, but it is intriguing to think that this passage reflects an extension of the cosmic game, revealing

\footnotetext{
${ }^{228}$ The authenticity of this play as Euripidean has been contested since antiquity. For a brief but sound overview of the argument, see Kovacs (2002) 352-353. As with Plato's Minos discussed above, confirmed authorship is less important than the text itself, as any additional sources help prove the prevalence of ludic elements in Greek literature.

${ }^{229}$ Euripides, Rhesus 182-183

${ }^{230} L S J$ s.v. $\beta \alpha ́ \lambda \lambda \lambda \omega$ A.II.7
} 
that it contains a chance element. Even though the cosmic player is in control, its moves may depend on the rolls of cosmic dice. Euripides further develops this idea in the Suppliants, a section of which was discussed earlier:.231

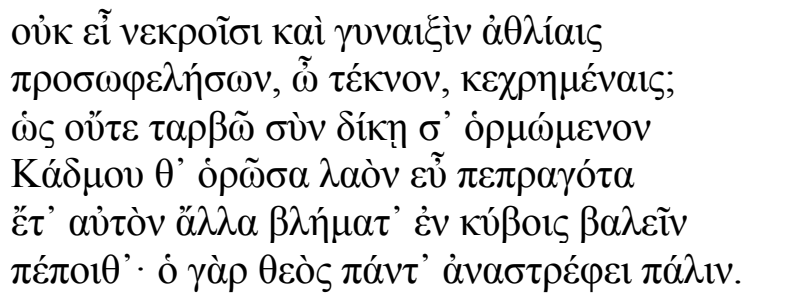

My son, will you not aid the dead and these miserable women in their time of need? I do not fear for you, since you set out with justice on your side, and while I see the people of Cadmus prospering, still I believe that they will throw other casts with their dice; for the god turns all things back again.

In this passage, Aethra is speaking to Theseus, her son. Aethra expands upon Dolon's perspective by professing that one's lot, prosperity or disaster, is malleable; although life is a gamble, the dice roll more than once. The statements are more similar than disparate, however, and the common element is that dice determine human reality. Aethra's mention of a god who overturns all things also recalls the cosmic player, who controls the universe on its game board. Whether the unspecified god controls the dice or arranges his pieces according to them, Euripides' character likens mortal affairs as subject to him and the game. ${ }^{232}$ As people cannot alter what the dice reveal, they can only make the best of their circumstances and hope, as Aethra does, for better luck in future throws.

Socrates, a contemporary of Euripides, is explicit about the ludic framework of existence and the proper way to live. The philosopher states that "life is like a kind of

\footnotetext{
${ }^{231}$ Euripides, Suppliants 326-331

${ }^{232}$ Here, as in a previous section, I translate using masculine pronouns in order to stay true to the Greek text under examination; I am not intimating that the cosmic player is always portrayed or perceived as male.
} 
board game, and it is necessary for each circumstance to be arranged as though a game piece, for it is not possible to throw [the dice] all over again or to change the position of

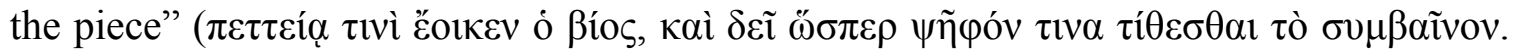

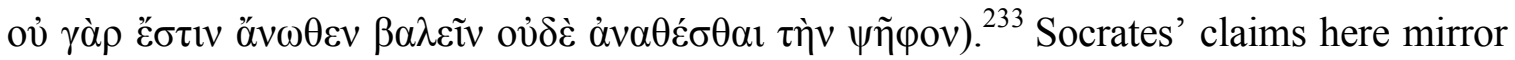
what his character says in Plato's Republic about his polis, both the city and the game: one must take the utmost care in arrangement, for any error can be detrimental to the efficacy of the whole. In the passage under consideration here, the philosopher advises about chance occurrences by comparing incidents in life and the results of dice rolls, each of which has a seemingly random nature. All one can do is react accordingly.

Plato adopts his teacher's parallel between life and a game, including the necessity to manage affairs rationally, as though allocating resources in a game. Near the end of the Republic, Socrates has the following exchange with Glaucon: ${ }^{234}$

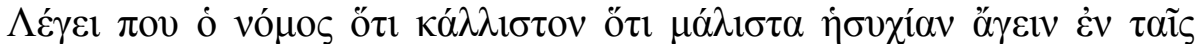

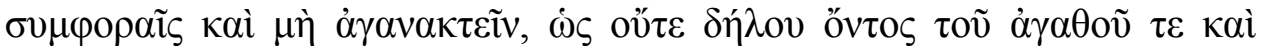

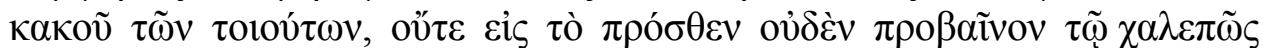

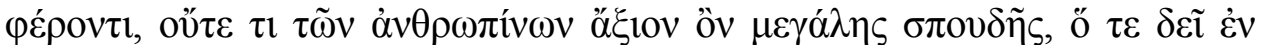

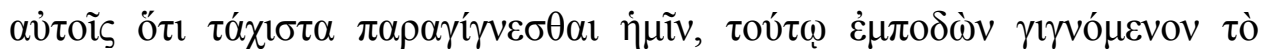
$\lambda v \pi \varepsilon \bar{\sigma} \sigma \alpha \mathrm{l}$.

Tív, $\tilde{\eta} \delta$ ö

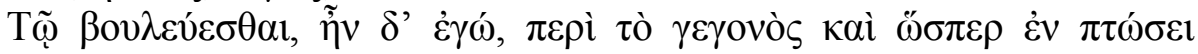

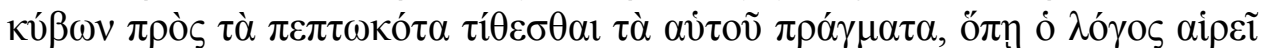

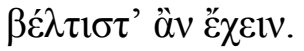

"The law surely says that the noblest thing is to keep as calm as possible in chance events and not to be vexed, as neither is the good and the bad of such situations clear, nor is it profitable in the future for someone bearing it badly, nor is any human affair worth serious attention, and being distressed gets in the way of what we need with us as quickly as possible in these circumstances."

"What thing," he asked, "do you mean?"

"Deliberation over what has happened," I said, "and, as in the fall of

${ }^{233}$ Socrates apud Stobaeus, Anthology 4.56.39

${ }^{234}$ Plato, Republic 604b-c 
dice, to arrange our affairs according to the dice throws in whatever way reason determines would be best."

For the character of Socrates, rational decision-making is of the utmost importance. Socrates declares that nomos explains decorum when facing chance events. While the word he uses ( $\sigma u \mu \varphi \circ \rho \alpha ́)$ often connotes misfortune, its fundamental sense simply refers to any given circumstance. ${ }^{235}$ One should not become vexed when facing an unfamiliar circumstance, Socrates says, because its full implications, either good or bad, are unknown. In ludic terms, the cosmic dice have been thrown, but the rolls have not yet been revealed.

The philosopher exhorts treating life as a game: just as one uses dice rolls as effectively as possible in a game, one must likewise react to chance occurrences in life with serenity and maximum economy. Calculation is applicable to both a game and life, certainly, but here the philosopher exhibits just how blurry the distinction is. He states that not one of mankind's affairs is worth taking seriously, invoking Plato's frequent association of play $(\pi \alpha 1 \delta ı \eta ́)$ and seriousness $(\sigma \pi 0 v \delta \eta \dot{)}) \cdot{ }^{236}$ If human affairs are not serious, then they fall to the other side of the dichotomy. Even before alluding to dice, Socrates implies that living is little more than a game. The comparison, then, is not between the seriousness of life and the playfulness of dicing, but between two different games, life and dice, each of which can be taken quite seriously, but should be played calmly instead.

It is tempting to push this passage yet further into the confluence of life and play. Upon careful inspection, no word for playing or a game is present save the kuboi and the concomitant words for throwing them. Perhaps Socrates is not identifying a mortal game

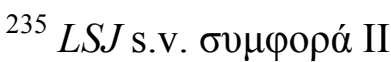

${ }^{236}$ Ardley (1967) 226
} 


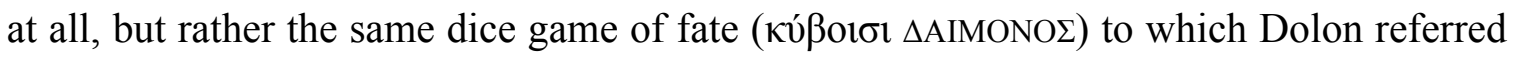
in Euripides' Rhesus. It is just possible that Socrates, whose relationship with a personal $\delta \alpha i ́ \mu \nu$ is infamous, advocates the proper behavior when perceiving a shift in circumstances because this is no different than any other roll of the cosmic dice.

Plato's near-contemporary Alexis appears to maintain the simile of life as like a dice game. Noting the same shifting fortunes of existence as Euripides' Aethra, one of his characters states: ${ }^{237}$

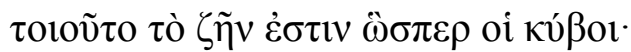

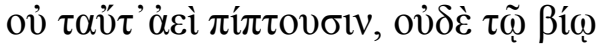

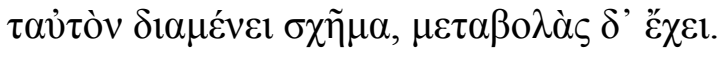

Living is just like a game of dice: they do not always fall the same way, and the same pattern does not persist in life, but it has changes.

Like some of the other authors discussed in this chapter, Alexis-through the mouth of his character-is vague about whose dice game is being played; he may mean a mortal's game or the cosmic game played with mortals. Without additional context for these lines, a definitive answer is unobtainable. The fragment by itself is a straightforward comparison, but when read in the literary milieu of the other passages in this chapter, new possibilities unfold; I explore these possibilities in the next chapter, where I explore Terence's reception of this theme - and perhaps these very lines —in the Adelphoe.

Although a full consideration of imperial Greek exceeds the scope of this chapter, a final example serves to show the longevity of the ludic theme under discussion. Around four centuries after Alexis, the Stoic philosopher Epictetus, as recorded by his pupil Arrian, declares that humans are responsible for their own actions, but should dispassionately accept events beyond their control; both collections of his teachings, the

${ }^{237}$ Alexis fr. 35 K-A 
Discourses and the Enchridion, begin by distinguishing between what is within and what exceeds human control. Moreover, in his encouragement to make the best use of what is in one's power and use all else as it occurs, Epictetus attributes matters beyond human control to the volition of a god. ${ }^{238}$ The philosopher adds the final piece of the puzzle when he states the way to maintain equanimity in the face of adversity: ${ }^{239}$

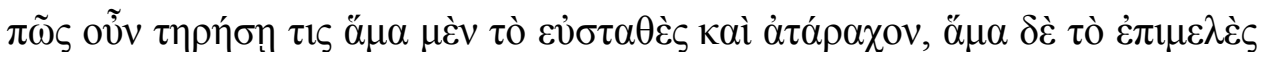

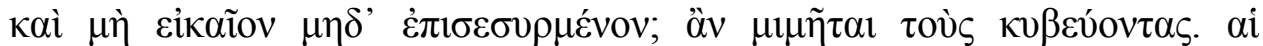

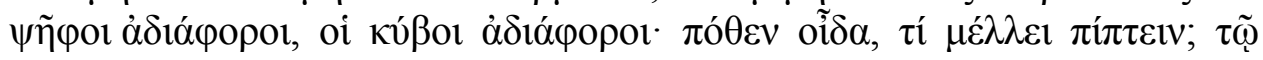

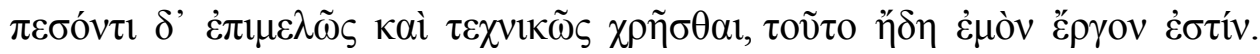

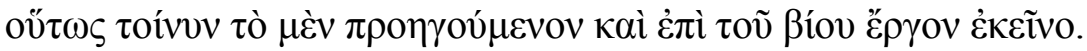

How can someone retain tranquility and equanimity, and at the same time take care and be neither hasty nor negligent? If he imitates those who play games with dice. The counters are indifferent, the dice are indifferent. How do I know what will fall? But to use what falls carefully and skillfully, that now is my task. In just the same way, this is the foremost task of life.

Epictetus' message echoes Socrates' as recorded by Stobaeus and in Plato's Republic. It is impossible to predict the future, just as it is impossible to predict how dice will fall, so one must remain calm and adapt to present circumstances. Game players accept their dice rolls, which are outside their control, dispassionately and move their pieces, which are within their control, as advantageously as possible. Epictetus' message is clear: to succeed in life, you just have to play the game.

${ }^{238}$ Epictetus, Discourses 1.1.17: "It is necessary to make the best use of the things in our control and to use the other things as they occur. 'How do they occur?' However the god

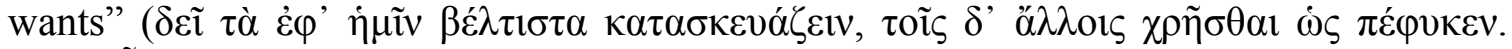

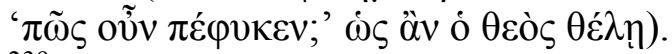

${ }^{239}$ Epictetus, Discourses 2.5.1-4 


\section{Conclusion}

Greek authors of various genres and time periods depict their world as a game board and their very existence as a kind of game. While not mutually exclusive of rival modes of thought, this method of relating humans to the universe pervades Greek literature from the very earliest texts. Writing reflects rather than records the matrices of its conception, necessitating that its audience examine not only the works themselves, but also the ideas behind them; considering ludic passages intertextually rather than as mere metaphor builds them into a conceptual tool for gaining deeper understanding of a Greek literary trope. Moreover, games are symbolic systems par excellence, so texts with ludic elements authorize readers to see deeper significance, to play with the underlying notions, as it were. This fact need not, however, imply a unified or formalized system of belief or thought, the existence of which would be impossible to prove. Rather, this chapter shows that centuries of Greek authors take recourse to the same ludic comparisons and present the world as (operating like) a game in terms that remain remarkably consistent across time and genre.

The first theme I explore is "the cosmic game," a motif by which Greek authors explain the organizing principle of the universe as a cosmic player making moves in a game of pessoi. In this model, humans are the pieces in this game or, to use a different ludic metaphor, are the pawns of the cosmic player. Through "the cosmic game," Greek authors can answer complex and esoteric questions by projecting them onto a simpler, more abstract, metaphorical screen. When authors anthropomorphize the organizing principle of the cosmos, their depictions and appellations vary, but a ludic component

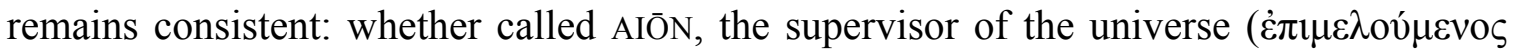




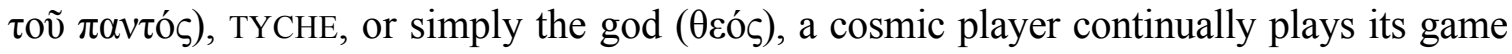
of pessoi with human lives as the pieces, moving them up and down the board and inverting their circumstances.

I end this section by using the implications of this theme to resolve a muchdebated passage in Sophocles' Ajax. Scholars often point to the seeming peculiarities of Ajax's speech, such as the possible gaming element and the hero's reference to being moved closer and further from death each day. The idea of the cosmic player unifies the disparate viewpoints, showing that the ludic features fit with the tenor of the speech, as well as earlier and later sections of the play. The cosmic player also resolves the uncertainty of the agent moving Ajax about. Finally, despite the objection that a board game would be an unexpected metaphor in Ajax's speech, the cosmic game conforms perfectly to the passage: in someone's rumination on providence, the workings of the universe, and the human condition is exactly where we should expect to find it.

In "cities and citizenship," I argue that Greek authors establish a discursive link between games and citizenship. While mortals may be only pieces in the cosmic game, the metaphor of humans as game pieces and the world as a game board exists without reference to a cosmic player, as the establishment and governance of cities are themselves games. The wordplay of polis as both the word for city and the name of a board game allows Greek authors to identify citizens, the pieces of a city, as pieces on a game board. Participating in the affairs of - especially managing - a city, then, becomes a kind of game: the citizen game pieces play their own game in the form of governance and legislation, the proper manner of which is, according to Plato, first learned playing (other) games during childhood. 
In the final theme, "playing your roll," I build on how the affairs of the polis are reflected in the homonymous game to discuss how the rolls of cosmic dice reveal people's fate. This theme holds many similarities to "the cosmic game," but includes a greater degree of human agency. Mortals are not in control of their circumstances, but how they respond to them is: Greek authors, either in their own words or through their characters, suggest that human affairs are determined in a game and advise treating them as such, that is, approaching each new situation as calmly and rationally as possible. Living properly is accepting the shifting circumstances on the board and adapting to them. Life may be a game, so the best thing one can do is play well. 


\section{Chapter 2: Ludic Ideology in Latin Literature}

\section{Introduction}

The previous chapter, "Ludic Ideology in Greek Literature," explores how the ancient Greeks represent aspects of life and the world in ludic terms, that is, how life is or is like a game. These literary topoi, including the existence and influence of a cosmic player, represent a mode of thought available to the contemporary population, but cannot be taken as a formalized belief akin to or part of religion. What we can say for certain, however, is that Greek authors seek to answer complex questions, such as what the organizing principle of the universe is and why different styles of lawmaking exist, by projecting them onto a simpler, more abstract, metaphorical screen. This approach persists through the literature of the Archaic, Classical, and Hellenistic Periods, including both poetry and prose. Regardless of whether this ludic mentality is belief, explanatory metaphor, or somewhere in between, the result of its existence is that centuries of Greek authors present the world as (operating like) a game in terms that remain remarkably consistent across time, genre, and social circumstances.

Given the extent of ludic ideology in Greek literature, it should come as no surprise to find Roman authors implementing the same elements. The Romans had a complicated relationship with their Greek forebears, especially regarding the conscious adoption and adaptation of literary forms. This much-discussed relationship does not need to be traced here. ${ }^{240}$ What matters for the current discussion is simply the existence

\footnotetext{
${ }^{240}$ On the Romans' relationship with Greek literature, see, e.g., Braund (2002) 242-264, who includes a guide for further reading; Feeney (2005) 226-240; Feeney (2016). See
} 
of the well-known connection, as ludic ideology is among the numerous continuities between Greek and Roman writings. Noting this literary relationship is not to say that the Romans could not or did not have recourse to ludic ideology without a Greek model. Indeed, the archaeological record for ludic material at Roman sites is so robust that using metaphors derived from games is perhaps even more appropriate for Roman authors than their Greek counterparts, as games appear to have had even greater cultural import in the Roman world. ${ }^{241}$ It is impossible, however, to discuss Roman literature without referring to its Greek counterpart, especially since the Romans themselves were so preoccupied with their literary predecessors.

The passages I analyze in this chapter are necessarily selective. Rather than list a multitude of episodes that show Roman authors playing with ludic ideology and Greek sources, I present a few examples and explore them in depth. This approach is meant to emphasize the precision with which Roman authors incorporate ludic themes from their predecessors, as well as the ways these later writers modify those themes to suit their own purposes. The result expands our understanding of how Roman authors interact with the literary tradition. Additionally, I have chosen genres absent from or only briefly discussed in this chapter's Greek counterpart, namely comedy, satire, lyric, and panegyric. This selection is intended to reinforce the pertinence of ludic themes across a diachronic, cultural, and generic expanse.

This chapter proceeds chronologically and thematically, covering over two

Gruen (1990) for a general introduction to Romans assimilating Greek culture and adapting it to suit their own purposes.

${ }^{241}$ On the abundance of games in the Roman archaeological record, see Lanciani (1892) 97-105, especially 97-98; Cilley (1986) 57-58; Purcell (2007) 90-97, especially 90. On the converse scarcity of games in the Greek archaeological record, see Cilley (1986) 5758; Schädler (2009) 173-196, especially 173. 
centuries and several literary genres. I begin with Terence and his final play, Adelphoe, often hailed as the playwright's best work. ${ }^{242}$ Staged in $160 \mathrm{BCE}$ at the funeral games of Aemilius Paulus, this comedy is an appropriate starting point for the present discussion in part because of its date, which comes less than a century after the so-called birth of Latin literature in $240 \mathrm{BCE}$, itself the date of Rome's earliest literary performance, Livius Andronicus' Latin adaptations of Greek plays. ${ }^{243}$ In addition, the Adelphoe, just like Andronicus' plays, has overt ties to Greek models: Terence himself declares that he based his work on Menander and Diphilus, so the connection to Greek literary predecessors is unmistakable. ${ }^{244}$ Terence's use of the ludic theme of "playing your roll" has models in several genres, however, not just comedy; tragedians and philosophers alike make use of the theme. The Adelphoe, then, is ideally situated for exploring the transference of ludic themes across generic, linguistic, and temporal boundaries.

Terence introduces his ludic theme when Micio compares life to a game played with dice, noting that one must use skill to set right whatever falls by chance. The quotation echoes passages from Greek literature advising humans to make the best of their circumstances, regularly expressed as an exhortation to make judicious use of the dice rolls of fate. The wording of the passage allows for an alternate interpretation, one in which mortals must cheat in the game to "correct" their circumstances, granting humans agency in spite of their allotted fortune. The passage is an early example of how Roman authors can play with ludic themes to suit their own purposes, even when closely

\footnotetext{
${ }^{242}$ Martin (1976) vii

${ }^{243}$ On the birth of Latin literature and the date 240 BCE, see Cicero, Brutus 18.72-73; Fantham (2014) 323-329. Cf. Cicero, de Senectute 50; Hendrickson (1939) 69; Conte (1994) 39-40.

${ }^{244}$ See the discussion below.
} 
following a Greek source.

Next, I turn to Horace, who shapes multiple ludic themes in his corpus. His position at the turn of Rome's governmental system also demonstrates the continued relevance of ludic themes to the literature of the late Republic and the early Principate, as well as the malleability of the themes to suit contemporary events. ${ }^{245}$ Moreover, his choice of satire allows for discussion of ludic themes in an entirely Roman genre, while his lyric odes invoke these themes from a variety of Greek generic predecessors.

In his final satire, Horace invokes the ludic themes of "the cosmic game" and "playing your roll" for humorous effect. He applies these themes to the falling of a curtain during a dinner party, undercutting the gravity of similar expressions in Greek literature. Horace's use of ludic themes is significant not only for its bathetic application, but also for the genre in question: the genre of satire has no forebear in Greek literature, as Quintilian declares with pride. ${ }^{246}$ As such, this passage illuminates the broad applicability of ludic themes across genres: even without a generic predecessor as a direct model, ludic themes remain relevant to Horace's literary project.

The cosmic game recurs in the first three books of Horace's odes. This ludic theme is prominent in 3.29 , which is the final poem of the collection before the sphragis of 3.30 and, as such, worthy of special consideration. ${ }^{247}$ It appears throughout the

${ }^{245}$ On the dating of and the inclusion of contemporary events in Horace's works, see Nisbet (2007) 7-21.

${ }^{246}$ Quintilian, Institutio Oratoria 10.93

${ }^{247}$ Cf. Nisbet and Rudd (2004) 345 on the "particular significance" of the penultimate poem of the collection. For more on the function of the sphragis in Latin literature, see Peirano (2014) 224-242, who addresses the sphragis in Horace, Carmina 3.30 and argues that "by collapsing the end of the book with that of the poet's life, the closing epitaph implicitly constructs the poetry as an extension of its author's body, while ultimately 
collection, however, and 3.29 incorporates related elements from three earlier poems. In 1.34 and 1.35 , Horace builds on Greek models from a variety of genres to cast FORTUNA as the cosmic player through her association with the inversion of mortals' circumstances. Horace also conflates Jupiter and FORTUNA, enhancing the stature of the cosmic player, and situates warfare as part of the cosmic game. The poet returns to this last idea in 2.1, where he implies that the one true subject of Pollio's history of the civil war is FORTUNA's game: he explicitly names FORTUNA's game as one of five themes in the work and suggests its influence over the others through its centralized placement and the clever wording of the passage. In 3.29, Horace recalls the three earlier odes and his final satire. He uses elements from each as he gradually builds to his climax, bringing ludic interpretations to mind throughout the poem before treating the cosmic game explicitly in lines 49-56, where he again comments upon the power of FORTUNA as the cosmic player before introducing a new idea: resigning the game by abandoning hope for worldly riches, instead gaining immortality through his writing.

I end this chapter with the Laus Pisonis, a hexameter panegyric of debated authorship. Its date of composition is likewise disputed, but all theories point to the middle of the first century CE, firmly within the Imperial period; the most convincing argument is for $65 \mathrm{CE}$, with Calpurnius Piso, the leader of a failed conspiracy against Nero in the same year, as the laudandus. The decades following Augustus' death saw formal and stylistic developments in Latin literature, including the emergence of

suggesting the possibility of a continued life for both in the memory of readers" (quotation from 226). 
professional poets advertising their services to potential patrons. ${ }^{248}$ The author of the Laus Pisonis is one such poet; in his advertisement, he praises Piso for a host of qualities, including an extended account of his would-be patron's skill at the board game ludus latrunculi. This technique further demonstrates the versatility of games in literature, as they even have a role to play in winning patronage.

The panegyrist recalls the ludic theme of "cities and citizenship" in his equation of humans with game pieces in relation to governance. In an effort to portray Piso as a credible alternative emperor to Nero, the author of the Laus Pisonis uses embodiment to construe Piso's skill at ludus latrunculi as evidence for his success as a military strategist. The poet's approach bears similarities to Cteson's interpretation of the suitors' game of pessoi in the Odyssey: in each case, the result of a game played with counters is equated with outcomes in the players' lives, such that victory in the game corresponds to victory in another arena. For the suitors, capturing the Penelope stone secures Penelope herself in marriage, while for Piso, winning a game with glass soldiers demonstrates the ability to win battles with human warriors and, by extension, govern Rome. It is fitting, then, that the aspiring emperor Piso, the prospective seat of Roman authority, is portrayed as an expert game player.

\section{Terence: Playing Your Roll in the Adelphoe}

As discussed in the previous chapter, there is a strand of Greek literature that represents humans' duty as accepting and making the best use of whatever FORTUNE

\footnotetext{
${ }^{248}$ Mayer (2005) 58-68, especially 61-64. Cf. Conte (1994) 436, “The panegyric genre must have flourished especially throughout the early Empire, since it won immediate support for the poets."
} 
bestows. To make sense of the random nature of existence, including successes and failures, Greek authors characterize humans as pieces in a game, their very lives the playthings of the divine. In this mode of expression, a preternatural force controls mortal affairs, so the ostensibly haphazard distribution of triumph and loss is part of an unknown master plan. As an extension of this cosmic game, the Greeks represent fate as allotted by the rolls of cosmic dice, either cast by the cosmic player or by humans themselves.

In the early second century BCE, the playwright Terence toys with the ludic view of life present in Greek literature. In the Adelphoe, the brothers Demea and Micio each raise one of Demea's biological sons with wildly different parenting styles. After Aeschinus, who has just had a child with the freeborn Pamphila, abducts an unnamed courtesan for his brother, Ctesipho, a series of misunderstandings ensues. By the time the two fathers meet and discuss how to handle recent events, the lenient Micio has learned the truth, while the stern Demea believes that Aeschinus took the girl for himself, in effect keeping a mistress instead of marrying the mother of his child. After Micio tells Demea that he has made arrangements for the wedding, they have the following exchange: ${ }^{249}$

DE. ceterum

placet tibi factum, Micio? MI. non, si queam mutare. nunc quom non queo, aequo animo fero. ita uitast hominum, quasi quom ludas tesseris: si illud quod maxume opus est iactu non cadit, 740 illud quod cecidit forte, id arte ut corrigas. DE. corrector! nempe tua arte uiginti minae pro psaltria periere: quae quantum potest aliquo abiciundast, si non pretio, gratiis.

DE: But does the matter please you, Micio?

MI: No, not if I could change it. Now, since I cannot change it, I am

${ }^{249}$ Terence, Adelphoe 736-744 
enduring it with a calm mind. Thus is the life of men, just like when you play with dice: if what you want most of all does not fall from your throw, then you must set right by skill what fell by chance.

DE: What an improver you are! Doubtless it is because of your skill that twenty minae have been lost for a music-girl: she must be cast aside somewhere as soon as possible, if not for any price, then for free.

Micio simultaneously espouses and reshapes the earlier Greek theme of "playing your roll." At first, he seems to toe the party line, as it were, declaring that although he would change matters if he could, he is unable and so will acquiesce and bear his lot with composure. ${ }^{250}$ That he then invokes the familiar Greek comparison of human life to a game with dice is perhaps of little surprise since Terence's work is an adaptation of a Greek original. ${ }^{251}$ What is compelling, however, is the wording of Micio's statement. The verb corrigere generally means "set right," with broad connotations ranging from straightening a curve to reforming indecorous behavior. ${ }^{252}$ The word's particular flavor here can alter the meaning of the entire passage and must be explored in some depth.

The informed reader or audience member, well aware of Greek ludic themes, arrives at lines 739-741 and understands them in light of the literary culture that provides Terence's source material. Among the many possible allusions, Plato immediately comes

${ }^{250}$ Johnson (1968) 178 comments that here "Micio begins to make excuses, but there is not the least admission of error." Johnson continues by stating that while Micio's outlook is unquestionably attractive, it labors to excuse his sloth, irresponsibility, and selfindulgence.

${ }^{251}$ Terence's Adelphoe is based on Menander's A A $\delta \varepsilon \lambda \varphi$ oí $\beta^{\prime}$, the second of his two plays of the same name. This identification is on the grounds of the similarity between Adelphoe 804 and a line from 'A $\delta \varepsilon \lambda$ poí $\beta^{\prime}$ preserved in the scholia to Plato's Phaedrus 279c. The stage record for Plautus' Stichus records that the Greek original was Menander's A $\delta \varepsilon \lambda \varphi o i$; since a Greek play already adapted by a Roman playwright was not supposed to be used by another, an offense Terence apologizes for making through negligence (Eunuchus 25-

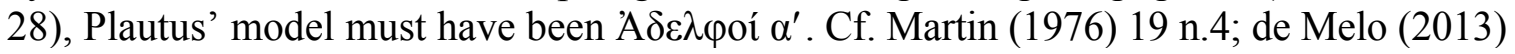
2-3. Terence's play also contains a scene he claims in the prologue (6-11) to have translated word-for-word from Diphilus' Synapothnescontes, a scene Plautus failed to include in his adaptation Commorientes and therefore not a violation of acceptable source material.

${ }^{252} O L D$ s.v. corrigo 
to mind: the character Socrates advises maintaining composure in chance events and, just as in the fall of dice, allocating resources as rationally as possible in any given circumstance. ${ }^{253}$ The similarities between Socrates' and Micio's words are readily apparent, though it will likely never be known if Menander, whom Terence later adapts, consciously imitates Plato or only uses a popular literary theme. ${ }^{254}$ In either case, Micio seems to say that human skill can turn whatever the cosmic dice bestow to its best use, implying a game that employs both dice and counters on a board, that is, a way to use the dice rolls. ${ }^{255}$ In this reading, faithful to the Greek theme, ut corrigas means something like "see that you put right" or "make sure you use as well as possible," an echo of the ludic use of $\tau i \theta \eta \mu 1 .{ }^{256}$ Micio's initial acceptance of his fate and claim of composure in the face of adversity strengthen this reading.

A second interpretation that strays from the familiar Greek theme is also possible. Without Micio's immediately previous acquiescence, lines 739-741 can imply cheating rather than making the best of a situation. In this reading, ut corrigas means "you must correct," granting humans agency to reshape the world in spite of what FORTUNE affords, as if rerolling the cosmic dice through duplicity. Whether a game of dice alone or a game

\footnotetext{
${ }^{253}$ Plato, Republic 604b-c. Other parallels are found in the section "Playing Your Roll" of the chapter "Ludic Ideology in Greek Literature."

${ }^{254}$ Fraenkel (2007 [1922]) 114 assumes that "the idea [of life being like a dice game] had most likely already become a commonplace" by Menander's time, at least in part because of Alexis' influence (in fr. $35 \mathrm{~K}-\mathrm{A}$, discussed in the previous chapter). Fraenkel provides Terence's lines 739-741 as evidence of Menander giving "elegant form to this aphorism." Cf. Fantham (1972) 70. McGlynn (1967) 2.233 offers some Greek precedents, though a more complete list can be found in the previous chapter.

${ }^{255}$ Cf. Martin (1976) 206-207. Both the Greeks and the Romans had games involving both dice and counters, so the imagery is appropriate for both cultures whether or not the disparate audiences would necessarily have pictured the same game.

${ }^{256}$ Cf. Martin (1976) 206-207, who notes some Greek parallels, all discussed in the previous chapter. See $L S J$ s.v. $\tau i \theta \eta \mu$ A.VII.2 for the meaning "to place as skillfully as possible the pieces which have been assigned to one by the luck of the dice."
} 
with dice and counters is imagined is extraneous to this argument, for the dice rolls themselves - either the culmination of the game or the mechanism for piece movementare changed. Perhaps Micio implies that this obstinacy in accepting one's fate is the way to succeed in life, (mis)quoting an aphorism even as he ignores its content and submits to his circumstances. The question of chief importance for present purposes, the degree to which Terence's play is faithful to its Menandrian source, is a matter of some debate. ${ }^{257}$ There is no reason to question that Menander includes a common Greek theme in his play, but it is uncertain whether Terence translates it loyally or subtly undercuts it with his crafty word choice.

Regardless of Micio's meaning, either making the best of present circumstances or refusing to be bound by them, his brother Demea believes Micio fails to take his own advice and responds with mockery. Picking up on his brother's last word, corrigas, Demea sarcastically calls Micio a corrector and expounds upon how his brother has not improved the situation at all. ${ }^{258}$ Demea acerbically insists that it must be because of Micio's ars, the quality by which one is supposed to "set right" the dice, cosmic or physical, that twenty minae have been lost, referring to payment eventually made for the abducted courtesan, whom he calls a music-girl. ${ }^{259}$ The verb Demea uses for "lose" is perire, which is not only linguistically similar to perdere, but also serves almost

${ }^{257}$ See Martin (1976) 19-28 for an overview of the arguments. Fraenkel (2007 [1922]) 114 assumes without discussion that the lines in question are Menandrian.

${ }^{258}$ Cf. Martin (1976) 207 on corrector as a sarcastic play on the final word of Micio's previous statement. As Martin notes, Demea's sarcasm continues with nempe and tua arte, the latter of which picks up Micio's use of arte in his previous statement.

${ }^{259}$ For the conflation of prostitutes and musicians in Greek, see the next chapter, "Games and Morality in Greek Literature." 
universally as its passive voice. ${ }^{260}$ Importantly, while perdere means ruin or loss generally, it can also indicate losses specifically from gambling. ${ }^{261}$ Demea, then, linguistically implies that Micio "gambled away" twenty minae immediately after the latter mentions how life is like a game with dice; according to Demea, his brother's ars has not allowed him to dispose his resources in a suitable fashion, but rather has led to greater forfeiture. ${ }^{262}$

Demea's verbal humor continues in the next and final line of the passage. He states that the music-girl must be gotten rid of at any price; even giving her away for free and not recouping any of Micio's twenty wasted minae is a superior choice to keeping her. While his message is severe, his diction contains yet more amusing wordplay. Demea says that she abiciundast, "must be cast aside," further invoking ludic imagery. The root of abiciunda is iacio, meaning "to throw" generally, but in specific contexts "to throw dice. ${ }^{263}$ Even as he mocks his brother for failing to correct life as if in a game with dice, Demea uses wording that resonates within that very framework, subtly suggesting that the music-girl can be cast away as easily as dice can be cast in a lusory contest. What is more, he acknowledges that his own actions are a kind of gamble: as he tosses the music-girl like a die, the returns he may get for her are uncertain, either an unknown quantity or nothing at

${ }^{260}$ OLD s.v. perdo; L\&S s.v. perdo I. A couple centuries later, Seneca, Epistulae Morales ad Lucilium 98.10 contrasts the two words as losing one's life and losing one's property: tam necesse est perire quam perdere.

${ }^{261}$ OLD s.v. perdo 1 and 6, "To use up extravagantly or to no purpose (material resources, opportunities, etc.), throw away, dissipate, waste"; $L \& S$ s.v. perdo I and II

${ }^{262}$ Greenberg (1980) 229-231 sees Micio as a kind of gambler, as he consciously takes risks in his interpersonal relationships, including his parenting method and a tendency to manipulate others. Greenberg sees this "gambling ethic" (231) in the passage under discussion, but interestingly does not address the fact that the characters discuss both dice and money actually changing hands.

${ }^{263}$ OLD s.v. iacio 3c. I have reproduced the definition as it stands in the dictionary, but this usage of the verb applies to all randomizing agents, not just dice. 
all; the stakes of this game are inverted such that the objective is losing an unwanted possession, not gaining desired goods or wealth.

Demea does not disagree with Micio's contention about the ludic aspects of life and necessity of human skill for success, he simply disagrees that Micio has the requisite ars to amend the family's current circumstances. He derides his brother's agency, not his claim itself, and linguistically places himself at the game board. Micio has "gambled away" twenty minae and Demea states he himself can certainly do no worse. The assertion is specious, since Demea is playing with house money, as it were, using Micio's "winnings" as his own stakes and he therefore has nothing to lose; he will at worst discard the (in his eyes) unwanted music-girl and at best do so while recouping some of Micio's financial losses. The brothers agree that the game is to ameliorate the situation, but they are looking at different boards: Micio is placating everyone, bankrolling Aeschinus' marriage to Pamphila and purchasing the courtesan for Ctesipho, while Demea is acting based on his limited knowledge. In other words, Demea and Micio think they are playing the same game, but Demea misunderstands the placement of the pieces, an error remedied about forty lines later when he discovers whose mistress the courtesan actually is.

In the Adelphoe, Terence encapsulates the kind of linguistic humor available to Roman authors toying with the ludic motifs of their Greek predecessors. The Roman playwright adopts a ludic theme, but toys with it by incorporating jokes that operate within its framework. Unfortunately, Terence's Menandrian source is lost, so we will likely never know for certain whether the Roman author faithfully transmits Greek witticisms or invents his own. What we can say for certain, however, is that Terence's linguistic wordplay works strikingly well in Latin, both translating a Greek literary theme and integrating humor 
based on it, setting the stage — sometimes quite literally_-for later Romans to play with Greek ludic themes in the Latin language.

\section{Horace: The Cosmic Game and Playing Your Roll in Sermones 2.8}

Roman authors accept their Greek predecessors' literary depiction of human life playing out on a game board. The theme of "the cosmic game" helps authors explain the inner workings of the universe, as they can attribute all events, especially inversions of circumstances, to a cosmic player shifting its pieces, that is, mortals' lives. The theme of "playing your roll" allows for human agency, as noted above, and contrasts the powerlessness of humans in the cosmic game, but ultimate control lies outside the human grasp. While Greek authors generally adopt a tone of fatalistic resignation to the cosmic game, Roman writers play with their source material, shaping the theme to fit new circumstances, sometimes for humorous effect.

The poet Horace adds much to the present discussion. He incorporates themes from his Greek predecessors in different ways, sometimes faithfully preserving the messages of their writings and other times adapting their ideas to suit his own purposes. In his final satire, Horace invokes lusory metaphor in two separate ways: he recalls two ludic themes, but reshapes each element amid a host of intricate allusions.

From its outset, Horace's Sermones 2.8 invites comparison to earlier, especially Greek, literature: the first few lines recall the openings of Plato's dialogues Symposium and Timaeus. ${ }^{264}$ The poem continues in the Platonic vein as the guests at Nasidienus

${ }^{264}$ Fraenkel (1957) 136-137; O’Connor (1990) 24, 32; Gowers (1993) 162-163 
Rufus' dinner party drink increasingly more and exchange philosophical musings. ${ }^{265}$ In the middle of the host's snobbish explanation of an elaborate dish, the canopy overhead collapses, ruining the food on the table and prompting the following exchange, reported by the dinner guest Fundanius: ${ }^{266}$

Rufus posito capite, ut si filius immaturus obisset, flere. quis esset finis, ni sapiens sic Nomentanus amicum 60 tolleret: 'heu, FORTUNA, quis est crudelior in nos te deus? ut semper gaudes illudere rebus humanis!' Varius mappa compescere risum uix poterat. Balatro, suspendens omnia naso, 'haec est condicio uiuendi,' aiebat, 'eoque responsura tuo numquam est par fama labori.'

Rufus, with his head hanging, wept as if his son had died prematurely. I do not know what end there would have been had that wise man Nomentanus not lifted his friend like this: "Alas, FORTUNA, what god is crueler to us than you? How you always delight in playing with human affairs!" Varius was scarcely able to suppress a laugh with his napkin. Balatro, who sneers at everything, said, "This is the condition of life, and therefore your reputation will never correspond equally to your work."

Nasidienus, with his banquet ruined by a chance occurrence, takes his bad luck to heart and weeps, powerless to countermand his fate. Nomentanus revives the party by railing against FORTUNA. He calls her the cruelest of the gods toward mortals and claims that she enjoys playing with human affairs. This second assertion has clear parallels to earlier Greek authors, in no small part because FORTUNA's near-equivalent in the Greek world is TYCHE, one of the names of the cosmic player. ${ }^{267}$ Nomentanus mentioning a divinity that

\footnotetext{
${ }^{265}$ Freudenburg (2001) 117

${ }^{266}$ Horace, Sermones 2.8.58-66

${ }^{267}$ E.g. Menander, Aspis 411, "The affairs of mortals are TYCHE, not prudence" (TYXH $\tau \grave{\alpha}$

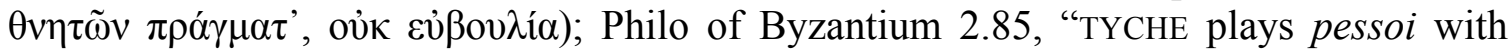

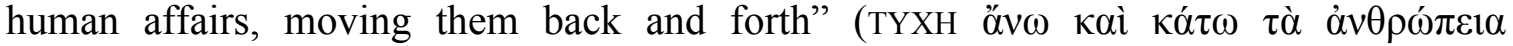
$\pi \varepsilon \tau \tau \varepsilon v i \varepsilon 1)$. The relationship between FORTUNA and TYCHE is complex, but the similarities far outweigh the differences. See Arya (2002) 36-41 et passim, with thorough
} 
embodies and brings about chance occurrences - or at least what people consider as such — is not in itself remarkable, nor is his complaint of a deity meddling with mortal lives. The combination of the two, however, is significant, especially when combined with a verb that indicates playing: by casting FORTUNA as a superhuman force who plays with human affairs, Nomentanus identifies her as the cosmic player, invoking the theme of "the cosmic game" and thereby inserting himself into this ludic theme's long tradition. While this passage is comprehensible without noting the presence of the cosmic game, a great deal of humor lies in how Horace plays with it.

In this passage, Horace subjects "the cosmic game" to bathetic inversion. Greek authors adopt the same theme when contemplating such gravely serious matters as dispossession from one's home or death, ascribing the vagaries of human existence to a superhuman force playing a game. Horace maintains the core concept, but he reduces the theme from grand considerations of mortal life to the falling of a single curtain onto a dinner table. Although Nasidienus has only lost part of an elaborate meal, he responds as if his son has died prematurely, which would perhaps be a far more appropriate circumstance for questioning how the universe operates, that is, for invoking "the cosmic game."

bibliography, for an examination of respective developments of FORTUNA and TYCHE. Although the two served distinct functions in local settings and cults, including having many and varied epithets, Arya argues that "Fortuna always maintained a comprehensive and all-encompassing personality...like Tyche, all of the distinctive, individual traits of the Roman goddess belonged to a collective (or universalized) identity that included both her benevolent and malevolent traits" (43). This is especially true in literature, where epithets are less frequent than in dedications, most of which are made with a distinguishing epithet (55-56). Moreover, though Arya outlines some of the nuances of a distinctly Roman FORTUNA coeval with the Roman Empire, he concedes that literature in the Roman world "melded together the histories and traits of Tyche and Fortuna" and "mirrors the prevalent understanding of Fortuna and Tyche.....e., a single, unpredictable deity" (46). 
Ridicule and misidentification conquer this scene. Fundanius calls Nomentanus wise (sapiens), casting him in the improbable position of a Stoic sage unperturbed by hardships. ${ }^{268}$ Nomentanus' apostrophe to FORTUNA finds a mixed response, furthering the complexity of the passage. He seems entirely out of place when he matches his host's overblown reaction: his emotional appeal is more appropriate for the tragic stage than a private dinner party, yet it proves to be just what Nasidienus needs even as it undercuts Nomentanus' role as a dispassionate Stoic. Varius chuckles as Balatro sneers and generalizes about life in a way that reaffirms the satiric view that fame never corresponds to effort. ${ }^{269}$ Varius' stifled laughter anticlimactically supplants the satiric outburst expected from the scene, while Balatro opposes Nomentanus' claim that FORTUNA is a divine entity by speaking about the instability of life in the fashion of an Epicurean. ${ }^{270}$ What these men seemingly fail to realize is that Nomentanus' interjection appeals to a deep-rooted theme in Greek - as well as earlier Latin-literature; their ignorance is all the more striking considering they are, respectively, a poet and a tag-along of the great literary patron Maecenas. If they are reacting to the fallen curtain rather than their fellow diner, then Nomentanus receives no response whatsoever from them, a silence as damning as the prospective retorts, for in either case they do not acknowledge Nomentanus' insight.

Why the comic playwright Fundanius calls Nomentanus wise is also ambiguous. He may refer to his fellow guest as sapiens in earnest, having grasped the allusion to the

\footnotetext{
${ }^{268}$ Freudenburg (2001) 119

${ }^{269}$ O'Connor (1990) 29

${ }^{270}$ Freudenburg (2001) 119-120
} 
ludic theme, but scholars generally see Fundanius' word choice as mockery. ${ }^{271}$ If this latter opinion is true, Horace has perhaps added another layer of humor to this passage: for all his pomposity elsewhere, Nomentanus here succeeds in showing the greatest connection to the textual world and in response is jeered at by those with supposedly greater literary pedigrees, an unexpected reversal worthy of satire; he may in fact have a taste for wisdom as well as victuals.

Sermones 2.8 also appeals to the Greek theme of "playing your roll" near the end of the poem. After the passage cited above, Balatro's speech continues with thinly veiled mockery, which Nasidienus misses and therefore thanks his guest—or rather his guest's tag-along - profusely. Horace declares that there is no play he would rather see (nullos his mallem ludos spectasse), subtly recalling his interlocutor's occupation as a comic playwright and perhaps inviting comparison to how the events would have transpired on stage. ${ }^{272}$ Horace's crafty word choice of the polyvalent ludos also reminds the audience of the lusory backdrop to this tale, rendering FORTUNA's games a spectacle. When Fundanius begins his story again, he notes the continued revelry and the host's attempt to salvage the banquet: "Back you come, Nasidienus, with a changed countenance, as if you will correct FORTUNA with skill" (Nasidiene, redis mutatae frontis, ut arte / emendaturus FORTUNAM). ${ }^{273}$ Besides reminding the audience of FORTUNA and the cosmic game, this line is indebted to the theme of "playing your roll" and to an earlier Roman adaptation of it.

Fundanius' portrayal of Nasidienus reshapes a passage from Terence's Adelphoe.

\footnotetext{
${ }^{271}$ E.g. Freudenburg (2001) 119, who believes that Fundanius calls Nomentanus wise "with searing irony." Cf. Rolfe (1901) 300, "said ironically." Gowers (1993) 166 n.191 reserves any specific value judgment, but claims that Nomentanus is sapiens "only in culinary matters."

${ }^{272}$ O'Connor (1990) 32. The quote is from Horace, Sermones 2.8.79.

${ }^{273}$ Horace, Sermones 2.8.84-85
} 
As discussed above, Terence plays with the Greek notion of using what the dice rolls of fate provide: the character Micio follows Greek authors in advocating acceptance of one's lot and making the best of any given situation. Although not perfectly happy with what has befallen, he acquiesces and says he will bear it with equanimity, then notes that in living as in dicing, if you do not get what you want most, you must use skill to set right what fell by chance (illud quod cecidit forte, id arte ut corrigas). ${ }^{274}$ Fundanius describes Nasidienus as though the latter has taken Micio's ludic philosophizing entirely out of context: the banquet host returns from his despair "as if he will change FORTUNA with skill" (ut arte / emendaturus FORTUNAM), an image that nearly echoes the Terentian line. Nasidienus seems to ignore Micio's acquiescence and interprets his words accordingly, changing the meaning of corrigas from "set right" to "correct." 275 The altered reading implies that humans can countermand a cosmic force, exactly what Nasidienus seeks to do. Besides the linguistic parallels present (mutare / mutatae, arte ut / ut arte, forte / FORTUNAM), the fact that Fundanius wrote comedies in the style of Terence invites us to see this connection. ${ }^{276}$

Just as Nasidienus wishes to rewrite his fortune, Fundanius' depiction of the dinner host reshapes a Greek literary theme and an early Latin espousal of it. Nevertheless, as so often in mythology, it is Nasidienus' very attempt to circumvent his destiny that leads to its culmination. He returns reinvigorated, followed by slaves

\footnotetext{
274 Terence, Adelphoe 737-741, quote from 741

275 OLD s.v. corrigo 4. Cf. Martin (1976) 207.

${ }^{276}$ For Fundanius as a comic playwright in the style of Terence, see Horace, Sermones 1.10.40-42, where the poet praises Fundanius as the foremost living author writing about Davus and Chremes, evoking characters from Terence's Heautontimoroumenos and Andria, respectively. Coincidentally, these lines include the word eludo, drawing another ludic connection, however distant, between the passages.
} 
carrying a dish (mazonomus, 86) sizable enough to carry six lines' worth of delicacies. ${ }^{277}$

The banquet recommences with food just as exquisite as before; Fundanius' only complaint is the host's incessant descriptions of the spread. The guests, however, have had enough. They sabotage Nasidienus' attempts to salvage his dinner party, collectively refusing to taste a single morsel from the new course, fleeing as though Canidia had ruined all the delicacies by blowing her horrid breath upon them. ${ }^{278}$ The meal, satire, and book all end with the hurried flight of the guests. This finale leaves FORTUNA's designs cosmetically altered but fundamentally unchanged; it is almost as if, when she did not obtain what she most wanted from her dice roll, she used her skill to set it right, marshaling the pieces of her cosmic game, i.e. the dinner guests, to effect her desired outcome.

\section{Horace: The Cosmic Game in the Carmina}

Horace's connection with the ludic themes of his Greek predecessors is clear in Sermones 2.8, but he further utilizes those motifs in the Carmina. One recurring theme is "the cosmic game," which the Roman author employs in a variety of circumstances. Invoking FORTUNA at times serves as shorthand for the cosmic game, so that mere mention of FORTUNA may call to mind the power of fate and the powerlessness of mortals to fight against it, a notion Horace uses for disparate purposes, including both reinforcing the effects of FORTUNA on all aspects of life and questioning how mortals can offer resistance.

\footnotetext{
${ }^{277}$ Horace, Sermones 2.8.86-91

${ }^{278}$ Fraenkel (1957) 148 suggests that Horace names Canidia here and in Sermones 2.1.48 only to link his two books of satires, rather than for any significance she adds to the text. Jones (2007) 83 sees deeper meaning and thinks that Fundanius uses Canidia's name either because he takes for granted that Horace will share his viewpoint or because Horace puts the name in Fundanius' mouth as a seal of approval.
} 
In other words, Horatian references to FORTUNA can bring with them the subtext of the cosmic game, adding nuances to their respective poems and providing implicit intertexts.

The most important ode for present purposes is Carmina 3.29. In order to understand that poem, however, we must take into account the author's earlier engagements with the same ludic theme. This section begins with Carmina 1.34 and 1.35, taken as a pair. These odes cast FORTUNA as the cosmic player through consistent association with the inversion of human affairs, a motif familiar from this ludic theme's appearances in Greek literature. These poems also establish warfare as part of the cosmic game, an idea Horace picks up again in Carmina 2.1. Here too the poet identifies FORTUNA as the cosmic player, even specifically naming her game as the subject of Pollio's history. In Carmina 3.29, Horace remarks upon FORTUNA's power over mortals alongside her insistence on playing her game, equating the two. This ode also addresses the ludic theme of "playing your roll," inserting human agency into the cosmic game, that is, allowing a mortal to resist the cosmic player. The ludic imagery is the key for unlocking this poem's meaning, opening the door to a greater understanding of how Horace interacts with his literary predecessors.

\section{Horace, Carmina 1.34 and 1.35}

In his first book of odes, Horace lingers briefly on FORTUNA's power of inversion, ending one poem and beginning the next with the same idea. Together, the poems stress FORTUNA's complete control over mortals and their affairs. ${ }^{279}$ The first of these odes

\footnotetext{
${ }^{279}$ The connections are so strong, in fact, that some scholars have contended for almost two centuries that the two odes are actually one poem. See Barber (2012) 505-513 for a
} 
involves an important conflation of FORTUNA and Jupiter: 280

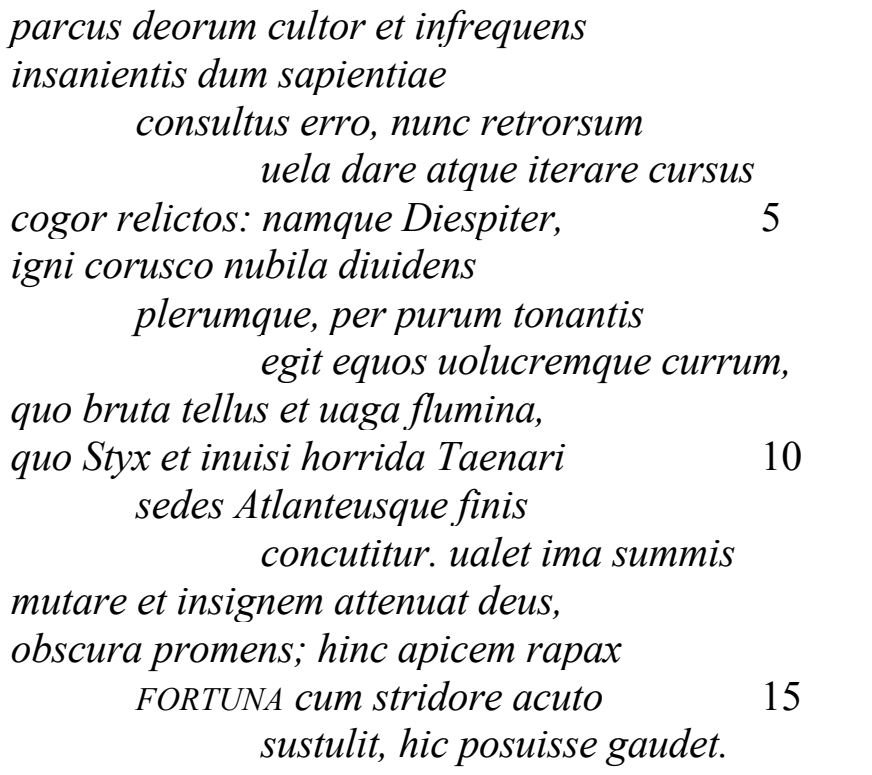

I was a sparing and infrequent worshipper of the gods while I went astray, practiced in senseless philosophy, but now I am forced to sail back and repeat my abandoned courses: for Jupiter, who commonly parts the clouds with his flashing fire, drove his thundering horses and flying chariot through a clear sky, at which the heavy earth and wandering rivers, at which Styx and the savage home of hated Taenarus and the Atlantean boundary were shaken. The god has the power to change the lowest with the highest and brings low the prominent, bringing the dark to light; with a piercing hiss, rapacious FORTUNA takes the crown from this spot and she is pleased to place it here again.

FORTUNA's role at first glance appears to be that of dutiful servant, taking commands from the god, unidentified at line 13, but presumably Jupiter, named (as Diespiter) in line 5, whose fearsome thunder from a cloudless sky ostensibly makes Horace rethink his views on philosophy and religion. ${ }^{281}$ With an awareness of the ludic themes, however, it becomes

recent argument and thorough bibliography. For continuities of theme and style in the poems, see Dettmer (1983) 317-319; Santirocco (1986) 73-78; Arya (2002) 265, 270.

${ }^{280}$ Horace, Carmina 1.34

${ }^{281}$ Specifically, Horace seems to reconsider Epicureanism. Lucretius, its leading Roman proponent, asked why thunder and lightning never came from a clear sky (de Rerum Natura 6.400-401). Scholars hold many competing views about this point. What is of primary interest here is not the sincerity or intricacies of any conversion by Horace, but 
clear that an equally authoritative being in this passage is FORTUNA, who becomes conflated with Jupiter as the cosmic player. $^{282}$

The last three lines of the passage fuse FORTUNA with Jupiter's eagle and with Jupiter himself. FORTUNA flies on her own wings, indicated here by stridore. ${ }^{283}$ Moreover, FORTUNA here supplants the eagle that takes and returns Tarquinius Priscus' cap in Livy. ${ }^{284}$ FORTUNA is thus a substitute for Jupiter's representative bird here, but she may also be seen as a substitute for the god. The word deus can refer to a female divinity in poetry, making the deus (13) as ambiguous as the exact gods denoted by deorum (1). ${ }^{285}$ The shift in subject from Jupiter to the unnamed deus to FORTUNA, then, marks deus as a liminal point, a stage of amalgamation equally valid for both the previous subject and the later one. ${ }^{286}$ This deus

rather the influence of the divine on his way of thinking as expressed through his writing. For the view that this poem reflects Horace abandoning himself to a life of "holy insecurity," see Reckford (1966) 499-532. For the interpretation of a poetic conversion, see Zumwalt (1974) 435-467; cf. Santirocco (1986) 75-76. For the suggestion that Horace is expressing a political conversion, such that the poem "can be read as an expression of renewed interest in Augustus and the policies of his regime," see Santirocco (1986) 75. For the view closest to my own, that Horace is acknowledging the inescapable power of a multifaceted divinity on human life, see Fredricksmeyer (1976) 155-176. Cf. Ullman (1936) 411-412; Fraenkel (1957) 255-256.

${ }^{282}$ For other conflations or equations of Jupiter and FORTUNA in the Carmina, see Dettmer (1983) 149, 424, 426.

${ }^{283}$ Cf. Vergil, Aeneid 1.397, stridentibus alis; Ovid, Tristia 1.1.75, pennae stridore. For other depictions of FORTUNA with wings, see Horace, Carmina 3.29.49-54, FORTUNA ...pennas and the discussion of that passage below.

${ }^{284}$ Livy, Ab Urbe Condita 1.34.8. The authenticity of the tale is questioned by Cicero, de Legibus 1.1.4. Nisbet and Hubbard (1970) 385 and Santirocco (1986) 74-75 note that apicem recalls not only Tarquinius Priscus, but also the crowns worn by Eastern kings, as at Horace, Carmina 3.21.20 (regum apices).

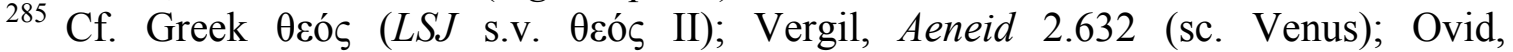
Metamorphoses 10.586 (sc. FORTUNA)

${ }^{286}$ As Fredricksmeyer (1976) 167 puts it, "Fortuna in the following line (15) as subject of the sentence comes at first as a surprise, since we expect deus, but this surprise itself increases our sense of the frequent unpredictability and apparent capriciousness of divine behavior. We quickly surmise that Fortuna is somehow equivalent with deus, Diespiter, and deorum, that is, Fortuna appears to be the deity in the particular manifestation of the 
also serves the role of the cosmic player inverting mortal circumstances, a function familiar for TYCHE, the Greek manifestation of chance and fate. ${ }^{287}$ The changes by FORTUNA and the deus match the reversal of Horace's beliefs seemingly caused by Jupiter, so that inversion not only serves as the focus of the poem, but also further coalesces the three named subjects.

The conflation stems from Horace's engagement with Greek ludic themes. Greek literature holds many examples of a preternatural entity playing with mortal lives. Greek authors consider various divine qualities and deities as the cosmic player with no detriment to the overall effect: whether called AIŌN, TYCHE, or simply the god, the message of a superhuman force maneuvering humans as pieces on a game board remains intact. ${ }^{288}$ The reversals of the passage above - the lowest with the highest, bringing the prominent low, bringing the dark to light—-belong to the same literary theme. In Greek literature, the cosmic player alters mortals' states of being, shifting them for undisclosed purposes, the same role that the deus serves in Horace's ode, including when named as Diespiter and as

unexpected, the inscrutable, and the capricious." Likewise 169: "Then deus (13), itself neutral, receives some qualification from Diespiter, but most importantly, it provides the bridge, the common denominator between Diespiter and the following Fortuna (15), and thus it shows that these two conceptions are essentially synonymous, in the sense that they are two different labels, or forms of appearance, of god." Cf. Mackay (1929) 11;

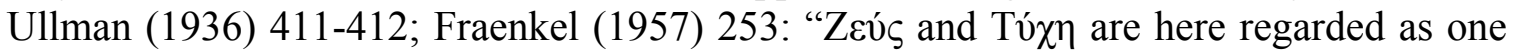
and the same all-governing Power"; Nisbet and Hubbard (1970) 385; Santirocco (1986) 73: "Horace is compelled to return to an earlier belief in the power of the god which, by the end of the poem, has become synonymous with the power of Fortuna"; Barber (2012) 509 n. 24.

${ }^{287}$ For the narrower arguments that the god here is solely a Stoic FORTUNA identified with Jupiter-either equated with him or serving as his lackey—or the Hellenistic TYCHE, see the bibliography in Fredricksmeyer (1976) 168 n. 18-19.

${ }^{288}$ FORTUNA is the Roman near-equivalent of the Greek TYCHE, who serves as the cosmic player in many passages, so the parallel is clear in that respect. The use of deus here corresponds to the use of $\theta \varepsilon$ ć $\varsigma$ as the cosmic player in Euripides, Suppliants 331. 
FORTUNA. ${ }^{289} \mathrm{~A}$ ludic theme is key to understanding the full impact of these lines: the emphasis is not, as it first appears, on Jupiter's might, but rather on the power of the cosmic player, however named, to invert mortal circumstances, exactly what Horace says happens to his beliefs about religion and philosophy.

Almost as if fearing the point would be missed, Horace's next poem, an ode to FORTUNA, begins by asserting that FORTUNA has the ability to invert all human affairs: ${ }^{290}$

O diua, gratum quae regis Antium, praesens uel imo tollere de gradu mortale corpus uel superbos uertere funeribus triumphos.

Oh goddess, you who rule over your beloved Antium, at hand either to raise a mortal body from the lowliest station or to turn proud triumphs into funerals.

The addressee is identifiable because FORTUNA had a well-known temple at Antium. ${ }^{291}$ The

${ }^{289}$ The adverbial pair hinc...hic (14-16) shows FORTUNA removing the cap and returning it to the same spot, exactly as in Livy. Rudd (2004) 87 and n.65 contends that Horace varies the Livian account and translates the relevant section of the passage as "Fortune snatches the crown from one head and likes to place it on another." Horace certainly modifies the story by generalizing it and substituting FORTUNA for the eagle, but he does not go so far to make FORTUNA transfer the crown from one owner to another. The altered state here is, rather, the addition of divine favor, just as in Livy's narrative.

${ }^{290}$ Horace, Carmina 1.35.1-4

${ }^{291}$ Rudd (2004) 87 n.66. Dettmer (1983) 318 believes that "The Roman reader would have known whom Horace meant by the phrase 'the goddess who presides at Antium' (1.35.1) from what follows." Cf. Barber (2012) 507-509, who asserts that the lack of addressee in 1.34 and the circuitous address to FORTUNA in 1.35, herself named at the end of 1.34, is evidence that the two odes originally constituted one poem. Horace is the first Latin author to link FORTUNA with Antium explicitly, though Livy, ab Urbe Condita 6.9, in which FORTUNA spares that city from Camillus' military force, perhaps implies such a connection. Jacobson (1968) 106-113 believes that the whole poem is an admonition to the princeps not to follow the example of Julius Caesar or Antony and suggests that Horace mentions Antium for its verbal similarity to Actium (111 n.31), a warning that "Fortuna, not really Augustus, was responsible for Antony's defeat, and she could easily inflict the same fate on Augustus." Santirocco (1986) 75 makes a less forceful argument, but similarly states that "this concept of Fortuna [as the maker and unmaker of kings] is 
poem continues by praising the prominence of the goddess, representing her as a being that strikes fear into the hearts of all for her ability to topple individuals, cities, and even entire countries. ${ }^{292}$ Horace ends the ode with a prayer that FORTUNA will protect Augustus in his foreign campaigns, a lament that Romans have inflicted too much harm on one another, and a wish that the goddess would reforge her blunted sword against Rome's foes instead, all of which place warfare firmly within the domain of FORTUNA's game. ${ }^{293}$

In his first book of odes, Horace toys with the literary theme of the world as a game with mortal lives as the pieces. By establishing FORTUNA, the Roman near-equivalent of TYCHE, as the cosmic player, he signals his use of a ludic theme from Greek literature, but he refrains from engaging in the motif as openly as he does in his final satire. These two poems, however, establish the backdrop for Horace's use of the theme in future odes.

at least potentially relevant to Augustus," who would lose the power he had won "should Fortuna fail him."

${ }^{292}$ Nisbet and Hubbard (1970) 389 assert that with imo in line 2, "Horace is clearly thinking of Servius Tullius, the slave's son who became king of Rome; he was believed to have founded many of the Fortuna cults." The commentators unnecessarily limit the broad applicability of Horace's message. It should be noted that the appearance of Servius Tullius one poem after an explicit mention of Tarquinius Priscus, the immediately previous king, would provide additional continuity, though Nisbet and Hubbard do not make this connection.

${ }^{293}$ Cf. Pindar, Olympian Odes 12, where the poet states that TYCHE both guides battles (3-4) and shifts mortals' circumstances (5-12), at times to their detriment and at others to their benefit. Horace returns to the idea in 4.14, where he praises Augustus and his stepsons for their military victories, declaring that propitious FORTUNA again gave favorable outcomes to war (37-38) and listing a series of Rome's enemies who fear Augustus (passim). The long-noted similarities of 1.35 to the opening of Lucretius, de Rerum Natura 1 are all the more interesting if one believes that Horace reconsiders his adherence to Epicureanism in the previous poem; see Jacobson (1968) 106-107 for a brief overview of the parallels. 


\section{Horace, Carmina 2.1}

At the very outset of his second book of carmina, Horace engages explicitly with FORTUNA as the cosmic player. In an ode to Gaius Asinius Pollio regarding his history of the civil war between Julius Caesar and Pompey, Horace writes: ${ }^{294}$

motum ex Metello consule ciuicum

bellique causas et uitia et modos

ludumque FORTUNAE grauisque

principum amicitias et arma

nondum expiatis uncta cruoribus,

periculosae plenum opus aleae,

tractas, et incedis per ignis

suppositos cineri doloso.

The civil unrest since Metellus was consul, and the causes and faults and phases of war, and FORTUNA's game, and the ponderous friendships of the leading men, and the weapons smeared with bloodshed still not expiated, a work full of dangerous gambles, all these you take as your theme, and you march over flames hidden under the deceitful ash.

The poet identifies the various themes of Pollio's work and warns that tensions still burn even though the fighting is finished. Among the themes Horace lists is FORTUNA's game (ludum ...FORTUNAE). Although Horace does not provide additional information, context allows readers to see that he is describing the cosmic game. The most obvious evidence is the explicit use of the word "game" (ludus), but there is much more besides. In his first book of odes, Horace links warfare to the cosmic game with FORTUNA as the cosmic player. The game in question in the passage above also involves the fates of mortals, an indication that they serve as the playing pieces. Similarly, when Horace designates Pollio's work as entirely a dangerous gamble, the word he uses is alea, which is a Roman game of chance as well as the Latin word for gambling generally; by transference alea means any hazard, venture, or uncertainty, but its root is a game, another indication that

${ }^{294}$ Horace, Carmina 2.1.1-8 
Horace is invoking ludic metaphor. ${ }^{295}$ Lastly, the civil war between Caesar and Pompey involved opposing factions within Rome, mirroring Socrates' claim that each city is really multiple cities, just like in the game polis. ${ }^{296}$

The appeal to FORTUNA's game, then, is not a throwaway phrase or careless word choice, but rather the significant invocation of a deep-rooted literary theme. Indeed, Horace establishes FORTUNA's game as the central element of Pollio's work. In five lines, Horace lists the five subjects that he says Pollio treats, each of which is mostly isolated to a single line: civil unrest, the stages of the war, FORTUNA's game, the alliances of the leading men, and the unatoned bloodshed of the civil war itself. In the exact center is FORTUNA, standing in the middle of the middle line, almost down to the syllable. ${ }^{297}$

FORTUNA and her game are also subtly linked with the subjects immediately previous and following. The meaning of modos in line 2 is vague, but commentators agree it means something along the lines of the war's phases or methods; it answers the "how" of the war, just as causas answers the "why." 298 Still, the interpretation prevalent before Dacier, that modos was explained as uices, is not wholly absent. Dacier's objection, supported by Fraenkel, is that Horace speaks of such vicissitudes in the next verse, so modos would anticipate the ludus FORTUNAE. The various details that comprise the modos are, no doubt, centered on humans, that is, the pieces of the game; if they are described as troops in their respective armies, so much the better, as that perfectly fits the

\footnotetext{
${ }^{295}$ OLD s.v. alea 1 and 2. For details of the game alea, see Schädler (1995) 73-98.

${ }^{296}$ Plato, Republic 422d-e

${ }^{297}$ FORTUNA is in the middle of the third line, her name being the fourth through sixth syllables of the nine in that line. When looking at the five lines collectively, there are twenty-four syllables, followed by ludumque FORTUNA, followed by twenty-five syllables. ${ }^{298}$ Dacier (1683) 19-20; Smith (1898) 104; Fraenkel (1957) 235-236; Nisbet and Hubbard (1978) 13
} 
martial element of FORTUNA's game.

The word grauis on line 3 likewise holds a faint tie to FORTUNA. As one reads this poem, moving from left to right, it at first seems that grauis agrees with FORTUNAE. Certainly it would not be out of place to call FORTUNA ponderous or burdensome, given the toll she takes on humans. This is especially true as the cosmic game is so often invoked to make sense of seemingly senseless circumstances, those that feel beyond human control; complaining of a grievous FORTUNA is well within the scope of this ludic theme. When one reaches the enclitic -que, it becomes clearer that grauis in fact goes with the following line. An oral recitation of this ode does not present the same ambiguity, however slight, since the Alcaic meter necessitates that the penultimate syllable of the line is scanned long: the word is grauiss, not grauis, so it can agree with neither ludum nor FORTUNAE. All the same, the word order and the use of enclitic -que rather than the conjunction et hints at a stronger connection than merely being part of the same list. Indeed, it is the friendships of leading men that are strained, alliances that seem to crumble under their own weight and, as with so much in the cosmic game, turn into their opposites: Caesar's and Pompey's pact degenerates into full-fledged war, the final item in the list and a subject already established as part of the FORTUNA's game. ${ }^{299}$

Once the presence of "the cosmic game" is noted, it seems that Horace roots Pollio's work in games. As discussed in the previous chapter, governance can be seen as a kind of game, so the mention of civil unrest since Metellus' consulship fits a ludic theme, especially given that motus in line 1 seems to indicate turmoil specifically in the

\footnotetext{
${ }^{299}$ For the grauisque / principum amicitias referring to the first triumvirate, specifically the alliance between Caesar and Pompey, cf. Smith (1898) 104; Nisbet and Hubbard (1978) 14.
} 
political sphere. ${ }^{300}$ Using ludic terms to describe the upheavals of warfare, the outcome of extreme divisiveness, is familiar from Greek literature as well. ${ }^{301}$ FORTUNA's game anchors the list of Pollio's subjects, which all relate to it in some way, primarily by being kinds of inversions of mortals' circumstances. Moreover, in line 6 Horace summarizes Pollio's work as full of a dangerous gamble, using a word that, as noted above, is also the name of a Roman game. ${ }^{302}$ We are perhaps also meant to recall Caesar's famous line iacta alea est(o), said at the crossing of the Rubicon. ${ }^{303}$ It is similarly possible, however, that the alea in question is played out on a larger, cosmic scale, that is, that FORTUNA is the one playing the game and Pollio's work is simply recording the moves.

\section{Horace: Carmina 3.29}

Horace's last treatment of the cosmic game in his odes is correspondingly his most comprehensive. In an ode inviting Maecenas to a modest dinner, the poet combines elements from earlier poems to illuminate not only FORTUNA's influence, but also his reactions to it. The most direct engagement with ludic themes comes near the end of the poem, where Horace describes FORTUNA as reveling in playing her game and manipulating mortal lives, situating her as the cosmic player. The portrayal of FORTUNA

\footnotetext{
${ }^{300}$ Nisbet and Hubbard (1978) 11 note that motus is "a common euphemism for political convulsions."

${ }^{301}$ E.g. Aeschylus, Seven Against Thebes 414; Euripides, Rhesus 446

${ }^{302}$ Cf. Nisbet and Hubbard (1978) 15: "there may be a tension between the weighty plenum and the flighty alea, which a Roman would connect with dice-throws."

${ }^{303}$ For Julius Caesar's quotation, see Plutarch, Life of Julius Caesar 32.6; Life of Pompey 60.2; Sayings of the Romans 206c.7; Suetonius, Julius Caesar 32; Appian, Roman History 2.35. Nisbet and Hubbard (1978) 15 believe that Pollio himself is the source of this anecdote and that he translated Caesar's original Greek phrase into Latin "to maintain the stylistic unity of his work." This claim may go too far, but they are correct to point out that Pollio was present for Caesar's utterance, at least according to Plutarch, Life of Julius Caesar 32.5.
} 
does not come as a surprise, however, as Horace gradually builds to his climax; throughout the ode, the poet uses wording suggestive of ludic themes, which, when recognized, reveal a richer reading and greater cohesion than has previously been understood. I follow Horace's lead and examine the poem from the beginning, exploring the ludic themes as they appear, ending with the poet's final treatment of the cosmic game in the Carmina. Although the poem is replete with allusions to earlier works, a full examination of these references exceeds the scope of this project, so I limit myself to the other poems with ludic themes discussed earlier in this chapter. ${ }^{304}$

After beginning the ode by describing the preparations he has made, Horace tries to convince Maecenas to abandon the noise, smoke, and heat of Rome and join him in the country. Horace argues that the rich often find joy eating dinners in a poor man's house, devoid of coverings and purple fabric (cenae sine aulaeis et ostro). ${ }^{305}$ This statement calls to mind Nasidienus' dinner party, during which a slave wiped the table with a purple cloth (gausape purpureo) and the awnings (aulaea) fell, triggering an outcry against FORTUNA and the cosmic game, as discussed earlier in this chapter. ${ }^{306}$ It is worth remembering that Maecenas was present at the previous dinner, to which Horace may be alluding as he invites his patron to his own meal. ${ }^{307}$ On account of these connections, then, the audience members may be on the lookout for ludic themes as early as the

${ }^{304}$ For more on the relationship of 3.29 to Horace's other works, see Hornsby (1958) 131; Dettmer (1983) 140-151, 166-167, 421-422; Santirocco (1984) 250-253; Santirocco (1986) 163-168 et passim; Porter (1987) 201-208, 211-214, 220, 223, 230-239 passim, 246-251 passim, 265-273 passim.

${ }^{305}$ Horace, Carmina 3.29.15

${ }^{306}$ Horace, Sermones 2.8.11, 54

${ }^{307}$ Nisbet and Rudd (2004) 352 note that "aulaea usually refers to curtains hung vertically, whether in the theatre, on the walls of a room, or on rails going round the dining-couches... but at the cena Nasidieni they were canopies above the table." They do not push the connection between the scenes further, however. 
fifteenth line of Carmina 3.29. They are not disappointed.

Horace next acknowledges Maecenas' concern for Rome's affairs, especially with regard to politics and foreign nations. The poet dismisses these cares and admonishes his patron to live in the moment: ${ }^{308}$

prudens futuri temporis exitum caliginosa nocte premit deus, 30

ridetque si mortalis ultra

fas trepidat. quod adest memento componere aequus.

Knowing future time, the god conceals the issue in dark night, and laughs if a mortal fears beyond what is proper. Remember to address whatever is at hand with a calm mind.

The word deus on line 30 provides more parallels to the other Horatian poems with the ludic theme of the cosmic game. Horace does not clarify the identity of the deity on line 30 and no god or goddess is found earlier in the poem to serve as an antecedent. Instead, the thought of an uncertain future and a laughing deity are the only clues, hinting at FORTUNA, who is said to take delight in playing with human affairs in Sermones 2.8 and whose inversions of circumstances make the future impossible to know in Carmina 1.34 and 1.35. Moreover, just as the deus in Carmina 1.34 .13 operates as a bridge between Jupiter and FORTUNA, conflating the two, the deus of this passage coalesces the same two deities: the poet goes on to say in 3.29.43-45 that Jupiter, named as Pater, can fill the sky with black clouds or pure sunlight, then one stanza later shifts to FORTUNA as the subject, stating that she delights in playing her game and toying with humans (discussed below). These depictions expand lines 29-32, where the deus both uses darkness and mocks mortals. Like the deus of 1.34.13, then, the deus of 3.29.30 takes elements of Jupiter and

${ }^{308}$ Horace, Carmina 3.29.29-33 
FORTUNA from other sections of its respective poem and combines them, offering an amalgam as the cosmic player. $^{309}$

A different ludic theme is found in the next part of the passage. Since the future is unknowable, Horace advises dealing calmly with present circumstances. The exhortation for equanimity in the face of uncertainty is a play on the carpe diem motif and its importance for Horace's poem as a whole is evident from its placement: it is housed in the exact center of the sixty-four-line poem, in the second half of line 32 and the first half of line $33 .{ }^{310}$ Additionally, while no game elements are immediately apparent, this passage may be read in light of ludic themes: Horace's advice is not merely aphoristic, but rather recalls the ludic theme of "playing your roll," bringing to mind Terence and Menander in the first section of this chapter and the other Greek models for this theme discussed in the final section of the previous chapter. ${ }^{311}$ In his own voice or that of a character, each of these authors remarks upon the nature of life being like a game played with dice, often including the need for composure when using the results of the dice rolls, whatever they may be. Much like line 15 earlier, Horace's admonition here suggests ludic themes and helps build up to the deep engagement with "the cosmic game" near the end

${ }^{309}$ Cf. Hornsby (1958) 133, who notes the repetition of the black cloud in lines 30 and 43-44, observes the doubtfulness about the future caused by juxtaposing the black cloud and pure sunlight in lines 43-45, remarks that "Fortuna, herself, is personified if indeed not deified" and "echoes the deus of verse 30," and comments upon FORTUNA's preoccupation "with her own games."

${ }^{310}$ Fraenkel (1957) 223-229; Porter (1987) 202, cf. 237-239; West (2002) 252-253. Cf. Hornsby (1958) 129, 132, 135; Williams (1969) 148. Santirocco (1984) 251 and (1986) 164 seems to miss the weight of these lines and calls them "an almost perfunctory injunction to enjoy life."

${ }^{311}$ For convenience, I list the relevant passages here. They are: Aeschylus, Agamemnon 32-33; Libation Bearers 969-971; Sophocles fr. 947; Euripides, Suppliants 326-331; Rhesus 182-183; Socrates apud Stobaeus, Anthology 4.56.39; Plato, Republic 604b-c; and Alexis fr. 35 K-A. 
of the poem. ${ }^{312}$

Immediately following the previous passage, the second half of line 33 and all of line 34 reinforce the importance of focusing on the present: "other matters are moved in the same way as a river, now in the middle of the channel" (cetera fluminis / ritu feruntur, nunc medio alueo). ${ }^{313}$ The simile continues by describing a river, identified from context as the Tiber, at times tranquil and at times in spate. ${ }^{314}$ The "other matters" (cetera) in line 33 refer to the future, contrasting "what is present" (quod adest) in line $32 .{ }^{315}$ The simile, then, carries on the message of the previous lines and applies to the inscrutability of the future; as one scholar puts it, the passage "pictures the changeability of man's fortune by describing the extreme changes in appearance and behaviour of the great river." 316

The line and a half that introduce the simile, however, give another, ludic sense. The Latin word alueo has a wide variety of definitions, including that of a game board. ${ }^{317}$ While context shapes our understanding of the word, at this point, the end of line 34, a ludic interpretation is justified, especially in light of the other hints earlier in the poem. In this reading, future events are moved in the manner of a river inasmuch as they advance inexorably in their course and there is little a mortal can do to change them. The passive voice of feruntur is significant: future affairs do not simply move, but rather are moved,

\footnotetext{
${ }^{312}$ West (2002) 253 contends that aequus in line 33 corresponds to the Epicurean principle of ataraxia, as well as "a familiar theme of ancient wisdom": scorning what is at hand and hoping for what is unattainable, exemplified by Pindar, Pythian Odes 3.1923. This interpretation is not mutually exclusive with my own.

${ }^{313}$ Horace, Carmina 3.29.33-34

${ }^{314}$ Horace, Carmina 3.29.33-41

${ }^{315}$ For cetera referring to the future, see Smith (1898) 257; Williams (1969) 148. Cf. West (2002) 253: "everything else, everything that is not the here and now"; Nisbet and Rudd (2004) 356: "cetera describes everything outside the immediate present."

${ }^{316}$ Fraenkel (1957) 223

${ }^{317}$ OLD s.v. alueus 5; L\&S s.v. II.C
} 
implying agency from an unnamed source. Furthermore, the nunc medio alueo may apply not to the river, but rather to the cetera. In this case, the future occurrences that mortals will face are fixed firmly on a game board and directed by an agent. All the hallmarks of the cosmic game are present: mere lines after the mention of a deus laughing at mortals fearing the unknown comes the implication of an agent shaping the future and playing with human lives in a game. The subsequent seven lines describe the river at peace in its channel and in a raging flood, clarifying that alueo must belong with the Tiber. Even so, the ambiguity at the end of line 34 anticipates the consideration of FORTUNA and the cosmic game that comes just after the end of the river simile.

After using the simile of the Tiber at times calm and at times in spate to describe the inscrutability of future events, Horace reinforces the carpe diem motif he began in the exact center of the poem. Horace states that the man who can say "I have lived" (uixi) at each day's end will be his own master and will live happily. ${ }^{318} \mathrm{He}$ then expands upon the description of the deus in line 30, which, as stated above, serves as an amalgam of Jupiter and FORTUNA as the cosmic player. The poet declares that although Pater may bring either dark clouds or clear sunshine tomorrow, he can neither alter the past nor reshape what the fleeing hour has brought. Here the present is so brief that it flies away even as it appears. ${ }^{319}$ Horace then engages with the cosmic game explicitly as he turns his attention to FORTUNA: $:^{320}$

FORTUNA saeuo laeta negotio et ludum insolentem ludere pertinax 50

transmutat incertos honores, nunc mihi, nunc alii benigna.

${ }^{318}$ Horace, Carmina 3.29.41-43

${ }^{319}$ West (2002) 254

${ }^{320}$ Horace, Carmina 3.29.49-56 
laudo manentem; si celeris quatit

pennas, resigno quae dedit et mea

uirtute me inuoluo probamque 55

PAUPERIEM sine dote quaero.

FORTUNA, delighting in her cruel business and steadfast in playing her haughty game, shifts her fleeting gifts, kind now to me, now to another. I praise her while she remains; if she shakes her swift wings, I return what she gave, wrap myself with my virtue, and seek honest PAUPERIES, who has no dowry.

This passage unites the components of Horace's other depictions of FORTUNA as the cosmic player, offering a composite view of the subject. ${ }^{321}$ After the hints and allusions throughout the ode thus far, the ludic theme of "the cosmic game" takes center stage; its presence is evident here from the explicit gaming words (ludum, ludere), as in 2.1. In this passage, the game manifests itself in the transference of FORTUNA's favors from one mortal to another, in this case from Horace to someone else. In such circumstances, the poet outlines his reaction, perhaps implying appropriate measures to take when bereft of the gifts of FORTUNA, that is, how to survive being merely a pawn in the cosmic game.

This passage's very construction expresses the power of FORTUNA as the cosmic player. The first quatrain's meticulous wording reflects the complexities of understanding the cosmic game: the interlocked word order of line 49 juxtaposes saeuo with laeta, the competing elements of FORTUNA's favor or disfavor; the polyptoton of ludum and ludere (50) reinforces the ludic ideology behind the passage; the chiastic structure of lines 50-51 replicates FORTUNA's power of inversion, marked here by accusative noun and adjective, verb, nominative adjective, verb, accusative adjective and noun; the doubling of nunc with

${ }^{321}$ Contra West (2002) 254, who argues that "At line 48 the general philosophical reflections end, and as Horace begins to explain his own creed, the inscrutable god (gods to not interfere with humans in Epicureanism) of lines 29 [sic] and 44 is replaced by fickle and malicious Fortune." I contend that the sections of the poem operate as a unified whole, but do not attempt to reconstruct Horace's personal beliefs. 
a dative (52) depicts the great rapidity with which FORTUNA can shift her favor, producing an image of FORTUNA abandoning Horace almost as soon as he acknowledges her kindness to him; the adjectives modifying FORTUNA underpin her unrelenting influence, as laeta is in the middle of the first line (49), pertinax is in nearly the exact middle of the strophe (50), and benigna is the final word (52). ${ }^{322}$ On the antepenultimate point, Horace further highlights FORTUNA's prominence by placing her, through the adjective pertinax, at the very center of the chiastic pattern, not unlike FORTUNA's placement in 2.1 , discussed above. Here the word FORTUNA is placed closest to the verbs, bolstering her position as causative agent, while the direct objects are one step further removed, grammatically showing the flow of action from the deity to her recipients in either direction. ${ }^{323} \mathrm{In}$ addition, the only two verbs indicate play and change, the binary elements of FORTUNA that this passage highlights. Indeed, the adjective pertinax underscores FORTUNA's unremitting persistence in playing her game, which is changing the affairs of mortals. Additionally, nunc...nunc (52) may remind the audience of the earlier adverbial pair nunc...nunc (3436). As discussed above, the first instance comes at the end of line 34 (nunc medio alueo) and may foreshadow the ludic theme in the present passage.

The second quatrain's message comes more from its content than from its form, in part because it reintroduces themes from earlier poems. Indeed, 3.29 recalls many earlier works, but, as stated above, I limit myself to the other poems with ludic themes discussed

${ }^{322}$ Cf. Hornsby (1958) 133-134, who lists some of the same evidence and remarks that the word order is how "Horace underlines the fickleness of Fortuna" (quote from 133).

${ }^{323}$ It may be argued that the structure in lines $50-51$ is not perfectly chiastic because 1) the first verb is an infinitive and the second is finite and 2) the first adjective is, strictly speaking, a participle and the second is a true adjective. These variations are of less consequence than the overall effect of the word-picture, however, and do not detract from the points I outline here. 
in this chapter. Horace admits that he honors FORTUNA only as long as she remains with him, perhaps an understandable reaction, though one that calls into question the sincerity of his would-be conversion in 1.34, discussed above. The adjective celer (53) reinforces how swiftly FORTUNA may shift her favors, i.e. how rapidly the cosmic player may change her plans and manipulate her mortal pieces in new ways, while pennas (54) recalls FORTUNA's wings, to which Horace alludes in 1.34.15..$^{324}$

The second quatrain also introduces a new idea: abandoning the cosmic game. While Horace elsewhere emphasizes the futility of resisting FORTUNA's might, he now presents an alternative to the hope of currying her favor: in 3.29 , he finds peace in resignation to the cosmic player. When Horace enfolds himself in his virtue, he calls to mind the metaphor of the philosopher's cloak, an inner state of being that leaves the "wearer" impervious to external misfortunes, an image that goes back as far as Plato and plays on the cloak as the hallmark of a philosopher. ${ }^{325}$ Horace reimagines his depiction in

${ }^{324}$ West (2002) 255 sees the allusion and goes so far as to claim that FORTUNA actually turns into a bird in the present passage. This assertion overstates the case. As discussed above, FORTUNA merges with Jupiter's eagle as she amalgamates with Jupiter himself, but FORTUNA is regularly depicted in literature with wings, as is her counterpart TYCHE. See Arya (2002) 60-61, 68-69, 111-112, 115-116, who notes that the wings are uncommon, though not unheard of, in statuary (89). Arya comments, with bibliography, that the wings emphasize the fickle side of the goddesses' nature $(112,115-116)$, which is why Plutarch, On the Fortune of the Romans 318A depicts the goddess (since he makes no distinction between FORTUNA and TYCHE) shedding her wings when she comes to the Rome, as she intends to stay and bring the Romans only good fortune. Cf. Fronto's letter to Antoninus (p. 150.21 van den Hout) in which he describes FORTUNA with wings at Antium, further tying together Carmina 1.34, 1.35, and 3.29. As Arya (2002) 69 notes, although Plutarch and Fronto are imperial authors, their sources for these portrayals are considered to be Hellenistic rather than contemporary, therefore reflecting shared imagery before the development of FORTUNA-specific attributes in the imperial period.

${ }^{325}$ Rudd (2004) 215 n.80; cf. Nisbet and Rudd (2004) 361. See, e.g., Plato, Symposium 219b-220b, where Alcibiades tries to seduce Socrates in the winter by getting under his cloak, but is rebuffed, allegedly because of the same perseverance Socrates exhibited at Potidaea, where he endured the exceptionally harsh winters of the region; Phaedo 87a- 
1.35: while FORTUNA changes vestments when she forsakes the houses of the powerful in the earlier ode (mutata potentis / ueste domos inimical linquis, 23-24), now Horace is the one who swaps his garb as he abandons FORTUNA. Moreover, in 1.35, Horace introduces FORTUNA's companions NECESSITAS (17), SPES (21), and FIDES (21). Here in 3.29, the author presents an alternate divine quality, PAUPERIES (56). We can discern that PAUPERIES is the personification of an abstraction in the same manner as NECESSITAS, SPES, and FIDES because of her stated lack of a dowry, an incoherent nuptial image if the subject is not anthropomorphized. ${ }^{326}$ By returning what FORTUNA gave him and seeking PAUPERIES, we sense that Horace is divorcing FORTUNA, seemingly following the formula for divorce outlined in the Twelve Tables of 451-450 BCE. ${ }^{327}$

In pursuing marriage with PAUPERIES, who has no dowry and therefore nothing material to confer, Horace signals an abandonment of the hope for wealth, the customary standard of worldly success. Indeed, the poem ends with another metaphor: though his mast

$88 \mathrm{c}$, where it is used to debate the immortality of the soul; Aristophanes, Plutus 842-846, where the character of the Just Man dedicates the cloak he shivered in for thirteen winters, and 897, where he says he can sense the cold from his interlocutor's tattered cloak; Xenophon, Memorabilia 1.6.2, where Antiphon the Sophist converses with Socrates about the latter's poverty, including his cloak being both cheap and never changed in summer or winter according to the weather; Dio Chrysostom, Discourses 72.2 , where a cloak without a tunic is confirmed as standard attire for a philosopher; Herodian, History of the Empire 1.9.3, where this manner of dress is reaffirmed as the look of a philosopher ( $\varphi \imath \lambda$ $\lambda$ ó $\varphi$ ov $\sigma \chi \tilde{\eta} \mu \alpha$ ). See Urbano (2014) 175-194 for the ways the Christians of the second to fifth centuries CE adopted and reshaped the image of the philosopher's cloak.

${ }^{326} \mathrm{Cf}$. Smith (1898) 260. For quaero as seeking marriage, cf. Horace, Epistles 1.2.44-45: quaeritur...uxor.

${ }^{327}$ West (2002) 254-255. For the formula of divorce and its source in the Twelve Tables, see Cicero, Philippics 2.28.69: illam suam suas res sibi habere iussit, ex duodecim tabulis clauis ademit, exegit. The divorce formula also appears in Plautus, Amphitryon 928: ualeas, tibi habeas res tuas, reddas meas. Cf. Cohen (1994) 183 and n. 25; de Melo (2011) 105 n. 35. For the creation of the Twelve Tables, see Livy, ab Urbe Condita 3.34. Smith (1898) 259 and Fraenkel (1957) 226 see the phrasing resigno quae dedit rooted instead in commercial dealings. 
may groan during a storm, Horace refuses to resort to pitiable prayers and promises to the gods to save his riches from the sea. Rather, he forsakes the ship and its costly cargo, trusting the Dioscuri to safeguard him as he rows away in a small, two-oared skiff. While Horace may still be subject to FORTUNA, his resignation means she has nothing left to take from him; although he may still be a piece in the cosmic game, he acquiesces to losing, no longer playing his roll because he has ceased rolling the dice, as it were. With this variation on the cosmic game, Horace reinforces the ludic theme as a vehicle for considering humanity's place in the universe even as he reevaluates how to secure his own. This mindset carries into Carmina 3.30, the final ode of the collection, in which Horace confirms that his legacy is not the achievement of contemporary riches, but rather an eternal, poetic fame, a kind of success that it seems even FORTUNA cannot overturn.

\section{Cities and Citizenship in the Laus Pisonis}

The Laus Pisonis is a work of debated authorship and date that has received varied interest over the years. This panegyric of 261 hexameter lines praises a certain Piso for his personal and professional excellence in a variety of fields. The poem is notable in part for its extended scene describing Piso's mastery of the board game ludus latrunculi. ${ }^{328}$ This episode is less directly engaged with ludic themes than the passages discussed earlier in this chapter, but deserves consideration for its connection between games and governance, as well as how the author uses embodiment in conjunction with a game in pursuit of his poetic

\footnotetext{
${ }^{328}$ Although recent interest in the poem has yielded praise, early assessments were not always so charitable; some view the ludic section as the sole redeeming feature of an otherwise lackluster work. For example, Summers (1920) 94 calls the poem "an industrious, uninspired piece of work whose only interest lies in its detailed allusion to the ancient game of latrunculi."
} 
project.

Brief contextualization is necessary for understanding what the ludic material adds to the poem. While the addressee and date of the Laus Pisonis have been debated, scholarly consensus holds that the laudandus is Gaius Calpurnius Piso, the leader of an anti-Neronian conspiracy in $65 \mathrm{CE}$, with a composition date somewhere between $40 \mathrm{CE}$ and $65 \mathrm{CE}$, the year after his consulship and the year of his suicide, with a date near the end of this window the most convincing. ${ }^{329}$ The identity of the author, however, enjoys no such consensus; candidates include Calpurnius Siculus, Lucan, and Statius, while recent scholarship advises caution in naming an author, especially a recognized one. ${ }^{330}$ I follow scholarly agreement where it exists and opt for Gaius Calpurnius Piso as the addressee, a composition date shortly before Piso's death, and an anonymous author.

As the poet advertises his skill as a panegyrist through the Laus Pisonis, he portrays Piso as an ideal leader. Piso was himself not wholly devoid of criticism and even succumbed to some of the same flaws as the man he was meant to replace; although he was praised for his eloquence and generosity, he also indulged in excess and enjoyed acting in tragedies. ${ }^{331}$ The Laus Pisonis situates Piso as a credible alternative emperor by

${ }^{329}$ See Green (2010) 497-523 for the convincing arguments in favor of Calpurnius Piso and $65 \mathrm{CE}$, including summary and bibliography of earlier scholarship. One of the most important pieces of evidence is the scholion to Juvenal, Satires 5.109 that directly links a Calpurnius Piso of the Claudian era with the game ludus latrunculi, both noting his great skill at the game and matching the description in Tacitus of the man who gave his name to the conspiracy against Nero.

${ }^{330}$ See Green (2010) 498 and n. 5 for a detailed review of scholarship. The difficulties of identifying the author date back to its very first edition: Ullman (1929) 109 notes that the panegyric was first published in Sichard's 1527 edition of Ovid, but Sichard says that the manuscript he used, now lost, attributes the poem to Vergil, while the surviving florilegia name Lucan as its author.

${ }^{331}$ Tacitus, Annales 15.48, 15.65. Rees (2013) 95-106 argues that the Laus Pisonis is an unacknowledged source for Tacitus' account of the Piso and the eponymous conspiracy, 
reinterpreting or excusing his existing traits, especially his lack of military experience, in a positive light. ${ }^{332}$ Most relevant to present purposes, the author of the poem employs embodiment to construe Piso as a talented military strategist because of his skill at the game of ludus latrunculi. ${ }^{333}$ The poet encapsulates the ideas of real soldiers in the glass game counters, such that victory at the game equates to military success. ${ }^{334}$ This approach inverts aspects of the ludic theme "cities and citizenship" discussed in the previous chapter: in those passages, authors consider governance and cities as though a game, whereas the author of the Laus Pisonis suggests that Piso is fit to govern the city of Rome because he plays an actual game well.

In seeing the Laus Pisonis as operating in the vein of this ludic theme, it is significant that the game Piso plays so well, ludus latrunculi, appears to be identical to polis, the Greek game at the heart of so many passages in the previous chapter. ${ }^{335}$ That is, Piso is skilled at playing a game named "city." Moreover, Greek authors describe managing a city as a game played in the form of governance and legislation, the proper

but that the historian accepts only some of its terms and offers a corrective to the veneration of Piso found in the poem and subsequent authors familiar with it, such as Martial and Juvenal, who give the panegyric a second wind.

${ }^{332}$ Purcell (1995) 16; Green (2010) 506; Mader (2013) 623-624. Cf. Champlin (1989) 116-124, who argues for a composition date of $40 \mathrm{CE}$ in part because Piso still had hope of winning future glory, especially regarding military leadership.

${ }^{333}$ Contra Rees (2013) 102, who believes that in Tacitus' use of the Laus Pisonis as a source, the historian "denounces Piso for a lack of moral gravitas (identifiable in interstices and details of the poem, such as his skill in the board-game ludus latrunculi, 190-208, but of course never articulated as such)." Rees is right to detect a connection between morality and Piso's skill at ludus latrunculi, but misunderstands the passage: more than simply not articulating Piso's gaming as a moral failing, the poet actually praises it.

${ }^{334}$ See Rieche (2007) 87 for a more general assessment stemming from the Laus Pisonis: "The images used in descriptions of ludus latrunculorum are closely connected with warfare and fighting. The player takes over the part of the commanding strategist."

${ }^{335}$ On ludus latrunculi and polis being the same game, see Austin (1940) 264; Schädler (2002) 99; Schädler (2007) 361. 
manner of which is, according to Plato, first learned by playing games when young. Piso's keen aptitude for polis / ludus latrunculi, then, proves his ability to play the game of governance. Remarkably, Plato's Socrates refers to all cities, excluding his hypothetical ideal one, as in reality many cities of rival factions, just as in the game polis. ${ }^{336} \mathrm{By}$ contesting Rome's leadership, then, Piso is playing the game well, especially given that the objective of polis / ludus latrunculi is to take over the opponent's city, as the Laus Pisonis makes clear.

The poem reaches its climax with the praise of Piso's aptitude at ludus latrunculi. ${ }^{337}$ This section translates Piso's skill at symbolic warfare into actual martial prowess: ${ }^{338}$

te si forte iuuat studiorum pondere fessum 190

non languere tamen lususque mouere per artem, callidiore modo tabula uariatur aperta calculus et uitreo peraguntur milite bella, ut niueus nigros, nunc et niger alliget albos. sed tibi quis non terga dedit? quis te duce cessit calculus? aut quis non periturus perdidit hostem? mille modis acies tua dimicat: ille petentem, dum fugit, ipse rapit; longo uenit ille recessu, qui stetit in speculis; hic se committere rixae audet et in praedam uenientem decipit hostem; 200 ancipites subit ille moras similisque ligato obligat ipse duos; hic ad maiora mouetur, ut citus ecfracta prorumpat in agmina mandra clausaque deiecto populetur moenia uallo. interea sectis quamuis acerrima surgant proelia militibus, plena tamen ipse phalange aut etiam pauco spoliata milite uincis, et tibi captiua resonat manus utraque turba.

If perhaps it pleases you, tired from the weight of your studies, nevertheless not to be inactive but to start games of skill, then in a rather clever manner a piece is disposed on the open board and wars are waged with glass soldiery, so that white binds the black pieces, now black traps

\footnotetext{
${ }^{336}$ Plato, Republic 422e

${ }^{337}$ Champlin (1989) 118-119; Green (2010) 500, 514; Mader (2013) 624

${ }^{338}$ Laus Pisonis 190-208
} 
the whites. But who has not fled from you? With you as leader, who has yielded - which piece? Or who, about to be destroyed, did not destroy an enemy? Your battle line fights in a thousand ways: that one, while he flees, himself captures his pursuer; that one, who stood on watch, comes from a distant corner; this one dares to engage himself in the quarrel and ensnares the enemy coming after his prey; that one stealthily enters duplicitous delays and, seemingly trapped, himself ensnares two others; this one is moved to greater things, so that he, stirred to action, may rush forth into the battle line, broken in formation, and, with the wall cast down, devastate the enclosed city. Meanwhile, although the fiercest battles may arise with cut up soldiers, nevertheless you yourself win with a full phalanx or certainly deprived of only a little soldiery, and each of your hands resounds with the captured crowd (of pieces).

This passage casts Piso as both a diligent man and a victorious general. The introduction defends Piso against accusations of indolence by clarifying his fitting use of time: he plays latrunculi only after he has engaged with his studia thoroughly, even then as a means to avoid inactivity or, perhaps, to reinvigorate his labors. ${ }^{339}$ According to the author of the poem, then, Piso's game playing is an intellectual activity that does not interfere with his responsibilities and complements his assiduousness. ${ }^{340}$ The next undertaking is to translate

${ }^{339}$ Similar claims are made about the jurist Publius Mucius Scaevola. Valerius Maximus, Facta et Dicta Memorabilia 8.8.2 reports that when wearied by forensic work, Scaevola refreshed his mind by playing ball, at which he excelled, and that he sometimes played board games after regulating the laws of men and the rites of the gods well for a long time. Quintilian, Institutio Oratoria 11.2.38 remarks that Scaevola's prodigious memory for the move order in playing the board game duodecim scriptorum reflected well on his ability to give order to speeches. Cicero, de Oratore 1.217 also records Scaevola's prowess at ball and duodecim scriptorum through the character Marcus Antonius, who cautions that if a prominent representative of one art masters a second, the latter not be attributed to his skill at the first, lest people say, on the example of Scaevola, that being good at ball games and board games belongs to the art of civil law.

${ }^{340}$ The status of the game in contemporary Rome is difficult to assess. The author of the Laus Pisonis may have had in mind the charges of his contemporary Seneca, who states that it would take quite a long time to list all the people who have wasted their lives playing latrunculi, playing ball, or getting a good suntan (de Brevitate Vitae 13.1) and elsewhere alludes to latrunculi as a superfluous pursuit (Epistulae Morales ad Lucilium 106.11). Conversely, Seneca praises Julius Canus for his tranquility after being given a death sentence and notes that he was playing latrunculi when the centurion came for him (de Tranquilitate Animi 14.7-8). Martial, Epigrams 7.72.1-8 casts the game as a 
Piso's skill at ludus latrunculi into prowess as a general commanding real soldiers. ${ }^{341}$ The author performs this transformation in three stages, first easing from ludic to martial imagery (192-196), then providing a battle narrative for the personified pieces (197-200), and last slipping from martial back to ludic imagery (201-208).

After establishing latrunculi as a worthwhile pursuit, the panegyrist slowly conflates Piso as a game player with Piso as a victorious general. Although filled with martial imagery, the opening of the passage (192-196) is decidedly in the realm of the game: it is on a board (tabula, 192) that a counter (calculus, 193) is played and glass soldiery (uitreo...milite, 193) is used to wage wars (peraguntur...bella, 193). The whites (niueus...albos, 194) and blacks (nigros...niger, 194) are metonyms of the pieces of the rival players, differentiated by color, but already the author slips away from overt mention of game counters. The word alliget (195) is a technical term for immobilizing, not capturing, opposing pieces, but it is also the first active verb applied to Piso's men. ${ }^{342}$ The panegyrist continues to blur glass and human soldiers when he asks who has not fled from Piso, who has yielded with him as leader, and who did not kill an enemy before dying himself, all questions with active verbs (dedit, 195; cessit, 195; perdidit, 196). Readers are

commendable pastime, though in the context of Saturnalia. Ovid, Tristia 2.471-492 complains that other authors have written with impunity about subjects played with during the Saturnalia, including ludus latrunculi (477-480), but does not limit the game to the winter festival: in a similar passage (Ars Amatoria 3.353-380), he advises women to learn to play games, including latrunculi (357-360), and states that love is often won through playing.

${ }^{341}$ It is relevant that immediately before section under examination, the panegyrist describes Piso as accomplished at physical sports, including simulated combat and ball games (178-189). After offering that substitute for experience as a soldier, the poet presents the board game as a substitute for experience as a general.

342 For ligare and its compounds meaning "to immobilize" in ludus latrunculi, see Richmond (1994) 169-173. For attempts at full reconstructions of the game mechanics, which exceed the scope of this chapter, see Richmond (1994) 164-179; Schädler (1994) 47-67; Schädler (2001) 10-11. 
led to interpret the subjects of the rhetorical questions as actual soldiers on a battlefield, as shown by the delay of the word calculus (196) and the anthropomorphism of the pieces, which now have backs (terga, 195), a leader (duce, 195), the prospect of death (periturus, 196), and the ability to kill enemies (perdidit hostem, 196). ${ }^{343}$ In Latin, game pieces are customarily referred to as dying when captured, but the humanization of the counters affixes an emotional component to this description. ${ }^{344}$ Furthermore, the rapid string of apostrophic rhetorical questions heightens the emotional tenor of the passage in the same way as the beginnings of aristeiai in epic poetry. ${ }^{345}$

After six lines of blurring ludus latrunculi with real combat, the poet writes what feels like an authentic battle narrative, largely abandoning the game (197-200). The poet claims that Piso's battle line fights in a thousand ways (mille modis acies tua dimicat, 197), surely an exaggeration that exceeds the limited number of allowable moves in a board game with only ten or twenty pieces per side. ${ }^{346}$ The emphasis on individuals (ille, 197; ipse, 198; ille, 198; hic, 199) contradicts the rule of two pieces being necessary to capture an opposing one. ${ }^{347}$ These lines do not depict ludus latrunculi accurately, but rather escalate the personification of the pieces; the soldiers now have watchtowers (speculis, 199) set at a distance from the battle (longo...recessu, 198), the human attributes of daring (audet, 200) and deception (decipit, 200), and a plethora of active verbs (dimicat, 197;

\footnotetext{
343 Green (2010) 517

${ }^{344}$ For captured pieces referred to as dying, see Ovid, Ars Amatoria 3.358 (unus cum gemino calculus hoste perit); Tristia 2.478 (cum medius gemino calculus hoste perit); Martial, Epigrams 14.17.2 (calculus hac gemino discolor hoste perit).

${ }^{345}$ Green (2010) 517 makes this comparison and cites several examples: Homer, Iliad 5.703-704 (Hector); 8.273 (Teucer); 11.299-300 (Hector); 16.692-693 (Patroclus); Vergil, Aeneid 11.664-665 (Camilla).

${ }^{346}$ The number of pieces seems to have been variable based on a likewise mutable board size. See Schädler (2001) 11 for the number of pieces.

${ }^{347}$ See the earlier note on captured pieces referred to as dying.
} 
fugit, 198; rapit, 198; uenit, 198; stetit, 199; audet, 200; decipit, 200).

In the final section of the panegyric (201-208), the poet eases back into ludic imagery, adding reminders about the game as cautiously as he omitted them in the first section. When one of Piso's men enters duplicitous delays (ancipites subit ille moras, 201), there is a play on words: these delays are duplicitous both because they are dangerous and because there is a twofold foe, confirmed on the next line (duos, 202), a subtle reminder that two pieces are needed to capture an enemy. ${ }^{348}$ Likewise, while the piece continues to be personified (ille, 201; ipse, 202), the technical terms for immobilizing opposing counters (ligato, 201; obligat, 202) remind us that this soldier is made of colored glass, not flesh and blood. Even when the phalanx is broken and a city is about to be sacked, a quintessential picture of war, the invader regains his former passivity; he does not take on greater things of his own accord, but is moved to them (hic ad maiora mouetur, 202). ${ }^{349}$ Similarly, the agmina (203) may be a human army, but the very next word, mandra (203), seems to be a gaming term for an intact body of pieces. ${ }^{350}$ The final sentence of the section concludes the transition back to reality. The combatants are cut up (sectis, 205), another bit of wordplay: as soldiers they are wounded, but as gaming pieces they are carved, perhaps by a lathe. ${ }^{351}$ The penultimate line shifts perspective from the soldiers back to Piso by announcing the victor with a second-person verb (uincis, 207), then the final line reminds the audience that Piso was playing a game all along: while his own phalanx remains completely or mostly

\footnotetext{
${ }^{348}$ OLD s.v. anceps 1-4 and 8, respectively

${ }^{349}$ The mention of a city in this ludic context may also remind one of the Greek board game polis, which may be the same game: see the discussions in Austin (1940) 263-267; Richmond (1994) 177-179; Hübner (2009) 87-88.

${ }^{350}$ Austin (1934) 28; Richmond (1994) 173-177

${ }^{351}$ OLD s.v. seco 1 and 2c. For the idea of carved figures, cf. Vergil, Aeneid 3.464: dona...auro grauia sectoque elephanto.
} 
intact (plena ...phalange / aut tantum pauco spoliata milite, 206-207), his hands rattle with the multitude of pieces he has taken from his opponent (tibi captiua resonat manus utraque turba, 208). The spell is broken and, no matter how fierce the contest (sectis quamuis accerima surgant / proelia militibus, 205-206), we see Piso emerge victorious, but on a symbolic battlefield, not a real one.

The procedure of the Laus Pisonis is an inversion of an epexegetical technique found in earlier Greek writers, who analogize situations or actions with games in order to clarify the content of their texts. For example, Polybius describes Hamilcar's military superiority over the troops of Mathos and Spendius in ludic terms: ${ }^{352}$

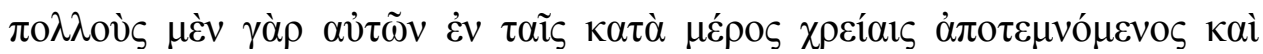

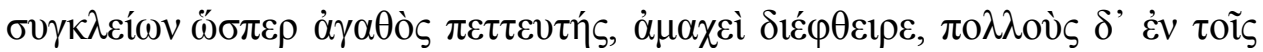

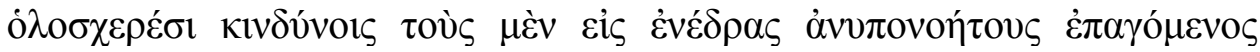

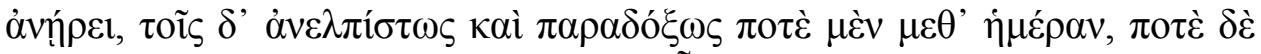

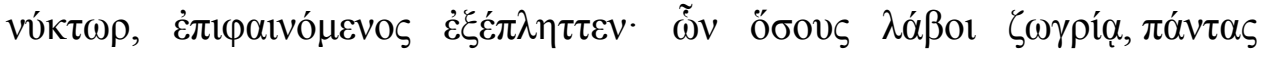

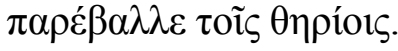

In partial engagements he utterly destroyed many of them without resistance, cutting them off and surrounding them like a good pessoi player, while in widespread battles he killed many by devising unsuspected ambushes, and he frightened them into hopelessness by appearing unexpectedly, sometimes by day and sometimes by night. However many of them he captured alive, he threw them all to the elephants.

There are many parallels between this passage and the Laus Pisonis. Polybius describes Hamilcar as a good game player because of his skill as a general, whereas the poet of the Laus Pisonis styles Piso as a good general because of his skill at a game. In each passage, the hero is victorious by means of traps (moras, $\dot{\varepsilon} v \varepsilon \dot{\delta} \delta \alpha \varsigma$ ) and a variety of other strategies, but the authors focus on opposite characteristics: Polybius concentrates on Hamilcar, whose military experience is unquestioned, to show his strategic mastery, while the

${ }^{352}$ Polybius, Histories $1.84 .7-8$ 
panegyrist's attention is on the glass soldiers, whom he anthropomorphizes in order to give Piso the appearance of military experience. Similarly, Hamilcar can win without a fight ( $\dot{\alpha} \mu \alpha \chi \varepsilon i)$, but Piso conquers with small or nonexistent losses no matter how fierce the combat (quamuis acerrima ... / proelia); both leaders are triumphant, but the intensity of the battles leading to their victories reflects the writers' disparate purposes. Each author also notes that his subject has captured enemy forces. A likewise compelling correspondence is that the Polybian passage begins shortly after the siege of a city, perhaps adding ludic resonance to the game polis; Hamilcar successfully defends his fortifications, whereas Piso's soldier breaks into his adversaries' position. ${ }^{353}$ Whether the panegyrist specifically had the Polybian passage in mind is neither known nor particularly significant, for in either case, the Latin author adopts an earlier Greek theme and adapts it to his own purposes. ${ }^{354}$

The poet's approach also bears similarities to Cteson's interpretation of the

${ }^{353}$ Polybius, Histories 1.84.1-2: "It turned out for Mathos and Spendius that they were no less besieged than they were besieging. For they were brought to such a lack of

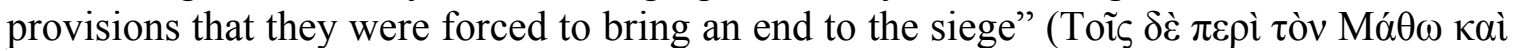

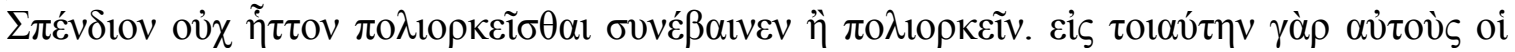

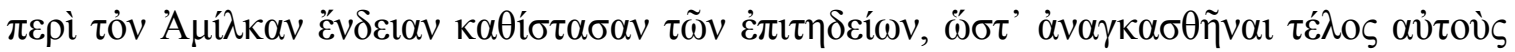

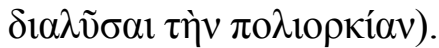

${ }^{354}$ Plutarch, Parallel Lives, Pyrrhus 26.1-2 records a secondhand quotation about a less victorious general and his strategic deficiency: "And in military experience, personal prowess, and courage, [Pyrrhus] was believed to be foremost by far of the kings of his time, but what he won through his actions he lost through his hopes; because of desire for what he did not have, he failed to secure what he had already won. For this reason, Antigonus used to compare him to a gamester who throws the dice often and well, but

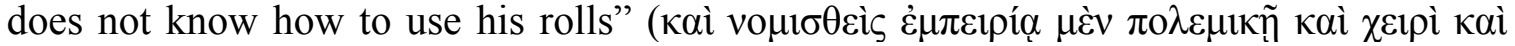

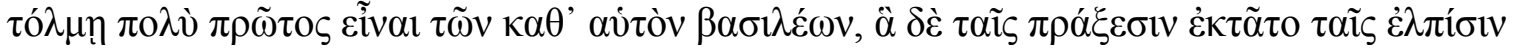

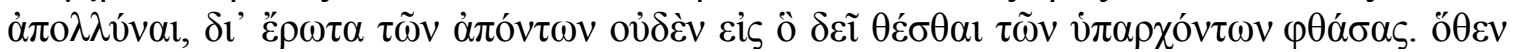

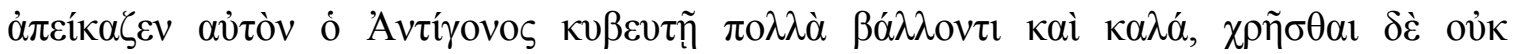
$\dot{\varepsilon} \pi \imath \tau \tau \alpha \mu \varepsilon \dot{v} \omega \tau$ oĩ $\varsigma \varepsilon \sigma o \tilde{\sigma} \sigma$ ). This anecdote would date to the early third century BCE, so although Plutarch's work did not appear until the early second century CE, the author of the Laus Pisonis may have known his source. See Romm (2012) vi for the dating of Plutarch's Parallel Lives. In any case, the comparison of prowess as a game player and as a military strategist was an established technique literary before the Laus Pisonis. 
suitors' game of pessoi in the Odyssey. In each case, the result of a game played with counters is equated with outcomes in the players' lives, such that victory in the game corresponds to victory in another arena. For the suitors, capturing the Penelope stone secures Penelope herself in marriage, while for Piso, winning a game with glass soldiers demonstrates the ability to win battles with human warriors. The parallel is noteworthy for its chronology as well as its content. Athenaeus reports Cteson's interpretation of the suitors' game via Apion of Alexandria. ${ }^{355}$ Apion lived in Rome and died under two decades before the prospective publication date of the Laus Pisonis, so literary discussions pertaining to embodiment and the effects of the symbolic on the real world may have been current during the anonymous poet's early years.

The author of the Laus Pisonis emphasizes his subject's suitability to lead human troops through his prowess at ludus latrunculi. The poet carefully blends real and imaginary warfare to cast Piso the game strategist as Piso the military strategist. His approach surpasses that of Ctesiphon's description of Penelope's suitors, who hope that winning the Penelope stone in their game of pessoi will result in winning Penelope herself in real life; the author of the Laus Pisonis does not exhibit mere hope, but rather suggests actual transference, such that his subject's success at commanding symbolic soldiers equates to aptitude for leading real ones. The poet strives to compensate for Piso's lack of military experience while presenting him as a credible alternative to Nero. Appropriate for this aim is the fact that the winner of ludus latrunculi is hailed as imperator, surely the

${ }^{355}$ Athenaeus, Deipnosophistae 1.16e: "Apion of Alexandria says that he heard from

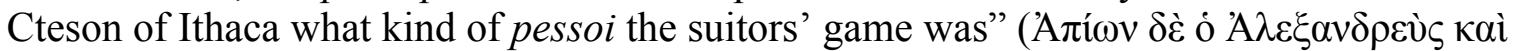

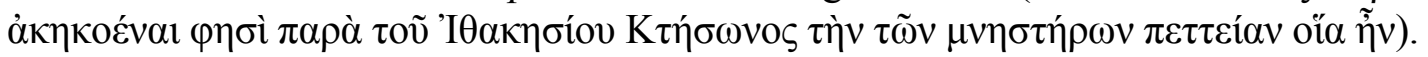


most fitting title for any pretender to the throne. ${ }^{356}$

\section{Conclusion}

Roman authors adopt the ludic themes of their Greek predecessors and adapt them for a variety of purposes. Intertextual readings reveal the debt that Roman authors owe to their Greek forebears, as well as their manners of divergence. Some writers, such as Terence, likely consciously emulate Greek models, while others, such as the anonymous poet of the Laus Pisonis, work in the same literary milieu, but may not follow specific examples. In all cases, however, the texts considered in this chapter bear testament to the endurance of ludic themes from Greek to Latin literature.

Early in the history of Latin literature, Terence plays with the ludic theme of "playing your roll" in the Adelphoe. This theme has antecedents in a wide variety of genres, to which later authors, including Greek comic playwrights, respond in their own works. The Menandrian play that served as Terence's primary model has survived in only a few fragments, though, so it is unknown to what extent the Roman author follows or deviates

${ }^{356}$ An anecdote about Proculus provides both evidence for the winner of ludus latrunculi being called imperator and also an interesting parallel for someone considered qualified to be emperor because of his skill at the game. See Scriptores Historia Augusta, Quadrigae Tyrannorum 13.1-2: "He was called to imperial power almost as a game and a joke... For when he was playing latrunculi at a certain banquet, and he had come out as imperator ten times, a certain jokester, himself not unrenowned, said 'Hail, Augustus,' fastened a purple wool garment he had brought in around his shoulders, and worshipped him; then fear set upon all of the participants and so there was then an attempt to gain the army and imperial power" (in imperium uocitatus est, ludo paene ac ioco... nam cum in quodam conuiuio ad latrunculos luderetur, atque ipse decies imperator exisset, quidam non ignobilis scurra "Aue" inquit "Auguste," adlataque lana purpurea umeris eius uinxit eumque adorauit; timor inde consciorum atque inde iam exercitus temptatio et imperii). Regardless of the account's historicity, there is no reason to doubt the use of imperator in a ludic context or the idea that some could see victory at symbolic warfare as evidence for successful military leadership. 
from it. In any case, Terence uses wordplay to create humor, adapting a ludic theme by inserting jokes that operate within its framework. The character Micio possibly undercuts the theme of and advocates cheating in the game of life rather than making the best use of one's circumstances, then Demea, after mocking his brother for not playing well enough, engages in a series of ludic puns that places him in the role of the game player. Whether Terence transmits the witticisms of his Greek original or invents his own, he shows translatability and adaptability of ludic themes, setting the stage for later Roman authors to play their own linguistic games.

Horace takes up the torch and toys with ludic themes in the Sermones. In his final satire, he inverts the accustomed gravity of "the cosmic game": the character Nomentanus applies it not to deprivation or death, but to a falling curtain ruining one course at a dinner party. The narrator Fundanius embraces the ambiguity of Micio's reference to playing one's roll in the Adelphoe and takes it one step further, remarking that Nasidienus, the host of the dinner party, seemed determined to change his fortune through skill rather than accept his circumstances. Horace's satire shows that even without a direct generic model, ludic themes remain a viable resource for expressing considerations about the cosmos and humans' relationship with its organizing principles, as well as how those ideas can be adapted to suit the author's intended purpose, in this case for humorous effect.

The same motif appears again in the first three books of Horace's Carmina. The ludic theme recurs throughout the collection, each time with a different effect. In 1.34 and 1.35, Horace builds on Greek models from a variety of genres to cast FORTUNA as the cosmic player through her association with the inversion of mortals' circumstances. Horace also conflates Jupiter and FORTUNA, enhancing the magnitude of the cosmic player, and 
situates warfare as part of the cosmic game. This last idea appears again in 2.1, where the poet states that the true subject of Pollio's history of the civil war is FORTUNA's game: he explicitly names FORTUNA's game as one of five themes in the work and implies its influence over the others through its centralized placement and the passage's wording. In 3.29, Horace recalls the three earlier odes and his final satire. He uses elements from each as he gradually builds to his climax, bringing ludic interpretations to mind throughout the poem before treating the cosmic game explicitly. Near the end of the ode, he again comments upon the power of FORTUNA as the cosmic player before introducing a new idea: resigning the game by abandoning hope for worldly riches, instead gaining immortality through his writing. This idea is a new twist on the cosmic game that reinforces the ludic theme as a vehicle for discussing mortals' connection to the cosmos.

The Laus Pisonis portrays its laudandus as credible leader and marks his skill at ludus latrunculi, the same game as the Greek polis, as a beneficial quality. As the anonymous poet crafts a work that may win him patronage, Piso's talent for the game supplants his lack of true military experience, such that the ability to lead and capture glass troops equates to success with human ones. The ludic imagery of the poem has disparate Greek precedents. One is Cteson's explanation of the suitors' game, where capturing a stone counter called Penelope equates to securing Penelope herself in marriage; this account may have entered Rome via Apion just decades before the composition date of the Laus Pisonis, perhaps pointing to it as an influence. Another potential model is Polybius' Histories, in which the author describes Hamilcar's military prowess in terms similar to Piso's in the Laus Pisonis. Whether the panegyrist follows a specific model or draws on an established literary technique, the end result is that the Laus Pisonis magnifies the 
comparison between a board game and military strategy and directly equates the two. Moreover, the author reverses the expected polarity, as it were: the poet does not project a complicated subject onto a more easily comprehensible game, but rather amplifies the game to match its macrocosmic counterpart.

The texts considered in this chapter show the versatility of ludic imagery in Latin literature. Whether generating humor, considering humans' relation to the cosmos, or seeking patronage, games provide a medium through which authors pursue their literary objectives. Intertextual readings show that these writers do not merely draw parallels with quotidian amusements, but rather that games afford modes of expression identifiable by continuities in lusory motifs and imagery. Moreover, intertextual investigation shows the endurance and adaptability of ludic themes, as Roman authors apply them to new aims and genres. When considered as part of a larger pattern and not as isolated episodes based on daily life, the games Roman authors play with ludic themes reveal new avenues for research into how Roman authors adopt and adapt the works of their Greek predecessors. 


\section{Chapter 3: Games and Morality in Greek Literature}

\section{Introduction}

A previous chapter outlined the ideological implications of games in the Homeric corpus. Homer's text and later Greek interpretations not only possess philosophical connotations, but also open avenues of discussion about Greek morality. Knucklebones in the Iliad and pessoi in the Odyssey serve different functions, but each game is associated with proper human behavior and transgressions of it.

In the penultimate book of the Iliad, Patroclus' shade appears to Achilles and indirectly connects a game of chance with morality. ${ }^{357}$ Patroclus admits that he murdered Amphidamas' son after becoming enraged during their game of knucklebones. Moreover, he reveals that part of his past—presumably known to Achilles, but just now disclosed to the audience-when asking Achilles to bury his bones in the same urn as Achilles' own. There is a strong chiastic relationship between the two incidents: Patroclus previously cast knucklebones and killed someone, now he has been killed and wants his bones cast together with Achilles'. The reversal of action and the shift in Patroclus' role from agent to patient indicate continuity; just as an animal's death is required to obtain knucklebones, so Patroclus' death necessarily precedes the placement of his bones. Homicide and (un)suitable treatment of others pervade the speech: Patroclus violated the standards of his home, evidenced by his subsequent need to depart it, and he now hopes Achilles will grant him a final request. Proper treatment of the dead is a key moral theme in the Iliad, especially in the final few books, and its juxtaposition with knucklebones in

${ }^{357}$ Homer, Iliad 23.83-92 
this passage foreshadows later Greek authors' use of games as a battleground for contesting morality.

In the Odyssey, Penelope's suitors' game of pessoi also introduces a negotiation of Greek morality. The suitors stand-or, more precisely, sit—in contrast to Odysseus: they subsist on the efforts of others, devouring Odysseus' larders while their own stores remain untouched, violating the reciprocity inherent in xenia, and remaining inactive during the hero's adventures. The whole of their languor is marked by their first appearance, when we, through Athena's eyes, see them playing pessoi ${ }^{358}$ Cteson's later expansion and explanation of the scene (via Apion, quoted by Athenaeus) likewise shows transgression of proper behavior and argues that the suitors' luxurious living, epitomized by their pessoi playing, leaves their hands soft and unable to string Odysseus' bow; their lifestyle runs counter to the heroic ideal Odysseus exemplifies and ultimately leads to their demise. $^{359}$

While knucklebones and pessoi serve different functions in the Iliad and the Odyssey, both games are associated with standards of conduct and breaches of those standards. In each scene, the games exemplify the indecorous behaviors of the players, so we can see a link between games and morality in Homer, albeit perhaps more explicitly in the Odyssey than in the Iliad. Later Greek authors also adopt moral stances to games and help situate games in the environment of the ancient world. As I argue in this chapter, Greek orators in particular contest the morality of games of skill, but inextricably link games of chance with financial exchange and reprove them as immoral.

This chapter investigates the moral valuation of games in Greek oratory, which is

${ }^{358}$ Homer, Odyssey 1.106-112

359 Athenaeus, Deipnosophistae 16e-17b 
particularly suited to negotiating cultural values because of speakers' frequent appeals to the standards they supposedly share with the jurors and the audience members. The first two authors I consider write in the guise of the heroes Palamedes and Odysseus, thereby serving as a bridge between the Homeric world and the realities of fifth- and fourthcentury BCE Athens. Subsequent orators speak in their own voices or, in the case of the logographers, through those for whom they write speeches. In all cases, the orators sketch a picture of how the ancient Greeks - or the fifth- and fourth-century BCE Athenians, at least-viewed games in daily life, though the accuracy of that picture is an open question. ${ }^{360}$ That is, I do not mean to imply that the social norms the orators describe correspond with historical realities, nor do I contend that a monolithic set of universally agreed upon standards existed. Rather, I explore these texts as portraying a particular image of contemporary society, not as facsimiles of social realities. This chapter functions alongside the chapter "Ludic Ideology in Greek Literature": the earlier chapter explores the role games serve in the higher literatures, predominantly epic, philosophy, and tragedy, while the present discussion moves into the realm of the practical and the everyday. The evidence still comes from literature, but employs writings that purport to arise from the daily life of the community.

Although eloquence and persuasion are systematized in oratory, they precede its development as a genre and are not confined to it. Nor should we expect this "vast topic that lay at the very heart of Greek life" to be limited to a single period or genre. ${ }^{361}$ From our earliest literature onwards, our sources record the ancient Greeks as consistently

\footnotetext{
${ }^{360}$ As I discuss later in this chapter, I do not mean to imply that the social norms the orators describe correspond with historical realities, nor do I contend that a monolithic set of universally agreed upon standards existed.

${ }^{361}$ Edwards (2016) 205
} 
prizing effective communication. Even in Homer, we find that Achilles, renowned largely for his martial prowess, was trained "to be a speaker of words and a doer of deeds." Achilles must have paid attention to his schooling, for at the outset of the Iliad, he is the one who assembles the Greeks and is first to speak, exhorting Agamemnon to discover the source of Apollo's wrath and remove the plague afflicting the army. ${ }^{363}$

Epic is not the only Greek genre that values eloquence. Tragedy includes scenes that showcase articulate speech, such as the messenger's report of the Battle of Salamis in Aeschylus' Persians. The genre of history too employs set speeches, such as Pericles' funeral oration in Thucydides. From the work of historians we see the importance of public speaking outside the literary sphere, as Athenian leaders, including Themistocles and Pericles, were proficient speakers as well as statesmen and generals. ${ }^{364}$ For instance, Herodotus records that before the Battle of Salamis in 480 BCE, Themistocles gave the best address of all to the assembled fighting men, contrasting the better and worse elements of human nature and the human condition and urging his audience to choose the better. ${ }^{365}$ Herodotus does not recount the speech itself, but emphasizes its force and effect on its audience. Similarly, Gagarin argues that although Thucydides wrote the three speeches he attributes to Pericles, they may still offer some sense of Pericles' virtuosity at

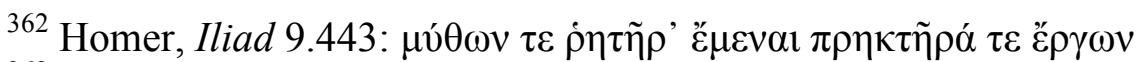

${ }^{363}$ Homer, Iliad 1.53-67. See Pernot (2005) 1-7 for a discussion of rhetoric and the power of the spoken word in Homer.

${ }^{364}$ Davies (1978) 124. Cf. Gagarin (2007) 29: “[T]hroughout his work Thucydides makes clear that political leadership in the fifth century was primarily dependent on rhetorical ability." On the intersection of rhetoric and politics in Classical Greece, see Worthington (2007) 255-271.

${ }^{365}$ Herodotus, The Histories 8.83
} 
public speaking. ${ }^{366}$

The ancient Greeks' fixation on formal speaking reached its zenith in the public oratory of the late fifth and fourth centuries BCE. The traditional account situates the emergence of oratory as a (more or less) distinct genre around the middle of the fifth century BCE with the work of the Sicilians Corax and Tisias. ${ }^{367}$ The sources are inconsistent and the two Sicilians may in fact have been one and the same person; if a historical Corax, distinct from Tisias and not just another name for him, actually existed, then all that is known about him is that he focused on arguments from likelihood. ${ }^{368}$ In any case, the visit of Gorgias, another Sicilian, to Athens in $427 \mathrm{BCE}$ as the spokesperson for the Leontinian embassy appears to have sparked the powder keg: Gorgias not only persuaded the Athenians to join in an alliance against Syracuse, but also motivated formal training in oratory, of which he was a preeminent teacher. ${ }^{369}$

The importance of oratory for the Athenians, who provide so many of our sources, was tied to the affairs of the polis. ${ }^{370}$ Life in the city required participation, their democratic rights to which citizens exercised in the Assembly and the large juries of the

366 Gagarin (2007) 29. The speeches are found in Thucydides, History of the Peloponnesian War 1.140-144, 2.35-46, 2.60-64. The first and third of these are speeches to the Assembly, while the second is the famed funeral oration. The dearth of comparanda prohibits pursuing this argument any further, as the historiographer may have modified events to suit his own agenda.

${ }^{367}$ See, for example, Hinks (1940) 61-69; Kennedy (1999) 21; Schiappa (1999) 4-6, 3047; Usher (1999) 1-4; Pernot (2005) 10-12; Cooper (2007) 203-204; Gagarin (2007) 3034; Edwards (2016) 206.

${ }^{368}$ Cole (1991) 65-84, especially 70-71; Kennedy (1999) 21; Cooper (2007) 204; Gagarin (2007) 30. Cf. Schiappa (1999) 34-39, who also emphasizes the problems of seeking a historical Tisias.

${ }^{369}$ Usher (1999) 4; Bons (2007) 39-40; Edwards (2016) 206. Cf. Kennedy (1999) 34-35.

${ }^{370}$ Erskine (2007) 272 
courts. ${ }^{371}$ Persuasion was paramount in each of these arenas, as the individual citizen needed to prove to the Assembly that his proposal was profitable and to a court that his suit was just, so one's speaking ability had a direct impact on his efficacy in public life. ${ }^{372}$ In other words, oratorical training was more than just education or literary studies for a citizen: it was the foundation of his successful participation in the polis. ${ }^{373}$ It is little wonder, then, that we see such a sudden boom in oratory once formal study of it is introduced.

Here I pause to mark a distinction in terms. As scholars have noted, the split between "oratory" and "rhetoric" is in many ways a false division, as orator is the Latin equivalent of the Greek word rhetor. ${ }^{374}$ Still, I follow specialists in the field in their usage of the terms, such that "oratory" is the actual practice of eloquence, while "rhetoric" is the theory of how to perform it. ${ }^{375}$ Accordingly, this chapter's focus is on texts that purport to record actual performances—-written, spoken, or both—and their underlying principles, not theoretical works that outline how to craft or deliver a performance. By examining consistencies in oratory, however, we can connect the dots to identify

${ }^{371}$ Bons (2007) 38; Worthington (2007) 255

${ }^{372}$ Davies (1978) 124; Bons (2007) 38-39; Erskine (2007) 272. Cf. Day (2007) 379-380.

${ }^{373}$ Cf. Aristotle, Rhetoric 3.1.4-5, who comments that rhetoric is not right, but is necessary, since effective delivery nearly always results in victory in the courts and Assembly because the jurors are unskilled. This is not to say that the entire citizenry participated in such contests or even wanted to do so. Worthington (2007) 263 observes that "[n]ot every citizen attended the Assembly (or law courts, for that matter), and many of those that did attend might never have addressed their peers or moved proposals" and concludes that the evidence "indicates that people were generally satisfied with their lot in the [sic] life and were not as intent on upward mobility (socially or even politically) as today." Hansen has compiled the evidence and statistics for citizen participation in the polis, conveniently assembled into one collection of articles, his The Athenian Ecclesia II. The most relevant essays are Hansen (1989a) 1-24; Hansen (1989b) 25-72; Hansen (1989c) 93-127.

${ }^{374}$ Edwards (2016) 205

${ }^{375}$ Edwards (2016) 205 
individual statements as part of larger rhetorical strategies available to those addressing the public, as discussed below. All the same, because my focus is on the texts of forensic speeches, which themselves actualize rhetorical strategies, I move with some freedom between the terms oratory and rhetoric.

Oratory is an ideal source for examining ancient negotiations of morality. ${ }^{376}$ Forensic speeches are especially useful, as they are designed to convict or acquit the accused of wrongdoing, that is, of transgressing the boundaries set by the community. ${ }^{377}$ Regardless of these speeches' efficacy or if, in some cases, they were ever even delivered, they can help reconstruct the standards of ancient Greek society as portrayed by their authors: as these speeches' authors or speakers seek to prove or disprove the violation of cultural values, they simultaneously delineate what those values are and what behaviors constitute transgression, for a litigant would only be successful by appealing to the jury's shared ideals; as one scholar puts it, "to be persuasive an orator had to move with the attitudes, values and prejudices of his audience. ${ }^{378}$ Although other genres can be useful sources for cultural information and ethical stances, oratory is particularly suited for the task because of its transparent agenda: oratory does not primarily aim to please its audience members or exhort them to a better way of living, but rather outlines contemporary practices as they actually stand while discussing possible infringement of

${ }^{376}$ Cf. Day (2007) 379: "The rhetoric produced in a society provides some of the best evidence one can have about the ethical views generally accepted in that society."

377 Aristotle, Rhetoric 1.3.1-3 states that there are three kinds of rhetoric: deliberative (for private advice and the Assembly), forensic (for the courts), and epideictic (for display).

${ }^{378}$ Davies (1978) 124. Cf. Day (2007) 379: "The aim of rhetoric in actual practice is persuasion, and persuasiveness is relative to the audience; the audience will be swayed in proportion as its members perceive the speaker's conclusions as following from principles that they themselves accept.... So the speaker, knowing this, will act on it, and present his case in a way that emphasises continuity with his audience's beliefs, and thus the text of his speech constitutes fine evidence about those beliefs to the historian." 
those accepted customs or, rather, what our sources represent as accepted customs. ${ }^{379}$

The expression of cultural values, actual or idealized, in oratory finds a counterpart in lists of inventions or first discoverers, including the progenitor(s) of oratory itself, mentioned above. ${ }^{380}$ Coinciding with the height of Athenian oratory, many authors of the fifth and fourth centuries BCE provide such inventories, often attributing them to a culture hero, such as Palamedes or Prometheus. ${ }^{381}$ The discoveries included in these lists are nearly always described as valuable to society and their inventors, therefore, as benefactors. ${ }^{382}$ It follows that catalogs of first discoverers identify creations or developments that the community of the catalogs' origin esteems. ${ }^{383}$ Oratory and lists of inventions, then, both purport to isolate shared, cultural values, so an examination of their intersection is instructive.

The invention of games is often attributed to Palamedes, who serves as an arena for orators to contest the morality of those discoveries. When Gorgias writes a speech in the guise of Palamedes defending himself against the accusation of treason, the foundation of his argument is that he has discovered many inventions useful to humanity,

${ }^{379} \mathrm{Cf}$. Gagarin (2000) xix: "[T] he orators... are now seen as primary representatives of Athenian moral and social values, and as evidence for social and economic conditions, political and social ideology, and in general those aspects of Athenian culture that in the past were commonly ignored by historians of ancient Greece but are of increasing interest and importance today."

${ }^{380}$ See Pernot (2005) 10 on antiquity's recourse to first inventors and how rhetoric fits into the pattern.

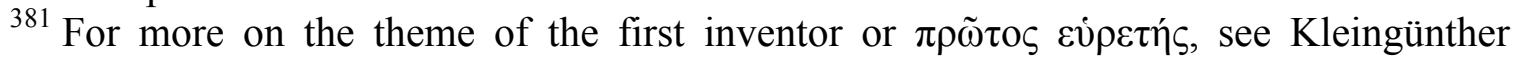
(1933), who views it as an outgrowth of the historical investigation of the sixth and fifth centuries BCE. He argues that the idea of inventors postdates Homer and Hesiod, in whose works gods and men possess certain skills and can teach others, but do not create or discover their abilities.

${ }^{382}$ For more on beneficent culture heroes and their inventions, especially as pertains to aspects of language, see Gera (2003) 122-126.

${ }^{383}$ While single authors wrote these works, their very survival through replication and dissemination points to shared values. 
including pessoi. Gorgias' student Alcidamas, meanwhile, presents the opposing view: he adopts the guise of Odysseus and expounds upon Palamedes' disservices to society. Odysseus claims that Palamedes merely takes credit for the beneficial discoveries others have made, while all of his own inventions are injurious to the community. Chief among these inventions are pessoi and dice, though they meet strikingly different degrees of vituperation: the former only leads to disputes among idlers, while the latter are a very great evil, for the losers suffer damages and even the winners are met only with rebuke. Odysseus argues further that any profits gained from dice are useless and that most are wasted on the spot. The character Odysseus assumes that financial stakes are part of any dice game; the gambling element serves an important role in differentiating pessoi as a bothersome invention from dice as a very great evil. These speeches contest the morality of games through the figures of their alleged inventor and an early detractor.

The speech put in the mouth of Odysseus posits monetization as an integral element of vice. In other orators as well, as I argue throughout this chapter, when otherwise innocuous activities gain a financial element or an extant one is unduly augmented, these pursuits concomitantly acquire a charge of immorality. Thus it is that Greek orators consider games variously, but uniformly excoriate gambling. The same principle also applies to activities commonly associated with games. Sex is a natural feature of life, but when combined with a monetary element, it becomes a cultural construct open to criticism: prostitution, both patronizing the institution and selling one's own body. Eating and drinking are even more quotidian acts and disproportionate expense on them is a common accusation of moral shortcomings.

Activities become vices not only when monetized, but also when taken to excess. 
A fondness for lavish dinners and costly wines may be a mark of degeneracy, but even more telling is the quantity ingested: gluttony and drinking to intoxication are readily apparent displays of poor moral fiber. An unrestrained sexual appetite is likewise evidence of immorality, perhaps because it can lead to adultery and threaten the legitimacy of bloodlines and inheritances. Games can serve ideological and instructive purposes, as outlined in a previous chapter, and can be an appropriate outlet for leisure, but they can also be taken to excess, diverting players' attention from work and worthier pursuits, hence the earlier association of pessoi with idlers.

Quotidian activities that are customarily neutral, that is, behaviors that have no inherent moral valuation, transform into vices when monetized and/or taken to excess. That multiple vices follow this pattern and are often treated together by ancient sources allows us to see them as a unit. Games become gambling or, less commonly, gaming too often; sex becomes fornication, encompassing both adultery and prostitution, which itself includes both purchasing intercourse from others and selling oneself; and eating and drinking become consumption, comprising inordinate expenditure and immoderate ingestion. These three vices—gam(bl)ing, fornication, and consumption—form a trio of interconnected vices that permeates Greek discussions of morality. Oratory develops the vice trio and solidifies it as the quintessential model of iniquity. ${ }^{384}$

What I term the vice trio is a new approach to questions of morality in the ancient

${ }^{384}$ This is not to say that the orators themselves establish these particular acts as vices or first associate them. Rather, I view the orators' writings under consideration as exemplifying a literary trope, which itself may reflect contemporary conversations about standards of propriety. Although pursuing this last point exceeds the scope of my argument, it must be remembered that the successful speaker is the one who convinces the audience; for forensic oratory, that means persuading the jury that a transgression has or has not occurred, either by appealing to the jury members' existing values or by shaping new ones in the course of argumentation. 
world. Previous scholarship has not taken a comprehensive view of gam(bl)ing, fornication, and consumption, each with its organic and monetized subspecies, as a unified whole, though scholars have at times noted the association of the three activities in question, either for their interrelation or their common attribution of deviancy. ${ }^{385} \mathrm{My}$ view of a composite vice trio allows for new light to be shed on accusations of immorality in the ancient world, especially in oratory, where those accusations are most prominent. This approach broadens our understanding of the rhetorical strategies available to speakers in the ancient world, as invoking the constituent parts of the vice trio becomes a readily-accessible tactic for pitting the imagined audience-including members of the jury — against one's opponent. This forensic trope is useful for each kind of litigant, both the accuser trying to prove malfeasance and the defendant maintaining that the case and the accuser are unjust.

Viewing these vices as a unit also reveals new information about ancient ascriptions of immorality. By mapping out the vice trio in oratory, modern readers can see how ancient Greek authors portray these vices as interrelated and how they manipulate that connection to their own advantage. The relationship among the vices is not always readily apparent to a modern audience, but we can nevertheless see through the eyes of our sources and connect the dots to reveal a more detailed picture of ancient negotiations of morality than has previously been discovered. The methodology of the vice trio also helps elucidate a particularly enigmatic wrinkle in the fabric of cultural connections: why ancient authors, especially orators, so frequently portray games

${ }^{385}$ On the interrelation, e.g. Fagan (2006) 373-376, the section entitled "Drinking, Gambling, and Hired Sex: Fun at the Roman Tavern." On the common attribution of deviancy, e.g. Laurence (1994) 70: "Typically, deviant behaviour includes prostitution, 'excessive' alcoholic consumption and gambling." 
alongside sex, food, and drink.

\section{Gorgias}

Gorgias of Leontini is an early source that ascribes a moral value to games. His Defense of Palamedes is not the recorded version of a speech actually delivered in court, but matches the style of forensic oratory as recorded in later sources; this faux-rensic oratory, so to speak, retains all the elements of courtroom speeches and is an equally valid source for reconstructing contemporary morality. ${ }^{386}$ In Gorgias' fabricated defense speech for Palamedes against the charge of treason, the hero declares that he is not a traitor, but rather a great benefactor to the judges, the Greeks, and all of humankind. ${ }^{387}$ At the heart of his claim lie his many inventions, including games: ${ }^{388}$

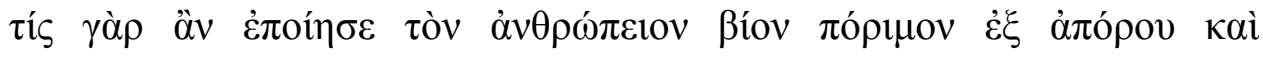

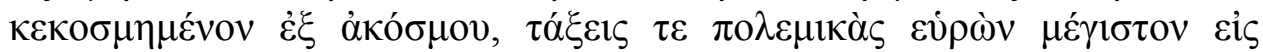

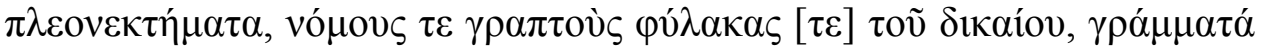

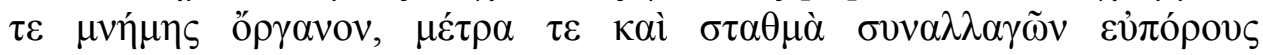

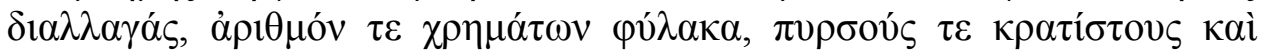

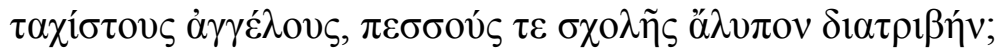

For who (else) could have made human life resourceful from the resourceless and ordered from the disorderly, by devising battle lines as the greatest thing for successes (in war), and written laws as the keepers of justice, and writing as a tool of memory, and measures and weights as easy reconciliations of commercial dealings, and number as the guardian of property, and fire signals as the best and fastest messengers, and pesso $i$ as a harmless pastime for leisure?

${ }^{386}$ On the structure of the Defense of Palamedes perfectly mirroring the style of judicial rhetoric, see Bons (2007) 40-41. The term faux-rensic oratory is my own. Although it is an admittedly bad pun, it pithily captures the spirit of such speeches, which scholars often must inelegantly resort to calling epideictic speeches couched in the form of forensic speeches (Edwards (2007) 49), argumentation of a fictional case (Bons (2007) 37), or some similar expression.

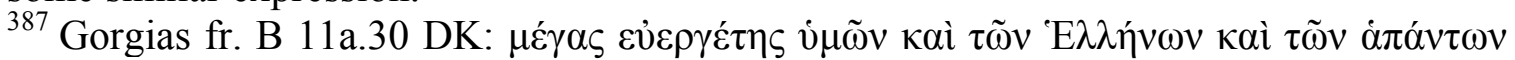
$\dot{\alpha} v \theta \rho \omega \dot{\pi} \pi \omega v$.

${ }^{388}$ Gorgias fr. B 11a.30 DK 
Palamedes avers that his inventions are benefits by listing them in their proper usage, contextualizing each creation as an improvement in a given domain. The elements of the seemingly disjointed list of inventions find unity in their roles as organizing principles and their connection with civic morality. As Kurke has argued, each one of Palamedes' discoveries constitutes a symbolic signifying system that imposes second-order structure: battle lines organize troops, written laws systematize civic affairs, measures and weights regulate the exchange of goods, number manages possessions, and fire signals transform and convey messages. ${ }^{389}$ Moreover, all of the inventions hold positive moral value in their connection to the city, as shown by Palamedes' contextualization for each one. ${ }^{390}$ Kurke deliberately leaves pessoi out of her initial analysis, but after an examination of board games in Archaic and Classical Greece affirms that they share the same features as the other inventions in Gorgias' list: she states that according to Greek thinking, pessoi teaches players how to be citizens in the polis, arguing that the game polis in particular stresses the importance of keeping one's place in the hoplite battle line, thereby connecting the game with Palamedes' invention of military tactics, and trains players to

\footnotetext{
${ }^{389}$ Kurke (1999a) 251; Kurke (1999b) 251; Kurke (2002) 19

${ }^{390}$ Kurke (1999a) 251; Kurke (1999b) 251; Kurke (2002) 19. Steiner (1994) 127-185 argues that the Greeks of the sixth and fifth centuries BCE associated some symbolic inventions with Eastern despots: writing, coinage, and trade, each either explicitly attributed to Palamedes or a logical consequence of his creations. Steiner makes a strong case, but I follow Kurke in seeing that "at least by Gorgias's time, the identification of these symbolic systems with the order of the polis was an available one for a Greek audience" (1999a: 252 n.8). Spatharas (2001) 196 notes that the common denominator of Palamedes' inventions is that they all further develop an already civilized community. Cf. Detienne (2003) 129, who points out that Palamedes is not known for discoveries that separate humans from animals, such as fire, clothing, or forms of sustenance, but rather for those that resolve problems.
} 
submit to the rules and symbolic order of the city. ${ }^{391}$

While Kurke's analysis succeeds in linking the items in the list of inventions, it goes rather far afield to do so and relies on a specific game, polis, found nowhere in the text. Moreover, it seems far too careless for Gorgias, a famed teacher of rhetoric, to have composed an argument entirely self-contained save the final element. Kurke's own framework, however, can explicate the inclusion of pessoi in the passage as it stands. The very presence of pessoi indicates that it fits with the other items, that is, that it is a symbolic signifying system that imposes second-order structure and is useful for the city. The righteous civic function pessoi serves is, as with that of the other discoveries in the list, made clear through the context that Gorgias' Palamedes provides, though its intricacies must be explored in greater detail.

Like the other inventions Palamedes names, pessoi is a symbolic system, as all board games are. ${ }^{392}$ While pessoi is already a self-contained entity with organizational rules, it becomes an agent of order through its application to leisure: as participants arrange their pieces during play, they simultaneously structure their time. According to Palamedes, the provision of a harmless manner in which to spend leisure is the municipal benefit pessoi offers. All inventions meet a need or want, so we are left to presume that before Palamedes' invention of pessoi, there were no anodyne uses of leisure. We are not told how people previously occupied their free time, but ostensibly they spent it poorly; were Palamedes' contemporaries spending their leisure engaged in activities culturally approved as good, there would be no need for a divertissement described only as

${ }^{391}$ Kurke (1999a) 270; Kurke (1999b) 260; Kurke (2002) 27

${ }^{392}$ Cf. Nicolau (2009) 28-29: "in board games man finds himself playing less physically and more in another signification level, characterized by being almost fully theoretical and symbolic" (quote from 29). 
"harmless." Pessoi, then, serves as a neutral pursuit: at worst it is an activity that causes no one pain and at best it deters players from the grievous endeavors in which they would otherwise engage when at leisure. Pessoi is itself morally neutral, but the invention of a morally neutral pastime is, in this case, itself a benefit that improves society.

Other Greek thinkers bolster this interpretation of pessoi as a neutral leisure activity, which Gorgias' Palamedes asserts is itself a beneficial invention. According to Xenophon's account, one such person was Socrates, Gorgias' contemporary and intellectual rival. ${ }^{393}$ Socrates' student chronicles his teacher's views on the intersection of leisure, pessoi, and morality: ${ }^{394}$

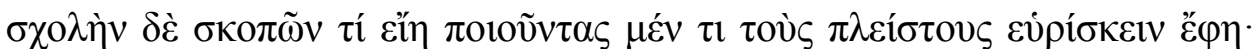

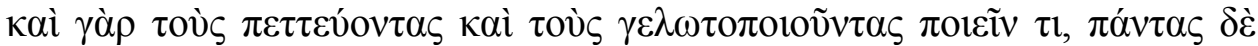

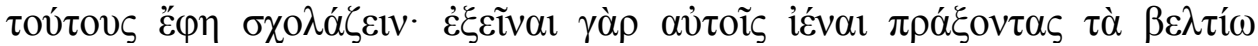

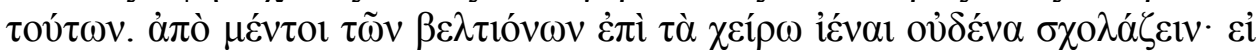

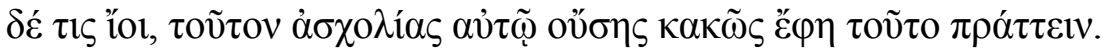

Reflecting on what leisure is, he said he found that most men do something; for even those playing pessoi and those making jokes do something, and he said that all these men are at leisure, as it is possible for them to go do things better than these. No one, however, is at leisure to go from better pursuits to worse ones: Socrates said that if anyone makes that move, he acts badly in this respect, with no leisure existing for him.

In Socrates' view, at least as Xenophon records it, anyone who plays pessoi is at leisure,

${ }^{393}$ Xenophon is careful to present himself as a reliable source for Socrates' sayings, most often by highlighting his own presence at the conversations. On Xenophon's attention to inscribing authority his texts, see Hose (2016) 245. On this tactic in the Memorabilia specifically, see also Pelling (2017) 250-254. On Xenophon as a reliable Socratic witness, see Hägg (2012) 19-28 passim, who notes, with bibliography, that recent scholarship sees the differences between Xenophon's and Plato's depictions of Socrates not as the result of Xenophon offering an inferior representation, but rather that these two disciples emphasize different aspects of their common master.

Using Xenophon's account of Socrates' sayings to inform our reading of Gorgias depends in part on Xenophon being a reliable Socratic witness. Xenophon repeatedly stresses his own participation

${ }^{394}$ Xenophon, Memorabilia 3.9.9 
matching the Palamedes' claim in Gorgias that he invented pessoi as a harmless pastime for leisure. For the most part, Socrates says, leisure is not a nonevent, as the majority of people fill their free time with one activity or another. Even playing pessoi qualifies as doing something: it is not pure inactivity, but is an enterprise in and of itself. Having established that leisure is doing something and that playing pessoi counts as doing something, he makes the deduction that those who play pessoi are at leisure.

In the second part of the passage, Socrates adds a wrinkle to his definition of leisure. He claims that an integral element of leisure is the ability to engage in better pursuits. Those who move from better engagements to worse ones, however, are not at leisure. This statement is seemingly paradoxical: if playing pessoi is leisure and one can move from pessoi to better pursuits, playing pessoi is of necessity worse than those pursuits better than it, so how can moving from better to worse pursuits not qualify as leisure? The ostensible contradiction has a dual resolution, partly mental and partly syntactical. Playing pessoi is a liminal undertaking: while itself an activity, as leisure it falls between activities considered good and bad. ${ }^{395}$ When someone shifts from playing pessoi to a better pursuit, he or she is no longer at leisure, as the better pursuit qualifies as the antithesis of leisure, presumably a kind of work, discussed below. So too do activities worse than playing pessoi count as something other than leisure and it is in this light that the last sentence of the passage must be read. On this understanding, Socrates is not saying that no one is at leisure to move from better activities to worse ones, where the contrast is between the two classes of activities and leisure denotes available time. ${ }^{396}$ Rather, the contrast is to activities that themselves exemplify leisure: no one may shift

395 See Turner (1974) 53-92 for a general discussion of the liminality of play.

${ }^{396}$ See Rancière (2004) 270-272 on the intersection of leisure and time in antiquity. 
from pursuits better than playing pessoi to pursuits worse than playing pessoi and continue to be at leisure, as doing so jumps from one non-leisure activity to another, skipping the liminal step that is leisure. According to Socrates, then, playing pessoi is not only a neutral activity, but also the central order in comparison to which he defines the suitability of other activities. ${ }^{397}$

Greater clarity comes from a parallel reading with an earlier passage in the same work. In the first book of the Memorabilia, Xenophon recounts some of the accusations leveled against Socrates and the philosopher's responses. One such charge is the (mis)use of celebrated authors to teach immorality: ${ }^{398}$

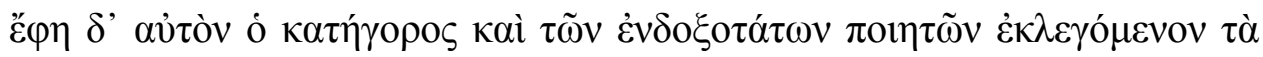

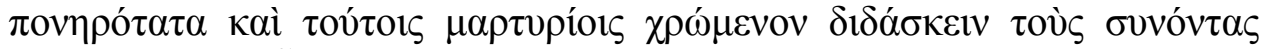

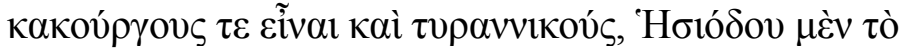

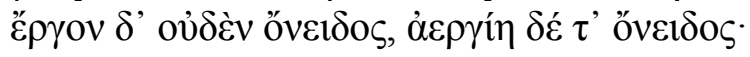

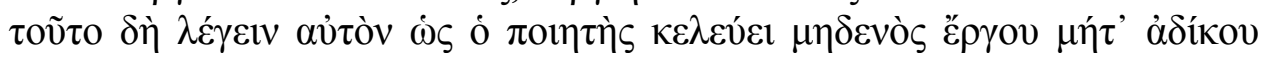

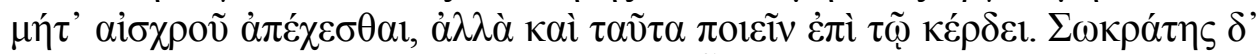

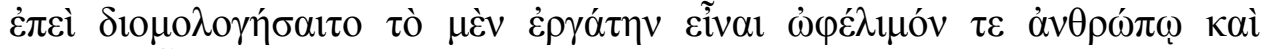

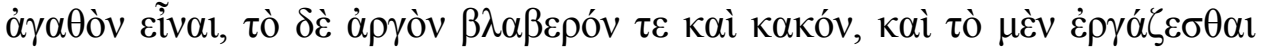

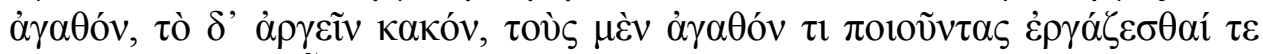

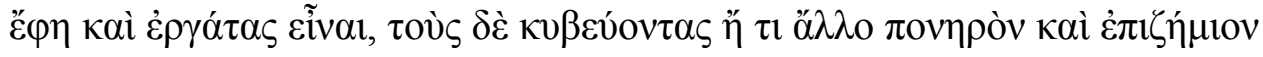

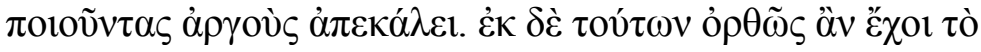

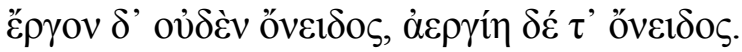

And his accuser said that he selected the most immoral passages from even the most esteemed poets and used them as evidence to teach his companions to be maleficent and tyrannical, such as the line from Hesiod

"No work is a disgrace, but idleness is a disgrace."

Allegedly he said that the poet recommended refraining from no work, neither the unjust nor the shameful, but rather encouraged doing even these things for gain. But whenever Socrates would agree that to be a worker is

${ }^{397}$ Strauss (1972) 81 has a similar reading and identifies the ambiguity of the passage: "As for leisure, it is a state, not of abstention from doing, but of doing something rather inferior - a state between the ascent to a higher activity and leisurelessness, i.e., descent from a higher activity; it is in this sense a state of rest. Socrates does not spell out here what is superior not only to leisurelessness but even to leisure."

${ }^{398}$ Xenophon, Memorabilia 1.2.56-57. The quotation in this passage is from Hesiod is Works and Days 311. 
beneficial for a man and good, and to be idle is harmful and bad, and that on the one hand working is good, and that on the other hand being idle is bad, he said that those doing something good work and are workers, but those gambling or doing anything else injurious and leading to loss he stigmatized as idle. According to these ideas the line is correct that

"No work is a disgrace, but idleness is a disgrace."

As Xenophon records it, Socrates defines what "work" is in order to interpret Hesiod's line. Work, according to Socrates, is not just doing something in general, but is specifically doing something beneficial. Consequently, work cannot be disgraceful because by definition work is doing something that is not disgraceful; anything

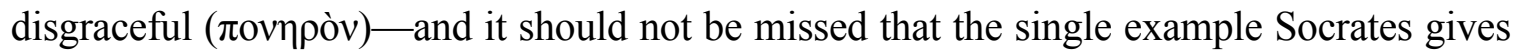
is gambling — falls into a separate category altogether. ${ }^{399}$ The opposite of work is idleness

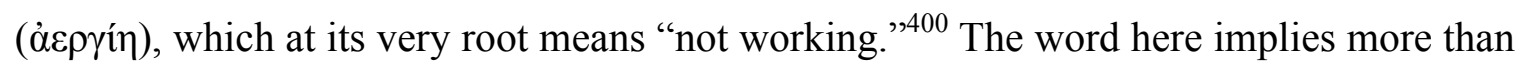
simply not laboring, however, and suggests sloth or a willful avoidance of work. ${ }^{401}$ In Socrates' conception, eschewing work likewise eschews doing something good, therefore idleness is a disgrace: those who gamble or do anything else disgraceful are in fact doing something, perhaps one could even say working at something, but the nature of their activity precludes them from being called workers; their actions instead mark them as idlers.

This passage can inform our reading of the previous one. When we consider the two passages together, we see that in the binary system of good work and bad idleness

\footnotetext{
${ }^{399}$ As Kidd (forthcoming b) has convincingly shown, кvßzí $\alpha$ and its congeners mean

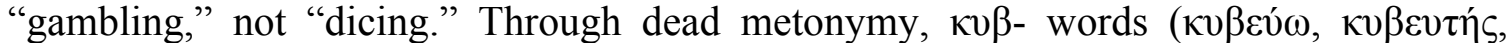

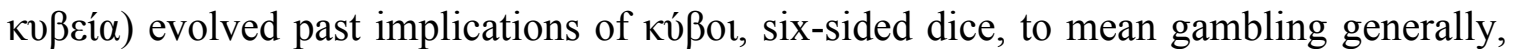
no matter the apparatus, including but not limited to dice, knucklebones, spinning coins, folding leather straps, guessing the number of objects hidden in someone's hand, and cockfights.

${ }^{400}$ LSJ s.v. à $\varepsilon \rho \gamma i ́ \alpha$ I.A.1

${ }^{401}$ Macleod (2008) 139
} 
there is a gray area in between, a liminal zone of activity neither good nor bad: leisure. In other words, it is not a binary system at all, but rather a ternary one. Morally speaking, actions exist linearly from harmful to neutral to good, where the harmless central divide is leisure. To wit: in Memorabilia 3.9.9, Socrates names playing pessoi a leisure activity and notes that it is leisure precisely because the players could be doing something better. When read with 1.2.56-57 in mind, we now understand that the better pursuits with which playing pessoi and leisure are contrasted are work, which itself is doing something good. Socrates also says in 3.9.9 that anyone who moves from better pursuits to worse ones is not at leisure; as discussed above, this statement is best understood with the full force of the comparative adjectives in mind: the hypothetical person is moving from pursuits better than playing pessoi to pursuits worse than playing pessoi. The claim that such a person is not at leisure is valid because anyone who does so shifts from work, i.e. doing something beneficial, to idleness, i.e. doing something immoral, passing over the liminal step of leisure, which is evaluated as neutral.

It must not be missed that Xenophon's Socrates defines his terms in relation to games. He identifies playing pessoi, meaning playing a board game with stone counters, as neither good nor bad, but as inherently neutral and therefore characteristic of leisure. Conversely, he describes gambling, playing a game with financial stakes, as the model of behavior that is disgraceful and/or brings loss. This separation speaks to an assumption that underlies nearly every source from antiquity: games with a chance element, such as dice, are associated with gambling, while games of pure skill, those without any randomizing agents, encapsulated in the term pessoi, are free from such charges. Socrates' use of games in each definition also marks them as examples readily accessible 
to and understood by his audience, perhaps a testament of the pervasion of games in contemporary culture.

Returning to the Gorgianic passage with which this section began, we now better understand Palamedes' claim that inventing pessoi as a harmless pastime for leisure is a benefit to society: for the times when people are not working, he offers an anodyne diversion as a substitute for deleterious pursuits and idleness. The fact that Palamedes then builds his defense on the inherent beneficence of his inventions is further evidence that he considers pessoi — in its capacity to structure leisure harmlessly — as advantageous as his other creations, especially given the fact that he caps his list with it. He argues that he turns his attention to helpful inventions, thereby making a sign that he avoids shameful and wicked actions, as it is impossible for someone devoted to good deeds to engage in evil ones; since he does no wrong, he does not deserve to be wronged. ${ }^{402}$ The hero classifies all of his discoveries as useful, their intrinsic good serving as evidence not only that he did not commit any wrongs, but also that it is impossible for him to do so. ${ }^{403}$ Palamedes, then, clearly marks pessoi as one of his creations so beneficial to Greeks and all humankind that it exculpates him of any possible misconduct.

The hero also moves beyond the catalog of his creations to profess his innocence. In addition to his inventions, Palamedes contends that he does not merit ill treatment by situating himself as a constructive force in society: he is harmless to the elderly and

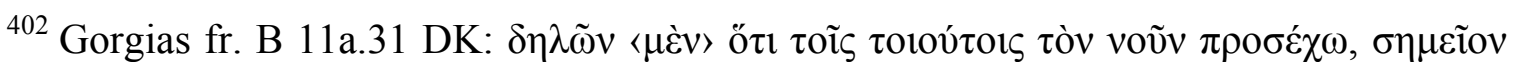

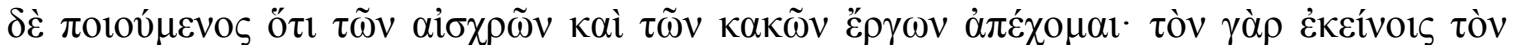

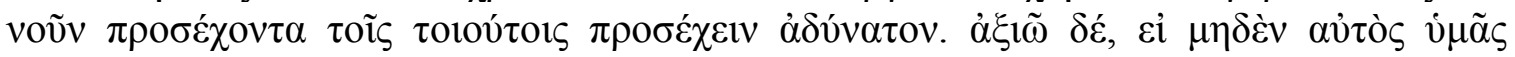

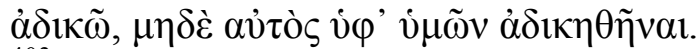

${ }^{403}$ McComiskey (2002) 49-50 notes that Gorgias here anticipates Aristotle's claim in Rhetoric 2.1.2 that a successful speaker should not only make a demonstrative and persuasive argument, but should also present himself as a certain kind of person to the judge. 
useful for the young, free of jealousy yet full of compassion, esteeming virtue above wealth, neither unprofitable in councils nor idle in battles, doing what is ordered, and obeying his commanders. ${ }^{404}$ As Palamedes enumerates his admirable qualities, his claims grow increasingly civic: he outlines his value first as an individual and then as a member of society. In other words, Palmedes asserts his personal morality, then his civic morality. The two become inextricably bound, for the hero claims that his dedication to inventions that benefit the state is a sign ( $\sigma \eta \mu \varepsilon i \tilde{o v})$ that he avoids evil deeds. As Kurke puts it, "The proof that he participates properly in the symbolic activities of war and councils, and submits to the symbolic authority of 'those in power' emerges logically from his commitment to symbolic inventions. In this sense his discoveries are doubly $\sigma \eta \mu \varepsilon \tilde{o}$ v (as Gorgias playfully signals): they are 'signifying systems' in themselves, and they signify the proper moral and political commitment to the community."

\section{Alcidamas}

Gorgias' Defense of Palamedes finds its counterpoint in Odysseus Against the Treachery of Palamedes, a constructed speech couched as forensic oratory and attributed to Alcidamas. The Odysseus is a set piece of the eponymous hero's accusation and denigration of Palamedes. The attribution of the Odysseus to Alcidamas is debated, but the fact that this text seems to respond to Gorgias' Palamedes is all the more striking

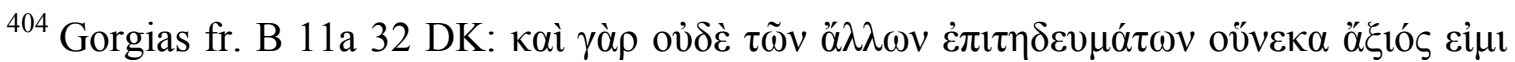

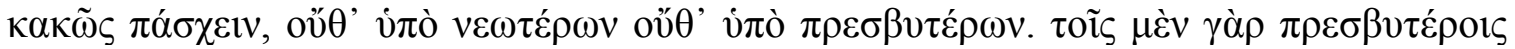

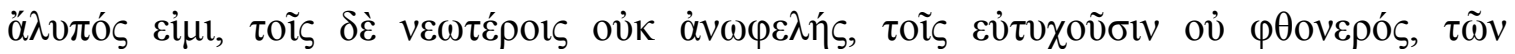

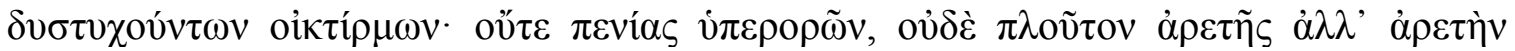

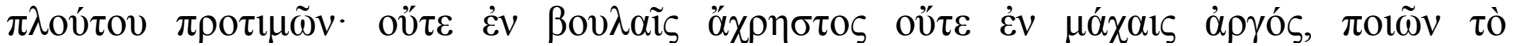

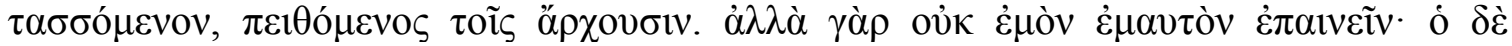

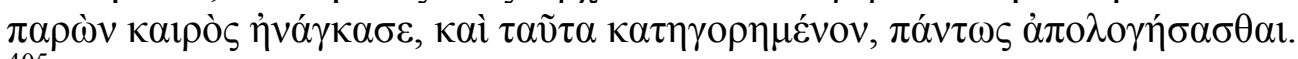

${ }^{405}$ Kurke (1999a) 252
} 
because Alcidamas was Gorgias' pupil and successor, so if the ascription is correct, Alcidamas may have been working from his mentor's framework. ${ }^{406}$ Indeed, in this speech he may be demonstrating the Gorgianic trick of being able to argue both sides of an issue. Regardless of the author's true identity, the Odysseus links Palamedes' inventions, including games, to personal and civic morality, but does so to condemn their discoverer rather than exonerate him.

As his final argument, Odysseus disputes Palamedes' role as both an inventor and as a profitable member of society. Odysseus inveighs against the other hero for his shameless deception in claiming certain creations as his own: ${ }^{407}$

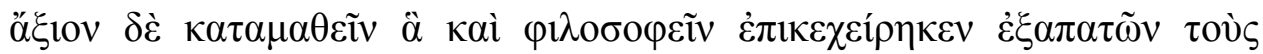

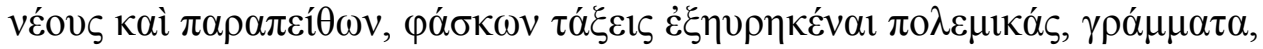

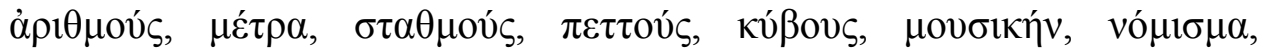

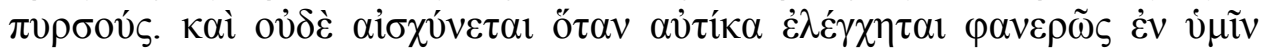
$\psi \varepsilon v \delta$ ó $\mu \varepsilon v o \zeta$.

It is worth examining closely in just what matters he tried to contrive, deceiving the young and beguiling them, claiming to have invented battle lines for war, writing, number, measures, weights, pessoi, dice, music, coinage, fire signals. And he is not even ashamed when it is immediately proven that he is clearly lying to you.

This list of discoveries is remarkably similar to the catalog Gorgias' Palamedes presents, but with two key differences: written laws do not appear here, while dice, music, and coinage have been added. Dice are particularly salient to the present discussion: unlike pessoi, dice imply gambling, a particular sticking point. Odysseus then progressively dismantles Palamedes' role as an originator by remarking that other people in fact

${ }^{406}$ For an overview of the arguments for and against the authenticity of the speech's attribution to Alcidamas, see O'Sullivan (2008) 638-647, who adds a fresh linguistic consideration to the discussion. For Alcidamas as the author responding to his teacher's defense of Palamedes, see Edwards (2007) 49-51.

${ }^{407}$ Alcidamas, Odysseus 22 
developed many of the inventions Palamedes claims. ${ }^{408}$

By casting into doubt Palamedes' association with these communally useful inventions, Odysseus calls into question the other hero's personal and civic morality. First, Palamedes' personal morality is suspect because he has purportedly lied and claimed credit for the work of others. Second, his civic morality is dubious precisely because these inventions are beneficial for society: if he is not their true creator, then his claim to being a benefactor to the community is invalid.

Odysseus continues his condemnation by disputing the uses of the inventions he leaves as genuinely Palamedean, arguing that they are detriments to society: ${ }^{409}$

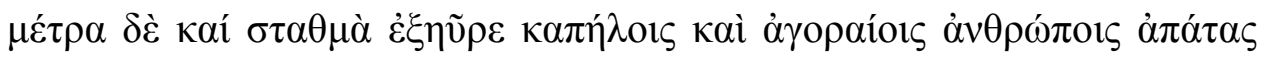

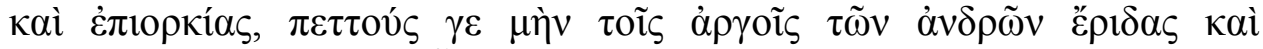

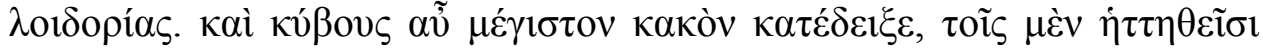

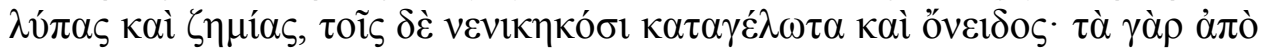

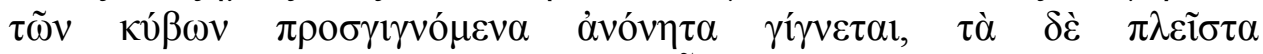

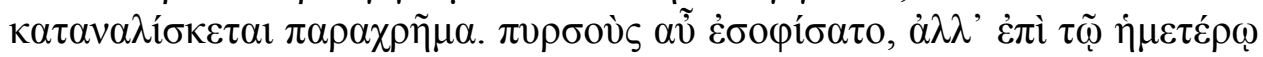

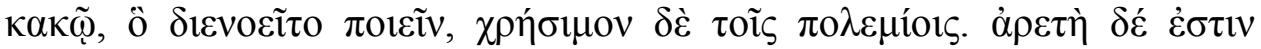

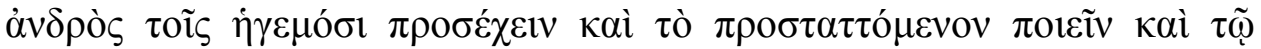

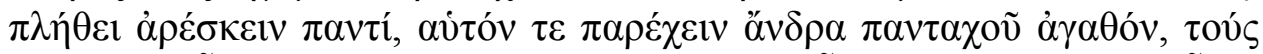

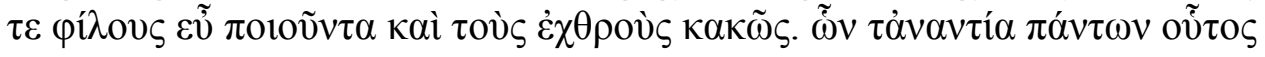

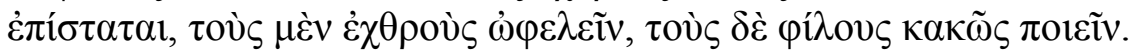

He invented measures and weights as tricks and perjuries for hucksters and men in the market, pessoi as disputes and abuses for the idle of our men. And moreover, he invented dice, a very great evil, on the one hand grief and damage for the losers, on the other hand derision and rebuke for the winners. For the profits accrued from dice are useless, and in fact most are wasted on the spot. Furthermore, he cleverly devised fire signals, but with evil for us, as he intended to make it, and as something useful for our enemies. But the virtue of a man is to give heed to the leaders and to do what is ordered and to please the whole population, to show himself an

${ }^{408}$ Odysseus states that battle lines were already used by Nestor and Menestheus in the generations before Palamedes (23); writing was brought forth by Orpheus, who learned it from the Muses (24); music by Linus, the son of Calliope (25); number by Musaeus the Athenian (25); and coinage by the Phoenicians, the most erudite and powerful of the barbarians (26).

${ }^{409}$ Alcidamas, Odysseus 27-28 
altogether good man, treating his friends well and his enemies badly. This man knows the opposites of all these things: he knows how to aid his enemies and how to treat his friends badly.

Alcidamas' Odysseus recasts Palamedes' discoveries as societal ills in a way reminiscent of the opposing hero's defense speech in Gorgias: the delivery method of listing inventions and their uses remains identical, but Odysseus has altered the purpose of each creation from help to harm. Moreover, echoes of the Gorgian Palamedes' description of his own moral character abound in Odysseus' definition of virtue, but Odysseus inverts the intent to argue it is exactly what Palamedes is not, rather than what he is. ${ }^{410}$ The reversals in this speech mark it as a rhetorical exercise, not a record of normative belief, but this chapter's concern is the contestation of games' moral value as portrayed in literary sources, not a reconstruction of actual Athenian standards, which, like these speeches, comprised competing views.

Games occupy the central position of Odysseus' excoriation. His claim that pessoi leads to disputes and abuses among idlers is a far cry from Palamedes' that it structures leisure time in an innocuous way. Moreover, it undercuts the idea that pessoi occupies a liminal space between good and bad, between work and idling. Alcidamas instead places pessoi back into a binary system, rather than the ternary one outlined above. By associating pessoi with idlers, the orator situates it in opposition to work, i.e. doing something good, and marks it as a destructive activity; this point is made all the clearer by his claim that pessoi only leads to disputes and abuses. There is a certain sense of dramatic irony here, since during Odysseus' long nostos, his wife's suitors will idle

${ }^{410}$ Kurke (1999a) 253 pushes the symbolic nature of Palamedes' inventions even further: "In his assertion of what man's aretē ought to be, the speaker [of the Odysseus] echoes almost exactly the language of Gorgias's Palamedes, exposing thereby the effort required to disengage this string of semiotic inventions from the symbolic order of the polis." 
around his home playing pessoi.

The Ithacan hero reserves his harshest criticism for dice, which he calls a very great evil. Dice bring nothing but sorrow: the losers face forfeitures and concomitant sadness, while the winners meet only mockery and reproach from the rest of the community, as Odysseus himself is demonstrating. Even the profits from dice games are without utility, so he claims, not least because most of them are lost immediately as play continues. ${ }^{411}$ In this line of reasoning, while neither kind of game is applauded, dice are far more destructive than pessoi. Alcidamas' Odysseus highlights the central divide: he assumes dice games are played with stakes, while he makes no mention of exchanging money or goods in conjunction with pessoi. His utmost condemnation, then, in fact lies not with the games themselves, but with gambling, which games of chance facilitate.

The intersection of games and morality takes a new turn in Alcidamas. While his Odysseus character censures both kinds of games he mentions, that is, both games of skill and games of chance, the vehemence of his reproach is far greater concerning dice, the root cause being the unprofitable exchanges inherent to the gambling assumed to take place with such games. Links between games of chance and gambling continue throughout Greek literature and come to dominate much of the discourse concerning games and morality, while games not explicitly tied to financial exchanges, such as pessoi, hold a more malleable position.

\footnotetext{
${ }^{411}$ On this point, see Callistratus' nearly contemporary speech to the Spartans in 371 BCE. Xenophon, Hellenica 6.3.16-17: "Indeed I do not approve of those gamblers who, if they are lucky once, gamble for double the stakes, for I see the majority of them

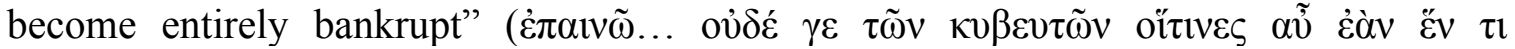

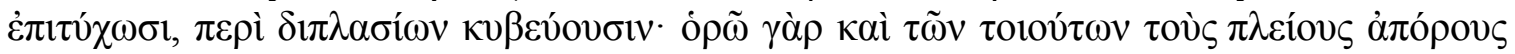

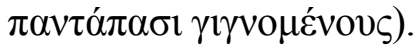




\section{Isocrates}

Like Alcidamas, his contemporary and fellow student of Gorgias, the rhetorician Isocrates denounces games. Also like his fellow orator, he draws a sharp divide between playing games generally and gambling, showing far greater disdain for the latter. Gambling is one of a number of interrelated vices Isocrates claims are rampant in Athens, sources of corruption he directs his students to avoid, as their ancestors did.

Isocrates probably wrote his speech Areopagiticus in the wake of the Social War, which ended in 355 BCE. ${ }^{412}$ In this speech, the orator notes that the Athenians' ancestors cared for the education of the young, something for which he claims his contemporaries have no concern. He says that Athenians of bygone days were concerned with the morality of the polis and therefore compelled the young to adopt occupations and pursuits fitting their circumstances: they filled the needier citizens' time with farming and trade, eliminating the idleness that they saw as the root of wickedness, and they directed those of sufficient means toward pastimes they believed would enable some to achieve excellence, while allowing others at least to abstain from most vices. ${ }^{413}$ The Athenians then cultivated the behavior of the youths, both by punishing those who did wrong and by keeping careful watch, thereby predicting those likely to go astray and taking appropriate action. $^{414}$ The result was a citizenry of moral caliber far superior to that of Isocrates' day: ${ }^{415}$

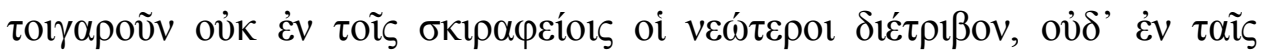

\footnotetext{
412 Norlin (1929) 100

${ }^{413}$ Isocrates, Discourses 7: Areopagiticus 44-45. The pursuits toward which the earlier Athenians pushed the well-off youths were horsemanship, athletics, hunting, and philosophy.

${ }^{414}$ Isocrates, Discourses 7: Areopagiticus 46-47

${ }^{415}$ Isocrates, Discourses 7: Areopagiticus 48-49
} 


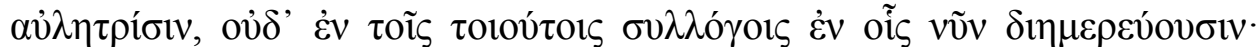

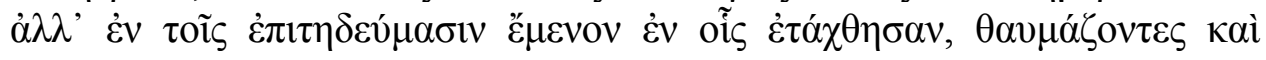

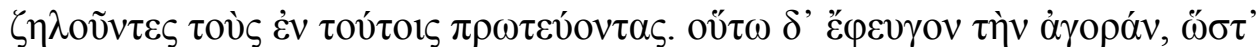

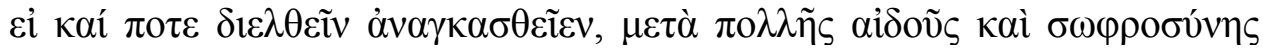

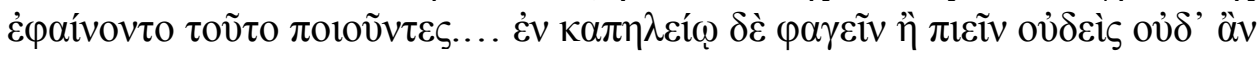

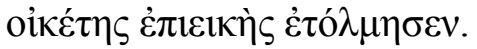

Therefore the young men did not waste their time in the gambling-houses, nor with the flute-girls, nor in the kind of assemblies in which they now pass their days; but they remained in the pursuits they were assigned, admiring and emulating those men who were the best at them. And they avoided the marketplace to such an extent that when they were forced to pass through it, they were seen doing it with great sobriety and discretion.... No one, not even a reasonable household slave, would dare to eat or drink in a tavern.

Isocrates is explicit about what constitutes proper behavior: the youths of an earlier, better Athens shunned gambling-houses, flute-girls, and drinking in taverns, as well as parties and the marketplace. The orator observes three specific vices that earlier Athenians avoided by naming how one might engage in such behaviors: gambling occurs at gambling-houses, flute-girls provide sex, and taverns allow for drinking. ${ }^{416}$ Notably, Isocrates does not denigrate games, sex, or drinking themselves here, but rather the commercialized versions of these activities: gambling, fornication, and consumption. He likewise condemns the public arena, especially the marketplace, for the ready access it provides to these vices.

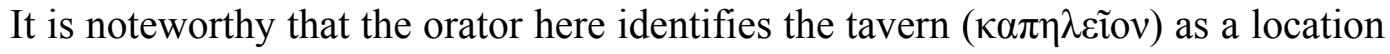
of immorality, as Alcidamas' Odysseus claims that Palamedes invented weights and

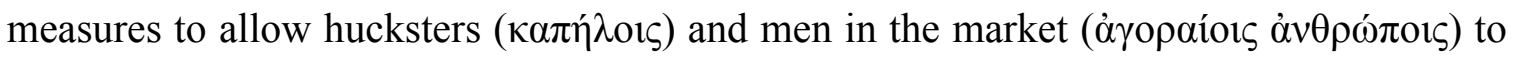
commit fraud: the former of these indicates any sort of deceitful retailer, but especially a

\footnotetext{
${ }^{416}$ The flute-girls are linked to sex because of the implication that they are also prostitutes. For flute-girls as prostitutes in Greek literature, see Davidson (1997) 81-82, 92-93, 95-96, 124; Hamel (2003) 7-13.
} 
tavern-keeper, that is, the very person who operates an establishment that Isocrates labels inherently iniquitous. ${ }^{417}$ In remarking upon the morality of an earlier Athens, the orator also implies that contemporary youths behave worse than a reasonable slave of bygone days. Isocrates returns to these behaviors and this comparison in a later, more famous speech: the Antidosis.

Isocrates says that he wrote the Antidosis when he was eighty-two years old, meaning 354-353 BCE. ${ }^{418}$ In the Antidosis, written as a courtroom speech, Isocrates declares that his accusers and the jurors have driven the Athenian youths away from appropriate pursuits, such as proper governance of their households and of the city. In his lament for Athens' current state of affairs, he marks a moral distinction between games and gambling, as well as their associated activities: ${ }^{419}$

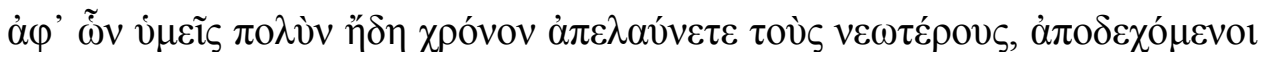

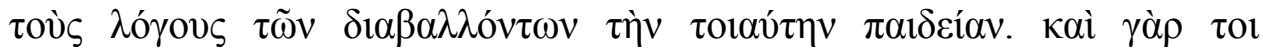

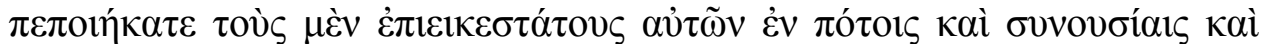

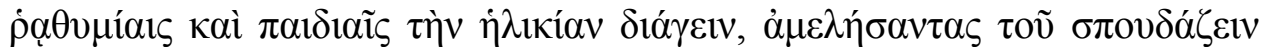

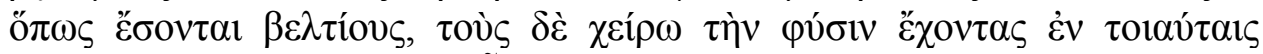

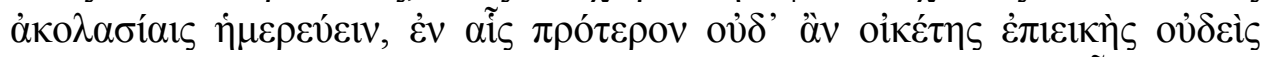

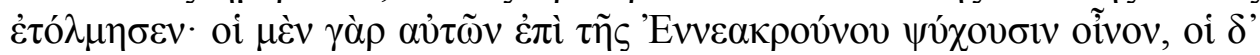

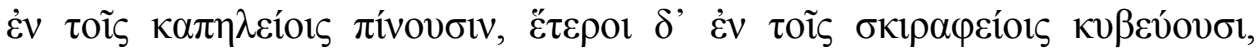

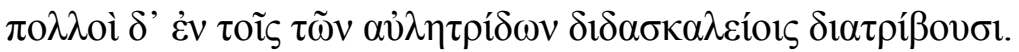

You have driven the young men away from these [worthy] pursuits for a long time already, accepting the words of those who denounce such an education. For you have actually caused the most virtuous of them to spend their youth in drinking bouts and parties and laziness and games, neglecting earnestness about how they will be better men, while those who have a worse nature spend the day in such great licentiousness, in which not even a reasonable household slave in the old days would have dared occupied himself. For some of them cool their wine at the Nine Spouts fountain, some drink in taverns, others gamble in the gambling-houses, and many

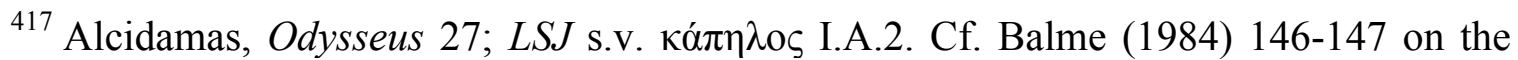
perennial bad reputation of kapeloi for cheating their customers.

${ }^{418}$ Norlin (1929) 183. Isocrates mentions his own age in section 9.

${ }^{419}$ Isocrates, Discourses 15: Antidosis 286-287 
pass their time around the schools of the flute-girls.

This speech shares many elements with the Areopagiticus of just a year or two earlier, including the pursuits of the young men. Isocrates criticizes the depravity of contemporary youths and those who have allowed Athens to fall into such a condition. The latter spurn a proper education $(\pi \alpha 1 \delta \varepsilon i ́ \alpha v)$ and, consequently, the young men in their

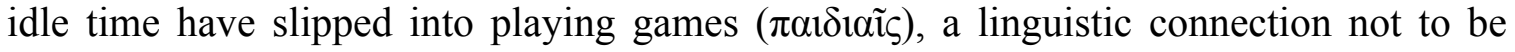
missed. ${ }^{420}$ Isocrates divides the young men into two categories and comments that even the most virtuous among them have fallen into wantonness, wasting their youth in drinking, partying, relaxation, and games. The second sort, those of a worse nature, spend their days in remarkably similar activities, as they too drink, play games, and loiter.

As earlier scholarship has noted, the second, worse class of youths adds a monetary element and moves its behavior from its proper, private location of the symposium to the public domain: instead of simply drinking, these young men drink in taverns; rather than playing games, they gamble; instead of just idling, they lounge around the schools for flute-girls. ${ }^{421}$ In addition, a sexual component exists for the last of these criticisms, as the flute-girls are likely also prostitutes. ${ }^{422}$ In that event, the worse young men are seeking to pay for sex, further proof of the mercantile nature of their activities. This understanding also gives a new sense to the actions of the better youths. They spend their time in ouvovoíars, a word that means "parties," as translated above, but

\footnotetext{
${ }^{420}$ Ober (1998) 275 observes that the proper education to which Isocrates refers, one that allows for wise governance of both one's house and the city at large, is exactly the sort of education Isocrates himself offered to his students.

${ }^{421}$ Kurke (1999a) 285; Kurke (2002) 36-37

422 Too (2008) 229. See also the note above on flute-girls as prostitutes in Greek literature.
} 
more generally denotes any kind of intercourse: social, verbal, or sexual. ${ }^{423}$ The implication may be that the better young men engage in sex at their parties, while the worse sort skulk around prostitutes and look to purchase it, offering one more parallel to the behaviors of the two classes of youths. This parallel, moreover, makes the vice trio equally applicable to both grades of young men: the better youths engage in games, sex, and drinking, the worse in gambling, fornication, and consumption; the venues and expenditures are the only differences between their actions.

In this passage, Isocrates repeats and expands his claim in the Areopagiticus that contemporary youths behave worse than a reasonable household slave of days past. In the earlier speech, the orator states that such a slave would not have been caught drinking in a tavern, implying that the youths of his day do exactly that; he also notes that the young men of an earlier era did not waste their time with gambling-houses or flute-girls, with the same insinuation that this is no longer the case for contemporary youngsters. In the Antidosis, on the other hand, Isocrates unambiguously charges the worse sort of youths with a series of licentious transgressions, including drinking in a tavern, gambling in gambling-houses, and loitering around flute-girls, all of which a decent slave in the old days would have avoided. Through their behavior, these young men prove themselves morally inferior to a slave, but the comparison holds another point: their lack of restraint marks them as slaves to their dissipated lifestyle, showing that they have less control over their own lives than an actual slave. ${ }^{424}$

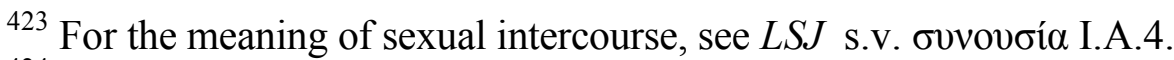

${ }^{424}$ Cf. Kurke (1999a) 285-286 and Kurke (2002) 37: "The unfavorable comparison of the worse sort of young men to the 'self-respecting house slave' is not fortuitous: Isocrates implies that in their addiction to the pleasures of drinking, dicing, and ogling girls, these youths have relinquished the self-control and autonomy that make them free men." 


\section{Aeschines}

The orator Aeschines, a younger contemporary of Isocrates, also connects games to morality through gambling, which he likewise links to the vices of fornication and consumption. Furthermore, he speaks of actual enslavement to vice. All these elements fuse in his prosecution of Timarchus, which occurred in 346-345 BCE, less than a decade after Isocrates' Areopagiticus and Antidosis. ${ }^{425}$ The speech Against Timarchus provides an abundance of evidence and warrants sustained investigation.

Aeschines launches a double attack on his foe, alleging that he prostituted himself to other men and squandered his patrimony. ${ }^{426}$ These two formal charges are not concerned with illegal actions per se, but rather with supplying evidence of disgraceful living that disqualifies Timarchus from public life; the accusations are grounds for stripping Timarchus of his citizen's rights to hold public office, speak in the Assembly, and bring cases to court. ${ }^{427}$ Like prostitution and wasting one's inheritance, gambling is not illegal, but it is crucial to proving that Timarchus lived disgracefully and deserves

\footnotetext{
${ }^{425}$ For the date of the trial, see Fisher (2001) 6-8 with bibliography.

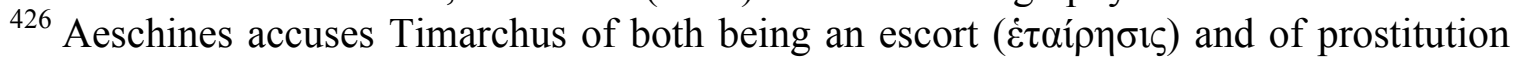

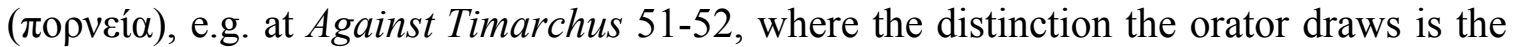
number of sexual partners. The precise difference exceeds the bounds of the present discussion. For ease of language, I use "prostitution" to refer to both accusations, as Aeschines himself uses the terms nearly indiscriminately.

${ }^{427}$ For detailed background on the charges and their intersection with the law, morality, and public life, see Fisher (2001) 5-6 and 36-67. According to Aeschines, Against Timarchus 29-31, the chief concerns are that someone who sells his body will freely sell the common interests of the city and that someone who mismanages his own property will likewise mismanage the affairs of the city. Aeschines notes (28-29) that the same law gives two other cases for disgraceful living: mistreatment parents, since someone who abuses even his parents will abuse others in the city, and military evasion or cowardice, as someone who fails to defend the city has no right to advise it.
} 
disenfranchisement. ${ }^{428}$ Aeschines portrays gambling, along with fornication and consumption, as a vice that enslaves Timarchus and prompted so many of the behaviors for which he is now under suit: he prostituted himself and squandered his patrimony in pursuit of his debauched lifestyle, including his passion for gambling.

Aeschines presents a series of Timarchus' lovers, with each of whom the defendant became more entrenched in vice. ${ }^{429}$ According to the Athenian orator, as soon as Timarchus was past childhood, he moved in with a physician at the Piraeus, supposedly to study medicine, but in reality to prostitute himself whenever possible, accumulating a client list of merchants, other foreigners, and even Athenian citizens, all of whose names the orator declines to give. ${ }^{430} \mathrm{~A}$ certain Misgolas, reputable in all ways except his mania for young, male musicians, learned the truth and paid Timarchus to move in with him, a perfect match for each of their desires. ${ }^{431}$ According to Aechines, Timarchus eagerly accepted the offer: ${ }^{432}$

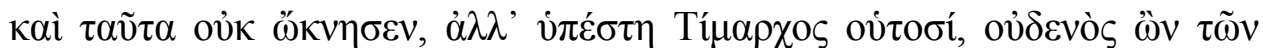

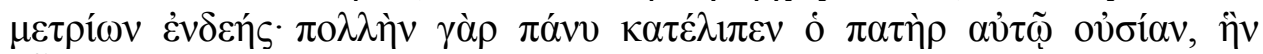

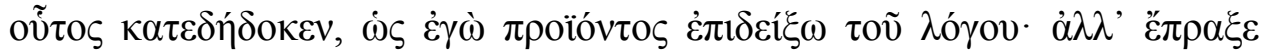

\footnotetext{
${ }^{428}$ Cf. Lysias, Against Alcibiades 1 27, where, in a case to disenfranchise Alcibiades for dereliction of military duty, the prosecutor notes that the defendant gambled away his patrimony, a second ground for stripping away citizen's rights. See de Brauw (2001) 170174 for an analysis of the juxtaposition of laws and personal character-nomoi and tropoi - in Greek oratory, including this speech.

${ }^{429}$ Worman (2018) 428-429 comments that at points in his speeches when Aeschines focuses on character assassination most concertedly, his characterization focuses especially on the body in performance.

${ }^{430}$ Aeschines, Against Timarchus 40

431 Aeschines, Against Timarchus 41-42. Davidson (2007) 563-564 notes that Aeschines describes Timarchus' sexual proclivities, in stark contrast to Misgolas', as entirely heterosexual; Timarchus' enthusiasm is not for the acts he will gladly let Misgolas do to him, but rather for the concomitant financial rewards, which he can used to fund his debauched lifestyle.

${ }^{432}$ Aeschines, Against Timarchus 42. See Davidson (1993) 64-66 for parallels between this passage and fish-consumers in Greek comedy.
} 


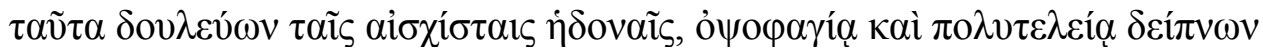

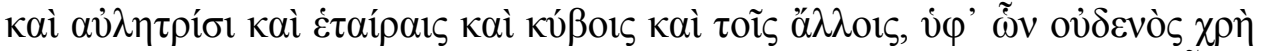

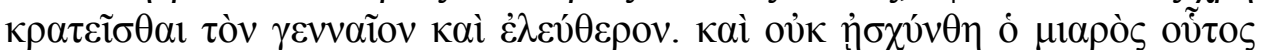

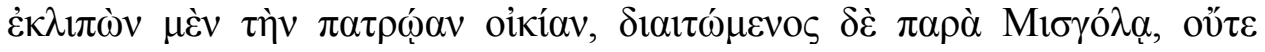

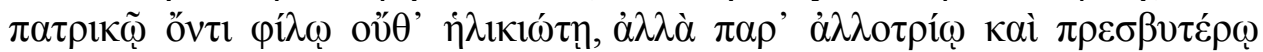

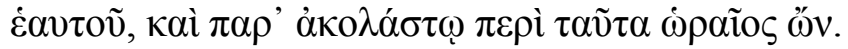

And Timarchus did not shrink from these things, but rather he consented to them, though he lacked nothing within reason; for his father left for him an altogether large property, which he squandered, as I will show as I move forward in my speech. But he did these things because he was enslaved to the most shameful pleasures, to dainty living and to extravagance at his dinners and to flute-girls and to courtesans and to dice and to those other things by not one of which a noble-born and free man ought to be ruled. And this rogue was not ashamed that he deserted his father's home, living with Misgolas, who was neither a friend of his father nor a man of his own age, but a stranger and someone older than himself, and licentious in such matters, while Timarchus himself was in the bloom of youth.

Aeschines accuses Timarchus of pursuing the same shameful pleasures as Isocrates laments the young men of Athens, perhaps even including Timarchus, do: frittering away their money on consumption, fornication, and gambling. Timarchus' profligacy at the table includes both food and drink, as a later section makes clear. ${ }^{433}$ There is also a perverse irony in the fact that Timarchus sells his own body because of his passion for sleeping with prostitutes. Moreover, it is clear that Aeschines inextricably links dice with gambling because he associates them with the squandering of an inheritance, intimating wagers that Timarchus loses. ${ }^{434}$

${ }^{433}$ Aeschines, Against Timarchus 96: "Then he turned to devouring his patrimony. And he not only ate it up, but, if it is possible to say this kind of thing, he drank it up too"

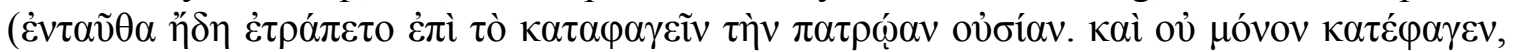

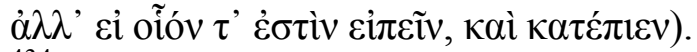

${ }^{434}$ The only other way the dice could lead to financial loss is if participants gave a sort of entry fee for each game and played without stakes, a pay-to-play transaction notionally on par with prostitution. I have found no evidence to support such a practice in antiquity, but rather any finances linked to the games were wagers one hoped to recoup with profit through winning. 
Timarchus is deeply entrenched in the three interconnected vices and surpasses even the worse kind of youths Isocrates bemoans. He ravages his own finances through both eating and drinking, each of which Isocrates laments, though he focuses on the latter. Timarchus also participates on each end of the prostitution spectrum, both providing and purchasing sex. Additionally, he lusts after both flute-girls and courtesans, showing a desire for both common and elite prostitutes. ${ }^{435}$ Gambling is perhaps the worst offense of all, as money is lost with nothing in return save, perhaps, the thrill of the game and short-lived hopes of victory. Timarchus' passions are so great that he devours his income and sizable patrimony, exceeding the sins of Isocrates' youths both in expenditure and in the magnitude of his depravity.

In his misbehavior, Timarchus surpasses not only other debauched youths, but also slaves. Aeschines is explicit that Timarchus conducts himself so shamefully because

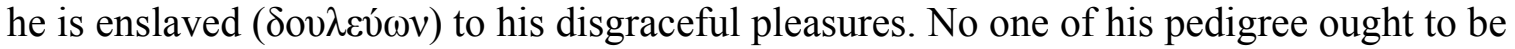
controlled by such iniquities ( Isocrates gripes that the young men of his time are worse than an honest slave of bygone days in their behavior, Aeschines asserts that Timarchus' conduct actually makes him a slave, as he is subservient to his own depravity. In this way, Timarchus is not just a slave, but also a bad one, for he lives in servitude to behaviors that even a reasonable slave avoids.

\footnotetext{
${ }^{435}$ Although flute-girls attended symposia and cost more than pornae, they remained low-class prostitutes. See Davidson (1997) 80-82: "Although a few among them rose to the highest ranks of the courtesans, it seems quite clear that the flute-girls were always considered among the cheapest and most despised of hired women" (quote from 82). Cf. Hamel (2003) 7-13. For differences in price, see Davidson (1997) 237 et passim; Cohen (2015) 162-171. For the continuum of prostitution from pornae to hetaerae, with aulètrides somewhere between them, see Davidson (1997) 73-108; Hamel (2003) 4-13.
} 
Despite whatever pleasures Timarchus afforded, Misgolas could not afford him and consequently dismissed him, after which time he lived with a man named Anticles, who subsequently moved to Samos as a member of a new colony there. ${ }^{436}$ At this time, Timarchus devoted his attention all the more to gambling: ${ }^{437}$

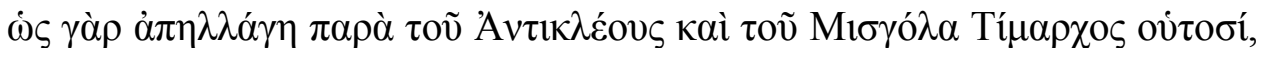

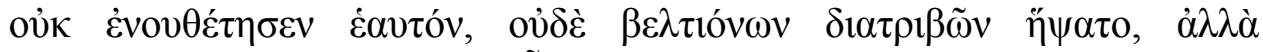

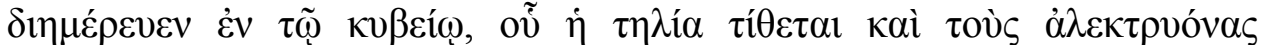

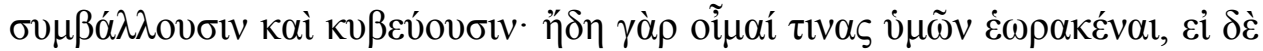
$\mu \eta \dot{\alpha}, \dot{\alpha} \lambda \lambda^{\prime} \dot{\alpha} \kappa \eta \kappa о \varepsilon ́ v \alpha 1 ~ \gamma \varepsilon$.

For after this same Timarchus departed from Anticles and from Misgolas, he did not take a hard look at himself, nor did he engage in better pastimes, but instead spent his days in the gaming-house, where the table is set and men throw gamecocks together in combat and gamble; I think some of you have already seen it, and if not, you have at least heard of it.

Aeschines localizes Timarchus' misbehavior in the same way Isocrates does for the worse sort of youths: placing the events in the public domain marks them as unseemly. Aeschines is even more specific than his predecessor, however, and pinpoints a single gambling establishment. The place is ostensibly an infamous one at that, as he presumes his audience members have heard of it, if not seen it themselves.

This passage also helps clarify the status Aeschines gives to gambling in contemporary Athens, as a conceit of the genre is that the orator's words would fall on deaf ears if he were not appealing to a shared, societal belief. ${ }^{438}$ Aeschines implies that Timarchus should at this time have admonished himself, suggesting that the latter man was well aware of the communal standards of conduct and the fact that he was defying them. Logically following his lack of introspection, Timarchus did not take the

${ }^{436}$ Aeschines, Against Timarchus 53

437 Aeschines, Against Timarchus 53

${ }^{438}$ On this point, see the Introduction to this chapter. 
opportunity to reform after a second lover left him, but rather entrenched himself in gambling even more deeply, eschewing better pursuits. Aeschines' claims assume shared values, the very tenets Timarchus transgressed, including the poor valuation of gambling relative to other endeavors. It is important to note here that although gambling falls outside the expressed norms of acceptable behavior, one cannot presume that actual practice conforms to this communal censure of gambling; members of the community clearly violate this principle, as the gaming-house would otherwise have no clientele. ${ }^{439}$

Perhaps unsurprisingly, the infamous gaming-house where Timarchus spent his days afforded him contact with other debauched individuals. One such character appears in the very next section and helps flesh out Timarchus' views on morality: ${ }^{440}$

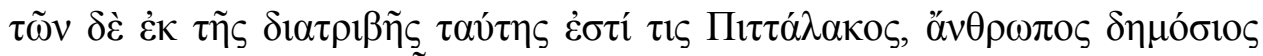

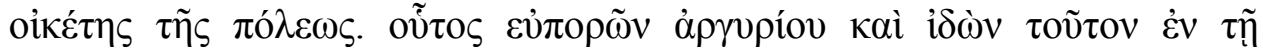

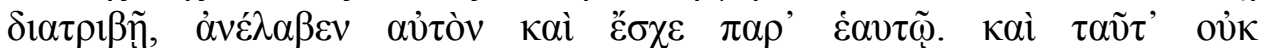

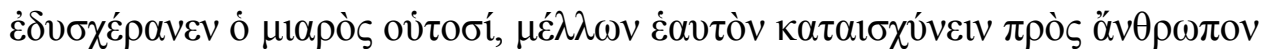

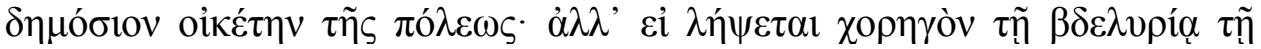

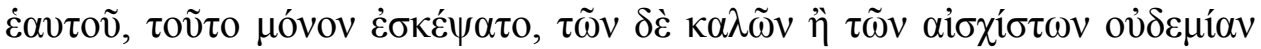

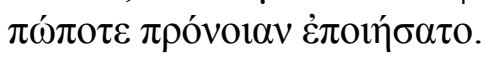

One of those in this business is a certain Pittalacus, a man belonging to the people, a slave of the city. He was well supplied with money and, seeing Timarchus in that business, took him and kept him at his own home. And this foul wretch here felt no qualms about it, that he was going to dishonor himself with a public man, a slave of the city; but whether he was going to receive a financier for his debauchery, he considered that alone, and he never had a single thought about what is good or what is most shameful.

Although the exact connection between the two men is uncertain, it is clear that Timarchus met Pittalacus through gambling. The word $\delta \iota \alpha \rho \imath \beta \eta$, translated as "business" above, can mean either a specific leisure pursuit or the location for that activity, so the men

${ }^{439}$ Cf. Gusfield (1967) 179: "Standards...may be dishonored every day yet remain important statements of what is publicly approved as virtue."

${ }^{440}$ Aeschines, Against Timarchus 54 
encountered one another either in the aforementioned gaming-house or gambling elsewhere. ${ }^{441}$ According to Aeschines, Timarchus' only concern is funding his depravity: he does not care about morals or propriety as long as he can continue serving his passions, that is, achieving self-gratification through his pursuits. Since Pittalacus appears to operate a gambling establishment, discussed below, the two men seem to be a perfect pair. Aeschines dares not go into detail about the sordid acts Pittalacus and Timarchus perform. ${ }^{442}$ While this evasion implies sexual degeneracy, Pittalacus is more important for present purposes for what happens to him than what he himself does.

As Aeschines explains, the seemingly ideal match did not last, as Timarchus found a better offer. ${ }^{443} \mathrm{~A}$ man named Hegesandrus returned from the Hellespont after serving as treasurer for the general Timomachus, flush with embezzled wealth, and

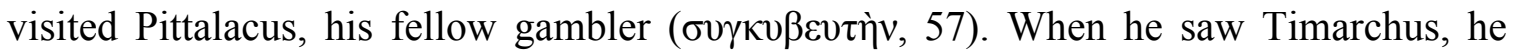
lusted after him and asked Pittalacus to let him take Timarchus home. After Pittalacus refused, Hegesandrus asked Timarchus directly, who was instantly persuaded to move on to a more affluent lover. Pittalacus, enraged to have wasted so much money on Timarchus, kept visiting Hegesandrus' house and became a nuisance. Hegesandrus and Timarchus responded harshly: ${ }^{44}$

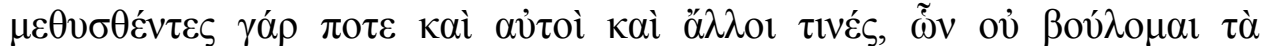

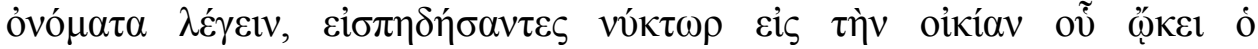

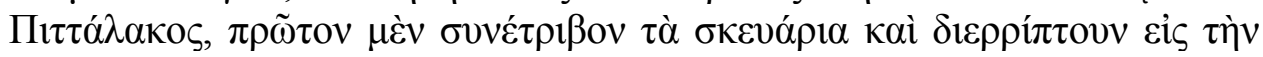

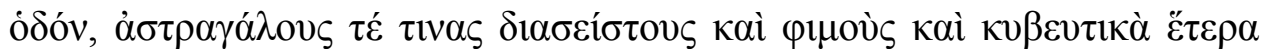

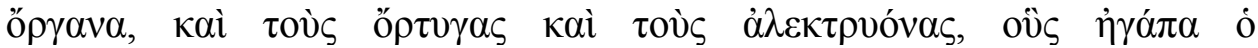

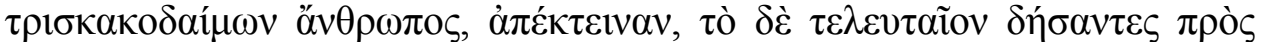

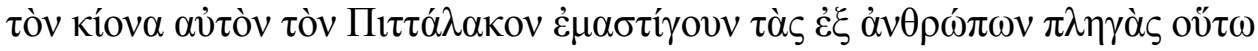

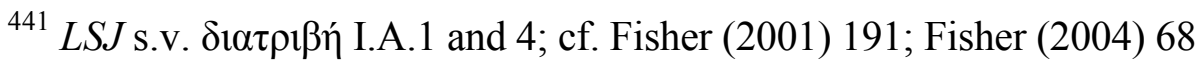

${ }^{442}$ Aeschines, Against Timarchus 55

${ }^{443}$ Aeschines, Against Timarchus 55-58

${ }^{444}$ Aeschines, Against Timarchus 58-59 


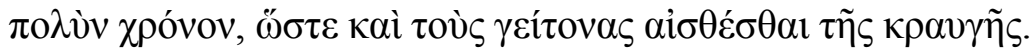

One night when they were drunk, they and some others, whose names I do not wish to say, burst into the house where Pittalacus was living. First they shattered his gaming equipment and threw it into the street, certain shaken knucklebones and dice-boxes and other gambling tools, and the quails and gamecocks, which that thrice-unlucky man prized, they killed, and finally they tied Pittalacus himself to a pillar and flogged him with the worst whippings in the world for such a long time that even the neighbors heard the shouting.

This passage reveals more of Timarchus' personality. In addition to having no concern for propriety or personal morality, as seen above, Aeschines here shows Timarchus transgress in a new way entirely. Fueled by his excessive drinking, Timarchus savagely beat his former lover for the crime of being angry that he was spurned, which is, of course, not legally a crime at all. Timarchus' morality is even more suspect than it was before, as his violent tendencies have been exposed.

This passage also shows that Pittalacus may have operated a gambling establishment. He met Timarchus through gambling and Aeschines describes him as a man who spends his time in that business (54). Hegesandrus, his fellow gambler, visited Pittalacus' house after returning to Athens flush with cash (57), likely looking to gamble. ${ }^{445}$ The present passage also details all of the gaming equipment he kept in his home. A later passage reiterates that Hegesandrus discovered Timarchus spending his

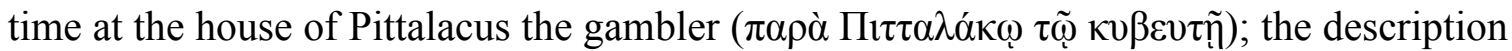
of Pittalacus only as a gambler is perhaps another indication of his profession, whereas the reference to his home may identify the location of his operation. ${ }^{446}$ While he may

\footnotetext{
${ }^{445}$ Cf. Fisher (2004) 68 n. 16

${ }^{446}$ Aeschines, Against Timarchus 68. This passage is an affidavit Aeschines proposes for Hegesandrus, to which, according to the orator, the latter man will refuse to swear and will thereby perjure himself.
} 
only have been an enthusiast, the context of Aeschines' descriptions and Pittalacus' possession of such varied ludic paraphernalia indicate that he managed or was involved in managing a gambling establishment, perhaps out of his own home. ${ }^{447}$

In addition to Timarchus' violent behavior, the trio of vices-gam(bl)ing, fornication, and consumption-is at work here: Timarchus is with his current lover, Hegesandrus, and is attacking his former lover, Pittalacus, to each of whom he prostituted himself; he has drunk to the point of intoxication; and he met both lovers through gambling. Moreover, in the description of when he and his associates destroyed all of Pittalacus' gaming equipment, there is a subtle implication of play. The scholia on the passage claim that "shaken knucklebones" is a technical term gamblers used; the knucklebones are shaken ( $\delta 1 \alpha \sigma \varepsilon i ́ \sigma \tau o u \varsigma)$ because people often fastened silver or bronze bells to them in order to produce certain sounds and enjoyment during the game. ${ }^{448}$ One commentator has proposed that listeners would understand the knucklebones to be loaded. ${ }^{449}$ Conversely, another commentator suggests that the knucklebones would be shaken vigorously before being thrown, perhaps to satisfy players that they were not loaded, as Harpocration seems to suggest. ${ }^{450}$ This last idea gets close to the point of the clever wordplay in this passage. As was suggested nearly three centuries ago, the

${ }^{447}$ Cf. Fisher (2004) 68 with bibliography. See Taylor (2015) 49-51 for an analysis of what the Pittalacus episode reveals about social mobility in Athens. She notes that gambling allowed Pittalacus a way to define his own status by acquiring economic and social resources: he is wealthy and able to attract affluent and prominent friends and lovers. His social capital fails him, however, when pitted against the wealthier and better connected Hegesandrus.

${ }_{448}$ Dindorf (1862) ad loc.; Dilts (1992) ad loc.

${ }^{449}$ Adams (1919) $51 \mathrm{n} .2$

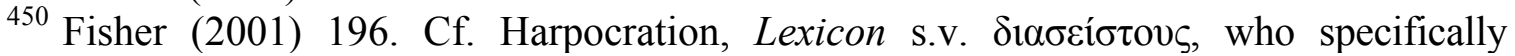
references this passage from Against Timarchus and says that players shook knucklebones

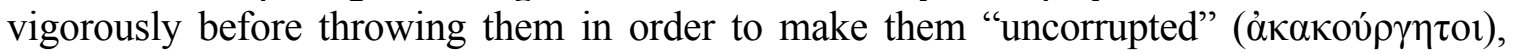
with "corrupted" presumably meaning loaded. 
knucklebones are shaken because Pittalacus' attackers had shaken them many times

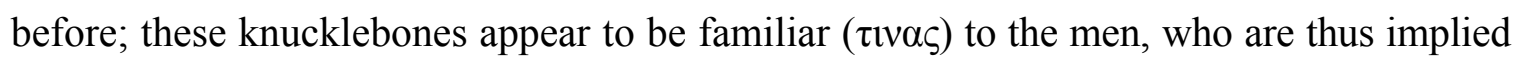
to be part of Pittalacus' clientele. ${ }^{451}$ Moreover, when the men throw the shaken knucklebones and dice-boxes into the street, Aeschines uses a compound word ( $\delta 1 \varepsilon \rho \rho i ́ \tau \tau o v v)$ that in its uncompounded form and in other compounds is frequently used of throwing knucklebones or dice, while dice-boxes are the very instruments one uses for that activity. The assailants are, in a sense, adhering to their customary pursuits: even when their purpose is destruction, these men cannot help but give one more throw, as gambling is such an integral part of their lives. Likewise, when they kill Pittalacus' fowl, these men abuse the very things they had previously used in their games: in quailtapping, people strike the birds or pull their feathers, but the birds are not expected to die; gamecocks invariably perish, but from fighting other birds, not humans. ${ }^{452}$

Further evidence that the three vices are interrelated comes when Pittalacus seeks reparations for the assault. The next day, he enters the marketplace and presents himself uncloaked, presumably to show his bruises, at the altar of the mother of the gods, where a crowd gathers. ${ }^{453}$ Hegesandrus and Timarchus fear that their foul behavior will be revealed to the whole city at the imminent meeting of the Assembly, so they and some of their

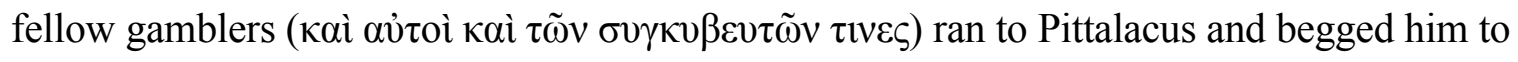
leave, saying that the whole affair was merely a drunken brawl ( $\pi \alpha \rho$ otví $\alpha)$; Timarchus even

${ }^{451}$ d'Orville (1737) 305-307, accepted by Benseler (1855) 157, though the latter cites the incorrect page number.

${ }^{452}$ For more information on the various games played using birds, see Pollux, Onomasticon 9.102 and 9.107-109. Cf. Aristophanes, Birds 1297-1299; Fisher (2001) 196. See Demosthenes, Against Conon 9 for an intriguing reversal of human an animal, where a man, after he wins a fight, crows in imitation of victorious gamecocks while his friends encourage him to bend his arms and flap them like wings.

${ }^{453}$ Aeschines, Against Timarchus 60 
took him by the chin and promised to do anything he wished. ${ }^{454}$

The same constellation of vices is as integral to the aftermath of the assault as to the attack itself. The assailants' excuse may have been a common one, as drunken violence does not seem to have been infrequent in the Greek world. ${ }^{455}$ Common or not, the inebriation and concomitant misconduct are essential components of both the crime and the perpetrators' justification of it. Timarchus' gesture, moreover, is both a common form of supplication and a sign of affection, meant to remind Pittalacus of previous intimacies, while his words ostensibly offered not just proper treatment, but also readiness to accept any sexual act, as before. ${ }^{456}$ Importantly, Hegesandrus and Timarchus were accompanied by some of their fellow gamblers. These gamblers seem to have been the other men involved in the attack: they are first described as certain others with Hegesandrus and

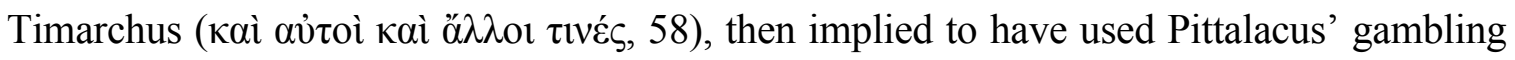

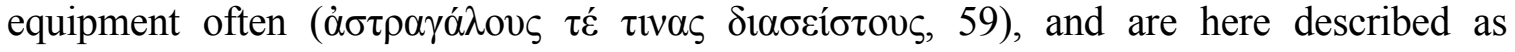

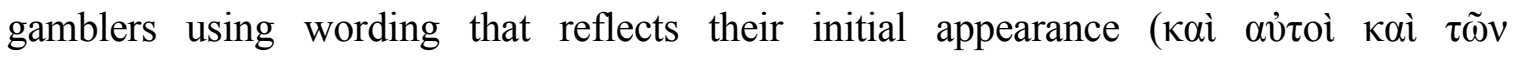
$\sigma v \gamma \kappa v \beta \varepsilon v \tau \tilde{\omega} v \tau \imath v \varepsilon \varsigma, 60)$. If these were in fact the same men, they would have had good reason to try to persuade Pittalacus not to publicize the events of the previous night, for they would be protecting themselves as well as their companions Hegesandrus and

\footnotetext{
${ }^{454}$ Aeschines, Against Timarchus 60-61

${ }^{455}$ Fisher (2001) 198-199: "That the Greeks had words meaning something like 'be offensively drunk' (paroinein)' [sic], 'drunken misbehaviour' (paroinia) and that it nearly always indicates drunken fighting, suggests a ready acknowledgement of the pervasiveness of the phenomenon." Defense speeches against allegations of assault often claimed that the incident was insignificant, e.g. Lysias, Against Simon 43; On a Wound by Premeditation 19; Against Tisis fr. 279 Carey; Demosthenes, Against Conon 14.

${ }^{456}$ Fisher (2001) 199
} 
Timarchus. ${ }^{457}$ Each of the vices is echoed: the perpetrators call their drunken assault merely a drunken brawl, Timarchus attempts to sway his former lover by offering future sexual services, and the men who destroyed Pittalacus' gambling equipment are now explicitly named as gamblers.

Aeschines conveniently summarizes each of the charges - prostitution and squandering one's patrimony-later in the speech. He claims that Timarchus' prostitution is the only logical conclusion from the evidence. He says that when a handsome young man spends his nights in others people's houses, enjoys expensive dinners without contributing to them, keeps extremely expensive flute-girls and courtesans, gambles, and pays for nothing himself, but another man bankrolls everything, then no divination is required to see that the young man is affording "certain pleasures"- to use Aeschines' own, admittedly euphemistic language - for his financiers. ${ }^{458}$ Moreover, once Hegesandrus' funds, including those from his marriage to an heiress, were gambled away, eaten up, or otherwise squandered, Timarchus had lost his youthful charm and, accordingly, his ability to obtain new lovers to sponsor his lifestyle. He craved the same pleasures as always, however, and funded his daily habits by selling his sizable patrimony, ignoring each property's value and hawking it for what it would fetch on the spot, so great was his haste for gratification. ${ }^{459}$ One should note that Timarchus is so debauched that he squanders not only his own inheritance, but Hegesandrus' wife's as well.

Regardless of what actually transpired, Aeschines' portrayal of the events informs

${ }^{457}$ Cf. Fisher (2001) 198, who believes the detail that Hegesandrus and Timarchus are accompanied by their fellow gamblers "is meant to increase the impression of the perpetrators as a co-ordinated gang of dissolute characters."

${ }^{458}$ Aeschines, Against Timarchus 75-76

${ }^{459}$ Aeschines, Against Timarchus 95-96 
our understanding of the public view of gambling. In describing Timarchus' behavior as aberrant, the orator is appealing to common standards of virtue and deviance; these codes, even if they differ from daily practice, remain examples of what is publicly construed as proper and improper conduct. Gambling is at the forefront of Aeschines' grievances: it is one of a trio of vices that controls Timarchus' life and is the reason he squandered his patrimony; Timarchus wasted both his youth and his inheritance gambling and leading an altogether dissolute lifestyle. Like so many wagers before, Timarchus lost the case and was imposed with total disenfranchisement.

\section{Lysias}

The Greek orators' outspoken condemnation of games, particularly their denunciation of gambling, may shed light on a passage by their fellow rhetorician Lysias. The logographer Lysias worked before all the other orators discussed above save Gorgias, but he is considered last to facilitate comparison between his work and later ones where the evidence is more robust. The more secure instantiations of the vice trio in later orators may shade our understanding of an ambiguous passage from the Lysianic corpus.

The point of comparison comes in Mantitheus' defense speech. Having been appointed to public office, Mantitheus must pass a dokimasia, the judicial examination of his right to hold office. The principal charge against him is that he served in the cavalry under the Thirty; the amnesty of 403-402 BCE made prosecution for this act impossible, but the allegation could be considered when Mantitheus appeared in court for another 
reason, such as his dokimasia. ${ }^{460}$ Mantitheus notes his respectable conduct in personal life, then offers a defense of his actions in public life: ${ }^{461}$

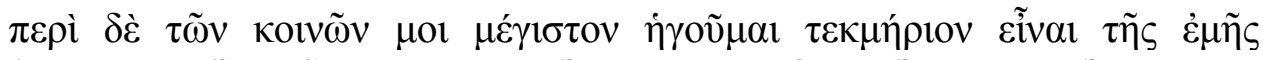

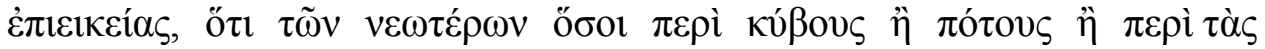

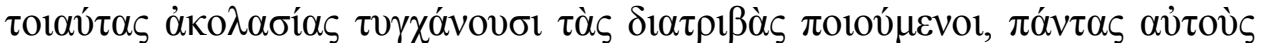

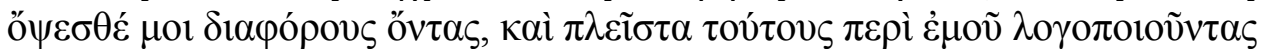

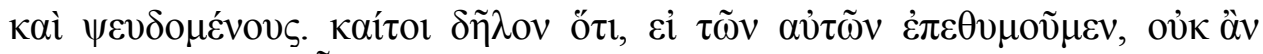

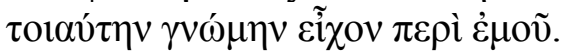

In public affairs, I think that the greatest proof of my virtuousness is that of the young men who waste their time with dice or drinks or such licentiousness, you will see that all of them are at variance with me and fabricate the greatest tales and lie about me. Indeed it is clear that if we desired the same things, they would not have this disposition towards me.

Mantitheus argues that his greatest qualification for office is his dissimilarity to the unprincipled young men of Athens. These youths waste their time with games of chance and drinking, as well as other, unspecified actions that seem to go hand in hand with them. On comparison with the moral rebukes of later orators, the implication may be sex, perhaps with prostitutes.

Lysias' speech, which Mantitheus delivers, conceivably operates within the same framework as Isocrates' later claims about contemporary youths' engagement with the vice trio. As discussed above, Isocrates outlines two kinds of young men, who spend their days in much the same behaviors: even the most virtuous play games, drink, and have sex, while those of a worse nature squander money on these activities. Isocrates even says that the worse sort spend the day in licentiousness ( $\dot{\alpha} \kappa о \lambda \alpha \sigma i \alpha$ ), the same word in Lysias' speech, and both orators likewise describe the young men as frittering away their time $(\delta 1 \alpha \tau \rho i ́ \beta \omega)$ in such pursuits. Isocrates encompasses all three vices with the word $\alpha \kappa \circ \lambda \alpha \sigma i \alpha 1$,

\footnotetext{
${ }^{460}$ Todd (2000) 177-178

${ }^{461}$ Lysias, For Mantitheus 11
} 
while Aeschines, immediately after describing Timarchus' addiction to all three, describes

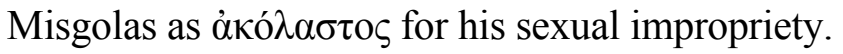

Mantitheus may imply that the young men who slander him are engaged in the vice trio. Although Mantitheus never mentions monetary exchanges, his explicit reference to dice suggests gambling, just as his remark about drinking indicates excessive consumption, for his avoidance of the other young men's conduct is inconsequential

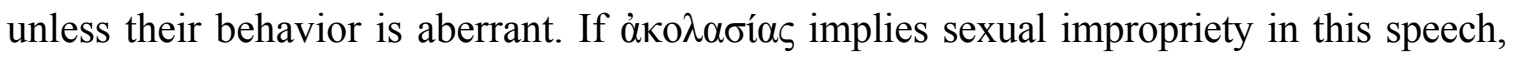
then nearly half a century before Isocrates, a Greek orator already considered gambling, sex, and drinking as an interwoven trio of vices that could be leveraged against one's enemies. If that is indeed the case, then this is the earliest example of the vice trio in Greek oratory and may influence our examination of similar passages in the oratorical corpus.

\section{Conclusion}

From our earliest source onward, Greek literature places a high value on effective communication. As historians and other authors make clear, public speaking was requisite for leadership even before it became systematized in rhetoric. The height of public speaking in the Greek world is the public oratory of late fifth- and fourth-century BCE Athens, which provides a wealth of sources for examining ancient morality. Forensic speeches, those concerned with proving or disproving transgressions, are especially useful because of their appeals to communal values: as the authors or speakers seek to prove or disprove the violation of cultural values, they simultaneously delineate exactly what those values are and what behaviors constitute transgression. As such, these speeches demonstrate negotiations of values, since the logographers may be convincing 
their audiences to agree on what the communal values are even as they deliberate possible infractions.

Forensic oratory sheds light on the moral valuation of games. In the guise of Palamedes and Odysseus, authors of fabricated speeches couched as courtroom speeches, a kind of faux-rensic oratory, argue for and against the civic and personal value of games, both games of skill and games of chance. Gorgias' Palamedes describes his inventions as benefits to the jury, Greece, and all of humankind, concluding his list of beneficial creations with pessoi, which he calls a harmless pastime for leisure. The beneficence is the development of an anodyne pursuit for structuring leisure: since all inventions fill a need, we can infer that Palamedes' contemporaries engaged in wicked pursuits in the times they were not working. A parallel reading with two passages from Xenophon, who claims to record the thoughts of Gorgias' contemporary Socrates, clarifies that playing pessoi could be seen as an intrinsically neutral activity, a gray area between working, i.e. doing something righteous, and idling, i.e. undertaking injurious activities. In Alcidamas' response to his teacher Gorgias, the character Odysseus denies the existence of the ternary system of idling (bad), leisure (neutral), and work (good). Instead, he subtly insists on a binary by classing pessoi players as idlers, eliminating the neutrality of leisure. By examining these authors together, we can uncover evidence of contemporary debates about morality and the ethical valuation of certain activities.

The greatest condemnation lies not with the games themselves, but with the financial stakes assumed to be integral to games of chance. Indeed, Alcidamas states that pessoi causes disputes and abuses among idlers, but names dice, themselves physical manifestations of chance and facilitators of gambling, as a very great evil. Moreover, he 
and other orators strongly suggest that monetization is an integral element of vice. Gambling, the commercialized version of playing games, becomes inextricably linked with the monetized versions of sex and eating and drinking: fornication and consumption. These elements comprise the vice trio, which likewise encompasses each activity when taken to excess, including at the expense of more worthwhile pursuits.

The vice trio becomes a motif in Greek oratory. The orators argue that those who engage in these activities possess weak character and are a detriment to their fellow members of society, to whose shared values the orators claim to appeal. In the case of Timarchus, Aeschines contends that his personal habits are so toxic that he must be barred from public life-an opinion perhaps actually shared by the community, as Timarchus was convicted and stripped of his citizen's rights. By noting the similarities in accounts from one orator to the next, we can uncover the vice trio as a readily accessible rhetorical strategy for turning the audience, including the jury, against one's courtroom opponent. Moreover, if the vice trio is acknowledged as a cohesive unit, it can perhaps shed light on other, previously murky passages, such as what Lysias means by the vague

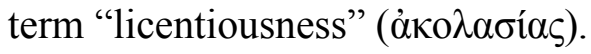




\section{Chapter 4: Games and Morality in Latin Literature}

\section{Introduction}

The previous chapter traces the moral function of games in Greek oratory. As outlined there, the orators treat games in general as unconstructive, while they portray games of chance as evils to the community and worthy of harsh rebuke. The orators often do not consider games in isolation, however, and frequently link them with sex, food, and drink. These elements of daily life acquire a moral dimension, the value of which depends on how one engages with them.

In Greek literature, games are part of a trio of activities that are morally neutral, but transform into vices when monetized and/or taken to excess. Games become gambling or, less commonly, gaming too often; sex becomes fornication, encompassing both adultery and prostitution, which itself includes both purchasing intercourse from others and selling oneself; and eating and drinking become consumption, comprising inordinate expenditure and immoderate ingestion. These three vices-gam(bl)ing, fornication, and consumption-form a trio of interconnected vices that permeates discussions of morality in Greek oratory.

The present chapter shows the usage of the vice trio in Latin literature. Just as the first two chapters of this dissertation trace the same ludic themes in Greek and Latin literature, but focus on different genres, this chapter follows the previous chapter, but concentrates on comedy and history rather than oratory. These two genres offer disparate engagement with the vice trio: comedy uses it to create humor, while history follows oratory in using it as invective. By comparing these two radically different approaches to 
the vice trio, we can see how Roman authors indirectly acknowledge its existence as they take recourse to it for their various purposes.

I begin with Plautus, whose plays come not long after the so-called birth of Latin literature. ${ }^{462}$ The playwright presents the same combination of iniquities in several plays, always as a source of humor, though each time in a different manner. Most of the passages discussed also feature a parasite, a natural additional element, but one that does not always appear in conjunction with the vice trio.

Plautus often uses the vices to facilitate wordplay and engender humor. For example, in the Curculio, the eponymous parasite comments that the young men have given him the nickname Harlot (Scortum) because he so often attends and eats at banquets despite being uninvited. He does not argue with this appellation, however, because with some verbal gymnastics he uses it to rationalize his behavior. He reasons that prostitutes get invited to dinners, where their lovers call out their names for luck in the gambling that accompanies such events. If he is a prostitute, then he is not uninvited (in-uocatus), but rather called upon (inuocatus), so his presence is warranted, while it is only logical that he eats at a dinner party.

When Plautus plays with the vice trio, he incidentally proves its existence. By toying with the features, the playwright creates humor, while simultaneously revealing the background for those jokes. This approach stands in stark contrast to other authors' methods of employing the same ideas, approaches that more closely resemble the Greek orators.

${ }^{462}$ On the birth of Latin literature its date of 240 BCE, see Cicero, Brutus 18.72-73; Fantham (2014) 323-329. Cf. Cicero, de Senectute 50; Hendrickson (1939) 69; Conte (1994) 39-40. 
The equestrian orator Gaius Titius was active in the mid-second-century BCE. Not much about his life is known save that he was an accomplished orator, so it is unsurprising to see parallels between his surviving work and that of the Athenian orators. Like Isocrates especially, Titius lambasts his contemporaries for their dissolute lifestyle. In a speech supporting the sumptuary legislation of $161 \mathrm{BCE}$, he describes the behavior of his fellow magistrates in terms of the same combination of degenerate behaviors. As the statutes of the sumptuary legislation were not enforceable, Titus' speech reveals that such laws were symbolic statements of Roman values, public affirmations of propriety. Titius' harangue outlines exactly the behaviors that the law's proponents sought to curtail, if not in actual practice then at least in the public eye. Titius' oratorical remonstration is limited to his contemporaries' engagement with the vice trio and their dereliction of duty in pursuit of those iniquities, allowing it to bridge the gap between the Greek and Roman worlds in the use of this method of critique.

The vice trio also helps resolve a textual problem in Sallust's Bellum Catilinae. When the historian describes Catiline's followers, he catalogues the three kinds of prodigals who have devastated their patrimonies by means of three body parts: nam quicumque inpudicus adulter ganeo manu uentre pene bona patria lacerauerat. ${ }^{463}$ The spendthrifts in question, however, do not correspond exactly to the body parts in the commonly accepted reading given here, a fact exacerbated by the confused state of the manuscripts, which contain different series of wastrels and record additional profligates in suprascript and marginalia. Scholars have proposed many different solutions, including various textual emendations and the deletion of some words as glosses that crept into the

${ }^{463}$ Sallust, Bellum Catilinae 14.2 
main text when it was recopied. I trace the history of the passage's emendations and use the vice trio to navigate the possibilities, ultimately concluding with a specific emendation as the likeliest solution.

First, I argue against athetizing the first tricolon wholesale. I argue against the claim that these words' absence from Fronto and Augustine in their quotations of the relevant passage exposes them as intrusive glosses. Rather, I contend that since these authors by their own admission are concerned only with the style and effect of the passage, they quote only the portion relevant to their discussions. Second, I note the frequency with which a later hand added alea to many of the manuscripts, usually after ganeo. While most editors consider it an intrusive gloss on manu, I follow the emendation attributed to Wölfflin and argue that alea should be corrected to aleo and restored to the series, while I follow Paul in excising inpudicus; if retained, it contradicts one of Sallust's statements only sentences later, thereby undercutting the authority of the historian's account. The emended reading eliminates this contradiction and offers two asyndetic tricola in chiasmus, such that the second tricolon contains a one-to-one correspondence to the first, linking each wastrel to the body part he uses to dissipate his inheritance: "for whatever adulterer, glutton, or gambler had squandered his patrimony with his hand, belly, or penis" (nam quicumque adulter ganeo aleo manu uentre pene bona patria lacerauerat).

After showing the likelihood of this emendation on the strength of Sallust's text alone, I offer comparanda from other authors and potential models for the historian's passage. I argue that Sallust draws on the long literary tradition of the vice trio in the way he describes Catiline and his followers. The previous chapter describes this tradition in the 
Greek orators at length, so I do only sketch those arguments here for context. Sallust's claim that Catiline's closest followers devastated their patrimonies with the same iniquities the Greek orators denounce, including the added element of financial misconduct, shows that the historian is working in the same literary milieu.

Sallust's passage has even closer parallels, some of which he likely used as models. A fragment from Naevius provides a similar asyndetic string of insults, including terms that match Sallust's in the emended passage. ${ }^{464}$ Catullus' harangue against Caesar and Pompey for their patronage of Mamurra offers another parallel: "shameless and a glutton and a gambler" (inpudicus et uorax et aleo) ${ }^{465}$ Moreover, Catullus' claims that Mamurra dissipated his own patrimony and now squanders others' inheritances reinforce the element of profligacy. ${ }^{466}$ Catullus' inpudicus is the same word that I argue should be excised from Sallust, so the similarity of the Catullan passage may have prompted scribal revision.

Sallust's closest Latin model may be Cicero's orations against Catiline. Cicero describes the same characters only two decades before the probable publication date of Sallust's Bellum Catilinae, discussed below. In several passages from the second oration, Cicero portrays the degeneracy of Catiline's followers, who, at least according to this speech, waste their patrimonies and their lives in the vice trio. I show that Cicero uses the combination of these iniquities and prodigality in unison as charges throughout his oratorical career, from his prosecution of Verres in $70 \mathrm{BCE}$ to his speeches condemning Antony in 44-43 BCE, before turning to a model Cicero and Sallust share: Theopompus.

\footnotetext{
${ }^{464}$ Naevius fr. 118 Ribbeck: "you're the worst of the very worst, reckless, glutton, debauchee, gambler" (pessimorum pessime, audax, ganeo, lustro, aleo)

${ }^{465}$ Catullus, Carmina 29.2, 10

${ }^{466}$ Catullus, Carmina 29.17, 21-22
} 
Theopompus of Chios lambasts Philip's coterie in nearly the same terms Sallust does Catiline's. I trace the parallels in content and style to show the near certainty that the Roman historian uses his Greek counterpart as inspiration, including engagement with all three components of the vice trio and the use of a tricolon. That Theopompus studied under Isocrates strengthens the comparison of Sallust to the Greek orators and bolsters the vice trio as a literary tradition.

Sallust diverts from his closest models when he rejects the ascription of homosexuality to Catiline and his inner circle. Theopompus describes Philip's clique as including anyone in Greece or among the barbarians who is $\lambda \alpha \dot{\sigma} \sigma \alpha v \rho \circ \zeta$, meaning a pathic homosexual. This word matches Cicero's description of Catiline's followers as inpudici, which has much the same meaning and is the same term in Catullus 29, another comparandum for Sallust. I conclude that the similarity of these passages to Sallust's may have led an over-zealous scribe to add inpudicus to the text, causing or augmenting the confused state of the manuscripts, but that the emendation given above is the likeliest when considering the vice trio in Sallust's models in conjunction with his later rejection of homosexuality in Catiline's camp.

\section{Plautus}

Plautus presents the vice trio throughout his corpus. The context of that presentation varies from work to work, however, and the vice trio yields different effects each time. Moreover, the playwright's consistent use of gam(bl)ing, consumption, and fornication together reinforces their collective identity even as it shows their pliability. In the plays under consideration, Plautus uses the vice trio to build layers of meaning, 
playing with multiple senses of words to yield passages richer than they appear on first inspection. In each case, the playwright presents all three members of the vice trio, but emphasizes and/or toys with one for humorous effect. Though the predominant vice is not always gam(bl)ing, I explore each of these passages in equal detail, as they showcase the same characteristics and each reinforces the interconnectivity of the same three vices.

Most appearances of these iniquities in Plautus also feature a parasite. The system of Roman patronage is complex and I do not examine the institution here. ${ }^{467}$ Rather, I focus on the different ways Plautus connects parasitic characters to the vice trio, which changes from play to play. The parasite was a man on the fringes of the elite, seeking subsistence and upward mobility through sycophancy, pandering to aristocratic sensibilities, and, when necessary, deception — whatever his patron required. ${ }^{468}$ As scroungers seeking to live off the wealth of others, parasites naturally evoke pecuniary interests, while the vice trio affords opportunities for financial as well as moral malfeasance. ${ }^{469}$ Plautus' addition of parasites presents a novel element that enhances rather than distracts from the discussion of the vice trio.

The parasite Ergasilus delivers the first lines immediately after the prologue to the Captivi. He begins his speech and the play proper by considering the status of his kind: ${ }^{470}$

iuuentus nomen indidit Scorto mihi, eo quia inuocatus soleo esse in conuiuio. 70 scio absurde dictum hoc derisores dicere,

${ }^{467}$ For parasites and Roman patronage, the best study is still Damon (1997). For Roman patronage generally, see Carcopino (1941) 191-193; Balsdon (1969) 21-24; Dudley (1970) 42-45; Wilkinson (1974) 24.

${ }^{468}$ Purcell (1995) 7; Damon (1997) 79. Cf. Bond (2011) 93 on the Roman aristocracy as largely contemptuous of parasites.

${ }^{469}$ Purcell (1995) 8 notes that Roman attacks on games in general are closely linked to sex and symposia, the typical concerns of parasites.

${ }^{470}$ Plautus, Captivi 69-77 
at ego aio recte. nam scortum in conuiuio

sibi amator, talos quom iacit, scortum inuocat.

estne inuocatum an non est? est planissume;

uerum hercle uero nos parasiti planius,

quos numquam quisquam neque uocat neque inuocat.

quasi mures semper edimus alienum cibum.

The young men gave me the name "Harlot" for this reason: because invocated, I am accustomed to being present and eating at a banquet. I know that the mockers say this has been said inappropriately, but I affirm it was said rightly. For when a prostitute is at a banquet, her lover, when he throws the dice, calls out her name. Is she invocated or no? Most clearly she is. But the truth is, really, by Hercules, we parasites are called upon more correctly, whom no one ever either invites or invokes. Like mice, we always eat another's food.

Despite not being invited, Ergasilus attends banquets and partakes of the spread. This habit earns him the nickname "Harlot" from the young men, indicating that such events include the presence of prostitutes, who are not invited guests, but are nevertheless accepted attendees. Ergasilus justifies his actions by playing on the dual sense of inuocatus (70), which means both "called" and "not called." 471 According to his version of events, he does not come uninvited (in-uocatus), but rather because he has been invoked (inuocatus), referring to the custom of calling out the name of one's lover for luck when throwing a randomizing agent. ${ }^{472}$ His rationalization is not only clever, but it also utilizes the vice trio to achieve its effect: he arrives uninvited to dinner parties, prime locations of consumption; because of his actions he is dubbed a prostitute, a person whose occupation facilitates fornication; and he justifies his attendance with gaming imagery, maintaining that if he is indeed a prostitute, his name is called out by his lover during the gambling that occurs at conuiuia, and thus he has in fact been invited. Ergasilus exploits the interconnectivity of these vices to prove-at least to himself - that

${ }^{471}$ OLD s.v. inuocatus; s.v. inuoco 1

${ }^{472}$ OLD s.v. inuoco $1 \mathrm{c}$ 
he deserves a place at the table. ${ }^{473}$ There is some humor in the fact that the vice trio appears in the first lines after the prologue, which promises an unconventional, improving play of high moral tone; that promise is undercut already in the prologue itself, a process Ergasilus' speech continues. ${ }^{474}$

Ergasilus' clever wordplay centers on the stereotypical raison d'être of the parasite: eating another's food. The verb esse can mean either "to be (present)" or "to eat," so in line 70 , the parasite may be confessing his predilection for attending parties uninvited, but he may be admitting simply to showing up and eating the food, a far less social connotation. ${ }^{475}$ With comedic timing, Ergasilus delays solving the riddle he has posed for his audience by debating the validity of his new moniker; even when he finally reveals his meaning by alluding to gaming practices, he delays the operative word, inuocat, until the very end. ${ }^{476}$ After three lines of suspense, Ergasilus explains why his nickname allows him to be present. The parasite then humorously inverts his own revelation in line 77. Ergasilus' comparison to murine ingestion of another's food brings eating, not mere presence, to the fore. His imagery and use of the verb edimus, from esse, offer a new interpretation. He truly does attend just for the comestibles, but he is not alone: line 74 (estne inuocatum an non est? est planissume) can now read "does [the prostitute] eat uninvited or does she not eat? Well of course she eats!" Ergasilus offers a second explanation of his actions by reinterpreting his own carefully chosen words: while

${ }^{473}$ Likewise important is the end of the speech, where Ergasilus points out the home of his patron's father and remarks that he has often exited through those doors intoxicated.

${ }^{474}$ On the prologue undercutting its own promise of high morality, see Beacham (1991) 36.

${ }^{475}$ OLD s.v. sum; s.v. edo

${ }^{476}$ See Maltby (1999) for Ergasilus' comedic timing. Cf. Beacham (1991) 36-37 on Plautus putting dramatic development aside to allow time for characters to banter and tell jokes. 
her lover is busy gam(bl)ing, a prostitute eats at a party even without a formal invitation.

Invited or uninvited, named in a game of chance or present for an occupational reason, Ergasilus exploits the vice trio to argue that his new sobriquet warrants his consumption. Ultimately, Ergasilus' inventive logic proves unnecessary, as he receives an invitation to dinner that night (176) and later an invitation in perpetuity (897).

In the Curculio, the eponymous parasite capitalizes on vice to achieve his goals. Curculio is sent on a quest by Phaedromus, his patron, to borrow money in order to purchase Planesium, a girl owned by the procurer Cappadox. On his travels, Curculio meets the soldier Therapontigonus, who invites him to dinner after learning that he knows Cappadox and Lyco, the baker holding the money with which he will purchase Planesium, the same girl Phaedromus desires. Upon returning home, the parasite recounts the meal and his actions to his patron once the latter has promised him dinner in exchange for good news: ${ }^{477}$

CU. postquam cenati atque appoti, talos poscit sibi in manum, prouocat me in aleam, ut ego ludam: pono pallium;

ille suom amiculum opposiuit, inuocat Planesium.

PH. meosne amores? CU. tace parumper. iacit uolturios quattuor. talos arripio, inuoco almam meam nutricem Herculem, iacto basilicum; propino magnum poclum: ille ebibit, caput deponit, condormiscit. ego ei subduco anulum, deduco pedes de lecto clam, ne miles sentiat.

rogant me serui quo eam: dico me ire quo saturi solent. ostium ubi conspexi, exinde me ilico protinam dedi.

CU: After we had dined and drunk heavily, he demanded the knucklebones be placed in his hand, then he challenged me to gamble, hoping that I would play. I wagered my cloak, he staked his mantle against it, and then he called upon Planesium.

PH: My love?

$\mathrm{CU}$ : Be quiet for a moment. He threw four vultures. I picked up the dice, I called upon Hercules as my auspicious nurse, and I cast the king's throw. I

${ }^{477}$ Plautus, Curculio 354-363 
gave him a huge goblet, he drank it, he laid down his head, and then he fell asleep. I stole his ring and removed my feet from the couch stealthily so that the soldier would not notice. The slaves asked me where I was going; I said I was going where people who are full are accustomed to going. When I caught sight of the door, I immediately took myself through it.

The parasite cannot help but get sidetracked when he sees the possibility of dining at another's expense. He happens to see the soldier Therapontigonus on the street, ingratiates himself, and receives an invitation to the evening meal, his acceptance of which he considers a moral obligation. ${ }^{478}$ During dinner, the two engage in consumption; Curculio states not just that they drank, but that they drank heavily, while just one additional drink - huge though it was - causes Therapontigonus to fall asleep. Curculio perhaps also alludes to how zealously he himself imbibed when he admits he left upon catching sight of the door: presumably he had entered through the same location, but he does not simply walk to the egress, he must find it first, possibly a subtle admission of his own intoxication.

When challenged to gamble, Curculio agrees and set the stakes without hesitation. When Curculio wins the throw, as is evident from the context, he gives Therapontigonus enough to drink that he falls asleep and produces two distinct gains for himself. ${ }^{479}$ First, the soldier is unable to continue gambling, leaving the parasite the sole winner of the game. Second, Curculio steals the soldier's signet ring and flees with it, allowing him to forge a letter to Lyco the banker, pose as the soldier's proxy, and receive the courtesan Planesium from the pimp Cappadox for his patron Phaedromus, thus cementing his place in his patron's good graces - and at his table. Curculio does not just engage in vices, he

\footnotetext{
${ }^{478}$ Plautus, Curculio 350: uocat me ad cenam; religio fuit, denegare nolui.

${ }^{479}$ On Curculio's throw winning, cf. Wolbergs (1978) 377-378.
} 
manipulates others with them: he dines at the soldier's expense, gambles for his own gain, ensures his aleatory success by compelling his competitor to over-imbibe, and then uses the opportunity to steal from the soldier to enable his patron's engagement with a prostitute, securing himself a feast from his patron for the good news. Curculio's motivation is consumption, the promise of which leads him to facilitate fornication for his patron, while gam(bl)ing brings personal gain; consumption steals the limelight in this scene, but other vices reinforce it.

Later in the play, Curculio seems to reveal a predilection for gambling. Planesium demands to know the provenance of the ring that the parasite stole from Therapontigonus.

After a series of excuses, including the claim that it was a gift from his aunt and that Planesium's father had given it to him, Curculio admits the truth: ${ }^{480}$

$C U$. dixi equidem tibi, unde ad me hic peruenerit. quotiens dicendum est? elusi militem, inquam, in alea. 609 TH. saluos sum, eccum quem quaerebam. quid agis, bone uir? CU. audio. si uis tribus bolis, uel in chlamydem. TH. quin tu is in malam crucem cum bolis, cum bulbis? redde mihi iam argentum aut uirginem. $\cdots$ PH. miles, quaeso ut mihi dicas unde illum habeas anulum, quem parasitus hic te elusit.

CU: Truly, I have told you whence this reached me. How often does it need to be said? I am saying that I took it from the soldier in gambling. TH: I am saved, for here is the person I was trying to find. How do you do, good sir?

CU: I hear you. If you like, we'll play with three throws of the dice, perhaps for that cloak.

TH: Why don't you go get hanged with your throws and your onions? Now give me back the money or the girl. ... PH: Soldier, I want you to tell me where you got that ring, which this parasite swindled from you.

When Curculio admits how he obtained the soldier's ring, he pretends to be repeating

${ }^{480}$ Plautus, Curculio 608-612, 629-630 
what he already said, despite admitting earlier that he refused to tell Planesium. His admission has wordplay that nearly rivals Ergasilus'. First, Curculio makes his confession as though he were quoting himself, denoted by inquam. ${ }^{481}$ Second, he utilizes the polysemous word eludo: he claims to have won the ring in gambling, but Phaedromus sees through the charade with the more common use of the verb, noting that the parasite tricked the soldier out of his ring. ${ }^{482}$ Curculio does not lie outright in this passage, but deliberately obfuscates the truth with his wordplay.

Perhaps revealing his penchant for gambling, Curculio's first words to the soldier once he arrives are a challenge to a game of dice for the latter's cloak. The audience is left wondering if the parasite told the whole story to his patron: Curculio won the soldier's mantle in their previous aleatory encounter, but only mentions taking the ring, not the actual stakes of the game. Curculio knew that the signet ring would be necessary to deceive Lyco and receive Planesium, thereby earning a spot at Phaedromus' table. Nevertheless, he leaves open the possibility that in his drunkenness he misheard the soldier's wager, thinking anulum instead of amiculum, but he also could also have omitted select details from his account. ${ }^{483}$ It is interesting that he challenges the soldier for his chlamydem here rather than his amiculum; the word choice may simply be for variety, but it may also indicate a different garment, conceivably a subtle indication that Curculio absconded with both the ring and the cloak. The parasite cheekily offers a new challenge: he offers three throws of the dice, rather than the single cast that left the soldier bereft of his possession(s) earlier. His willingness to give the soldier more

\footnotetext{
${ }^{481}$ Cf. OLD s.v. inquam 1; LS s.v. inquam I

${ }^{482}$ Cf. OLD s.v. eludo $1 \mathrm{~b}$ and 2; LS s.v. eludo IIA and B2

${ }^{483}$ See Welsh (2006) 138-139 for a possible sexual joke from Cappadox when Therapontigonus realizes that Curculio has taken his anulum.
} 
opportunities to win should not be taken as (only) the hallmark of a compulsive gambler. Rather, it seems that Curculio knows something the others do not; for someone who spends his life eating through others' resources, the parasite is curiously willing to wager his own possessions, seeming confident he will emerge victorious. His enthusiasm for gambling mirrors his readiness to do whatever will earn him a meal, bringing to mind something Micio says in a play by Terence, Plautus' near-contemporary and comedic successor: ${ }^{484}$

ita uitast hominum, quasi quom ludas tesseris: si illud quod maxume opus est iactu non cadit, illud quod cecidit forte, id arte ut corrigas.

This is the life of men, just like when you play with dice: if what you most dearly want does not turn up with your throw, then that which fell by chance, you must correct by art.

I discuss this passage in an earlier chapter, but it adds to the present discussion as well. When arrangements are not to a parasite's liking, he alters his circumstances. It is possible that Curculio applies that same mentality to his gambling, explaining both his excellent dice throw and his eagerness to play again. The soldier wants nothing to do with him, however, and tells him to go to hell with his throws and his onions. This retort is at first bewildering, for no onions have been mentioned, but the soldier replies to the parasite in the fashion of a parasite: with a pun. The bolis in question can certainly be throws of the knucklebones, as Curculio intended, but they can also be "choice morsels," the primary targets of parasites. ${ }^{485}$ Therapontigonus supplies the linguistically comparable bulbis to pair with bolis, reappropriating Curculio's word to craft an

\footnotetext{
${ }^{484}$ Terence, Adelphoe 4.7.21-23

${ }^{485}$ OLD s.v. bolus 1 and 2; LS s.v. bolus IA and IIB. Cf. Terence, Heautontimoroumenos 673: crucior bolum tantum mi(hi) ereptum tam desubito e faucibus, "I am tortured that such a choice morsel has been snatched so suddenly from my jaws."
} 
alliterative, culinary joke. ${ }^{486} \mathrm{~A}$ scant few lines later, Therapontigonus realizes that he is Planesium's brother and allows Phaedromus to marry her. Curculio proposes a unique dowry fit for a parasite: as long as Phaedromus lives, he must feed Curculio, a perpetual invitation to the table as eternal thanks for helping him get the girl: "I will provide the dowry... that always, as long as he lives, he will feed me" (ego dotem dabo / ... ut semper, dum uiuat, me alat). ${ }^{487}$

The Asinaria similarly shows the connection of parasites to consumption, fornication, and gam(bl)ing. The soldier Diabolus wishes to hire the courtesan Philaenium to live with him for an entire year. He hires his parasite, someone with notorious verbal acuity, to write the contract to ensure specific and favorable terms. Partway through the stipulations comes the following section: ${ }^{488}$

PAR. tecum una potet, aeque pocla potitet:

abs ted accipiat, tibi propinet, tu bibas, ne illa minus aut plus quam tu sapiat. DIAB. satis placet.

PAR. suspiciones omnes ab se segreget. neque illaec ulli pede pedem homini premat, cum surgat, neque <cum > in lectum inscendat proximum, neque cum descendat inde, det cuiquam manum: spectandum ne cui anulum det neque roget. talos ne cuiquam homini admoueat nisi tibi. cum iaciat, 'te' ne dicat: nomen nominet. deam inuocet sibi quam libebit propitiam, deum nullum; si magis religiosa fuerit, tibi dicat: tu pro illa ores ut sit propitius. neque illa ulli homini nutet, nictet, annuat. post, si lucerna exstincta sit, ne quid sui membri commoueat quicquam in tenebris. DIAB. optumest. ita scilicet facturam. uerum in cubiculodeme istuc-equidem illam moueri gestio.

${ }^{486}$ Contra Riley (1912) ad loc., who states that "He probably uses the word 'bulbis' solely for its similarity to 'bolis,' by way of alliteration." The alliteration is certainly there, but the significance of the word choice does not end there.

${ }^{487}$ Plautus, Curculio 663-664

${ }^{488}$ Plautus, Asinaria 771-791 
nolo illam habere causam et uotitam dicere.

PAR. scio, captiones metuis. DIAB. uerum. PAR. ergo ut iubes

tollam.

PAR: She must drink from a single cup with you and she must always drink the same amount as you: she must receive the cup from you and give it to you so that you can drink. She must not taste it less or more than you do.

DIAB: That is acceptable enough.

PAR: She must remove all suspicions from herself. She must neither press upon any man's foot with her foot, nor must she step upon the neighboring couch when she rises, nor extend her hand to anyone when she climbs down from there. She may not give her ring to anyone to see, nor ask to look at anyone's ring. She may not give the knucklebones to any man whatsoever except you. When she throws, she may not say "you"; she must mention your name. She may call upon a goddess that she deems is favorable towards her, but she may not call upon a god. If she is quite religious, she must tell you so that you can pray on her behalf that he may be propitious. She may not nod, wink, or make a promise to any man. Ultimately, if the lamp goes out, she should not even move one of her limbs in the dark.

DIAB: That is excellent. She has to behave just so. Actually, in the bedroom-remove that part. In fact, I really want her to be moved. I do not want her to have an excuse and say it is forbidden.

PAR: I understand. You are afraid of quibbles.

DIAB: Exactly.

PAR: Well then, as you wish, I will remove that part.

The parasite accounts for all the familiar behaviors. In a humorous twist from the frequent moralizing in Roman theater, Diabolus actually wants Philaenium to engage in all three, provided she does so with only him. ${ }^{489} \mathrm{He}$ is not trying to curtail her participation in any of the vices, but rather to ensure that she matches his enthusiasm for each: she must equal his drinking, call upon his name when throwing the knucklebones, and - as Diabolus himself admits — be devoid of any excuse not to have sexual

\footnotetext{
${ }^{489}$ See Moore (1998) 67 for the frequent moralizing Roman theater and Plautus' skepticism towards it. Cf. Moore (1998) 89-90 for the note that Plautus often mocks moralizing, not morality itself.
} 
intercourse ${ }^{490}$ Through his precise contractual phrasing, the parasite functions not as the pursuer of vice, but rather as its guarantor.

In the final scene of the Asinaria, Plautus again combines the same three vices. By defrauding his wife, Demaenetus produces the cost for Philaenium before Diabolus could, thereby preempting the latter's contract, and arranges for Philaenium to live with his son Argyrippus instead. Demaenetus' one stipulation is that he himself gets to spend that night with Philaenium, a requirement to which Argyrippus reluctantly agrees. To celebrate their successful venture, Demaenetus, Argyrippus, and Philaenium celebrate at the house of Cleareta, Philaenium's procuress and mother, with drinking and, once it is prepared, dinner: ${ }^{491}$

ARG. iace, pater, talos, ut porro nos iaciamus. DEM. maxime. te, Philaenium, mihi atque uxoris mortem. hoc Venerium est. pueri, plaudite et mi ob iactum cantharo mulsum date.

ARG: Father, throw the knucklebones so that I can throw again. DEM: By all means! I throw for you, Philaenium, and for the death of my wife. It is the Venus throw! Boys, applaud and put honeyed wine in my cup on account of my throw!

Demaenetus is drinking and throwing knucklebones before committing adultery with a prostitute. Furthermore, he wishes to trade in the wine already on the table, which he just ordered refilled fifteen lines earlier, for mulsum in celebration of his aleatory achievement— the best dice throw deserves the best drink available. ${ }^{492} \mathrm{He}$ is taking all of

\footnotetext{
${ }^{490}$ Fontaine (2010) 34 notes that talos in line 779 may also mean "ankles" here, a double entendre referring to a sexual position akin to Ovid, Ars Amatoria 3.775-776: Milanion umeris Atalantes crura ferebat / si bona sunt, hoc sunt accipienda modo.

${ }^{491}$ Plautus, Asinaria 904-906

${ }^{492}$ The relative values of mulsum and wine in the Roman world are irrelevant to this scene. What matters is that Demaenetus calls for a drink to celebrate his throw and specifies mulsum, not better wine or anything else, showing the high regard he held for the honeyed beverage.
} 
his behaviors to excess: besides calling upon Philaenium's name when throwing the dice, already marking her as his proper lover, he includes a wish for the death of his own wife.

Throughout the passage, Demaenetus engages in a kind of vicious substitution not unlike that of Penelope's suitors in Homer's Odyssey, discussed in an earlier chapter. He has already warped a typical Plautine plot by redefining his role as a senex: he shifts from stern paterfamilias to the helpful, avuncular character who facilitates the adulescens in his attempts to win the girl, but then changes roles again and replaces the miles as the rival for her affections. ${ }^{493}$ As Demaenetus himself admits in line 87 , he substituted authority over the household for his wife's dowry (argentum accepi, dote imperium uendidi). In the passage above, he casts the knucklebones, an action inextricably bound with fluctuating fortunes. He substitutes Philaenium for his wife in his invocation for luck, then further alters the supplication and requests the death of his wife; rather than calling on his lover to bring him good fortune in his game, he prays that his game will reveal his good fortune and bring misfortune upon his former lover. He casts the Venus, the best possible throw, perhaps revealing the inversion of his circumstances and newfound control over his life. Finally, he substitutes the wine already on the table with the superior honeyed wine, in two lines completing exchanges related to all three vices. At that moment, Demaenetus' wife Artemona, having learned of the situation from Diabolus' parasite, with whom she was spying on the scene, enters the room and reverts her husband's perfidy: his adultery is foiled, his providential game is over and he is once again under the control of his wife, his drinking is finished, and the only banquet he will enjoy is crow. The parasite facilitates the vice trio for his patron and frustrates it for those

${ }^{493}$ Konstan (1978) 215-221 
opposing him, but in each case is entangled with others' pursuit of consumption, fornication, and gam(bl)ing.

The Bacchides also contains wordplay and these vices, but a parasite is only obliquely connected. The namesakes of the play are two sisters, both named Bacchis and both prostitutes. At the outset of the comedy, one Bacchis fears that once her sister's year of service with a certain soldier has expired, he will not release her, but will compel her to be a servant in his house in perpetuity. The first Bacchis approaches the young man Pistoclerus and beseeches him to enter their house and serve as their protector, attempting to persuade him through seduction. Pistoclerus at first refuses, noting the corruptive effect entering the brothel would have on his virtue: ${ }^{494}$

PIST. quid ego metuam rogitas? adulescens homo penetrem me huius modi in palaestram, ubi damnis desudascitur? ubi pro disco damnum capiam, pro cursura dedecus?

BACCH. lepide memoras. PIST. ubi ego capiam pro machaera turturem, ubique imponat in manum alius mihi pro cestu cantharum, pro galea scaphium, pro insigni sit corolla plectilis, 70 pro hasta talos, pro lorica malacum capiam pallium ubi mihi pro equo lectus detur, scortum pro scuto accubet? apage a me, apage.

PIST: You ask what I fear? I, a young man, should enter an athletic school of this sort, where one sweats to his own ruin? Where I would have damage instead of a discus, disgrace instead of a race?

BACCH: You speak so charmingly!

PIST: Where I would have a turtledove for my sword, and where another would put in my hand a goblet instead of a gauntlet? A wine bowl for my helmet, a plaited wreath for my crown, knucklebones for my spear, a soft cloak for my cuirass, where I would be given a sofa for my steed, where a bimbo instead of my buckler would lie beside me? Get away from me, get away!

Pistoclerus lists the exchanges he would have to make if he entered the brothel, trading his athletic equipment for the refinery of the courtesans' abode. The passage is filled with

${ }^{494}$ Plautus, Bacchides 65-73 
masterful wordplay centered on the exchanges of exercise accouterments for their amatory counterparts. Pistoclerus' fear is that he will swap his manly pursuits for the vice trio, each related to the trappings he pinpoints. Five such exchanges are of particular importance for the present discussion: pro galea scaphium, an inverted helmet is concave like a wine bowl; pro cestu cantharum, the handle of the wine jug fits into one's palm like the strap of a wrapped boxing glove; pro hasta talos, a spear and knucklebones are thrown; pro equo lectus, one climbs onto both a horse and a bed; and scortum pro scuto accubet, one can sleep beside a prostitute in the same fashion a soldier on duty would sleep next to his shield. ${ }^{495}$ These five substitutions show the close relationship of the vices under consideration, for if Pistoclerus enters the brothel, the dangers to his virtue are consumption, fornication, and gam(bl)ing, as well as general luxury, for instance the soft cloak and woven chaplet. ${ }^{496}$

The unnamed parasite makes only a brief appearance in this play: a scant thirty-

${ }^{495}$ For these near parallels, cf. Barsby (2008) 102-103, save one inaccuracy: he states that there is "no particular similarity" between a cestus and a cantharus (102), but, as noted above, the key feature is how the objects interact with their user's hand, since a cestus is a strip of weighted leather wrapped around the pugilist's hand and a cantharus has handles, indicating manual use. Barsby also does not include a note on pro equo lectus, which may be a double entendre. Fontaine (2010) 211-212 sees in this final verse a reversed meaning of pro, "to be used for," so that Pistoclerus will receive a bed in order to make the horse, a sexual position, as at Ovid, Ars Amatoria 3.777-778 and Martial 11.104.14. See Adams (1982) 165-166 for other examples of riding imagery as a sexual metaphor, both with and without equus.

${ }^{496}$ For other sexual imagery that may also be at play in this passage, see Fontaine (2010) 210-212. As the carnal element is already clearly present, further evidence only strengthens the argument, so I do not dispute these less certain possibilities here. For example, the turtledove may be a culinary treat (as at Plautus, Mostellaria 46) or may be, as an ancient gloss gives, a euphemism for penis, on which see Adams (1982) 32 and his references. If it is the former, it is indicative of luxury; if the latter, the parallel of sword and penis may be tools used for thrusting. Cf. Vegetius, de Re Militari 1.12, who states that the Romans used the points of their swords, not the blades. 
three lines separate his first entrance from his final departure. ${ }^{497}$ He appears on stage just long enough to attempt to take possession of the Bacchis sister that his patron Cleomachus hired or, should she refuse to go, a refund of her price. ${ }^{498} \mathrm{He}$ enters, banters with and is rebuffed by Pistoclerus, and departs to take the latter's rejection back to his patron. Although the unnamed parasite does not heavily influence the plot, his role is similar to that of the other parasites discussed so far. Pistoclerus is with Bacchis, his moral upbringing succumbing to vice (prauos), much to the chagrin of his tutor. ${ }^{499}$ The parasite seeks to facilitate vice for his patron Cleomachus, necessarily thwarting it for Pistoclerus, who is currently engaging in those same vices with Bacchis.

The final play under examination is the Rudens, in which wordplay with gam(bl)ing, consumption, and fornication afford scope for humor. Although this play lacks a parasite, it features many uses of the clever slave, a role sometimes interchangeable with that of a parasite. ${ }^{500}$ In a scene that employs these vices, the slave Trachalio speaks with Amplesica, the slave girl of the pimp Labrax, whose ship sank when he attempted to abscond with a girl he had already sold: ${ }^{501}$

AMP. confracta est, mi Trachalio, hac nocte nauis nobis.

TRA. quid nauis? quae istaec fabulast? AMP. non audiuisti, amabo, quo pacto leno clanculum nos hinc auferre uoluit in Siciliam et quidquid domi fuit in nauem imposiuit?

ea nunc perierunt omnia. TRA. oh, Neptune lepide, salue,

\footnotetext{
${ }^{497}$ Plautus, Bacchides 573-605

${ }^{498}$ Damon (1997) 79 notes that a parasite's success in making himself welcome depended on "the fit between what the parasite offered and what his patron wanted" and states that in the Bacchides, "the fit was just about perfect."

${ }^{499}$ Plautus, Bacchides 405-414

${ }^{500}$ For example, the titular parasite of the Curculio is so helpful and clever that another character assumes he is a slave (623-624). For more on the substitutions of parasites and slaves in Plautus' comedies, see Damon (1997) 44. For the clever slave as Plautus' invention distinct from his Greek models, see Stace (1968) 73-77.

${ }^{501}$ Plautus, Rudens 354-363
} 
nec te aleator nullus est sapientior; profecto

nimis lepide iecisti bolum: periurum perdidisti.

sed nunc ubi est leno Labrax? AMP. periit potando, opinor.

Neptunus magnis poculis hac nocte eum inuitauit.

TRA. credo hercle anancaeo datum quod biberet.

AMP: Last night, my Trachalio, our ship wrecked.

TRA: What ship? What story is this?

AMP: Please, did you not hear how the pimp wanted to take us secretly from here to Sicily and how he put whatever there was at home on a ship? All that is lost now.

TRA: Oh, splendid Neptune, hail to you! No gambler is wiser than you; truly you made your throw most excellently: you destroyed the perjurer. But now where is the pimp Labrax?

AMP: He perished through drinking, I imagine. Last night Neptune challenged him to drink some huge goblets.

TRA: By Hercules, I believe what he had to drink was given with the cup of necessity!

This passage is riddled with puns, beginning when Trachalio claims that Neptune made a great throw. The word bolum can refer to the casting of a net, appropriate imagery for either a ship at sea or ensnaring the deceitful Labrax, especially since his name in Greek, $\Lambda \alpha ́ \beta \rho \alpha \xi$, is a kind of fish, but bolum also refers to the throwing of randomizing agents, hence Trachalio's designation of Neptune as a gambler. ${ }^{502}$ More gaming imagery lies in the verb perdere, which on the one hand means ruin or destruction generally, but on the other indicates loss specifically from gambling. ${ }^{503}$ Neptune's excellent dice throw won him all of the possessions previously in Labrax's home, as Amplesica states that the procurer put everything on the ship. As the laden vessel has sunk into the sea, Neptune's domain, it appears that the god collected his winnings immediately. The humor of this passage relies on the double senses of these words and the ludic wordplay introduced by the otherwise puzzling aleator.

${ }^{502} L S J$ s.v. $\lambda \alpha ́ \beta \rho \alpha \xi 1 ; O L D$ s.v. bolus 2 and 1, respectively; $L S$ s.v. bolus IA and B

${ }^{503}$ OLD s.v. perdo 1 and 6, "To use up extravagantly or to no purpose (material resources, opportunities, etc.), throw away, dissipate, waste"; $L S$ s.v. perdo I and II 
Labrax has not only lost all his possessions, but Amplesica postulates that he may even have lost his life. Her conjecture for her pimp's current whereabouts relies on yet more verbal wit. She supposes that he is dead from the great amount he had to drink; she asserts that Neptune challenged him to quite the drinking contest. The dark joke is that she thinks Labrax drowned, the magna pocula Neptune provided being the sea itself, not cups of wine. Trachalio banters back that the pimp's drink must have been given in an anancaeum, a large drinking vessel that had to be drunk entirely in a single attempt, as the name, from the Greek ó $v^{\prime} \alpha \gamma_{\kappa \eta}$, “necessity," suggests. ${ }^{504}$

This scene again demonstrates the manipulation of the vice trio for comedic effect. Two of the characters are a prostitute and her pimp, both with clear ties to fornication, and Trachalio likens a chance occurrence, the sinking of Labrax's ship, to a savvy roll by Neptune, even declaring the deity a gambler. With the framework set, Amplesica completes the triad by referencing drinking, adding morbid comedy by twisting the meaning from alcoholic consumption to drowning at sea.

Plautus employs the vice trio for comedic effect in several of his plays. Often with a parasite directly involved or not far off, consumption, fornication, and gam(bl)ing form a cohesive unit, such that engaging with one vice relates to the other two. In these scenes, characters exploit the vice trio, sometimes to produce verbal humor and other times to achieve their goals. By making regular use of the vice trio, Plautus reinforces its characteristic collectivity even as he shows its pliability in scenes where he emphasizes only one element, such as Ergasilus' justification for eating at parties even though he is uninvited, which relies on playing games with prostitutes to function. Throughout his

${ }^{504}$ Cf. Riley 1912 ad loc. 
corpus, the playwright demonstrates the existence of the vice trio through his manipulation of it.

\section{Gaius Titius}

Gaius Titius was an equestrian orator active in the mid-second century BCE. While little is known about his life, the existing sources emphasize his proficiency as an orator. ${ }^{505}$ Macrobius records that Titius opposed the luxury of his age and accordingly supported the consul Fannius' sumptuary law of 161 BCE, which restricted the sums one could spend on meals, forbade serving fattened hens, and limited the number of dinner guests outside the family. ${ }^{506}$ Titius advocates for the law by describing the vices of his fellow magistrates in a speech that Macrobius records partly to prove a point he is making about a species of fish and partly because he takes Titius' words as indicative of Rome at the time: ${ }^{507}$

id ostendunt cum multi alii tum etiam C. Titius, uir aetatis Lucilianae, in oratione qua legem Fanniam suasit. cuius uerba ideo pono quia non solum de lupo inter duos pontes capto erunt testimonio, sed etiam mores quibus plerique tunc uiuebant facile publicabunt. describens enim homines prodigos in forum ad iudicandum ebrios commeantes quaeque soleant inter se sermocinari sic ait:

"ludunt alea studiose, delibuti unguentis, scortis stipati. ubi horae decem sunt, iubent puerum uocari, ut comitium eat percontatum, quid in foro gestum sit, qui suaserint, qui dissuaserint, quot tribus iusserint, quot uetuerint. inde ad comitium uadunt, ne litem suam faciant. dum eunt, nulla est in angiporto amphora quam non inpleant, quippe qui uesicam plenam uini habeant. ueniunt in comitium, tristes iubent dicere. quorum negotium est narrant, iudex testes poscit, ipsus it minctum. ubi redit, ait se omnia audiuisse, tabulas poscit, litteras inspicit: uix prae uino sustinet

505 The principal source is Cicero, Brutus 167.

${ }^{506}$ Macrobius, Saturnalia 3.13.13, 3.16.14-16. For the details of the Fannian Law, see Pliny the Elder, Naturalis Historia 10.50.71, who provides the date; Aulus Gellius, Attic Nights 2.24; Smith (1890) 2.724; Balsdon (1969) 38-39; Gruen (1990) 172-173.

${ }^{507}$ Macrobius, Saturnalia 3.16.14-16 
palpebras. eunt in consilium. ibi haec oratio: 'quid mihi negotii est cum istis nugatoribus. quin potius potamus mulsum mixtum uino Graeco, edimus turdum pinguem bonumque piscem, lupum germanum qui inter duos pontes captus fuit?",

Not only do many others prove it [the point about the fish], but even Gaius Titius, a man of the same generation as Lucilius, who spoke in favor of the Fannian law with a speech. I include his words not only for the reason that they will serve as evidence of the wolf-fish caught between the two bridges, but because they will easily reveal even the morals of most people who lived during that time. Indeed, describing profligate men wandering into the forum drunk to serve as judges and the kinds of conversations they were accustomed to having among themselves, he says:

"They play alea with zeal, smeared with perfumes, surrounded by prostitutes. In the tenth hour, they order a boy to be summoned, so that he may go inquire at the comitium what business happened in the forum, who spoke in favor, who spoke against, how many tribes decreed it, how many forbade it. Then they hurry to the comitium lest they produce their own case. ${ }^{508}$ While walking, there is no pot in the alley that they do not fill, those men who of course have a bladder full of wine. They come into the comitium, gloomy, and they command the litigants to plead their cases. They relate whatever business there is, the judge demands witnesses, and he himself goes to urinate. When he returns, he says he heard everything, demands the accounts, examines the letters: he scarcely keeps his eyelids open because of the wine. They go into deliberation. This kind of talk is there: 'Why is it my business to deal with these trifles? Instead, why don't we drink mulsum mixed with Greek wine, eat a fat thrush and good fish, a true wolf-fish that was caught between the two bridges?"

The constellation of vices familiar from Greek oratory is present in Titius' rebuke. Alea, prostitutes, and drunkenness from wine epitomize gam(bl)ing, fornication, and consumption, while the exhortation to eat piscine delicacies bolsters the last of these. Moreover, Titius describes the judges not only as playing alea, but doing so enthusiastically, perhaps implying that they play too often as well as for stakes.

Beyond their personal iniquities, the judges show disdain for public affairs, which Titius indicates are these men's proper responsibility; Titius marks the substitution of

${ }^{508}$ Kaster (2011) 117 n.140: "The idiom Titius uses, litem suam facere (lit. 'to produce/cause one's own action at law'), refers to the liability of a judge incurred through malfeasance." 
personal pleasure for the administration of the state as an even greater transgression than the vices themselves. ${ }^{509}$ This passage recalls Isocrates' complaints that the young men of his day engage in the same depraved behaviors. ${ }^{510}$ More specifically, the orator laments that his contemporaries have driven the youths away from appropriate pursuits, such as proper governance of the city, thereby giving them license to indulge their passions. In Isocrates' demarcation of a better and a worse sort of youths, the judges Titius castigates would fall into the latter category, since their activities have moved into the public sphere, as opposed to a more appropriate private setting, and involve a financial element with gambling, hiring prostitutes, and perhaps drinking in taverns. ${ }^{511}$

The Lex Fannia - and other sumptuary legislation - was impractical and largely unenforceable. ${ }^{512}$ Indeed, the law's narrow focus on dining excluded expenditures on other luxury goods and services, showing that the goal of such legislation was likely not extensive social reform. ${ }^{513}$ Similarly, the limits on expenditures would be unenforceable without devoting immense resources to that task. ${ }^{514}$ It is unsurprising, then, that our sources do not record anyone being prosecuted for violating any sumptuary law. ${ }^{515}$

${ }^{509}$ Cf. Rosivach (2006) 9

${ }^{510}$ Isocrates, Areopagiticus 48-49; Antidosis 286-287

${ }^{511}$ Cf. Rosivach (2006) 9: "by having them say that at the moment they would rather be dining than in court, Titius knits symposiastic drinking, gambling, whoring and expensive dining together into a larger pattern of decadent partying."

${ }^{512}$ For the unenforceability and general disregard of sumptuary legislation in Rome, see, for example, Tacitus, Annales 3.52.

${ }^{513}$ Gruen (1990) 172-174; De Ligt (2002) 11-12; Rosivach (2006) 1; Koops (2016) 610. Contra McGinn (2008) 9, who cautions that "it seems hazardous to try to read legislative intent so directly from legislative effect." For a detailed discussion of the Lex Fannia's moral aspects and motives, see Sauerwein (1970) 76-89.

${ }^{514}$ Balsdon (1969) 39: the spending limits were unenforceable without "forms and returns and ration cards and a great number of police and civil servants" to check each family's budget. Cf. D'Arms (1984) 337; Gruen (1990) 173; Rosivach (2006) 11.

${ }^{515}$ Rosivach (2006) 11 n. 48 
If the law was unenforceable, it seems that its purpose was to reassert confidence in national identity and traditional morality, perhaps thereby meeting the aristocracy's need for group cohesion by supplanting its traditional ethos of competition. ${ }^{516}$ The Lex Fannia and similar statutes were symbolic statements of Roman values, communal affirmations of decorum in contrast to the ostentation that threatened the stability of the Republic. ${ }^{517}$ Titius' speech in favor of the Lex Fannia, then, outlines exactly the behaviors that the law's proponents sought to curtail, if not in actual practice then at least in the public eye. These behaviors are the three components of the vice trio: consumption, fornication, and gam(bl)ing. Titius castigates the profligate judges for all three of these behaviors as a unified whole, as he devotes the entire speech to illustrating their dereliction of duty in favor of drunkenness, expensive food, prostitutes, and gambling.

Titius' remonstration reinforces the role of the vice trio as part of invective in Latin literature. Roman authors have recourse to the vice trio as they censure their opponents and subjects, a tradition they inherit from Greek literature. Titius bridges the gap between Greece and Rome by showing the utility this convention of Athenian oratory has for a Roman statesman around a century after the so-called birth of Latin literature. He is an early example of Romans using the vice trio as a form of critique, which the remainder of this chapter explores.

${ }^{516}$ D'Arms (1984) 337 n. 29 notes that it is "useful to distinguish enforcing (which failed), from legislating (which may have achieved goals of its own)"; Gruen (1990) 172174: "The conclusion imposes itself that Fannius' law was more important for the message than for the content" (quote from 173); Crawford (1992) 76; Rosivach (2006) $11-12$.

${ }^{517}$ Wilkinson (2016) 155-157 argues that sumptuary laws under the emperors were meant to encourage Republican behavior or reaffirm the Republican past, though such tactics existed even during the Republic, the declining morals of which Livy, Sallust, Cicero, and others bemoaned. 


\section{Sallust}

The vice trio helps resolve a textual problem in Sallust's Bellum Catilinae. When the historian describes Catiline's followers, he catalogues the prodigals who have wasted their wealth by means of three body parts. The spendthrifts in question, however, do not correspond exactly to the body parts in the commonly accepted reading, a fact that the confused state of the manuscripts has exacerbated. Scholars have proposed many different solutions, including various textual emendations and the deletion of some words as glosses that crept into the main text when it was recopied. The vice trio helps navigate these possibilities to show that a specific emendation is the likeliest solution.

Sallust devotes his opening chapters to justifying his choice to write history and the circumstances leading to Catiline's conspiracy. More specifically, he describes the successes and subsequent moral decline of the Roman people. The historian declares that FORTUNA is integral to both elements of his introduction. First, he notes that FORTUNA rules all things and makes matters famous or obscure from caprice rather than truth, with the result that the talent of the Athenian historians has inflated the glory of Athenian achievements, highlighting the lack of such capable writers in Rome's own history. ${ }^{518}$ Second, he asserts that once Rome had subjugated its foes, FORTUNA began to rage and invert all things, introducing vices and luxury that spread like a plague, undermining the state and corrupting its youths. ${ }^{519}$

In Rome's debased condition, Sallust says, Catiline had no problems gathering

${ }^{518}$ Sallust, Bellum Catilinae 8.1-5

${ }^{519}$ Sallust, Bellum Catilinae 10.1-13.5. FORTUNA appears in 10.1, the youths in 12.2 and 13.4. 
around himself crowds of debauched individuals, almost like a personal bodyguard. ${ }^{520}$ We arrive at the crux of the scholarly debate when the historian describes Catiline's followers in greater detail: ${ }^{521}$

nam quicumque inpudicus adulter ganeo manu uentre pene bona patria lacerauerat...ei Catilinae proxumi familiaresque erant.

For whatever shameless person, adulterer, or glutton had squandered his patrimony with his hand, belly, or penis...these were Catiline's nearest friends and associates.

This is the Teubner text by Kurfess, who retained the same reading from earlier Teubner editors. ${ }^{522}$ Apart from minor variations in orthography and punctuation, nearly all editors and commentators for the past three centuries have printed this same text. ${ }^{523}$ Despite the apparent consensus, this passage has been fraught with scholarly attention since antiquity; over a century ago Ahlberg described the passage as locus a doctis uiris iterum iterumque tractatus. ${ }^{524}$ The number of conjectures has only grown since Ahlberg's time. ${ }^{525}$ Here I trace the history of the debate, then offer the vice trio as a possible means for reaching an accord. When paraphrasing scholars, I reproduce their punctuation, but when necessary alter their orthography, e.g. inpudicus for impudicus and uentre for ventre, so as not to distract from the core of the matter under discussion.

I begin with the branch of scholarship that maintains the most drastic truncation

${ }^{520}$ Sallust, Bellum Catilinae 14.1

${ }^{521}$ Sallust, Bellum Catilinae 14.2-3

${ }^{522}$ Kurfess (1957) 13. Cf. Dietsch (1859b) 156; Eussner (1908) 8; Ahlberg (1919) 12.

${ }^{523}$ Paul (1985) 158, who traces the evidence as far back as the editions of Wasse and Kortte in 1710 and 1737, respectively. For recent examples, see McGushin (1995) 17; Ramsey (2007) 31-32. Cf. Muse (2012) 3 and n. 6, who lists, besides Kurfess (1957) and Ramsey (2007) given above, Ernout (1941), Vretska (1976), and Flach (2007).

${ }_{524}^{524}$ Ahlberg (1911) 12

${ }^{525}$ Cf. McGushin (1977) 106: "It is not unlikely that this passage suffered from the attention of over-zealous scribes; it has attracted much comment subsequently." 
of the text. Reynolds typifies this line of thought in his $O C T$ edition, in which he prints nam quicumque [inpudicus adulter ganeo] manu uentre pene bona lacerauerat. ${ }^{526}$ Reynolds justifies the brackets with a citation to Sauppe, who, as his student Nitzschner reports, suggests that the tricolon preceding manu is a series of interpolated glosses. ${ }^{527}$ Nitzschner states that Sauppe's deletion is based on Fronto, who quotes this passage without a list of spendthrifts prior to the body parts: ${ }^{.52}$

- Sallustius - - <ait> quique manu uentre pene bona patria lacerauerat. uides quantum similitudine formae uerborum adsecutus sit, ut uerbum postremum, quamquam parum pudicum, non indecorum esse uideatur, ideo scilicet, quod <duo> uerba similia praecedant. quod si ita haec uerba contra dixisset: quique pene bona patria lacerauerat, inaudita obscenitas uerbis appareret --trat eis --duobus his uerbis manu, uentre adpositis - - aures tertioque --

- - Sallust - - says "and he who had squandered his patrimony with his hand, belly, or penis." You see how much he obtained by the likeness of the form of the words, so that the last word, although not really modest, does not seem inappropriate, certainly because these two similar words precede it. But if, to the contrary, he had spoken these words thus: "and he who had squandered his patrimony with his penis," an unheard obscenity appears in these words - - to them - - with these two words, hand and belly, placed before it - - the ears [hear it?] third --

Perhaps the first thing a reader notices is how fragmentary this passage is. ${ }^{529}$ While the sense of the text is still clear, using Fronto's lacunose passage to argue for a specific reading of Sallust's text is bound to fail. After all, besides the many gaps in Fronto's passage as we have it, including immediately before the quotation from Sallust, Fronto twice produces quique for quicumque as the subject of the quotation, though all

\footnotetext{
${ }^{526}$ Reynolds (1991) 13

${ }^{527}$ Nitzschner (1884) 16. Muse (2012) 41 points out that Leutsch (1869) 237 preceded Sauppe in proposing that the tricolon of epithets is a series of glosses.

${ }^{528}$ Fronto, Van den Hout 146.31-147.6

${ }^{529}$ I have reproduced Van den Hout's text, which marks lacunae with a double hyphen and editorial additions with angular brackets.
} 
manuscripts for Sallust agree on the reading quicumque ${ }^{530}$ Perhaps Fronto's erroneous form stems from the subsequent relative clause in Sallust's text (Bellum Catilinae 14.2: ... bona patria lacerauerat, quique alienum aes grande conflauerat) ${ }^{531}$

What can be said with more certainty is that Fronto's aim is not to preserve Sallust's original text, but rather to remark upon the effect of the historian's writing style. Fronto's interest in the quotation is in how placing penis last in a tricolon of uerba similia diminishes the indecency of the word. ${ }^{532}$ Fronto notes that were penis to come first in the list, it would be more offensive than it is in Sallust's passage, even though the word is not particularly immodest.

Augustine has a similar note when discussing the power of words. He says that each word moves the hearer by its sound, its meaning, or both, then ponders the effect of Sallust's quotation: ${ }^{53}$

unde enim est, quod non offenditur aurium castitas, cum audit manu uentre pene bona patria lacerauerat? offenderetur autem, si obscena pars corporis sordido ac uulgari nomine appellaretur, cum res eadem sit cuius utrumque uocabulum est, nisi quod in illo turpitudo rei quae significata est decore uerbi significantis operitur, in hoc autem sensum animumque utriusque deformitas feriret.

How is it that the chastity of our ears is not offended when it hears "he [who] had squandered his patrimony with his hand, belly, or penis"? But it would be offended if the obscene part of the body were called by a filthy and base name, since the designation of each is the same thing, except that in this [quotation] the foulness of the thing signified is concealed by the comeliness of the signifying word, for in this case the ugliness of each would strike both the sense and the mind.

Like Fronto, Augustine does not include the list of wastrels in his quotation of Sallust.

${ }^{530}$ See the apparatus criticus of Dietsch (1859b) 156.

${ }^{531}$ Zimmermann (1929) 50; Muse (2016) 504

${ }^{532}$ Van den Hout (1999) 347 remarks that similitudine formae refers to the fact that the words are all disyllabic.

${ }^{533}$ Augustine, de Dialectica 7 
Also like Fronto, Augustine is only concerned with one aspect of the passage, specifically the impact of the word penis: Augustine holds that the body part to which the word refers is sordid, but the word itself is not. ${ }^{534} \mathrm{~A}$ century and a half ago, Leutsch used this passage, but not Fronto's, to adduce that inpudicus, adulter, and ganeo are glosses. ${ }^{535}$ In a review a little over a decade later, Eussner objects that Augustine considers only the words pertaining to the aurium castitas. ${ }^{536}$ An additional piece of evidence that Augustine does not provide the entirety of Sallust's original quotation is the fact that he does not include the relative pronoun introducing the passage under consideration. While Fronto incorrectly gives quique for quicumque, Augustine is lacking a relative pronoun entirely. Both Augustan and Fronto, then, quote Sallust's passage, but do so in order to comment on matters of style or effect, as they themselves disclose in no uncertain terms. ${ }^{537}$ While these two authors confirm the accuracy of the second tricolon and the end of the clause (manu...lacerauerat), they should not be considered to record the quotation in its entirety, so the absence of the first tricolon in their texts does not indicate such an absence in Sallust's original. In light of this analysis, we see that Reynolds' brackets are erroneous, as their existence is based on the faulty belief that Fronto and/or Augustine

${ }^{534}$ This is perhaps in contrast to mentula, which seems to have had a much harsher tone. See Adams (1982) 9-12, 35-36.

${ }^{535}$ Leutsch (1869) 237

${ }^{536}$ Eussner (1881) 346

${ }^{537}$ Cf. Ramsey (2013) lvi, who comments that relative to the size of his corpus, Sallust is the most quoted Latin prose author, even more so than Cicero, but warns that "The quotations, however, typically serve to illustrate a particular form of a word or an usual [sic] meaning or locution, and so the immediate context from which the relevant words were excerpted tends to be of little concern. It is not uncommon for the text to be altered or abridged by the quoting author, who may be producing the quotation from memory." 
records Sallust's original passage. ${ }^{538}$

As noted above, most editors print what Reynolds condemned with brackets, but arguments abound as to what the printed text ought to be. There are over five hundred manuscripts that preserve the Bellum Catilinae, two of which date to the ninth century, while most of the others were copied in the eleventh century. ${ }^{539}$ The majority of scholarly debate over the text concerns the intrusion of alea, sometimes aleo, in some of the manuscripts in a variety of positions, mostly after ganeo. ${ }^{540}$ Further complicating the matter is that many manuscripts supply ganeo only in suprascript or only in the margin, including in the oldest manuscripts, leaving the appropriate word order in even greater doubt. ${ }^{541}$ In most cases, editors reject alea as an intrusive gloss explaining manu because of its shifting position and because it upsets the balance of the phrase. ${ }^{542}$ The text as generally accepted, however, leaves something to be desired: while inpudicus adulter could correspond with pene and ganeo could correspond with uentre, nothing in the first tricolon adequately balances manu. Jacobs and Kritz, followed by others, address these concerns by noting that manu indicates gambling, then suggest that manu and uentre both

${ }^{538}$ Woodman (2007) 11 nevertheless follows Reynolds' text (as he says on xxxii-xxxiii) in his Penguin translation, in which he omits the bracketed triad entirely and offers the rather strange interpretation "muscle" for manu: "Whoever had ravaged his ancestral property by means of his muscle, stomach or groin."

539 See Ramsey (2013) lii-lix for an overview of the manuscript tradition.

${ }^{540}$ Manuscripts also show the word alealaleo before ganeo or after manu. In one manuscript (m), alea has been corrected to aleo. The most complete apparatus criticus is that of Dietsch (1859b) 156, but see also Reynolds (1991) 13; Ramsey (2013) 40.

${ }^{541}$ The difficulties of which words to accept and in which order are equally pronounced in English translations. Scott-Kilvert (1962) gives "Every gambler, libertine or glutton..." (presumably aleo/aleator, inpudicus, ganeo) and Handford (1963) gives "Debauchees, adulterers, and gamblers..." (presumably inpudicus, adulter, aleo/aleator); neither indicates the Latin he translates. Cf. Paul (1985) 159 n. 8.

${ }^{542}$ Cf. Paul (1985) 158 
correspond with ganeo while pene corresponds to both inpudicus and adulter. ${ }^{543}$ This proposal results in a chiastic structure of aab bba, a solution with its own difficulties, including no exact parallel existing in Sallust. ${ }^{544}$

Wölfflin's explanation is more appealing: excise adulter as a gloss on inpudicus and read aleo, corrected from alea, after ganeo, resulting in the sequence inpudicus, ganeo, aleo manu, uentre, pene, which has the more usual chiastic structure abc cba. ${ }^{545}$ With this arrangement, the degenerates of the first tricolon have squandered their patrimonies with the body parts of the second tricolon, given in reverse order. The sexual

543 Jacobs (1852) 30; Kritz (1856) 52. Kritz cites Sallust, Bellum Catilinae 2.5 as a parallel, but it is not. Cf. Paul (1985) 158 n. 7. Greenough and Daniell (1903) 66 give the note "manu: i.e. gaming and other crimes which he had to pay for; cf. redimeret, [later in the sentence]," but make no mention of the chiastic structure because they strangely expunge pene without explanation, a divergence from Jordan (1876), their model text (as they say on iii).

${ }^{544}$ Paul (1985) 158 n. 7 notes that Kritz is followed by Opitz (1894), Wirz ( 1894), Kurfess (1922), Vretska (1976), and, with reservations, McGushin (1977). Citing Wirz, McGushin (1977) 106-107 does "not find this argument totally convincing," but is hesitant to accept more attractive solutions that stray from the generally accepted text, such as Wölfflin's. Muse (2012) 42 remarks that "Editors who accept this sequence are aware that manus most likely refers to gambling with dice...but rather than assigning this vice to its own type of wastrel, they suppose that the ganeo both gorges and gambles." Muse's comment echoes the note in Dietsch (1864) 70-71 n. 2: "Der ganeo (Kneipbruder) prasst und spielt (Cic. in Cat. II 10, 23...). Die Werkzeuge womit er sein Hab und Gut verzettelt, sind demnach die manus, mit welcher er die Würfel führt, und der venter," with further explanation of the chiastic arrangement. Contra Woodman (2007) 11, who renders manu as "muscle" and omits any mention of gambling. Muse (2016) changes his mind from his 2012 article and supports the idea of only two kinds of wastrels, but he bases his argument on Sallust's passage as a model for Lactantius, Divinae Institutiones 3.26.3-9, who writes three and half centuries later and whose passage bears far greater similarities to Cicero, in Catilinam 2.5.10, which itself seems to have influenced Sallust.

${ }^{545}$ Wölfflin (1873) 1662. Cf. Paul (1985) 158-159. Beroaldo (1501) 140 actually precedes Wölfflin by several hundred years in emending alea to aleo, though he notes it in his commentary on Apuleius, Metamorphoses, in his note on subit aleam, nowadays printed as subiuit aleam at 4.15. Nevertheless, editors and scholars credit the idea to Wölfflin, whose emendation also excises adulter, which Beroaldo retains and understands inpudicus as an adjective agreeing with it. As my argument concerns the entire emendation, I also refer only to Wölfflin for the remainder of this discussion. 
implications of inpudicus reinforce this reading, especially as it pairs with pene. ${ }^{546}$ Moreover, asyndenton, particularly three-term asyndenton, is a documented feature of Sallust's style, as is chiasmus. ${ }^{547}$ Instances of three-term chiasmus occur in Sallust, as does another case of three-term asyndenton in chiasmus in the same work: Sallust notes that his first inclination was to engage in political life, but he nevertheless avoided it, "for in place of propriety, in place of restraint, in place of excellence, there thrived impudence, largess, greed" (nam pro pudore pro abstinentia pro uirtute audacia largitio auaritia uigebant) ${ }^{548}$ If adulter is excised as a gloss on inpudicus, then the parallels in Sallust's text justify searching for a third noun to follow ganeo and to balance manu.

Waltz agrees with Wölfflin's argument for the most part, but disagrees with the emendation; he argues that Sallust intended an asymmetrical structure, proposing that adulter took the place of an original aleator because of the neighboring inpudicus. ${ }^{549} \mathrm{He}$ proposes the sequence inpudicus, aleator, ganeo, manu, uentre, pene, with the asymmetrical scheme abc bca designed to avoid the difficulty of pronouncing ganeo, aleator. ${ }^{550}$ Though inconcinnity is a hallmark of Sallust's style, Waltz's justification for it here is not persuasive. ${ }^{51} \mathrm{He}$ also argues that it is difficult to understand that a hand is

\footnotetext{
${ }^{546}$ OLD s.v. inpudicus 1

${ }^{547}$ McGushin (1977) 14-15; McGushin (1995) 5-6; Paul (1985) 160 and n. 14-16, with bibliography. For examples of asyndenton of three or more words, see Sallust, Bellum Catilinae 3.3, 9.2, 11.2, 11.6, 14.2, 16.2, 21.2, 54.4, and 59.5.

${ }^{548}$ Sallust, Bellum Catilinae 3.3. For examples of asyndetic lists in chiastic form, see Sallust, Bellum Catilinae 6.1, 10.2, 15.5, 20.7, 59.5, and 61.9. For three-term chiasmus, in Sallust's other history, see Sallust, Bellum Jugurthinum 84.2.

${ }^{549}$ Waltz (1904) 219

${ }^{550}$ Waltz (1904) 219. Köchly anticipated Waltz in this arrangement, including the use of aleator for adulter. See Paul (1985) 159 n. 9; Reynolds (1991) 13.

${ }^{551}$ On Sallust's style and inconcinnity, see Merivale (1966) xvi-xviii; McGushin (1977) 13-21, especially 14-16; McGushin (1995) 4-8, especially 5-6; Ramsey (2007) 10-14, especially 13-14; Ramsey (2013) xlii-lii, especially li-lii.
} 
rolling dice here despite Ovid, Epistulae ex Ponto 1.5.46, nec tenet incertas alea blanda manus. The association between manus and casting randomizing agents is closer than Waltz suggests, however, and there are many examples of this pairing. ${ }^{552}$

Waltz's explanation has not convinced subsequent editors, but Wölfflin's found early support. Summers follows Wölfflin, as does Rolfe in his Loeb edition, though both differ from Wölfflin in lengthening alea to aleator rather than emending it to aleo; Ramsey prints the commonly accepted reading, but remarks in his commentary that an "attractive proposal" is the text of Summers and Rolfe, though Ramsey does not cite anyone for the idea. ${ }^{553}$ Similarly, McGushin prints the usual reading in his school edition and in the commentary observes the benefit of the chiastic structure offered by Wölfflin's emendation, though McGushin does not name him, but states that "This and similar proposals do not seem compelling enough to allow us to discard the commonly accepted reading. ${ }^{554}$ As discussed above, however, the commonly accepted reading is by no means certain; devotion to one interpretation simply because it has historically held pride of place can only hinder progress. Interestingly, Ramsey appears to have had a change of heart only a few years after publishing his commentary, since in his revision of Rolfe's Loeb edition, he follows Wölfflin's text, though he places brackets around adulter rather

${ }^{552}$ See, for example, Augustine, City of God 6.7; Aulus Gellius, Attic Nights 18.13.4; Macrobius, Saturnalia 1.10.12; Martial, Epigrams 14.16; Ovid, Ars Amatoria 1.452, 2.203; Plautus, Curculio 354-355; Plautus, Vidularia 33; Lucius Pomponius Bononiensis, apud Nonius Aleonibus 147 M, Ribbeck (1898) 270; Propertius, Elegies 2.33b26; Pseudo-Cyprian, De Aleatoribus 5; Sidonius, Epistules 8.8.1. See also Suetonius, Augustus 71.3, where manus is used as the stakes of a game of chance; cf. OLD s.v. manus 26.

${ }_{554}^{553}$ Summers (1900) 8; Rolfe (1921) 24; Ramsey (2007) 95

${ }^{554}$ McGushin (1995) 67 
than excising it. ${ }^{555}$

Paul provides the most convincing argument. He follows Wölfflin in printing aleo, but contends that Wölfflin excises the wrong word. ${ }^{556} \mathrm{He}$ notes that inpudicus implies homosexuality here, as it does when Cicero describes Catiline's closest followers, discussed below. ${ }^{557}$ Paul comments that just a few sentences later, however, Sallust himself casts doubt on the rumors of Catiline having sex with the young men in his camp. ${ }^{558}$ For Sallust to apply this characteristic to Catiline's followers then deny the veracity of the imputation only lines later would undermine the authority of his own portrayal. ${ }^{559}$ Moreover, inpudicus appears in Sallust only here, while the historian brings an extended charge of adultery against Catiline's female companions later in the text, a charge that Cicero levels against Catiline's followers and one brought against Catiline himself. ${ }^{560}$ If aleo were omitted after ganeo by homeoteleuton, inpudicus, inspired by Cicero's similar invective, could have been supplemented to restore balance to the phrase. ${ }^{561}$ Paul's proposed sequence adulter ganeo aleo manu uentre pene is the most attractive option, but needs to be explored in greater detail.

The vice trio now comes into play. The arguments that can be made from Sallust's text, including the various manuscript readings, leave Paul's proposal as the likeliest candidate, but an analysis of comparanda is necessary to confirm the soundness of this reading. The vice trio aids this pursuit. Each word in the tricolon adulter ganeo

\footnotetext{
${ }^{555}$ Ramsey (2013) 40

${ }^{556}$ Paul (1985) 158-161

${ }^{557}$ OLD s.v. inpudicus 1b; Cicero, in Catilinam 2.10.23. Kortte even glossed the word with pathicus; cf. Paul (1985) 159 n. 10.

558 Sallust, Bellum Catilinae 14.7

${ }^{559}$ Paul (1985) 159

${ }^{560}$ Sallust, Bellum Catilinae 24.3-25.3; Cicero, in Catilinam 2.10.23; Asconius 91C

${ }^{561}$ Paul (1985) 161
} 
aleo matches one part of the vice trio: adulter corresponds with fornication, ganeo with consumption, and aleo with gam(bl)ing. The second tricolon manu uentre pene clarifies the means by which the wastrels of the first tricolon have devoured their patrimonies: the adulterer with his penis, the glutton with his belly, and the gambler with his hand. Incidentally, Wölfflin's original emendation, retaining inpudicus rather than adulter, likewise works with the vice trio, as fornication concerns an array of sexual deviancy, but the argument does not succeed for the reasons outlined above. All the same, this triad's cohesion lends credence to Paul's reading of Sallust's text and offers an avenue for examining possible influences.

Paul's reading would have Sallust match the complaints of the Greek orators, discussed in the previous chapter. In those authors, the vice trio is a means of attacking one's foes, whether actual humans or contemporary morality broadly. Isocrates rails against the wantonness of the youths of his day, even the best of whom spend their time indulging in the vice trio rather than pursuing a worthwhile education. Foremost in that education is proper governance of one's household, that is, how to preserve one's inheritance, exactly what the wastrels in Sallust have failed to do. As explored at length in the previous chapter, Isocrates also laments a worse category of youths, who engage in much the same activities, but with an added monetary element. That Sallust says Catiline's intimates devastated their patrimonies with the vice trio unmistakably indicates the same financial element. Moreover, the orator Aeschines impugns Timarchus for squandering his own patrimony indulging in the vice trio, as well as the subsequent steps he took to continue funding his debauched lifestyle. Aeschines uses the vice trio to explain why Timarchus has lost his right to speak to the Assembly: he asserts that 
Timarchus' love of the vices at question, themselves not illegal, drove him to prostitute himself and squander his patrimony, both of which result in the loss of rights as a citizen under Athenian law. The Athenian orators bemoan the vice trio and misuse of one's estate, especially one's inheritance, so finding the same combination in Sallust strengthens the reading. Even if Sallust does not have these authors in mind, he is working in a literary landscape in which these traits are used to condemn others.

Though Sallust's passage shares the vice trio as invective with the speeches of the Athenian orators, it has even closer parallels, some of which the historian may have used as models. One such passage is a fragment from Naevius: "you're the worst of the very worst, reckless, glutton, debauchee, gambler" (pessimorum pessime, audax, ganeo, lustro, aleo) ${ }^{562}$ Although we have no additional context for this line, it offers palpable similarities to the Sallustian quotation. Here too the author-or more likely a character in one of his works-delivers an invective comprising an asyndetic string of insults. Likewise, the vice trio is conspicuous in the list's last three items, two of which mirror the emendation of Sallust's text: ganeo and aleo epitomize consumption and gam(bl)ing in both authors, while Naevius' lustro, indicating a person who frequents brothels, is broader than and not mutually exclusive of Sallust's adulter in exemplifying fornication. ${ }^{563}$ In both content and form, then, Naevius' fragment presents a parallel and potential model for Sallust's text as emended above.

Another possible model far closer to Sallust's own time of composition is Catullus' twenty-ninth poem. The poet criticizes Caesar and Pompey for their patronage

\footnotetext{
${ }^{562}$ Naevius fr. 118 Ribbeck

${ }^{563}{ }^{O L D}$ s.v. lustro ${ }^{2}$; s.v. lustror ${ }^{1}$; s.v. lustrum ${ }^{1} 3$
} 
of Mamurra, whose crimes he alleges are unbearable except to a certain kind of person: ${ }^{.64}$

quis hoc potest uidere, quis potest pati,

nisi inpudicus et uorax et aleo,

Mamurram habere quod comata Gallia

habebat ante et ultima Britannia?

cinaede Romule, haec uidebis et feres?

5

cinaede Romule, haec uidebis et feres?

es inpudicus et uorax et aleo.

paterna prima lancinata sunt bona,

secunda praeda Pontica, inde tertia

Hibera, quam scit amnis aurifer Tagus.

nunc Galliae timetur et Britanniae.

quid hunc malum fouetis? aut quid hic potest

nisi uncta deuorare patrimonia?

Who can see this, who can endure it, except for the shameless and the glutton and the gambler, that Mamurra has what longhaired Gaul and remotest Britain had before? You sodomite, Romulus, you will see this and you will bear it?

...

You sodomite, Romulus, you will see this and you will bear it? Then you are shameless and a glutton and a gambler.

First his patrimony was consumed, second the plunder from Pontus, then third the loot from Spain, which the gold-bearing river Tagus knows. Now there is fear for Gaul and Britain. Why do you support this wicked man?

What is he able to do except devour sumptuous inheritances?

Probably writing in late 55 or early 54 BCE, Catullus alludes to Mamurra's service under

Pompey in Pontus and under Caesar in Spain and, more recently, Gaul and Britain. ${ }^{565}$

Catullus alleges that Mamurra devours vast sums of wealth, beginning with his own

${ }^{564}$ Catullus, Carmina 29.1-5, 9-10, 17-22

${ }^{565}$ Catullus mentions Mamurra's financial gains from Britain in verses 4, 12, and 20. Julius Caesar was the first Roman to enter the island with an army (Tacitus, Agricola 13), which he did in with invasions in two successive years, 55 and 54 BCE. Catullus alludes to Julia, Caesar's daughter and Pompey's wife, still being alive in verse 24. As Julia died in the fall of $54 \mathrm{BCE}$, during Caesar's second invasion of Britain, Catullus must have written the poem after the first invasion and before her death, so in late 55 or early 54 BCE. Cf. Merrill (1893) ad loc.; Batstone (1995) 174; Garrison (2012) 109. 
patrimony, then all of the spoils of war he gains on his campaigns with the Roman generals he serves. Moreover, he does so in such a way that the only person who could bear it must be shameless, a glutton, and a gambler. ${ }^{566}$ The word inpudicus indicates more than generalized shamelessness, however, and has homosexual connotations here, as it does in Cicero's denunciation of Catiline's followers, mentioned above and discussed below, and as Catullus himself makes plain with his use of cinaede to refer to Caesar; Catullus explicitly accuses Mamurra and Caesar of a homosexual relationship in his fifty-seventh poem, in which he calls them inprobis cinaedis. ${ }^{57}$

Catullus, Carmina 29 offers a parallel and potential model for Paul's emendation of Sallust's text. The poet rebukes anyone who would support Mamurra's squandering of his own and others' patrimonies, stating that anyone who does so must engage in all three elements of the vice trio. Moreover, Catullus' formulation inpudicus et uorax et aleo perfectly fits the chiastic arrangement of the Sallustian passage. ${ }^{568}$ Although Catullus' line does not share Sallust's asyndetic construction, the same general classes of vices are

\footnotetext{
${ }^{566}$ Just as lines 5 and 9 are identical (cinaede Romule, haec uidebis et feres?), some manuscripts duplicate line 10 (es inpudicus et uorax et aleo) following line 5, reinforcing the intensity of the denunciation.

${ }^{567}$ Catullus, Carmina 57.1, 10; also relevant for present purposes is the end of line 8, uorax adulter. Much ink has been spilled on Catullus' intended addressee(s). A full examination of this question exceeds the scope of the present discussion, but I contend that the initial addressee is Caesar, whose identity the context and parallel with Catullus' fifty-seventh poem confirm, while Pompey becomes a second addressee beginning in line 13, where the second-person adjectives and verbs shift from the singular to the plural: Mamurra is ista uestra diffuta mentula (13), not tua; Catullus asks multiple people why they support Mamurra, quid hunc malum fouetis (21); Catullus accuses multiple subjects of having destroyed everything, perdidisti omnia (24); and Catullus verifies the identities of both addressees when he calls them father-in-law and son-in-law, socer generque (24). The reference to Pontus perhaps also indicates Pompey. See Scott (1971) 17-25 and Cameron (1976) 155-163 for a dissection of the charges and their potential target(s), including the sarcastic sobriquet "Romulus."

${ }^{568}$ Cf. Muse (2012) 46
} 
present in the same order, as the passages share aleo for gam(bl)ing and uorax is synonymous with ganeo, each denoting excessive consumption. The sole change of significance is Sallust's adulter rather than Catullus' inpudicus, but, as Paul argues, Sallust does not appear to believe the rumors of homosexuality in Catiline's camp, so substituting another form of fornication, that is, adultery, fits Sallust's outlook while retaining the vice trio.

Cicero's descriptions of Catiline's followers share many of the same elements as the quotations discussed above, but as they concern the same subject as Sallust's text, they merit extended treatment. ${ }^{569}$ In his second speech against Catiline, Cicero criticizes the revolutionary's supporters at length. Cicero reinforces the kinds of dissolute characters that are Catiline's closest associates. He offers a protracted list of such people, including some by now familiar types: ${ }^{.50}$

tota Italia...quis ganeo, quis nepos, quis adulter...inueniri potest qui se cum Catilina non familiarissime uixisse fateatur?

In all of Italy...what glutton, what prodigal, what adulterer...can be found who would not confess to have lived with Catiline on the most intimate terms?

This passage bears striking similarities to the Sallustian text. The historian's relative pronoun quicumque is comparable to Cicero's series of degenerates introduced by quis, while its breadth matches the extensiveness of tota Italia. Additionally, the words ganeo and adulter are the same in Cicero and Sallust, while the former's familiarissime parallels the latter's proxumi familiaresque. The word nepos in Cicero has broader connotations

${ }^{569}$ The similarities throughout the works are strong enough that Scudder (1900) provides an entire edition of Sallust's text with running parallels from Cicero's Catiline orations in the footnotes.

${ }^{570}$ Cicero, in Catilinam 2.4.7 
than aleo in Sallust, but the terms share the imputation of wastefulness. Moreover, as nepos can also indicate a descendant, the idea of ravaging one's inheritance is perhaps present, matching the end of Sallust's phrase. The parallels between the two passages offer food for thought and both are perhaps indebted to the same source, discussed below. ${ }^{571}$

A bit later in the speech, Cicero censures Catiline's followers for their inhuman and unbearable impudence (non humanae ac tolerandae audaciae), then rebukes them in terms reminiscent of Alcidamas: $:^{572}$

patrimonia sua profuderunt, fortunas suas obliganerunt; res eos iam pridem deseruit, fides nuper deficere coepit; eadem tamen illa, quae erat in abundantia, lubido permanet. quodsi in uino et alea comissationes solum et scorta quaererent, essent illi quidem desperandi, sed tamen essent ferendi.

They have dissipated their patrimonies, they have pawned their fortunes; money abandoned them long ago, recently credit began to fail them; yet that same desire, which was present in their time of abundance, remains. But if in their wine and gambling they sought only revelries and harlots, they would be pitiable indeed, but nevertheless they might be tolerable.

Catiline's followers are not content, however, and Cicero continues by asking who can bear the fact that the worthless men that engage in these pursuits plot against the good men of the city. All of the familiar elements are present: Catiline's followers squandered their patrimonies with consumption, fornication, and gam(bl)ing, denoted by vino, scorta, and alea, respectively, while comissationes may encompass all three. ${ }^{573}$ Cicero, then,

${ }^{571}$ An additional parallel is that each list of Catiline's intimates includes parricides, though this detail falls outside the scope of the present argument.

${ }^{572}$ Cicero, in Catilinam 2.5.10

${ }^{573}$ I have only reproduced the most relevant section of the passage, but the next part makes clear that Catiline's followers do more than just seek out scorta and comissationes: he states that they are men who lie around at banquets, embracing shameless women, languid with wine, stuffed with food, and worn out by their lusts 
provides a parallel for Sallust's text as Paul emends it, as the Roman orator also describes Catiline's followers as wasting their inheritance through the vice trio.

Cicero often resorts to the vice trio in his prosecutorial speeches. ${ }^{574}$ Although the speeches against Catiline come relatively early in Cicero's career, they are not his first use of the vice trio against an opponent. In fact, Cicero uses the vice trio in his very first prosecution case, in which he charges Gaius Verres with corruption and extortion while governor of Sicily. After stating that the time restrictions for his speech limit how much evidence he can give, Cicero declares that he will ignore all of the offenses Verres committed before entering public life: ${ }^{575}$

omne illud tempus quod fuit antequam iste ad magistratus remque publicam accessit, habeat per me solutum ac liberum. sileatur de nocturnis eius bacchationibus ac uigiliis; lenonum, aleatorum, perductorum nulla mentio fiat; damna, dedecora, quae res patris eius, aetas ipsius pertulit, praetereantur; lucretur indicia ueteris infamiae; patiatur eius uita reliqua me hanc tantam iacturam criminum facere.

All that time that came before he entered magistracies and public life, may he have it passed over and free as far as I am concerned. Let there be silence regarding his nighttime, Bacchic revelries and sleeplessness; may there be no mention of his pimps, gamblers, procurers; the losses and dishonors that his father's estate and his own age suffered, let them be disregarded; may he win the disclosure of his former disgrace; the rest of his life allows me make this great omission of his crimes.

Cicero uses praeteritio, naming the transgressions when outlining what he will not discuss. The indiscretions of Verres' youth are the same three vices under consideration:

(accubantes in conuiuiis conplexi mulieres inpudicas uino languidi, conferti cibo...debilitati stupris). It should be noted that the adjective Cicero uses to describe these women is inpudicas.

${ }^{574}$ The question of whether Cicero actually delivered all of these speeches exceeds the scope of the present discussion, which concerns only the line of argument he outlines.

${ }^{575}$ Cicero, in Verrem 2.1.33 
Cicero claims that Verres stayed awake all night drinking, having sex, and gambling. ${ }^{576}$ Excess or financial impropriety is part of each charge, for the drinking is taken to the extreme of Bacchic revelries, pimps and procurers facilitate the fornication, and Verres incurred monetary losses while playing with gamblers: the damna Cicero mentions have the implication of financial damages from gambling. ${ }^{577}$ Verres, then, squandered his patrimony or the wealth that he stood to inherit one day, as Cicero remarks that his father's estate suffered the losses in question.

Cicero returns to these same ideas throughout the Philippics, which are nearly contemporaneous with the publication of Sallust's monograph. ${ }^{578}$ In order to avoid gratuitous repetition, however, I only reproduce selections from these passages and offer no further commentary: see, for instance, Cicero, Philippics 2.27.67, where the orator says Antony and his friends dissipated Pompey's estate, acquired at auction, in mere days

${ }^{576}$ van der Blom (2010) 133-134 comments that Cicero focuses on Verres' bad character and takes his guilt for granted, while when defending Flaccus for the same charges he avoids the question of guilt and focuses on Flaccus' good character.

${ }^{577}$ See e.g. Cicero, Philippics 2.27.67, damna aleatoria; Isidore, Etymologicae 18.66, canem...damnosus; 68 , de interdictione aleae: ab hac arte fraus et mendacium atque periurium numquam abest, postremo et odium et damna rerum; Juvenal, Satires 14.4, damnosa...alea; Martial, Epigrams 13.1.8, alea nec damnum nec...lucrum; 14.19.1, alea...damnosa; Ovid, Ars Amatoria 2.206, damnosi...canes; Tristia 2.474, damnosos canes; Persius, Satires 3.49, damnosa canicula; Propertius, Elegies 4.8.46, damnosi...canes. Cf. Seneca the Younger, Epistles 99.12, aleam...damnum, used broadly of loss from the hazard of living. The word canis in several of the examples above refers to the lowest possible throw, a one, which brings financial loss because all other throws beat it.

${ }^{578}$ Sallust must have published the Bellum Catilinae after the death of Julius Caesar, as he refers to him in the past tense at 53.6, and perhaps after the death of Cicero, the last leading personality involved. As the Bellum Catilinae appears to be Sallust's earliest work, the historian may have circulated his monograph in late 42 or early $41 \mathrm{BCE}$, leaving enough time for the composition of the Bellum Jugurthinum and the Historiae before the author's death in 35 BCE. For more details on the dates and order of composition, see Syme (1964) 128; McGushin (1977) 6-7; Ramsey (2007) 6; Ramsey (2013) xxxi-xxxiv. 
through the actions of the vice trio, then remarks that "such prodigality was not only great enough to consume one man's patrimony, as it did, but could have quickly devoured cities and kingdoms" (non modo unius patrimonium quamuis amplum, ut illud fuit, sed urbis et regna celeriter tanta nequitia deuorare potuisset); 3.14.35, where the orator says his audience knows the kinds of people who are Antony's friends and household, calling them "lustful, petulant, unclean, shameless, gamblers, drunks" (libidinosis, petulantibus, inpuris, inpudicis, aleatoribus, ebriis); and 13.11.24, where Cicero tells Antony that without Caesar's kindness, his noble birth would not have aided him at all, but "you would have wasted the whole span of your life in brothels, cookshops, gambling, and wine, just like you did when you used to lay your beard and your brain in the laps of mime actresses" (in lustris, popinis, alea, uino tempus aetatis omne consumpsisses, ut faciebas, cum in gremiis mimarum mentum mentemque deponeres).

Returning to the second Catilinarian oration, Cicero reprises his enumeration of Catiline's followers when he divides them into six categories. The last group weighs heavily on the present discussion: ${ }^{579}$

postremum autem genus est non solum numero uerum etiam genere ipso atque uita quod proprium Catilinae est, de eius dilectu.... in his gregibus omnes aleatores, omnes adulteri, omnes inpuri inpudicique uersantur.

There is a final class, last not only in number but also in kind and lifestyle, a class that is Catiline's personal entourage, of his own choosing.... In these crowds dwell all the gamblers, all the adulterers, all the unclean and shameless.

The latter portion of this passage bears strong similarities to Sallust's. The similarities have tempted some editors to emend the historian's text on the basis of Cicero's quotation. Paul observes that Sallust drew some inspiration from this passage and that

${ }^{579}$ Cicero, in Catilinam 2.10.22-23 
aleo in Sallust matches aleatores in Cicero. ${ }^{580}$ Conversely, editors who contend that inpudicus and adulter should both remain in Sallust's text, maintaining the usual reading, also cite this passage as evidence. ${ }^{581}$ It is also possible that the Ciceronian passage, with adulter and inpudici in the same inventory of miscreants among Catiline's closest associates, influenced scribal revisions of Sallust's text. ${ }^{582}$ For further elucidation, we turn to a model Cicero and Sallust share.

In describing Catiline's followers, both Cicero and Sallust are indebted to Theopompus' depiction of the coterie surrounding Philip II of Macedon. ${ }^{583}$ Theopompus regularly rails against moral failings for the detriments they bring to society ${ }^{584}$ His approach and use of the vice trio are perhaps unsurprising given that he studied under Isocrates, whose relevant works are examined in the previous chapter. ${ }^{585}$ In the fortyninth book of his Philippica, Theopompus lambasts Philip and his followers for their behaviors and ascribes each portion of the vice trio to them in quick succession: ${ }^{586}$

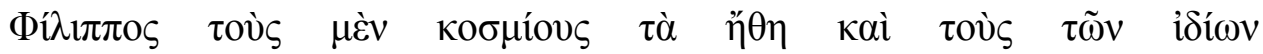

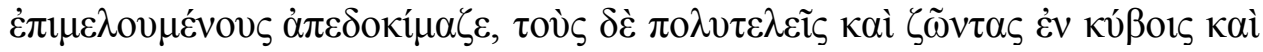

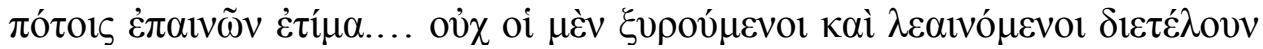

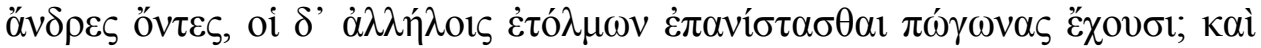

${ }^{580}$ Paul (1985) 160-161: “Though Sallust...in part rejects Cicero's description of the Catilinarians at Cat. 2.23 by questioning the ascription of pederasty to them, he nonetheless owes some of his inspiration to the Ciceronian passage, so that on those grounds aleo would be a reasonable reflection of Cicero's aleatores."

${ }_{582}^{581}$ E.g. Kritz (1856) 52

${ }^{582}$ Muse (2012) 46

${ }^{583}$ McGushin (1977) 105; Paul (1985) 161 and n. 19; Muse (2012) 46-47; Muse (2016) 504

${ }^{584}$ See, for example, Flower (1994) 69: "Theopompus saw luxury and moral incontinence as a fundamental cause of the social and political turmoil of the fourth century."

${ }^{585}$ On Theopompus studying under Isocrates, see $O C D$ s.v. Theopompus (3); Smith (1873) s.v. Theopompus (5) with detailed sources.

586 Theopompus, FGrH 115 fr. 225b = Athenaeus, Deipnosophistae 6.77.260d-f. Polybius, Histories 8.9.6-12 also records this fragment ( $F G r H 115$ fr. 225a) with trivially different wording in the first sentence. 


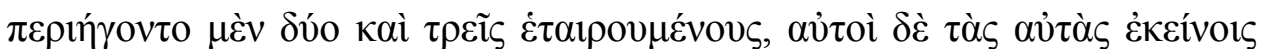

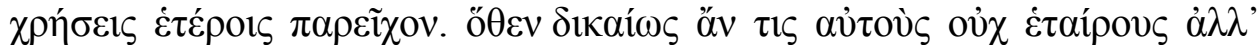

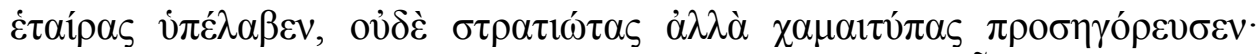

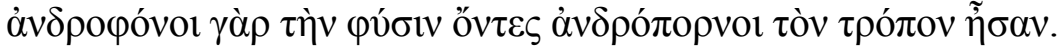

Philip rejected men who were moderate in character and managed their possessions, but he commended and bestowed honors on those who were extravagant and living their lives in dicing and drinking.... Did they not persist in being shaved and smooth, even though they were men, and did they not dare to mount one another, even though they had beards? And they would have two or three male lovers with them, but they themselves offered to others the same uses as those men. For that reason, someone

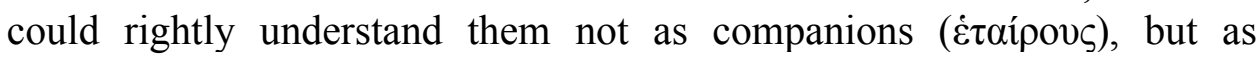

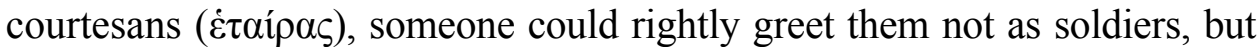

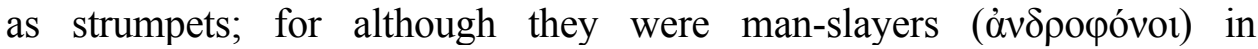
appearance, they were man-whores ( $\dot{\alpha} v \delta \rho o ́ \pi o \rho v o l)$ in practice.

The parallels in content among Theopompus, Cicero, and Sallust are clear: a powerful individual gathers a personal entourage of individuals who mismanage their assets and engage in the same kinds of vices. Moreover, Cicero, after the last passage of his cited above, proceeds to expound upon the sexual and homosexual practices of Catiline's retinue, just as Theopompus does. On the other hand, Sallust imputes the same categories of vice to Catiline's followers, but, as discussed above, does not believe the accounts of homosexuality in the camp, as he himself states. The vice trio is a valuable tool for seeing Theopompus as a potential source, as fornication encompasses a range of sexual deviancy, so Sallust does not have to mirror the Greek historian's account precisely; by looking too closely for an exact parallel, we risk missing Theopompus' passage as a model for Sallust except perhaps as mediated through Cicero. Moreover, the very fact that Sallust opposes the ascription of homosexuality to Catiline's followers may be him combating such rumors, but may also be his attempts to differentiate his own account from his model, perhaps pointing to the prevalence of stock accusations in moral criticism. 
In Sallust's passage under discussion, the historian's form may be no less indebted to Theopompus than its content. ${ }^{587}$ Sallust's next sentence nearly confirms that the Roman historian looked to his Greek counterpart for inspiration. Sallust records that Catiline corrupted those around him, rendering his friends equal in their iniquity, paralleling a similar claim Theopompus makes about Philip. To facilitate the comparison, I reproduce both passages here: ${ }^{588}$

nam quicumque adulter ganeo aleo manu uentre pene bona patria lacerauerat...ei Catilinae proxumi familiaresque erant. quod si quis etiam a culpa uacuus in amicitiam eius inciderat, cotidiano usu atque inlecebris facile par similisque ceteris efficiebatur.

For whatever adulterer, glutton, or gambler had squandered his patrimony with his hand, belly, or penis...these were Catiline's nearest friends and associates. But if anyone free from blame happened to fall into his friendship, then by daily practice and enticements he easily was made the same as the rest in degree and kind.

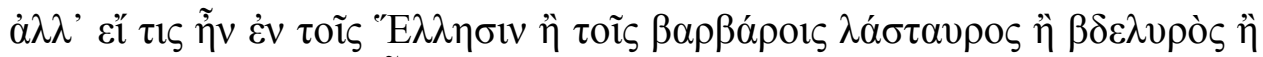

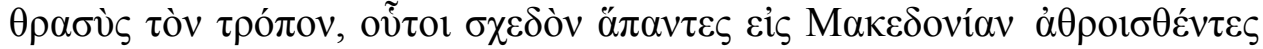

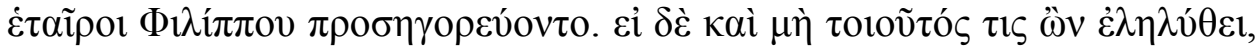

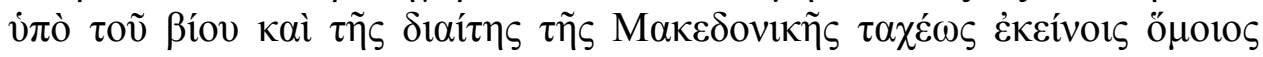

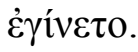

But if anyone among the Greeks or the barbarians was shameless or loathsome or impudent in character, nearly all of these men were gathered in Macedon and were greeted as Philip's companions. But if anyone had not been like this when he arrived, then by the Macedonian manner of living and mode of life he quickly became the same as the others.

The passages begin with the same sweeping generality, with Sallust's quicumque

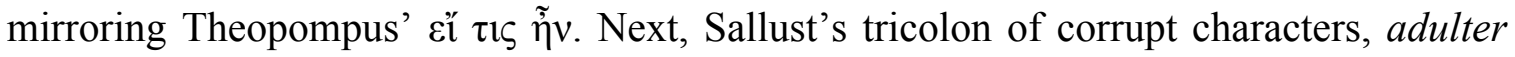

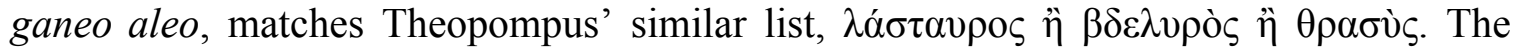

${ }^{587}$ See Wallin (1967) for a full treatment of Theopompus' stylistic influence on Sallust's Bellum Catilinae.

${ }^{588}$ Sallust, Bellum Catilinam 14.2-4; Theopompus, FGrH 115 fr. 224 = Athenaeus, Deipnosophistae 4.62.167b 
first of Theopompus' three epithets implies pathic homosexuality; it is synonymous with

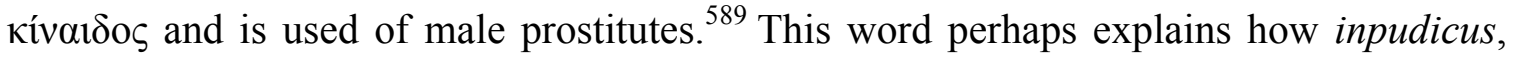
which has much of the same meaning, entered Sallust's text. As discussed above, Sallust rejects the attribution of homosexuality to Catiline's followers, instead ascribing to them a different form of fornication. ${ }^{590}$ The Roman historian offers more specificity than his Greek counterpart in the final two terms: ganeo and aleo paint a more lurid picture than

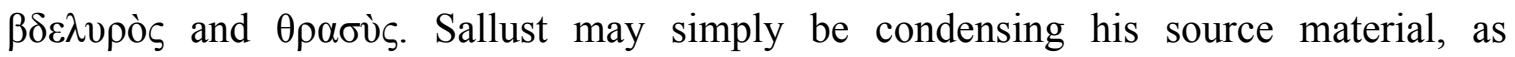
consumption and gambling belong to the next part of Theopompus' history, as does luxurious spending, which matches Sallust's account of squandered patrimonies. ${ }^{591}$ After the tricolon of degenerates, each historian describes the ne'er-do-wells as being on close terms with the named subject of the inquiry (ei Catilinae proxumi familiaresque erant;

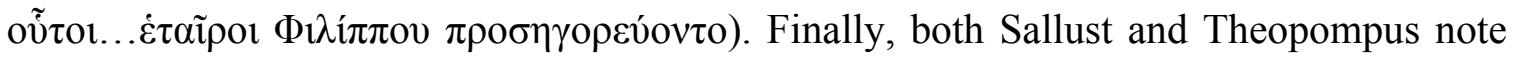
the corrupting influence of Catiline and Philip, respectively, whose coteries' lifestyles assimilated any honorable newcomer into their degeneracy.

Returning to the original problem, we can now address the likeliest emendation for the textual crux in Sallust. The tricolon of wastrels should not be excised or placed in brackets, as it is in Reynolds' $O C T$ and the editions of those who follow him. Fronto and Augustine do not quote Sallust in full, but neither do they claim to do so. Rather, each author explores the stylistic effects of the historian's second tricolon, specifically the

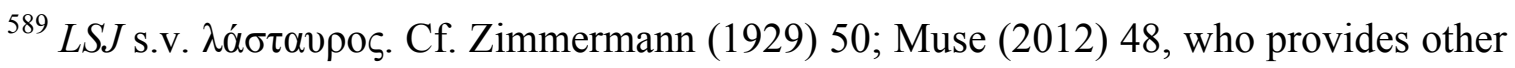
ancient sources.

${ }^{590}$ In the same way, gluttony and drunkenness are different, yet both signify consumption and authors may emphasize one, the other, or both.

${ }^{591}$ That fr. 224 directly precedes fr. 225 is known from Polybius, who writes them as an uninterrupted whole. Müller and Müller (1841) 1.320-321 fr. 249 print them as one fragment. 
effect of the word penis. Augustine highlights how the word indicates an indecent body part, but is not itself indecent, while Fronto notes that putting the word last in a list diminishes the immodesty of the word. Moreover, neither author provides the correct introduction for the quotation: Fronto's text is lacunose immediately before the citation of Sallust and has quique, though all manuscripts of Sallust agree on quicumque, and Augustine's text is missing a relative clause entirely. Were these authors quoting the entire Sallustian phrase, they would presumably include its beginning, correctly or at all. Neither does, but neither claims to either, as each expressly examines the stylistic impact of the phrase; Fronto and Augustine reproduce only the portion of Sallust's text relevant to their discussions. These two authors, then, cannot be used to revise Sallust, but they do confirm the end of the phrase (manu...lacerauerat) and controvert the inexplicable choice of some editors to delete the second tricolon, the accuracy of which is certain in the manuscript tradition. ${ }^{592}$

${ }^{592}$ The only variation in the second tricolon is that alea/aleo intrudes and follows manu in a couple of late manuscripts. For deletion of the second tricolon, see, e.g., Anthon (1854) 86, nam, quicumque inpudicus, adulter, bona patria lacerauerat; Merivale (1870) 9, nam quicumque inpudicus, adulter, ganeo,...bona patria lacerauerat (ellipsis in original), who claims (xxviii) to follow Kritz, but the latter does not expunge the second tricolon; Scudder (1900) 9, nam quicumque inpudicus, ganeo, aleo, bona patria lacerauerat, who claims (iii) "to have almost invariably adopted" Schmalz's fifth edition (1897), but in all editions, including the fifth, Schmalz retains the second tricolon (though he prints bene for pene in the second) and comments on the abc cba arrangement of the two tricola; Herbermann (1900) 11, nam quicumque impudicus, ganeo, aleo bona patria lacerauerat, who claims (iii) that his edition is based on the third edition of Schmalz (1891), with all the same issues as Scudder; Summers (1907) 8, nam quicumque inpudicus ganeo aleator bona patria lacerauerat, who claims to follow Jordan save changing inpudicus adulter ganeo to inpudicus ganeo aleator, but Jordan retains both tricola. Perschinka (1902) 10, nam quicumque bona patria lacerauerat, even more strangely excises both tricola. I note here that Allen, Allen, and Greenough (1885) 8 give the usual reading save expunging pene without explanation in the text or notes, a divergence from their model despite a prefatory note (v) that "This edition follows strictly the text of the fourth edition of Dietsch." In the revised edition, Greenough and 
Without excising everything between quicumque and manu, the manuscripts are in a confused state and leave four words in the series: inpudicus adulter ganeo alea. The typical reading balances the tricolon by excising the last of these, considering it a gloss on manu, but the simple emendation to aleo resolves much of the difficulty. ${ }^{593}$ In deciphering this sequence, we have a surfeit of comparanda taken not only from elsewhere in Sallust, but also from other authors and models; the Roman historian's passage does not emerge from a vacuum, but rather from a long literary tradition. Sallust's description of Catiline's supporters evokes the criticisms that the Greek orators level against their opponents: fornication, consumption, and gam(bl)ing, as well as concomitant financial mismanagement. Theopompus, trained by one of those Greek orators, provides a model, one that Sallust follows closely, in both style and content with his portrayal of Philip's companions. Sallust, however, condenses his model and combines the vice trio with the tricolon of those who engage in it, for the latter perhaps following the lead of Naevius (pessimorum pessime, audax, ganeo, lustro, aleo) or Catullus (inpudicus et uorax et aleo). The historian also owes a debt to Cicero, who describes the same characters in similar terms and who may also use Theopompus as a model. Cicero's use of the vice trio is not confined to his castigation of Catiline and his followers, however, as he launches comparable polemics against Verres and Antony.

Daniell (1903) 9-10 claim (iii) to follow the text of Jordan (1876), but likewise excise pene without comment, as does Bassi (1897) 16, who does not indicate his source text. For Lycurgus as the model for the anatomical tricolon linked with vice, see Muse (2012) 50-57.

${ }^{593}$ As stated above, editors cite Wölfflin for this emendation, but Beroaldo made it a few hundred years earlier and it is also attested in the manuscript tradition in manuscript (m), where a later hand corrected alea to aleo. The fact that three different editors separated by space and time independently take recourse to the same emendation points to its viability. 
There is a long tradition of combining accusations of deviancy with sex, ingestion, and games, often with a monetary component, into a single jeremiad. The strong correspondence between Sallust and Theompompus shows that the Roman historian becomes a part of this tradition in this passage, cementing the place of aleo in the series alongside ganeo.

Sallust is fond of tricolonic and chiastic constructions, which helps clarify the correct word order between quicumque and тапи, but shows the need to excise one of the first two words: aleo represents gam(bl)ing and corresponds with manu in the chiasm, while ganeo represents consumption and corresponds with uentre, but both inpudicus and adulter remain to represent fornication and correspond with pene. For the chiastic tricola to function, one of these two words must be an interpolation. The guilty party is inpudicus, which likely entered the manuscript on comparison with Sallust's sources. The historian, however, deviates from his closest models in that he does not attribute homosexuality to Catiline and his followers, instead opting for adultery as the final portion of the vice trio. ${ }^{594}$ Finally, if the chiastic structure links wastrels with the instruments of their prodigality, there is a logical flaw with retaining inpudicus. A gambler throws dice and hands over money with his own hand and a glutton fills his own belly. Inpudicus denotes the pathic homosexual partner, so while an adulterer uses his own penis to perpetrate vice, the "shameless" man—to use the word's etymology—does

\footnotetext{
${ }^{594}$ Sallust himself may indicate that such rumors were typical of powerful men when he denies its veracity in this case: he comments (14.7) that some believed Catiline had sex with the young men in his coterie, "but this rumor prevailed more from other reasons than because anyone ascertained it" (sed ex aliis rebus magis quam quod quoiquam id conpertum foret haec fama ualebat). The vague "other reasons" may indicate the accusations from Cicero or even that such allegations were a standard critique of powerful men.
} 
not.

Aleo could have been omitted after ganeo by homeoteleuton, leading a scribe familiar with Theopompus, Cicero, or Catullus to supplement inpudicus to restore balance to the phrase. An over-zealous scribe familiar with Theopompus, Cicero, and possibly Catullus could also have glossed adulter with inpudicus, the same word Cicero and Catullus use of pathic homosexuality, including Cicero using it of Catiline's followers, and that matches Theopompus' $\lambda \alpha$ ó $\alpha \alpha \nu \rho \varsigma^{595}{ }^{595}$ Efforts to retain Sallust's tricolonic structure may then have led to the subsequent confusion in the manuscript tradition, causing the expunction of ganeo in some manuscripts and aleo in others. Though aleo at some point erroneously shifted to alea, at least some of the copyists seem to be aware of the vice trio as a cohesive attack, as later hands add the missing vices in suprascript and in the margins of so many manuscripts.

We cannot say for certain what caused the uncertainty of the manuscript tradition, but we can remedy the situation. Most editors understand manu as indicating gambling, a sense we can bolster by restoring aleo to the text, while we can balance Sallust's syntactical construction by excising inpudicus, a charge the historian unequivocally contradicts only sentences later. On the strength of the vice trio and its appearance in the models and comparanda for Sallust's passage, taken alongside the historian's own statements, the reading nam quicumque adulter ganeo aleo manu uentre pene bona patria lacerauerat is the likeliest reading, with the added merit of the first tricolon containing all trisyllabic words, matching the three disyllables of the second. ${ }^{596}$

\footnotetext{
${ }^{595}$ See the earlier comment by McGushin on the likelihood that this passage suffered from the attention of over-zealous scribes.

${ }^{596}$ Paul (1985) 161 offers this final point.
} 


\section{Conclusion}

The vice trio serves a range of uses in Latin literature. In the earliest Latin literature to survive intact, the comedies of Plautus, it is a source for wordplay and a means of creating humor. As the Roman playwright makes puns with the vice trio, he concurrently shows its existence, as several characters' wit requires all three elements to function. This practice is clearest in the Curculio, in which the eponymous parasite employs fornication, consumption, and gam(bl)ing together to justify attending parties even though uninvited, and the Rudens, in which two characters riff on the vice trio to create morbid humor. Plautus' stance contrasts with the stern moralizing of the Athenian orators, but at times he nevertheless operates within the same framework to create jokes.

By contrast, the Roman orator Gaius Titius almost channels Isocrates and, to a lesser extent, Aeschines in his castigation of contemporary morals. In his support for the Lex Fannia, he denounces his fellow magistrates for their degeneracy. His aspersion isolates their dereliction of duty in favor of drinking all day, seeking delicacies, and gambling zealously with prostitutes all around. All of the examples he provides exemplify the vice trio, showing its power as a means of invective in Latin literature. His remonstration sets the stage for later Romans to use this constellation of vices in castigating others.

Having seen that Roman authors are no strangers to the vice trio, we can turn from identifying it in passages to solving a textual crux. The vice trio helps resolve a textual problem in Sallust's Bellum Catilinae contested by scholars for centuries. By comparing Sallust's text with his later statement, comparanda, and potential models, we can see that the likeliest emendation is the one that incorporates the vice trio, but does not 
connote pathic homosexuality to Catiline's closest associates. This emendation produces two sequential, asyndetic tricola that have a one-to-one correspondence in chiasmus.

The vice trio is simultaneously rigid and flexible, unified and disjointed. Each portion of the triad has multiple possibilities, which allows authors to use the same, broad idea while manipulating the individual elements to suit their own needs. This allows Sallust to invoke the vice trio even as he diverges from his closest models in not attributing homosexuality to his subject. The vice trio cannot always be neatly categorized, but we can say for certain that Roman authors continue the Greek tradition of using fornication, consumption, and gam(bl)ing as a cohesive unit to denote immorality and meet their literary needs. 


\section{Conclusion}

My project exposes new interpretations of familiar texts by tracing the implications of the gaming imagery that is often misunderstood or, worse, disregarded as mere metaphor. The passages I analyze are necessarily selective, as they span nearly a millennium, but represent themes that arise and may be assessed in other works as well. I create a broad framework for how Greek and Roman authors use games to address complex questions about humanity, propriety, and the nature of the universe. Modes of expression become systematized over time, such that we can trace instantiations of recurring themes across genres, space, time, and culture.

An immediate ramification of my work is the establishment of a more nuanced understanding of ludic material in ancient literature than scholars have previously recognized. I demonstrate how different authors may employ the same themes, but with innovations and variations that color the individual passages. For instance, in Horace's final satire, the gourmand Nasidienus weeps as if his son has died when a falling curtain ruins one course of his elaborate feast. His dinner guest Nomentanus lifts his host's spirits by railing against FORTUNA for always playing with mortal affairs. The humor of this outburst stems from its similarity to a motif in Greek literature: Nomentanus speaks about a trivial matter, the ruination of one course of a meal, in the same manner that characters in Greek tragedy rationalize gravely serious matters, such as dispossession from one's home and death.

Another example comes a few lines later in the same work when Nasidienus has composed himself and returns to the table, ready to change FORTUNA with his skill, as the 
narrator of the poem tells us. The joke here is that Nasidienus has critically misunderstood a different aphorism rooted in ludic imagery. Horace plays on a line by Terence, in which a character states that one must adapt to chance occurrences, as it is impossible to change them, while Nasidienus seems determined to do exactly that, correcting not just his fortunes, but the very embodiment of fortune! A few commentators have seen the connection to the Terentian line or a similar one in a fragment from Alexis, but none have recognized how deeply the theme permeates our sources; before Alexis we find it in Plato, Socrates as recorded by Stobaeus, Euripides, Sophocles, and Aeschylus, while after Horace we see the same theme in Epictetus, to name just one example. All of these authors work in the same framework, but in different contexts and often invoke this theme with different effects. It is only by recognizing their similarities that we can appreciate their differences.

Another consequence of my work is the recognition of a dichotomy in our sources' treatment of games used metaphorically and descriptions of people actually playing games. Authors represent people as though part of or playing a game in order to address concerns about humanity or, as with Horace above, to create humor by playing on those very ideas. Conversely, descriptions of people playing real games commonly have a moral component. Authors contest the moral value of games of skill, which are inherently neutral and may be used for good or for ill, depending on the author's aim. Games of chance, meanwhile, come up against harsh rebuke and authors censure their players as immoral. The denunciation often comes as part of a concerted castigation of related vices, each an otherwise neutral activity marked as wicked by its monetization or by being taken to excess. 
Rather than summarizing more of the arguments I have already made, I devote the rest of this conclusion to some of the implications of those ideas. I do not wish to end this project with a conclusion in the true etymology of the word, shutting off the work completely (cum + claudere). Instead, I prefer to subject the very word "conclusion" to a folk etymology, such that my conclusion plays with my project (cum + ludere).

My study answers questions about games in Greek and Latin literature, but it also opens new avenues for future research. Ctesiphon's explanation of the suitors' game in the Odyssey explores the mindset and character of the suitors as a whole. In Chapter 1, I examine Ctesiphon's claim that the suitors believed capturing the Penelope stone in their pessoi game would result in marriage to Penelope herself. I frame this in light of the suitors' penchant for symbolic substitution, as they eat Odysseus' food and drink his wine instead of their own, are served by others, and have sex with the maids instead of Penelope. This passage, as well as others in the same chapter, may point towards magical thinking. The symbolism of those episodes can be advanced further, as can the idea of magic, as the suitors' repeated game may be a kind of ritual. The same may be said of the Laus Pisonis, another work in which the movement or capture of stone counters is meant to be translatable to the real world.

My project also opens new avenues into studies of leisure in the ancient world. Scholars have long contested what exactly leisure is, both for moderns and for our forebears in antiquity. The literary sources I explore can be used to help explore the concept of leisure as negotiated in antiquity, as a construct in both literature and culture. As one scholar puts it, "leisure is a cultural artefact: how people describe, spend, and pay 
for their leisure time reveals processes of self-definition and cultural formation. ${ }^{, 597}$ Indeed, while some theorists state that leisure did not exist before the Industrial Revolution, the ancient Greeks and Romans were keenly aware of a separation between work and leisure and, moreover, valued leisure. ${ }^{598}$ Games will not solve this debate, but they have a part to play in the larger conversation, especially whether they contribute to, detract from, or are part of leisure.

The ludic themes I identify and trace can be explored in many other texts in a plethora of genres and time periods. To give but one example, Seneca tells us that the philosopher Julius Canus was playing ludus latrunculi when Caligula's centurion ordered him to join the line of those doomed to die. ${ }^{599}$ Canus counted the pieces and ordered his playing companion not to lie after his execution, as the philosopher was winning, and tells the centurion that he is the witness that Canus was ahead by one piece. Seneca asks "Do you think Canus was playing a game at the table? He was making a game!" (lusisse tu Canum illa tabula putas? inlusit!). The game he makes is the transformation of the world into a game, as Seneca's wording intimates. The word used for the line of prisoners is agmen, the same as a line of pieces in ludus latrunculi, while the centurion's order is that Canus is "moved along" (excitari), a term used of moving pieces in the same game. Canus is winning his own game by one piece, but in the larger game of life he is a piece being captured, as he is about to die. Seneca states that Canus wins the game of life as well, however, as he faces his death with tranquility. This discussion of morality and

${ }^{597}$ Connors (2000) 208

${ }^{598}$ On leisure not existing before the Industrial Revolution, see, for example, de Grazia (1962); Dumazedier (1967); Dumazedier (1974); Marrus (1974). On the people of antiquity as aware of the separation between work and leisure, as well as valuing leisure, see, for example, Cunningham (1980); Toner (1995); Fagan (2006).

${ }^{599}$ Seneca, de Tranquilitate Animi 14.7-8 
comportment in a philosophical treatise that employs a game of skill both as a game and as a metaphor unites many aspects of the ideas explored throughout this dissertation. Moreover, Seneca's claim in another work that playing ludus latrunculi makes men clever, but not good builds on the complex negotiation of these themes. ${ }^{600}$

The continuities and expressions do not end with antiquity. Again to give but one example, we find similarities in a lecture that the young Vladimir Nabokov delivered in December of 1925 to a recently formed literary circle in Berlin. His talk's topic is a recent bout between two heavyweight boxers. The lecture begins with an appraisal of the centrality of play in the universe: $:^{601}$

Everything in the world plays: the blood in the veins of a lover, the sun on the water, and the musician on a violin.

Everything good in life-love, nature, art and domestic puns - is play. And when we actually play - whether we throw peas at a tin battalion or approach the net barrier in tennis, what we feel in our very muscles is the essence of that play which possesses the marvelous juggler who tosses from hand to hand in an unbroken sparkling parabola - the planets of the universe.

People have played ever since they came into being. There are erasholidays of humanity - when people become especially enamoured of games. So it was in Ancient Greece, in Ancient Rome, and so it is in our own Europe of today.

Nabokov insists on the centrality of play in human culture, as did Huizinga and Caillois after him. He even sees a cosmic force controlling the universe, juggling it. It is intriguing to consider this idea alongside Xenophon's portrayal of Socrates, who states in that even jugglers and pessoi players do something, as they are at leisure, neither working nor idling. Pressing further, however, is a task for another project.

${ }^{600}$ Seneca, Epistulae Morales ad Lucilium 106.11

${ }^{601}$ The text is from Karshan (2011) 1, who translates the passage. 
I hope that the interpretational games within this dissertation helped sketch the rules for further investigation; there are plenty of games left to play. 


\section{Bibliography}

Adam, James. 1963. The Republic of Plato, Edited with Critical Notes, Commentary, and Appendices. $2^{\text {nd }}$ edition with an Introduction by D. A. Rees. 2 vols. New York: Cambridge University Press.

Adams, C.D. 1919. Aeschines: Speeches. Loeb Classical Library 106. Cambridge, MA: Harvard University Press.

Adams, J.N. 1982 [1990 reprint]. The Latin Sexual Vocabulary. Baltimore: Johns Hopkins University Press.

Ahlberg, Axel W. 1911. Prolegomena in Sallustium. Göteborg: Wald. Zachrissons Boktryckeri A.-B.

— - 1919. C. Sallusti Crispi Catilina, Iugurthina, Orationes et Epistulae ex Historiis Excerptae. Leipzig: Teubner.

Alexander, Michael C. 1990. Trials in the Late Roman Republic, 149 BC to 50 BC. Toronto: University of Toronto Press.

Allen, J.H, W.F. Allen, and J.B. Greenough. 1885. C. Sallusti Crispi: de Catilinae Coniuratione: The Conspiracy of Catiline as Related by Sallust. Boston: Ginn, Heath, \& Co.

— - 1903. C. Sallusti Crispi: de Catilinae Coniuratione: The Conspiracy of Catiline as Related by Sallust. Revised by J.B. Greenough and M.G. Daniell. Boston: Ginn \& Company.

Allen, Thomas W. 1912. Homeri Opera, Volume 5. Oxonii: E Typographeo Clarendoniano.

Anthon, Charles. 1854. Sallust's Jugurthine War and Conspiracy of Catiline. $10^{\text {th }}$ edition, corrected and enlarged. New York: Harper \& Brothers, Publishers.

Ardley, Gavin. 1967. "The Role of Play in the Philosophy of Plato." Philosophy 42.161: 226-244.

Arnott, W.G. 1979. Menander: Volume I. Loeb Classical Library 132. Cambridge, MA: Harvard University Press.

Arnott, W. Geoffrey. 1996. Alexis: The Fragments, A Commentary. Cambridge: Cambridge University Press. 
Arya, Darius Andre. 2002. The Goddess Fortuna in Imperial Rome: Cult, Art, Text. $\mathrm{PhD}$ dissertation. The University of Texas at Austin. Available online at https://repositories.lib.utexas.edu/bitstream/handle/2152/438/aryada026.pdf

Aubert, Jean-Jacques and Boudewijn Sirks, eds. 2002. Speculum Iuris: Roman Law as a Reflection of Social and Economic Life in Antiquity. Ann Arbor: The University of Michigan Press.

Austin, R.G. 1934. "Roman Board Games I." Greece \& Rome 4.10: 24-34.

— —. 1935. "Roman Board Games II." Greece \& Rome 4.11: 76-82.

— —. 1940. "Greek Board-Games." Antiquity 14: 257-271.

Baker, Robert J. 1988. "Maecenas and Horace Satires II.8." The Classical Journal 83.3:212-232.

Bakewell, Geoffrey W. 2008. "Aescylus' Supplices 11-12: Danaus as ПE $\Sigma \Sigma O N O M \Omega N . "$ The Classical Quarterly 58.1: 303-307.

— —. 2013. Aeschylus's Suppliant Women: The Tragedy of Immigration. Madison, WI: University of Wisconsin Press.

Bakola, Emmanuela. 2010. Cratinus and the Art of Comedy. New York: Oxford University Press.

Balme, Maurice. 1984. "Attitudes to Work and Leisure in Ancient Greece." Greece \& Rome 31.2: 140-152.

Balsdon, J.P.V.D. 1969 [2004 reprint]. Life and Leisure in Ancient Rome. Phoenix Press.

Barber, Daniel. 2012. "Address and the Continuity of Horace, 'Odes' 1.34-35." Hermes 140.4: 505-513.

— - 2014. "Presence and the Future Tense in Horace's Odes." The Classical Journal 109.3: 333-361.

Barsby, John. 1986 [2008 reprint of 1991 corrected reprint]. Plautus: Bacchides. Oxford: Aris \& Philips.

Bassi, Ignazio. 1897. C. Sallusti Crispi de Catilinae Coniuratione et de Bello Iugurthino. $3^{\text {rd }}$ edition. Torino: Stamperia Reale di G. B. Paravia e Comp.

Batstone, William W. 1995. "Notes and Comments." In Latin Lyric and Elegiac Poetry, edited by Diane J. Rayor and William W. Batstone, pp. 165-337. New York: Routledge. 
Beacham, Richard C. 1991. The Roman Theatre and its Audience. Cambridge, MA: Harvard University Press.

Beal, Don. 2001. "Learn from your opponent - but what if he/she/it knows less than you?" In Step by Step: Proceedings of the $4^{\text {th }}$ Colloquium Board Games in Academia, edited by Jean Retschitzki and Rosita Haddad-Zubel, pp. 123-132. Fribourg: Editions Universitaires Fribourg Suisse.

Beekes, Robert. 2010. Etymological Dictionary of Greek. 2 vols. Boston, MA: Brill.

Benseler, Gustav Eduard. 1855. Aeschines' Rede gegen Timarchs: Griechisch un Deutsch. Leipzig: Verlag von Wilhelm Engelmann.

Berger, Adolf. 1953. Encyclopedic Dictionary of Roman Law. Philadelphia: American Philosophical Society.

Beroaldo, Filippo. 1501. Commentarii Conditi in Asinum Aureum Lucii Apuleii. Venice: Simon Bevilaqua.

Bolton, J.D.P. 1967. “Horace’s Earliest Ode?” The Classical Quarterly 17.2: 451-454.

Bond, Sarah E. 2011. Criers, Impresarios, and Sextons: Disreputable Occupations in the Roman World. PhD dissertation. University of North Carolina at Chapel Hill.

Bons, Jeroen A.E. 2007. "Gorgias the Sophist and Early Rhetoric." In A Companion to Greek Rhetoric, edited by Ian Worthington, pp. 37-46. Malden, MA: Blackwell Publishing.

Bordo, Susan. 1999 [1997]. Twilight Zones: The Hidden Life of Cultural Images from Plato to O.J.. Berkeley and Los Angeles: University of California Press.

Botsford, George Willis. 2001 [1909]. The Roman Assemblies: From Their Origin to the End of the Republic. Union, NJ: The Lawbook Exchange, Ltd.

Bourdieu, Pierre. 1977. Outline of a Theory of Practice. Translated by Richard Nice. Cambridge: Cambridge University Press.

— - 1984. Distinction: A Social Critique of the Judgement of Taste. Translated by Richard Nice. Cambridge, MA: Harvard University Press.

- - 1990. The Logic of Practice. Translated by Richard Nice. Stanford: Stanford University Press.

Bowditch, Phebe Lowell. 2001. Horace and the Gift Economy of Patronage. Berkeley and Los Angeles: University of California Press. 
Braund, Susanna Morton. 2002. Latin Literature. New York: Routledge.

Broughton, T. Robert S. 1951. Magistrates of the Roman Republic. 3 vols. New York: American Philological Association.

Cameron, Alan. 1976. “Catullus 29.” Hermes 104.2: 155-163.

Canter, H.V. 1922. “'Fortuna' in Latin Poetry.” Studies in Philology 19.1: 64-82.

Capes, W.W. 1884. C. Sallusti Crispi de Coniuratione Catilinae liber, de Bello Iugurthino liber. Oxford: Clarendon Press.

Carcopino, Jérôme. 1941 [1991 reprint]. Daily Life in Ancient Rome: The People and the City at the Height of the Empire. Translated by E.O. Lorimer. London: Penguin Books.

Carey, C. 1989. Lysias: Selected Speeches. New York: Cambridge University Press.

Caston, Ruth Rothaus. 1997. "The Fall of the Curtain (Horace S. 2.8)." Transactions of the American Philological Association 127:233-256.

Champlin, Edward. 1978. "The Life and Times of Calpurnius Siculus. The Journal of Roman Studies 68: 95-110.

— —. 1989. "The Life and Times of Calpurnius Piso." Museum Helveticum 46: 101-124.

Chantraine, Pierre. 1968-1980. Dictionnaire étymologique de la langue grecque. Histoire de mots. 4 vols. Paris: Klincksieck.

Cilley, Richard Clark. 1986. Ancient Greek Board Games. MA thesis. University of Texas at Austin.

Clark, Albert Curtis. 1918. M. Tulli Ciceronis Orationes. $2^{\text {nd }}$ ed. Oxford: Clarendon Press.

Clark, Anna J. 2007. Divine Qualities: Cult and Community in Republican Rome. New York: Oxford University Press.

Clarke, John R. 2003. Art in the Lives of Ordinary Romans: Visual Representation and Non-elite Viewers in Italy, 100 B.C.-A.D.315. Berkeley: University of California Press.

Cohen, Edward E. 2015. Athenian Prostitution: The Business of Sex. New York: Oxford University Press. 
Cohen, Rip. 1994. "Speech Act Theory and the Plays of Plautus." In Modern Critical Theory and Classical Literature, edited by Irene J.F. de Jong and J.P. Sullivan, pp. 171-205. Leiden: Brill.

Cole, Thomas. 1991. “Who was Corax?” Illinois Classical Studies 16.1/2: 65-84.

Collard, Christopher. 1975. Euripides: Supplices. 2 vols. Groningen: Bouma's Boekhuis b.v. Publishers.

Connell, R.W. 2002. Gender. Malden, MA: Blackwell Publishing.

Connors, Catherine. 2000. "Imperial space and time: The literature of leisure." In Literature in the Roman World, edited by Oliver Taplin, pp. 208-234. New York: Oxford University Press.

Conte, Gian Biagio. 1994 [1999 reprint]. Latin Literature: A History. Translated by Joseph B. Solodow, revised by Don Fowler and Glenn W. Most. Baltimore: Johns Hopkins University Press.

Cooper, Craig. 2007. "Forensic Oratory." In A Companion to Greek Rhetoric, edited by Ian Worthington, pp. 203-219. Malden, MA: Blackwell Publishing.

Corbeill, Anthony. 2006. "The Republican Body." In A Companion to the Roman Republic, edited by Nathan Rosenstein and Robert Morstein-Marx, pp. 439-456. Malden, MA: Blackwell Publishing.

Corbett, Philip. 1986. The Scurra. Edinburgh: Scottish Academic Press.

Courtney, Edward. 1993. The Fragmentary Latin Poets. New York: Oxford University Press.

Crawford, Jane W. 1994. M. Tullius Cicero: The Fragmentary Speeches, an edition with commentary. $2^{\text {nd }}$ edition. Atlanta, GA: Scholars Press.

Crawford, Michael. 1992. The Roman Republic. $2^{\text {nd }}$ edition. Cambridge, MA: Harvard University Press.

Cunningham, Hugh. 1980. Leisure in the Industrial Revolution, c.1780-c.1880. New York: St. Martin's Press.

Dacier, André. 1683. Remarques Critiques sur Les Oeuvres d'Horace, Avec une Nouvelle Traduction. Volume 2. Paris: Thierry and Barnabin.

Damon, Cynthia. 1997. The Mask of the Parasite: A Pathology of Roman Patronage. Ann Arbor: The University of Michigan Press. 
D’Arms, John H. 1984. "Control, Companionship, and Clientela: Some Social Functions of the Roman Meal." Echos du Monde Classique 28.3: 327-348.

Davidson, James N. 1993. "Fish, Sex, and Revolution in Athens." The Classical Quarterly. 43.1: 53-66.

— - 2007. The Greeks and Greek Love: A Bold New Exploration of the Greek World. New York: Random House.

Davies, J.K. 1978. Democracy and Classical Greece. Stanford: Stanford University Press.

Dawe, Roger David. 1973-1978. Studies on the Text of Sophocles. 3 vols. Leiden: Brill.

Day, Jane M. 2007. "Rhetoric and Ethics from the Sophists to Aristotle." In $A$ Companion to Greek Rhetoric, edited by Ian Worthington, pp. 378-392. Malden, MA: Blackwell Publishing.

de Brauw, Michael. 2001. "'Listen to the Laws Themselves:' Citations of Law and Portrayal of Character in Attic Oratory.” The Classical Journal 97.2: 161-176.

de Grazia, Sebastian. 1962. Of Time, Work, and Leisure. New York: The Twentieth Century Fund.

de Jáuregui, Miguel Herrero, Ana Isabel Jiménez San Cristóbal, Marco Antonio Santamaria et al., eds. 2011. Tracing Orpheus: Studies of Orphic Fragments. Boston: De Gruyter.

De Ligt, Luuk. 2002. "Restraining the Rich, Protecting the Poor: Symbolic Aspects of Roman Legislation." In After the Past: Essays in Ancient History in Honour of H.W. Pleket, edited by Willem Jongman and Marc Kleijwegt, pp. 1-45. Leiden: Brill.

de Melo, Wolfgang. 2011. Plautus: Amphitryon, The Comedy of Asses, The Pot of Gold, The Two Bacchises, The Captives. Loeb Classical Library 60. Cambridge, MA: Harvard University Press.

— - 2013. Plautus: Stichus, Three-Dollar Day, Truculentus, The Tale of a TravelingBag, Fragments. Loeb Classical Library 328. Cambridge, MA: Harvard University Press.

Denniston, J.D. 1926 [1952 reprint]. M. Tulli Ciceronis in M. Antonium Orationes Philippicae Prima et Secunda. London: Oxford University Press.

Detienne, Marcel. 2003. The Writing of Orpheus: Greek Myth in Cultural Contact. Translated by Janet Lloyd. Baltimore: Johns Hopkins University Press. 
Dettmer, Helena. 1983. Horace: A Study in Structure. Hildesheim, Germany: OlmsWeidmann.

Diels, Hermann. 1912. Die Fragmente der Vorsokratiker. 2 vols. Berlin: Weidmann.

Dietsch, Heinrich Rudolf. 1854. Gai Sallusti Crispi Quae Supersunt. $2^{\text {nd }}$ edition. Leipzig: Teubner.

— - 1859a. Gai Sallusti Crispi Libri de Catilinae Coniuratione et de Bello Jugurthino. $3^{\text {rd }}$ edition. Leipzig: Teubner.

— - 1859b. Gai Sallusti Crispi Quae Supersunt: Commentationes Libri de Catilinae Coniuratione et de Bello Jugurthino. Leipzig: Teubner.

— - 1864. Gai Sallusti Crispi Libri de Catilinae Coniuratione, Bellum Jugurthinum, Orationes et Epistulae ex Historiis Excerptae Erklärt. Leipzig: Teubner.

— - 1874. Gai Sallusti Crispi Libri de Catilinae Coniuratione et de Bello Jugurthino: Accedunt Orationes et Epistulae ex Historiis Excerptae. $4^{\text {th }}$ edition. Leipzig: Teubner.

Diggle, James. 1983. "On the Manuscripts and Texts of Euripides, Medea." The Classical Quarterly 33.2: 339-357.

Dilts, Mervin R. 1992. Scholia in Aeschinem. Leipzig: Teubner.

Dindorf, Wilhelm. 1824. Julii Pollucis Onomasticon cum Annotationibus Interpretum. 3 vols. Leipzig: Kuehn.

- - 1852. Scholia Graeca in Aeschinem et Isocratem. Oxonii: E Typographeo Academico.

Donkers, Jeroen, Jos Uiterwijk, and Alex de Voogt. 2001. "Mancala games - Topics in Mathematics and Artificial Intelligence." In Step by Step: Proceedings of the $4^{\text {th }}$ Colloquium Board Games in Academia, edited by Jean Retschitzki and Rosita Haddad-Zubel, pp. 133-146. Fribourg: Editions Universitaires Fribourg Suisse.

d'Orville, Jacques Philippe. 1737. Critica Vannus in Inanes Joannis Cornelii Pavonis Paleas. Amsterdam: Janssonio-Waesbergii.

Dudley, Donald. 1970 [1991 reprint]. Roman Society. New York: Penguin Books.

Dugan, John. 2005. Making a New Man: Ciceronian Self-Fashioning in the Rhetorical Works. New York: Oxford University Press. 
Dumazedier, Joffre. 1967. Toward a Sociology of Leisure. New York: Free Press.

— - 1974. Sociology of Leisure. Translated by M.A. Mckenzie. New York: Elsevier Publishing Company.

Easterling, P.E. 1993. "Gods on Stage in Greek Tragedy.” In Religio Graeco-Romana: Festschrift für Walter Pötscher, edited by Joachim Dalfen, Gerhard Petersmann, and Franz Ferdinand Schwarz, pp.77-86. Horn: Verlag Berger.

Edwards, Brian. 1998. Theories of Play and Postmodern Fiction. New York: Garland Publishing.

Edwards, Catharine. 1989. Transgression and Control: Studies in Roman Immorality. $\mathrm{PhD}$ dissertation. Cambridge University.

- - 1993. The Politics of Immorality in Ancient Rome. Cambridge: Cambridge University Press.

— - 1997. "Unspeakable Professions: Public Performance and Prostitution in Ancient Rome." In Roman Sexualities, edited by Judith P. Hallett and Marilyn B. Skinner, pp.66-95. Princeton, NJ: Princeton University Press.

Edwards, Mike. 2007. "Alcidamas." In A Companion to Greek Rhetoric, edited by Ian Worthington, pp. 47-57. Malden, MA: Blackwell Publishing.

— - 2016. "Oratory: Practice and Theory." In A Companion to Greek Literature, edited by Martin Hose and David Schenker, pp. 205-216. Malden, MA: Wiley Blackwell.

Erskine, Andrew. 2007. "Rhetoric and Persuasion in the Hellenistic World: Speaking up for the Polis." In A Companion to Greek Rhetoric, edited by Ian Worthington, pp. 272-285. Malden, MA: Blackwell Publishing.

Eussner, A. 1908. Sallustius: Catilina Iugurtha ex Historiis Orationes et Epistulae. Leipzig: Teubner.

Fagan, Garrett. 2006. "Leisure." In A Companion to the Roman Empire, edited by David Potter, pp. 369-384. Malden, MA: Blackwell Publishing.

Fantham, Elaine. 1972. Comparative Studies in Republican Latin Imagery. Toronto: University of Toronto Press.

— - 2014. "Literature in the Roman Republic." In The Cambridge Companion to the Roman Republic, edited by Harriet I. Flower, pp. 323-347. $2^{\text {nd }}$ edition. New York: Cambridge University Press. 
Faris, Suzanne B. 2012. "Changing Public Policy and the Evolution of Roman Civil and Criminal Law on Gambling." UNLV Gaming Law Journal 3.2: 199-219.

Farmer, Matthew C. 2017. Tragedy on the Comic Stage. New York: Oxford University Press.

Feeney, Denis. 1998. Literature and Religion at Rome: Cultures, Contexts, and Beliefs. Cambridge: Cambridge University Press.

— - 2005. "The Beginnings of a Literature in Latin.” The Journal of Roman Studies 95: 226-240.

— - 2016. Beyond Greek: The Beginnings of Latin Literature. Cambridge, MA: Harvard University Press.

Finglass, P.J. 2011. Sophocles: Ajax, edited with Introduction, Translation, and Commentary. New York: Cambridge University Press.

Finley, M. I. 1973. The Ancient Economy. Berkeley and Los Angeles: University of California Press.

Fisher, Nick. 2004. "The Perils of Pittalakos: Settings of Cock Fighting and Dicing in Classical Athens." In Games and Festivals in Classical Antiquity: Proceedings of the Conference held in Edinburgh 10-12 July 2000, edited by Sinclair Bell and Glenys Davies, pp. 65-78. Oxford: Archaeopress.

Flower, Michael Attyah. 1994. Theopompus of Chios: History and Rhetoric in the Fourth Century BC. Oxford: Clarendon Press.

Fögen, Thorsten and Mireille M. Lee, eds. 2009. Bodies and Boundaries in GraecoRoman Antiquity. New York: Walter de Gruyter.

Fontaine, Michael. 2010. Funny Words in Plautine Comedy. New York: Oxford University Press.

Foucault, Michel. 1972. The Archaeology of Knowledge. Translated by A. M. Sheridan. London: Travistock Publications.

- - 1977. Language, Counter-Memory, Practice: Selected Essays and Interviews, edited by Donald F. Bouchard, translated by Donald F. Bouchard and Sherry Simon. Ithaca, NY: Cornell University Press.

Fraenkel, Eduard. 2007 [1922]. Plautine Elements in Plautus. Translated by Frances Muecke and Tomas Drevikovsky. New York: Oxford University Press.

— — 1957 [1980 reprint]. Horace. Oxford: Clarendon Press. 
Frakes, Robert M. 2001. Contra Potentium Iniurias: The Defensor Civitatis and Late Roman Justice. Munich: Verlag C. H. Beck.

Franklin, James. 2001. The Science of Conjecture: Evidence and Probability before Pascal. Baltimore: Johns Hopkins University Press.

Fredricksmeyer, E.A. 1976. "Horace C. 1.34: The Conversion." Transactions of the American Philological Association 106: 155-176.

Freudenburg, Kirk. 2001. Satires of Rome: Threatening poses from Lucilius to Juvenal. New York: Cambridge University Press.

Frisk, Hjalmar. 1960-1970. Grieschisches etymologisches Wörterbuch. Heidelberg: Winter.

Gagarin, Michael. 2000. "Series Introduction." In The Oratory of Classical Greece, Volume 2: Lysias, translated by S.C. Todd, pp. xi-xxx. Austin, TX: University of Texas Press.

— - 2007. "Background and Origins: Oratory and Rhetoric before the Sophists." In $A$ Companion to Greek Rhetoric, edited by Ian Worthington, pp. 27-36. Malden, MA: Blackwell Publishing.

Gantz, Timothy. 1993. Early Greek Myth: A Guide to Literary and Artistic Sources. Baltimore: Johns Hopkins University Press.

Garnsey, Peter. 1970. Social Status and Legal Privilege in the Roman Empire. Oxford: Oxford University Press.

Garrison, Daniel H. 2012. The Student's Catullus. $4^{\text {th }}$ edition. Norman, OK: University of Oklahoma Press.

Garvie, A.F. 1998. Sophocles: Ajax. Edited with Introduction, Translation, and Commentary. Warminster, Wiltshire: Aris \& Phillips.

Geertz, Clifford. 1973. The Interpretation of Cultures. New York: Basic Books, Inc., Publishers.

Gera, Deborah Levine. 2003. Ancient Greek Ideas on Speech, Language, and Civilization. New York: Oxford University Press.

Giannopoulou, Vasiliki. 2000. "Divine Agency and Tyche in Euripides' Ion: Ambiguity and Shifting Perspectives." In Euripides and Tragic Theatre in the Late Fifth Century, edited by Martin Cropp, Kevin Lee, and David Sansone, pp. 257-271. Champaign, Illinois: Stipes Publishing. 
Glare, P.G.W. 1990. Oxford Latin Dictionary. Combined edition, reprint. Oxford: Clarendon Press.

Gobet, Fernand, Alex de Voogt, and Jean Retschitzki. 2004. Moves in Mind: The Psychology of Board Games." New York: Psychology Press.

Goulet-Cazé, Marie-Odile. 1996. "Religion and the Early Cynics." In The Cynics: The Cynic Movement in Antiquity and Its Legacy, edited by R. Bracht Branham and Marie-Odile Goulet-Cazé, pp. 47-80. Berkeley and Los Angeles: University of California Press.

Gowers, Emily. 1993. The Loaded Table: Representations of Food in Roman Literature. Oxford: Clarendon Press.

Green, Peter. 1990. Alexander to Actium: The Historical Evolution of the Hellenistic Age. Berkeley and Los Angeles: University of California Press.

Green, Steven J. 2010. "(No) Arms and a Man: The Imperial Pretender, The Opportunistic Poet and the Laus Pisonis." The Classical Quarterly 60.2: 497-523.

Greenberg, Nathan A. 1980. "Success and Failure in the Adelphoe." The Classical World 73.4: 221-236.

Greene, William Chase. 1938. Scholia Platonica. Haverford, PA: American Philological Association.

Greenough, J.B. and M.G. Daniell. 1903. C. Sallusti Crispi: de Catilinae Coniuratione: The Conspiracy of Catiline as Related by Sallust. Revised edition of Allen and Greenough. Boston: Ginn \& Company.

Gruen, Erich S. 1990 [1996 reprint]. Studies in Greek Culture and Roman Policy. Berkeley and Los Angeles: University of California Press.

Gusfield, Joseph R. 1967. "Moral Passage: The Symbolic Process in Public Designations of Deviance." Social Problems 15.2: 175-188.

Gutzwiller, Kathryn. 2007. A Guide to Hellenistic Literature. Malden, MA: Blackwell Publishing.

Habinek, Thomas. 2009. "Situating Literacy at Rome." In Ancient Literacies: The Culture of Reading in Greece and Rome, edited by William A. Johnson and Holt N. Parker, pp. 114-140. New York: Oxford University Press.

Haddad-Zubel, Rosita. 2001. "Playing the board? Or playing the opponent's mind?" In Step by Step: Proceedings of the $4^{\text {th }}$ Colloquium Board Games in Academia, 
edited by Jean Retschitzki and Rosita Haddad-Zubel, pp. 191-202. Fribourg: Editions Universitaires Fribourg Suisse.

Hägg, Tomas. 2012. The Art of Biography in Antiquity. Cambridge: Cambridge University Press.

Hallebeek, Jan. 2013. "On the origin of the constitution Alearum lusus (C. 3,43,1) and its insertion into the Codex Justinianus." Tijdschrift voor Rechtsgeschiedenis 81: 129-143.

Halliwell, Stephen. 2008. Greek Laughter: A Study of Cultural Psychology from Homer to Early Christianity. New York: Cambridge University Press.

Handford, S.A. 1963. The Jugurthine War, the Conspiracy of Catiline. Harmondsworth: Penguin Books.

Hanink, Johanna. 2014. Lycurgan Athens and the Making of Classical Tragedy. Cambridge: University of Cambridge Press.

Hansen, Mogens Herman. 1989a. "The Athenian 'Politicians', 403-322 в.c." In The Athenian Ecclesia II: A Collection of Articles 1983-1989, pp. 1-24. Copenhagen: Museum Tusculanum Press.

— - 1989b. "Rhetores and Strategoi in Fourth-Century Athens." In The Athenian Ecclesia II: A Collection of Articles 1983-1989, pp. 25-72. Copenhagen: Museum Tusculanum Press.

— - 1989c. "The Number of Rhetores in the Athenian Ecclesia, 355-322 B.C." In The Athenian Ecclesia II: A Collection of Articles 1983-1989, pp. 93-127. Copenhagen: Museum Tusculanum Press.

— - 2002. "The Game Called Polis." In Even More Studies In the Ancient Greek Polis: Papers from the Copenhagen Polis Centre 6, edited by Thomas Heine Nielsen, pp. 9-15. Stuttgart: Franz Steiner Verlag Stuttgart.

Harnack, Adolf. 1888. Der pseudocyprianische Tractat de Aleatoribus: die älteste lateinische christliche Schrift, ein werk des römischen Bischofs Victor I. (Saec. II). Leipzig: J.C. Hinrichs.

Harris, Edward M. 1985. "The Date of the Trial of Timarchus." Hermes 113.3: 376-380.

Heath, Malcolm. 1987. The Poetics of Greek Tragedy. London: Duckworth.

Henderson, Jeffrey. 1990. The Maculate Muse: Obscene Language in Attic Comedy. Reprint with corrections and additions. New York: Oxford University Press. 
Hendrickson, G.L. 1939. Cicero: Brutus. Loeb Classical Library 342. Cambridge, MA: Harvard University Press.

Herbermann, Charles George. The Bellum Catilinae of C. Sallustius Crispus. 1900 [1913 reprint]. $2^{\text {nd }}$ edition. Boston: Benjamin H. Sanborn \& Co.

Hinks, D.A.G. 1940. "Tisias and Corax and the Invention of Rhetoric." The Classical Quarterly 34.1/2: 61-69.

Hollis, Adrian S. 2007. Fragments of Roman Poetry c.60 BC-AD 20. New York: Oxford University Press.

Hornsby, Roger A. 1958. “Horace, Ode 3. 29.” The Classical Journal 54.3: 129-136.

Horsfall, Nicholas. 2003. The Culture of the Roman Plebs. London: Duckworth.

Hose, Martin. 2016. "Philosophical Writing: Treatise, Dialogue, Diatribe, Epistle." In $A$ Companion to Greek Literature, edited by Martin Hose and David Schenker, pp. 235-255. Malden, MA: Wiley Blackwell.

Hübner, Robert. 2009. "Hinweise zum Verständnis des Begriffes $\alpha$ $\zeta v \xi$ beim Brettspiel." In “... vor dem Papyrus sind alle gleich!”: Papyrologische Beiträge zu Ehren von Bärbel Kramer (P. Kramer), edited by Reimar Eberhard, Holger Kockelmann, Stefan Pfeiffer, and Maren Schentuleit, pp. 80-92. Berlin: de Gruyter.

Huizinga, Johan. 1949. Homo Ludens: A Study of the Play-Element in Culture. Boston: Routledge \& Kegan Paul.

Hunter, R.L. 1983. Eubulus: The Fragments, Edited with a Commentary. Cambridge: Cambridge University Press.

Jacobs, Rudolf. 1852. C. Sallusti Crispi de Coniuratione Catilinae et de Bello Jugurthino Libri ex Historiarum Libris Quinque Deperditis Orationes et Epistulae. Leipzig: Weidmann.

Jacobson, Arthur J. 1999. "The Game of the Laws." Political Theory 27.6: 769-788.

Jacobson, Howard. 1968. "Horace and Augustus: An Interpretation of Carm. 1. 35." Classical Philology 63.2: 106-113.

Jebb, R.C. 1907. Sophocles: The Plays and Fragments, with Critical Notes, Commentary, and Translation in English Prose. Part VII: The Ajax. Cambridge: Cambridge University Press.

Johansen, H. Friis and Edward W. Whittle. 1980. Aeschylus: The Suppliants. 3 vols. Copenhagen: Gyldendalske Boghandel, Nordisk Forlag. 
Johnson, Timothy S. 2009. "Lyric, History and Imagination: Horace as Historiographer (C. 2.1)." The Classical Journal 104.4: 311-320.

Johnson, W.R. 1968. "Micio and the Perils of Perfection." California Studies in Classical Antiquity 1: 171-186.

Jones, Frederick. 2007. Juvenal and the Satiric Genre. London: Duckworth.

Jordan, Heinrich. 1866. C. Sallusti Crispi Catilina Iugurtha Historiarum Reliquae Potiores: Accedunt Epistulae ad Caesarem de Re Publica. Berlin: Weidmann.

— - 1876. C. Sallusti Crispi Catilina Iugurtha Historiarum Reliquae Potiores: Incerti Rhetoris Suasoriae ad Caesarem Senem de Re Publica. $2^{\text {nd }}$ edition. Berlin: Weidmann.

Jowett, B. and Lewis Campbell. 1894. Plato's Republic: The Greek Text, Edited, with Notes and Essays. 3 vols. Oxford: Clarendon Press.

Juul, Jesper. 2005. Half-real: Video Games between Real Rules and Fictional Worlds. Cambridge, MA: The MIT Press.

Kahn, Charles. 1979. The Art and Thought of Heraclitus: An Edition of the Fragments with Translation and Commentary. Cambridge: Cambridge University Press.

Kalas, Gregor. 2015. The Restoration of the Forum in Late Antiquity: Transforming Public Space. Austin: University of Texas Press.

Karshan, Thomas. 2011. Vladimir Nabokov and the Art of Play. New York: Oxford University Press.

Kaster, Robert A. 2011. Macrobius: Saturnalia, Books 3-5. Loeb Classical Library 511. Cambridge, MA: Harvard University Press.

Kellum, Barbara. 1999. "The Spectacle of the Street." In The Art of Ancient Spectacle, edited by Bettina Bergman and Christine Kondoleon, pp. 283-299. New Haven: Yale University Press.

Kennedy, George A. 1999. Classical Rhetoric \& Its Christian and Secular Tradition from Ancient to Modern Times. $2^{\text {nd }}$ edition, revised \& enlarged. Chapel Hill: University of North Carolina Press.

Ker, Walter C. A. 1968. Martial: Epigrams. 2 vols. Revised edition. Loeb Classical Library 94-95. Cambridge, MA: Harvard University Press.

Kidd, Stephen. 2016. "Play in Aristotle.” Classical Philology 111.4: 353-371. 
— —. 2017. "Pente Grammai and the 'Holy Line."” Board Game Studies 11: 83-99.

——. Forthcoming a. "Greek Dicing, Astragaloi, and the 'Euripides' Throw."

— —. Forthcoming b. "How to Gamble in Greek: the Meaning of KUBEIA."

Kimmel, Michael S. 2011. The Gendered Society. $4^{\text {th }}$ edition. New York: Oxford University Press.

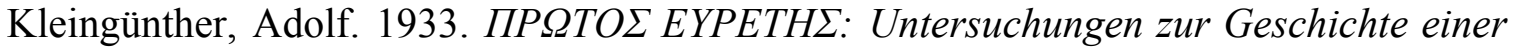
Fragestellung. Leipzig: Dieterich'schen Verlagsbuchhandlung.

Konstan, David. 1978. "Plot and Theme in Plautus' Asinaria." The Classical Journal 73.3: $215-221$.

Koops, Egbert. 2016. "Price Setting and Other Attempts to Control the Economy." In The Oxford Handbook of Roman Law and Society, edited by Paul J. du Plessis, Clifford Ando, and Kaius Tuori, 609-620. New York: Oxford University Press.

Kovacs, David. 2002. Euripides: Bacchae, Iphigenia at Aulis, Rhesus. Loeb Classical Library 495. Cambridge, MA: Harvard University Press.

Kritz, Friedrich. 1856. C. Sallusti Crispi: Catilina, Iugurtha, Historiarum Fragmenta. Leipzig: Sumptibus Librariae Hahnianae.

Kurfess, Alfons. 1957. C. Sallusti Crispi Catilina, Iugurtha, Fragmenta Ampliora. $3^{\text {rd }}$ edition. Leipzig: Teubner.

Kurke, Leslie. 1999a. Coins, Bodies, Games, and Gold: The Politics of Meaning in Archaic Greece. Princeton, NJ: Princeton University Press.

— - 1999b. "Ancient Greek Board Games and How to Play Them." Classical Philology 94.3: 247-267.

— - 2002. "Greek Games and Ideologies in the Archaic and Classical Periods." Paragrana: Internationale Zeitschrift für Historische Anthropologie 11.1: 15-50.

Lacey, W.K. 1986. Cicero: Second Philippic Oration. Warminster, Wiltshire: Aris \& Phillips.

Lamb, W.R.M. 1927. Plato: Charmides, Alcibiades I and II, Hipparchus, The Lovers, Theages, Minos, Epinomis. Loeb Classical Library 201. Cambridge, MA: Harvard University Press. 
Lamer, Hans. 1927. "Lusoria Tabula." Realencyclopädie der Classischen Altertumswissenschaft 13.2, cols. 1900-2029.

Lanciani, Rodolfo. 1892. "Gambling and Cheating in Ancient Rome." The North American Review 155.428: 97-105.

Laurence, Ray. 1994. Roman Pompeii: Space and Society. New York: Routledge.

Lawrence, Stuart. 2005. "Ancient Ethics, the Heroic Code, and the Morality of Sophocles' Ajax." Greece \& Rome 52.1: 18-33.

Leutsch, E.L. von. and F.G. Schneidewin. 1839. Corpus Paroemiographorum Graecoeum. 2 vols. Göttingen: Vanderhoeck and Ruprecht.

Leutsch, Ernst Ludwig von. 1869. Review of Adam Eussner, Exercitationes Sallustianae, in Philologischer Anzeiger 1: 235-237. Göttingen: Dieterichschen Buchhandlung.

Lowenstam, Steven. 1981. The Death of Patroklos: A Study in Typology. Königstein/Ts: Hain.

Lloyd-Jones, H. and N.G. Wilson. 1990. Sophoclea: Studies on the Text of Sophocles. New York: Oxford University Press.

Lloyd-Jones, Hugh and Nigel G. Wilson. 1997. Sophocles: Second Thoughts. Göttingen: Vandenhoeck \& Ruprecht.

Mackay, L.A. 1929. “Horace: Odes I.34, 35.” The Classical Review 43.1: 10-12.

Macleod, M.D. 2008. Xenophon: Apology and Memorabilia I, with Introduction, Translation and Commentary. Oxford: Aris \& Philips.

Mader, Gottfried. 2013. "Re-presenting Piso: Poetic and Political Agenda in the Laus Pisonis." Classical World 106.4: 621-643.

Maltby, Robert. 1999. "The Language of Plautus's Parasites." In Theatre: Ancient and Modern: Selected Proceedings of a Two-Day International Research Conference Hosted by the Department of Classical Studies, Faculty of Arts, the Open University, Milton Keynes, $5^{\text {th }}$ and $6^{\text {th }}$ January 1999, edited by Lorna Hardwick, Pat Easterling, Stanley Ireland, Nick Lowe, and Fiona Macintosh. Milton Keynes: The Open University. Available online at http://www2.open.ac.uk/ClassicalStudies/GreekPlays/Conf99/Maltby.htm

Manuwald, Gesine. 2007. Cicero, Philippics 3-9. 2 vols. Berlin: de Gruyter.

Marcovich, Miroslav. 1967. Heraclitus: Greek text with a short commentary, editio maior. Merida, Venezuela: The Los Andes University Press. 
- - 2001. Heraclitus: Greek text with a short commentary. $2^{\text {nd }}$ edition. Sankt Augustin: Academia Verlag.

Marcus, Ralph. 1953. Philo: Questions on Exodus. Loeb Classical Library 401. Cambridge, MA: Harvard University Press.

Marrus, Michael R. 1974. The Emergence of Leisure. New York: Harper Torchbooks.

Marshall, Bruce. 1978. “Q. Curius, Homo Quaestorius.” L'antiquité classique 47.1: 207209).

Martin, R.H. 1976. Terence: Adelphoe. Cambridge: Cambridge University Press.

Mastronarde, Donald J. 1994. Euripides: Phoenissae. Cambridge: Cambridge University Press.

Mayer, Ronald. 2005 [2008 reprint]. "The Early Empire: AD 14-68." In A Companion to Latin Literature, edited by Stephen Harrison, pp. 58-68. Malden, MA: Blackwell Publishing.

McComiskey, Bruce. 2002. Gorgias and the New Sophistic Rhetoric. Carbondale and Edwardsville, IL: Southern Illinois University Press.

McCormick, Betsy. 2015. "Afterword: Medieval Ludens." In Games and Gaming in Medieval Literature, edited by Serina Patterson, pp. 209-222. New York: Palgrave Macmillan.

McGinn, Thomas A.J. 1998. Prostitution, Sexuality, and the Law in Ancient Rome. New York: Oxford University Press.

— - 2008. "Something Old, Something New... Augustan Legislation and the Challenge of Social Control." Ancient History Bulletin 22.1-2: 1-32.

— - 2013. "Sex and the city." In The Cambridge Companion to Ancient Rome, edited by Paul Erdkamp, pp.369-385. New York: Cambridge University Press.

McGlynn, Patrick. 1967. Lexicon Terentianum. 2 vols. London: Blackie.

McGushin, Patrick. 1977. C. Sallustius Crispus: Bellum Catilinae. Leiden: Brill.

— - 1995 [2010 reprint]. Sallust: Bellum Catilinae. $3^{\text {rd }}$ edition. Bristol: Bristol Classical Press.

Merivale, Charles. 1870 [1966 reprint]. Caii Sallustii Crispi Catilina: for Use in Schools. London: Macmillan and Company Limited. 
Merrill, E.T. 1893. Commentary on Catullus. Cambridge, MA: Harvard University Press.

Minyard, John-Douglas. 1971. "Critical Notes on Catullus 29." Classical Philology 66.3: 174-181.

Mommsen, Theodor. 1899. Römisches Strafrecht. Leipzig: Verlag von Duncker \& Humblot.

Mommsen, T. and P. Krüger. 1967. Corpus Iuris Civilis vol. I: Institutiones, Digesta. Dublin: Weidmann.

Moore, Timothy. 1998. The Theater of Plautus: Playing to the Audience. Austin: University of Texas Press.

Morgan, Teresa. 2007. Popular Morality in the Early Roman Empire. New York: Cambridge University Press.

Most, Glenn W. 2011. "Heraclitus Fragment B 52 DK (on OF 242)." In Tracing Orpheus: Studies of Orphic Fragments, edited by Miguel Herrero de Jáuregui, Ana Isabel Jiménez San Cristóbal, Marco Antonio Santamaria et al., pp. 105-110. Boston: De Gruyter.

Muir, J.V. 2001. Alcidamas: The Works \& Fragments. London: Bristol Classical Press.

Müller, Karl and Theodor Müller. 1841. Fragmenta Historicum Gracorum vol. I. Paris: Didot.

Murray, H.J.R. 1913. A History of Chess. Oxford: Clarendon Press.

— - 1952. A History of Board-Games other than Chess. Oxford: Clarendon Press.

Muse, Kevin. 2012. "Sallust's Imitation of Greek Models at Catiline 14.2-3." Mnemosyne 65: 40-61.

— - 2016. "Lactantius Divinae Institutiones 3.26.7 and the Text of Sallust Catilina 14.2." Mnemosyne 69: 503-510.

Myers, David. 2006. “Signs, Symbols, Games, and Play.” Games and Culture 1.1: 47-51.

Naber, S.A. 1864-1865. Photii Patriarchae Lexicon. 2 vols. Leiden: Brill.

Nagy, Gregory. 1979. The Best of the Achaeans: Concepts of the Hero in Archaic Greek Poetry. Baltimore: Johns Hopkins University Press.

_ _. 1990. Greek Mythology and Poetics. Ithaca, NY: Cornell University Press. 
Nauck, August. 1889. Tragicorum Graecorum Fragmenta. $2^{\text {nd }}$ edition. Leipzig: Teubner.

N'Guessan Assandé, Gilbert and Jean Retschitzki. 2001. "Learning awale strategies." In Step by Step: Proceedings of the $4^{\text {th }}$ Colloquium Board Games in Academia, edited by Jean Retschitzki and Rosita Haddad-Zubel, pp. 175-182. Fribourg: Editions Universitaires Fribourg Suisse.

Nicolau, Gaspar Pujol. 2009. Traditional Cosmological Symbolism in Ancient Board Games. PhD dissertation. Universitat Internacional de Catalunya, Barcelona. Available online at http://www.tdx.cat/bitstream/handle/10803/387431/Tesi_\%20Gaspar_Pujol_Nicol au.pdf;jsessionid=3F3699CCF0C8DC8914047E651198A-AD8?sequence=1

Nisbet, Robin. 2007. "Horace: life and chronology." In The Cambridge Companion to Horace, edited by Stephen Harrison, pp. 7-21. New York: Cambridge University Press.

Nisbet, R.G.M. and Margaret Hubbard. 1970. A Commentary on Horace: Odes, Book I. Oxford: Clarendon Press.

— - 1978. A Commentary on Horace: Odes, Book II. Oxford: Clarendon Press.

Nisbet, R.G.M. and Niall Rudd. 2004. A Commentary on Horace: Odes, Book III. New York: Oxford University Press.

Nitzschner, Augustus. 1884. De Locis Sallustianis, Qui apud Scriptores et Grammaticos Veteres Leguntur. Hannover: Culemann.

Norlin, George. 1929. Isocrates: Volume II. Loeb Classical Library 229. Cambridge, MA: Harvard University Press.

Ober, Josiah. 1988. Political Dissent in Democratic Athens: Intellectual Critics of Popular Rule. Princeton, NJ: Princeton University Press.

Opitz, Theodor. 1894. C. Sallusti Crispi Bellum Catilinae, Bellum Iugurthinum, Orationes et Epistulae ex Historiis Ecerptae: für den Schulgebrauch erklärt. Leipzig: Teubner.

O’Connor, Joseph F. 1990. "Horace's Cena Nasidieni and Poetry's Feast." The Classical Journal 86.1:23-34.

Orr, Deborah. 2006. "Thinking through the Body: An Introduction to Beliefs, Bodies, and Being." In Beliefs, Bodies, and Being: Feminist Reflections on Embodiment, edited by Deborah Orr, Linda Lopez McAlister, Eileen Kahl, and Kathleen Earle, pp. 1-10. New York: Rowman \& Littlefield Publishers. 
O’Sullivan, Daniel E. 2012. "Introduction: 'Le beau jeu nottable." In Chess in the Middle Ages and Early Modern Age: A Fundamental Thought Paradigm of the Premodern World, edited by Daniel E. O’Sullivan, pp. 1-13. Berlin: Walter de Gruyter GmbH \& Co.

O’Sullivan, Neil. 2008. "The Authenticity of [Alcidamas] Odysseus: Two New Linguistic Considerations." The Classical Quarterly 58.2:638-647.

Parlett, David. 1999. The Oxford History of Board Games. New York: Oxford University Press.

Patterson, Serina. 2015. "Introduction: Setting Up the Board." In Games and Gaming in Medieval Literature, edited by Serina Patterson, pp. 1-20. New York: Palgrave Macmillan.

Paul, G.M. 1985. “Sallust, Catiline 14.2.” Phoenix 39.2: 158-161.

Pearson, A.C. 1917. The Fragments of Sophocles. 3 vols. Cambridge: Cambridge University Press.

Peirano, Irene. 2014. "'Sealing' the book: the sphragis as paratext." In The Roman Paratext: Frame, Texts, Readers, edited by Laura Jansen, pp. 224-242. New York: Cambridge University Press.

Pelling, Christopher. 2017. "Xenophon's Authorial Voice." In The Cambridge Companion to Xenophon, edited by Michael A. Flower, pp. 241-262. New York: Cambridge University Press.

Pennick, Nigel. 1989 [1997 reprint]. Secret Games of the Gods: Ancient Ritual Systems in Board Games. York Beach, ME: Samuel Weiser, Inc.

Pernot, Laurent. 2005. Rhetoric in Antiquity. Translated by W.E. Higgins. Washington, D.C.: The Catholic University of America Press.

Perschinka, Franz. 1902. C. Sallusti Crispi Bellum Catilinae, Bellum Iugurthinum, ex Historiis Quae Exstant Orationes et Epistulae. Wien: Verlag von Carl Gerold's Sohn.

Platner, Samuel Ball. 1929. A Topographical Dictionary of Ancient Rome. London: Oxford University Press.

Porson, Richard and Peter Paul Dobree. 2010 [1822]. Photiou Tou Patriarchou Lexeon Synagoge, Volume 2. New York: Cambridge University Press. 
Porter, David H. 1987. Horace's Poetic Journey: A Reading of Odes 1-3. Princeton, NJ: Princeton University Press.

Purcell, Nicholas. 1995. "Literate Games: Roman Urban Society and the Game of Alea." Past \& Present 147: 3-37.

— — 2007. "Inscribed Imperial Roman Gaming-Boards." In Ancient Board Games in perspective, edited by I.L. Finkel, pp. 90-97. London: The British Museum Press.

— - 2013. "'Romans, play on!' city of the Games." In The Cambridge Companion to Ancient Rome, edited by Paul Erdkamp, pp. 441-458. New York: Cambridge University Press.

Quintana Orive, Elena. 2009. “D. 11.5 (De aleatoribus) y C. 3.43 (De alea lusu et aleatoribus): Precedentes romanos del contrato de juego." Anuario Jurídico y Económico Escurialense 42: 17-38.

Ramsey, John T. 2003. Cicero: Philippics I-II. Cambridge: Cambridge University Press.

— - 2005. "Mark Antony's Judiciary Reform and Its Revival under the Triumvirs." The Journal of Roman Studies 95: 20-37.

- - 2007. Sallust's Bellum Catilinae. $2^{\text {nd }}$ edition. New York: Oxford University Press.

— - 2013. Sallust: The War with Catiline, the War with Jugurtha. Loeb Classical Library 116. Cambridge, MA: Harvard University Press.

Rancière, Jacques. 2004. "The Order of the City." Translated by John Drury, Corinne Oster, and Andrew Parker. Critical Inquiry 30.2: 267-291.

Raubitschek, A.E. 1949. "Phaidros and His Pupils.” Hesperia 18.1: 96-103.

Reckford, Kenneth J. 1966. "Horace, Odes 1.34: An Interpretation.” Studies in Philology 63.4: 499-532.

Rees, Roger. 2013. "The Lousy Reputation of Piso." In The Julio-Claudian Succession: Reality and Perception of the "Augustan Model", edited by A.G.G. Gibson, pp. 95-106. Leiden: Brill.

Reynolds, L.D. 1983. "Sallust." In Texts and Transmission: A Survey of the Latin Classics, edited by L.D. Reynolds. Oxford: Clarendon Press.

— - 1991. C. Sallusti Crispi Catilina, Iugurtha, Historiarum Fragmenta Selecta, Appendix Sallustiana. Oxford: Clarendon Press. 
Ribbeck, Otto. 1898. Scaenicae Romanorum Poesis Fragmenta, Volumen II: Comicorum Fragmenta. $3^{\text {rd }}$ edition. Leipzig: Teubner.

Richardson, jr., L. 1992. A New Topographical Dictionary of Ancient Rome. Baltimore: The Johns Hopkins University Press.

Richmond, John. 1994. "The Ludus Latrunculorum and Laus Pisonis 190-208." Museum Helveticum 51: 164-179.

Ridgeway, William. 1896. "The Game of Polis and Plato's Rep. 422 E." The Journal of Hellenistic Studies 16: 288-290.

Rieche, Anita. 2007. "Board Games and their Symbols from Roman Times to Early Christianity." In Ancient Board Games in perspective, edited by I.L. Finkel, pp. 87-89. London: The British Museum Press.

Riley, Henry T. 1912. The Comedies of Plautus. London: G. Bell \& Sons.

Roby, Henry John. 1886. An Introduction to the Study of Justinian's Digest. Cambridge: Cambridge University Press.

Rolfe, John Carew. 1901 [1976 reprint]. Q. Horati Flacci: Sermones et Epistulae. New Rochelle, NY: Caratzas Brothers, Publishers.

— — 1921. Sallust: with an English Translation. New York: G.P. Putnam's Sons.

Romm, James. 2012. Plutarch: Lives that Made Greek History. Indianapolis: Hackett Publishing.

Rose, Peter W. 1992. Sons of the Gods, Children of Earth: Ideology and Literary Form in Ancient Greece. Ithaca, NY: Cornell University Press.

Rosivach, Vincent J. 2006. "The Lex Fannia Sumptuaria of 161 BC." The Classical Journal 102.1: 1-15.

Rostovtsew, M. 1899. "Étude sur les plombs antiques." Revue Numismatique 4, 3.1: 2261.

Rostowsew, M. 1903. Tesserarum Urbis Romae et Suburi Plumbearum Sylloge. St. Petersburg, Commissionnaires de l'Académie impériale de Sciences.

Rudd, Niall. 2004. Horace: Odes and Epodes. Loeb Classical Library 33. Cambridge, MA: Harvard University Press.

Russell, Amy. 2011. The Definition of Public Space in Republican Rome. PhD dissertation. University of California, Berkeley. 
Russo, Joseph, Manuel Fernández-Galiano, and Alfred Huebeck. 1992. A Commentary on Homer's Odyssey, Volume III: Books XVII-XXIV. Oxford: Clarendon Press.

Ryan, F.X. 1994. "The Quaestorships of Q. Curius and C. Cornelius Cethegus.” Classical Philology 89.3: 256-261.

Sakellariou, M.B. 1989. The Polis-State: Definition and Origin. Athens: Research Center for Greek and Roman Antiquity, National Hellenic Research Foundation.

Salen, Katie and Eric Zimmerman. 2006. The Game Design Reader: A Rules of Play Anthology. Cambridge, MA: The MIT Press.

Sandbach, F.H. 1969. Plutarch: Moralia, Volume XV: Fragments. Loeb Classical Library 429. Cambridge, MA: Harvard University Press.

Santirocco, Matthew S. 1984. "The Maecenas Odes." Transactions of the American Philological Society 114: 241-253.

— - 1986. Unity and Design in Horace's Odes. Chapel Hill: University of North Carolina Press.

Sauerwein, Ingo. 1970. Die leges sumptuariae als römische Maßnahme gegen den Sittenverfall. PhD dissertation. Universität Hamburg.

Schädler, Ulrich. 1994. "Latrunculi - ein verlorenes strategisches Brettspiel der Römer." Homo Ludens: Der spielende Mensch 4: 47-67.

— - 1995. "XII Scripta, Alea, Tabula - New Evidence for the Roman History of 'Backgammon.'" In New Approaches to Board Games Research: Asian Origins and Future Perspectives, edited by Alexander J. de Voogt, pp. 73-98. Leiden: International Institute for Asian Studies.

_ _. 1998. "Mancala in Roman Asia Minor?” Board Game Studies 1: 10-25.

— - 2001. "Latrunculi: A Forgotten Roman Game of Strategy Reconstructed." Abstract Games 7: 10-11.

— - 2007. "The Doctor's Game - New Light on the History of Ancient Board Games." In Stanway: An Elite Burial Site at Camulodunum, edited by Philip Crummy, pp. 359-375. London: Roman Society Publications.

— - 2009. "Pente grammai - The Ancient Greek Board Game Five Lines." In Board Game Studies Colloquium XI Proceedings, edited by Jorge Nuno Silva, pp. 173196. Lisbon: Associação Ludus. 
— - 2013. "Games, Greek and Roman." In The Encyclopedia of Ancient History, edited by Roger S. Bagnall, Kai Brodersen, Craige B. Champion, Andrew Erskine, and Sabine R. Huebner, pp. 2841-2844. Malden, MA: Blackwell Publishing.

Schiappa, Edward. 1999. The Beginnings of Rhetorical Theory in Classical Greece. New Haven: Yale University Press.

Schmalz, Joseph Hermann. 1885. C. Sallusti Crispi Bellum Catilinae: für den Schulgebrauch. $2^{\text {nd }}$ edition. Gotha: Friedrich Andreas Perthes.

- - 1893. C. Sallusti Crispi Bellum Catilinae: für den Schulgebrauch. $4^{\text {th }}$ edition. Gotha: Friedrich Andreas Perthes.

- - 1897. C. Sallusti Crispi Bellum Catilinae: für den Schulgebrauch. $5^{\text {th }}$ edition. Gotha: Friedrich Andreas Perthes.

Schmidt, Moritz. 1867. Hesychii Alexandrini Lexicon, editio minor. Jenae: Sumptibus Hermanni Dufftii.

Schoenhardt, Carl. 1885. Alea: über die Bestrafung des Glücksspiels im älteren römischen Recht: eine Strafrechtsgeschichtliche Studie. Stuttgart: F. Enke.

Schwartz, David G. 2006. Roll the Bones: The History of Gambling. New York: Gotham Books.

Scodel, Ruth. 2001. "The Suitors' Games." The American Journal of Philology 122.3: 307-327.

Scott, William C. 1971. "Catullus and Caesar (C. 29).” Classical Philology 66.1: 17-25.

Scott-Kilvert, Ian. 1962. The War against Jugurtha, and the Conspiracy of Catiline. London: New English Library.

Scudder, Jared W. 1900. Gai Sallusti Crispi Bellum Catilinae: Sallust's Catiline with Parallel Passages from Cicero's Orations Against Catiline. Boston and Chicago: Allyn and Bacon.

Seaford, Richard. 2004. Money and the Early Greek Mind: Homer, Philosophy, Tragedy. New York: Cambridge University Press.

Serres, Michel. 1982. The Parasite. Translated by L.R. Schehr. Baltimore: Johns Hopkins University Press.

— - 1995. Genesis. Translated by Geneviève James and James Nielson. Ann Arbor: The University of Michigan Press. 
Shackleton Bailey, D.R. 1986. Cicero: Philippics. Chapel Hill: University of North Carolina Press.

— - 1988. Onomasticon to Cicero's Speeches. Norman, OK: University of Oklahoma Press.

— - 2010. Cicero, Philippics 1-6. Loeb Classical Library 189. Revised by John T. Ramsey and Gesine Manuwald. Cambridge, MA: Harvard University Press.

Sherman, Charles Phineas. 1922. Roman Law in the Modern World. $2^{\text {nd }}$ edition. New Haven, CT: New Haven Law Book Company.

Smith, Clement Lawrence. 1898. The Odes and Epodes of Horace. Edited, with Introduction and Notes. Boston: Ginn \& Company.

Smith, Justin E.H., ed. 2017. Embodiment: A History. New York: Oxford University Press.

Smith, William. 1873. A Dictionary of Greek and Roman Biography and Mythology. London: John Murray.

— - 1890. A Dictionary of Greek and Roman Antiquities. London: John Murray.

Snell, Bruno, Richard Kannicht, and Stefan Lorenz Radt. 1971-2004. Tragicorum Graecorum Fragmenta. 5 vols. Göttingen: Vandenhoeck \& Ruprecht.

Solmsen, Friedrich W. 1964. "Leisure and Play in Aristotle's Ideal State." Rheinisches Museum für Philologie 107: 193-220.

Spatharas, Dimos. 2001. Gorgias: an edition of the extant texts and fragments with commentary and introduction. $\mathrm{PhD}$ dissertation. University of Glasgow. Available online at http://theses.gla.ac.uk/2777/1/2001spatharasphd.pdf

Spawforth, A.J.S. 2012. Greece and the Augustan Cultural Revolution. Cambridge: Cambridge University Press.

Stace, C. 1968. "The Slaves of Plautus.” Greece \& Rome 15.1: 64-77.

Stafford, Emma. 2000. Worshipping Virtues: Personification and the Divine in Ancient Greece. London: Duckworth and The Classical Press of Wales.

Stangl, Thomas. 1909 [1967 reprint]. Pseudoasconiana: Textgestaltung und Sprache der anonymen Scholien zu Ciceros vier ersten Verrinen auf Grund erstmals verwerteten ältesten Handschriften. New York: Johnson Reprint Corporation. 
Steiner, Deborah Tarn. 1994. The Tyrant's Writ: Myths and Images of Writing in Ancient Greece. Princeton, NJ: Princeton University Press.

Stewart, J.A. 1893. "Plato, Republic 422 E.” The Classical Review 7.8: 359.

Strauss, Leo. 1972. Xenophon's Socrates. Ithaca: Cornell University Press.

Suits, Bernard. 1978. The Grasshopper: Games, Life, and Utopia. Reprinted in The Game Design Reader: A Rules of Play Anthology, edited by Katie Salen and Eric Zimmerman, pp. 172-191. Cambridge, MA: The MIT Press.

Summers, Walter Coventry. 1907. C. Sallusti Crispi Catilina. Cambridge: Cambridge University Press.

— - 1920. The Silver Age of Latin Literature: From Tiberius to Trajan. London: Methuen.

Taillardat, Jean. 1967. Suétone: Des Termes Injurieux, Des Jeux Grecs. Paris: Société d'Édition "Les Belles Lettres."

Taylor, Claire. 2015. "Social Networks and Social Mobility in Fourth-century Athens." In Communities and Networks in the Ancient Greek World, edited by Claire Taylor and Kostas Vlassopoulos, pp. 35-53. New York: Oxford University Press.

Thédenat, Henry. 1904. Le Forum Romain et Les Forums Imperiaux. Paris: Hachette.

Thraede, Klaus. 1967. “Zu Aristoteles Pol. A 1253a 6-7.” Hermes 95.1: 122-124.

Threadcraft, Shatema. 2016. "Embodiment." In The Oxford Handbok of Feminist Theory, edited by Lisa Disch and Mary Hawkensworth, pp. 2017-226. New York: Oxford University Press.

Tilley, Arthur. 1892. "Ludus Latrunculorum.” The Classical Review 6.8: 335-338.

Todd, S.C. 2000. The Oratory of Classical Greece, Volume 2: Lysias. Austin, TX: University of Texas Press.

Toner, J.P. 1995. Leisure and Ancient Rome. Malden, MA: Polity Press.

— — 2009. Popular Culture in Ancient Rome. Malden, MA: Polity Press.

Too, Yun Lee. 2008. A Commentary on Isocrates' Antidosis. New York: Oxford University Press.

Traub, Valerie. 2016. "Introduction-Feminist Shakespeare Studies: Cross Currents, Border Crossings, Conflicts, and Contradictions." In The Oxford Handbook of 
Shakespeare and Embodiment: Gender, Sexuality, and Race, edited by Valerie Traub, pp. 1-36. New York: Oxford University Press.

Tribble, Evelyn. 2016. "Pretty and Apt: Boy Actors, Skill, and Embodiment." In The Oxford Handbook of Shakespeare and Embodiment: Gender, Sexuality, and Race, edited by Valerie Traub, pp. 628-640. New York: Oxford University Press.

Trifilò, Francesco. 2011. "Movement, Gaming, and the Use of Space in the Forum." In Rome, Ostia, Pompeii: Movement and Space, edited by Ray Laurence and David J. Newsome, pp. 312-371. New York: Oxford University Press.

Turner, Victor. 1974. "Liminal to Liminoid, in Play, Flow, and Ritual: An Essay in Comparative Symbology." Rice University Studies 60.3: 53-92.

Ullman, B.L. 1929. "The Text Tradition and Authorship of the Laus Pisonis." Classical Philology 24.2: 109-132.

— —. 1936. "Horace and the Philologians." The Classical Journal 31.7: 403-417.

Urbano, Arthur P. 2014. "Sizing up the Philosopher's Cloak: Christian Verbal and Visual Representations of the Tribōn." In Dressing Judeans and Christians in Antiquity, edited by Kristi Upson-Saia, Carly Daniel-Hughes, and Alicia J. Batten, pp.175194. Burlington, VT: Ashgate.

Usher, Stephen. 1999. Greek Oratory: Tradition and Originality. New York: Oxford University Press.

van Brock, Nadia. 1959. “Substitution Rituelle.” Revue Hittite et Asianique 65: 117-146.

van den Hout, Michel P.J. 1975. M. Cornelii Frontonis Epistulae Adnotatione Critica Instructae. New York: Arno Press.

_ —. 1999. A Commentary on the Letters of M. Cornelius Fronto. Leiden: Brill.

van der Blom, Henriette. 2010. Cicero's Role Models: The Political Strategy of a Newcomer. New York: Oxford University Press.

van Leeuwen, Theo. 2008. Discourse and Practice: New Tools for Critical Discourse Analysis. New York: Oxford University Press.

Vernant, Jean-Pierre. 1978. "Ambiguity and Reversal: On the Enigmatic Structure of Oedipus Rex.” New Literary History 9.3: 475-501.

Versnel, H.S. 2011. Coping With the Gods: Wayward Readings in Greek Theology. Boston: Brill. 
Wallin, Reuben Bruce. 1967. The Stylistic Influence of Theopompus Upon the Catalina of Sallust. MA thesis. Stanford University.

Waltz, A. 1904. "Sur un passage de Salluste (Catilina, XIV, 2.)." Revue des Études Anciennes 6.3: 219.

Warmington, E.H. 1936. Remains of Old Latin, Volume II: Livius Andronicus, Naevius, Pacuvius, Accius. Loeb Classical Library 314. Cambridge, MA: Harvard University Press.

Waskul, Dennis and Phillip Vannini, eds. 2006 [2016 reprint]. Body/Embodiment: Symbolic Interaction and the Sociology of the Body. New York: Routledge.

Welsh, Jarrett T. 2006. "Cato, Plautus, and the Metaphorical Use of Anulus." Phoenix 60.1/2: 133-139.

West, David. 2002. Horace Odes III: Dulce Periculum. New York: Oxford University Press.

West, M.L. 1978. “Tragica II.” Bulletin of the Institute of Classical Studies 25: 106-122.

Whyte, William Foote. 1955. Street Corner Society: The Social Structure of an Italian Slum. $2^{\text {nd }}$ edition. Chicago: University of Chicago Press.

Williams, Bernard. 1993. Shame and Necessity. Berkeley and Los Angeles: University of California Press.

Williams, Gordon. 1969. The Third Book of Horace's Odes: Edited with Translation and Running Commentary. Oxford: Clarendon Press.

Williamson, Callie. 2005. Laws of the Roman People: Public Law in the Expansion and Decline of the Roman Republic. Ann Arbor: University of Michigan Press.

Wilkinson, L.P. 1974. The Roman Experience. New York: Alfred A. Knopf, Inc.

Wilkinson, Sam. 2012. Republicanism During the Early Roman Empire. New York: Continuum.

Wisén, Magne. 1905. De Scholiis Rhetorices ad Herennium codice Holmiensi traditis: Accedunt annotationes in Ciceronis De inventione libros criticae codicis Corbeiensis nitentes collatione quae adiecta est. $\mathrm{PhD}$ dissertation. Uppsala Universitet. Homiae: Ex Typographia Iduns Tryckeri.

Wolbergs, Thielko. 1978. "Palladas, AP 11, 377.” Hermes 106.2: 377-378. 
Wölfflin, Eduard. 1873. "Jahresbericht über Cornelius Nepos und Sallust." In Jahresbericht über die Fortschritte der klassischen Altertumswissenschaft, edited by Conrad Bursian, pp. 2.1659-1668. Berlin: S. Calvary \& Co.

Woodman, A.J. 2007. Sallust: Catiline's War, The Jugurthine War, Histories. London: Penguin Books.

Woodford, Susan. 1982. "Ajax and Achilles Playing a Game on an Olpe in Oxford." Journal of Hellenic Studies 102.173-185.

Worman, Nancy. 2014."Oedipus Abuser: Insult and Embodied Aesthetics in Sophocles." In Autour de l'insulte dans le monde grec archaïque et classique, edited by V. Azoulay and A. Damet, pp. 1-12. Available online at http://mondesanciens.revues.org/1237

- - 2018. "Aeschines and Demosthenes." In Characterization in Ancient Greek Literature, edited by Evert van Emde Boas and Koen De Temmerman, pp. 428442. Leiden: Brill.

Worthington, Ian. 2007. "Rhetoric and Politics in Classical Greece: Rise of the Rhētores." In A Companion to Greek Rhetoric, edited by Ian Worthington, pp. 255-271. Malden, MA: Blackwell Publishing.

Wyetzner, Peter. 2002. "Sulla's Law on Prices and the Roman Definition of Luxury." In Speculum Iuris: Roman Law as a Reflection of Social and Economic Life in Antiquity, edited by Jean-Jacques Aubert and Boudewijn Sirks, pp. 15-33. Ann Arbor: The University of Michigan Press.

Zetzel, James E.G. 1986. Review of L.D. Reynolds, Texts and Transmission: A Survey of the Latin Classics, in Classical Philology 81.3: 270-274.

Zimmermann, Rudolf. 1929. Der Sallusttext im Altertum. Munich: Urania Druckerei u. Verlags G.m.b.H.

Zumwalt, N.K. 1974. "Horace C. 1.34: Poetic Change and Political Equivocation." Transactions of the American Philological Association 104: 435-467. 


\begin{abstract}
VITA
Chris Dobbs was born and raised in the suburbs of Cincinnati, Ohio. Before coming to the University of Missouri, he earned a B.A. in Classical Humanities and a B.A. in Classical Languages from Miami University (2011), followed by an M.A. in Classics from Columbia University (2012). He is a recipient of the Green Chalk Teaching Award from the College of Arts and Science (2014). He is also an avid chess player, a fact that first sparked his interest in games in the ancient world, and was the 2012 Reserve Section Champion for the state of Missouri. He is currently the Arts, Languages, and Life Sciences Tutoring Coordinator at the University of Missouri Learning Center.
\end{abstract}

